\title{
Synthesis of 2,4,5-Trisubstituted Oxazoles via Pd-Catalyzed C-H Addition to Nitriles/Cyclization Sequences
}

\author{
Di Zhang, Hao Song, Na Cheng, Wei-Wei Liao* \\ Department of Organic Chemistry, College of Chemistry, Jilin University, Changchun 130012, China \\ E-mail:wliao@jlu.edu.cn
}

Table of Contents

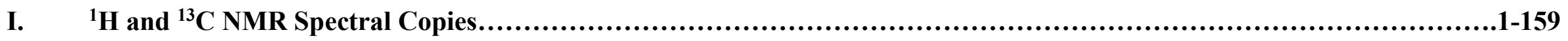




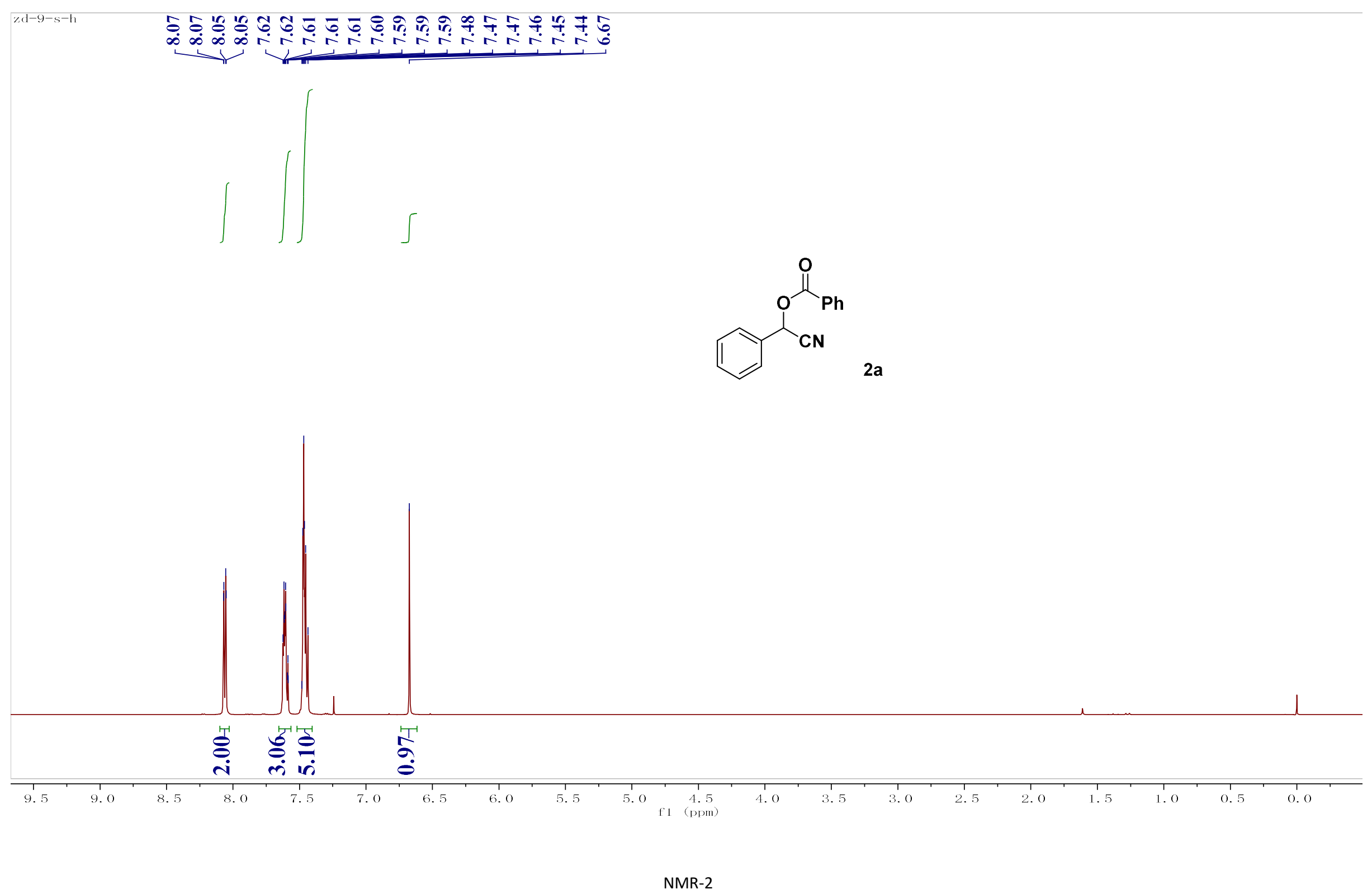




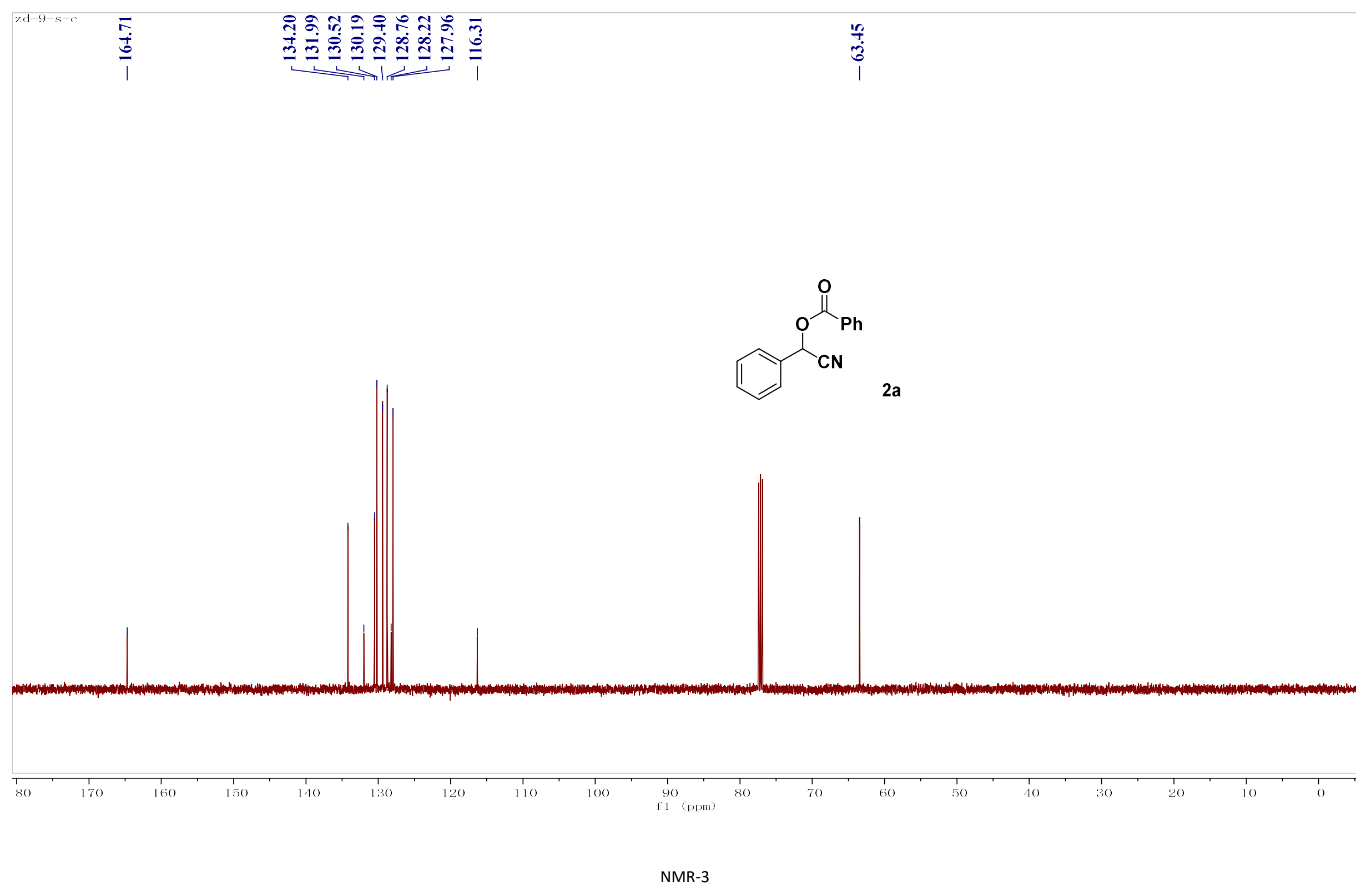




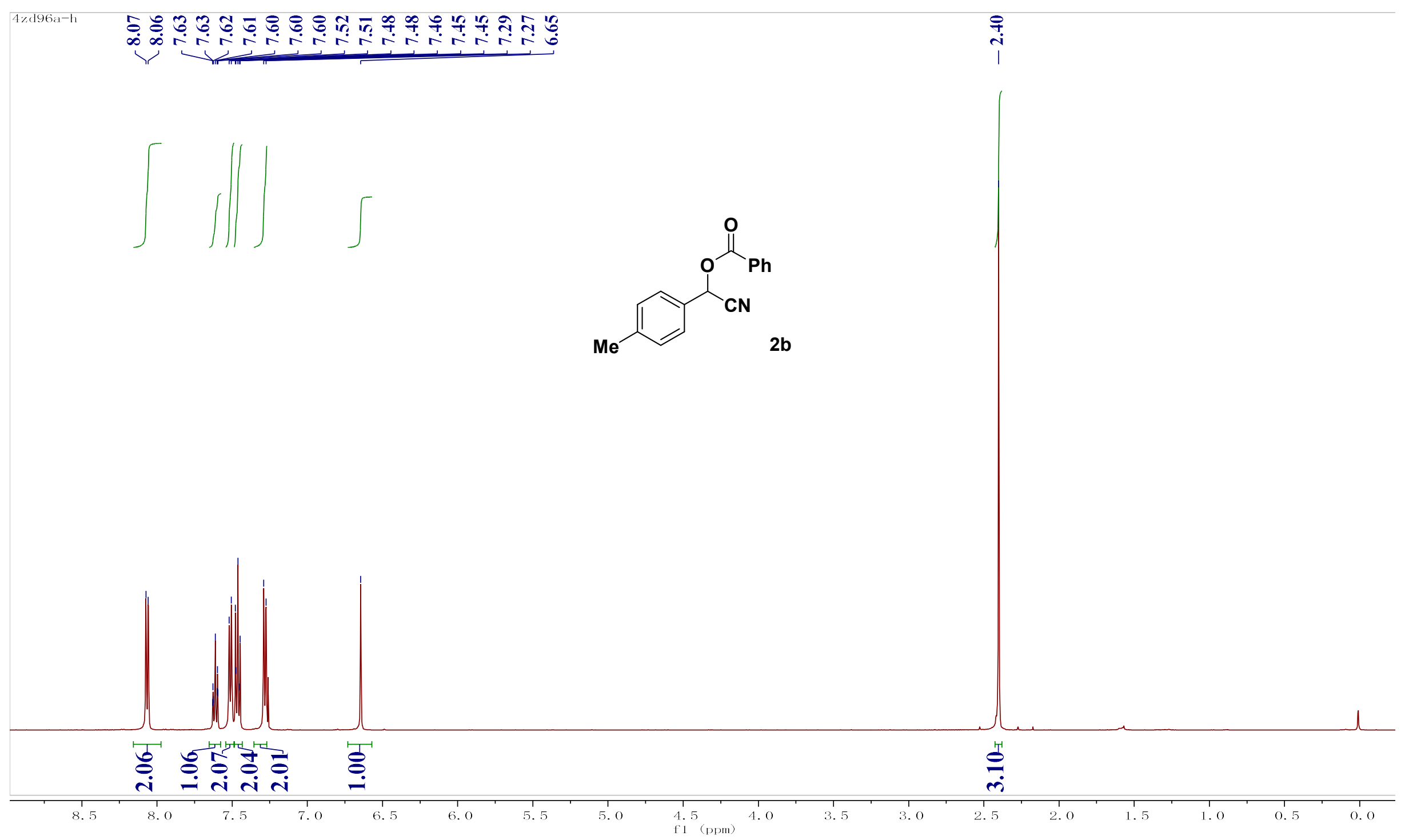

NMR-4 

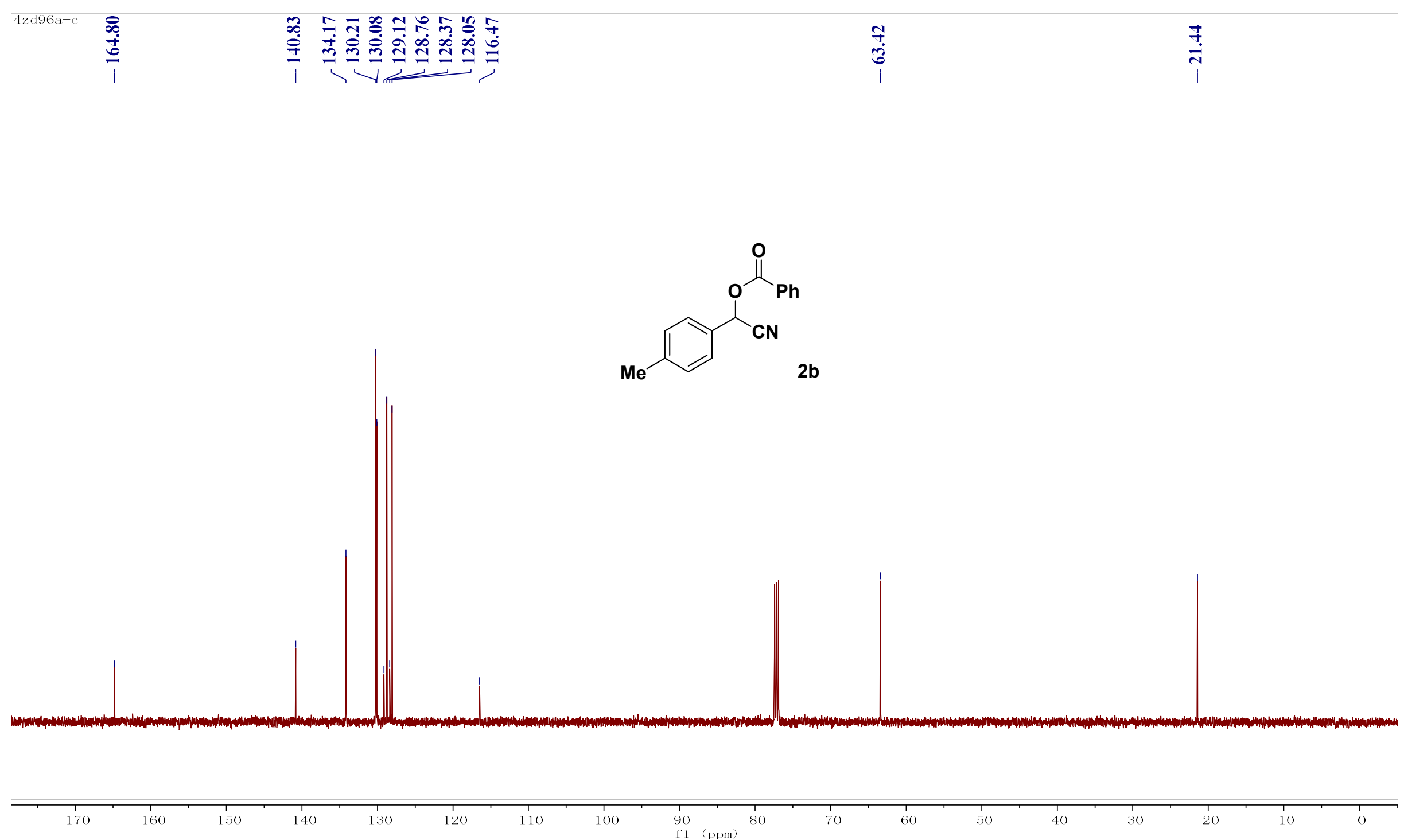

NMR-5 


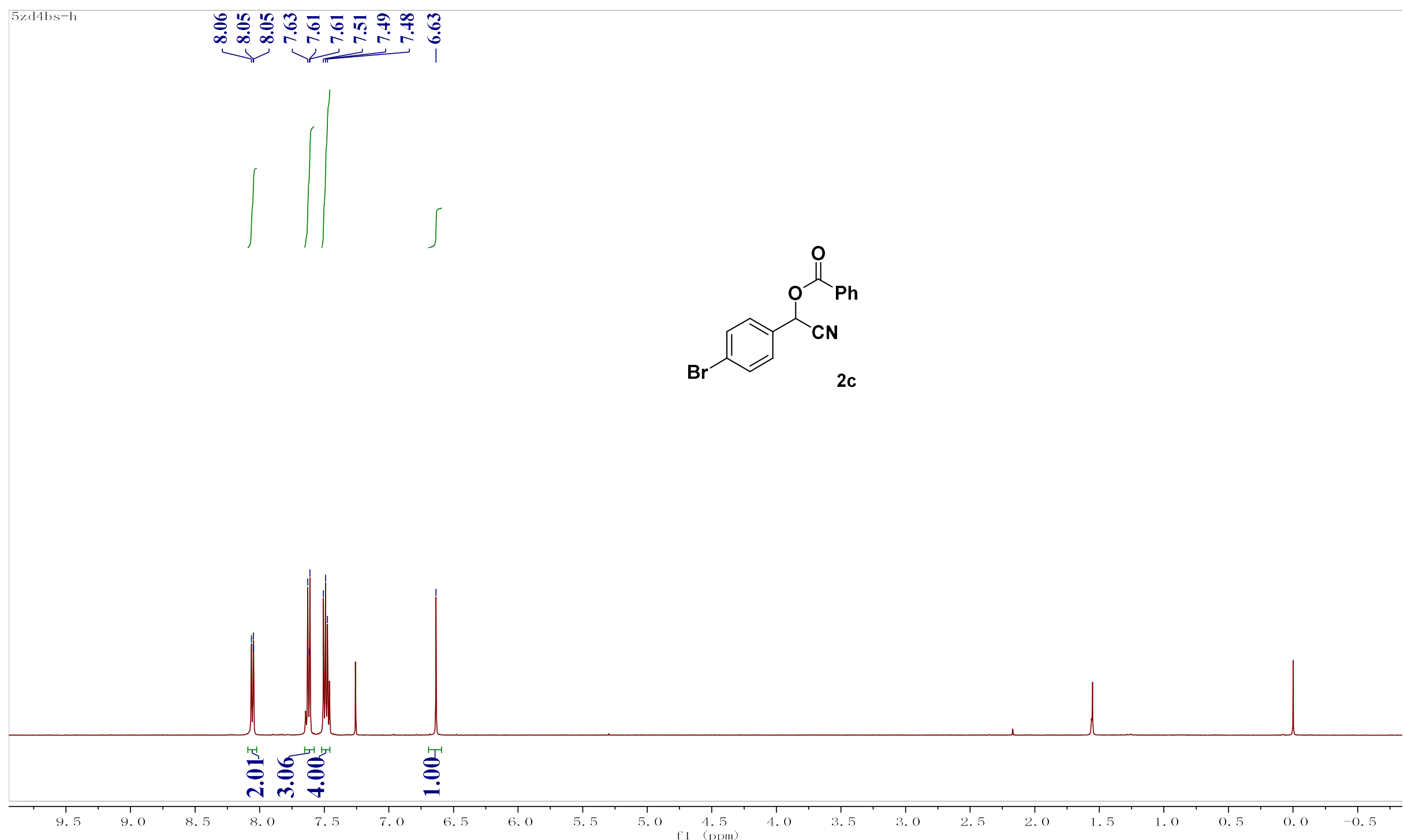

NMR-6 


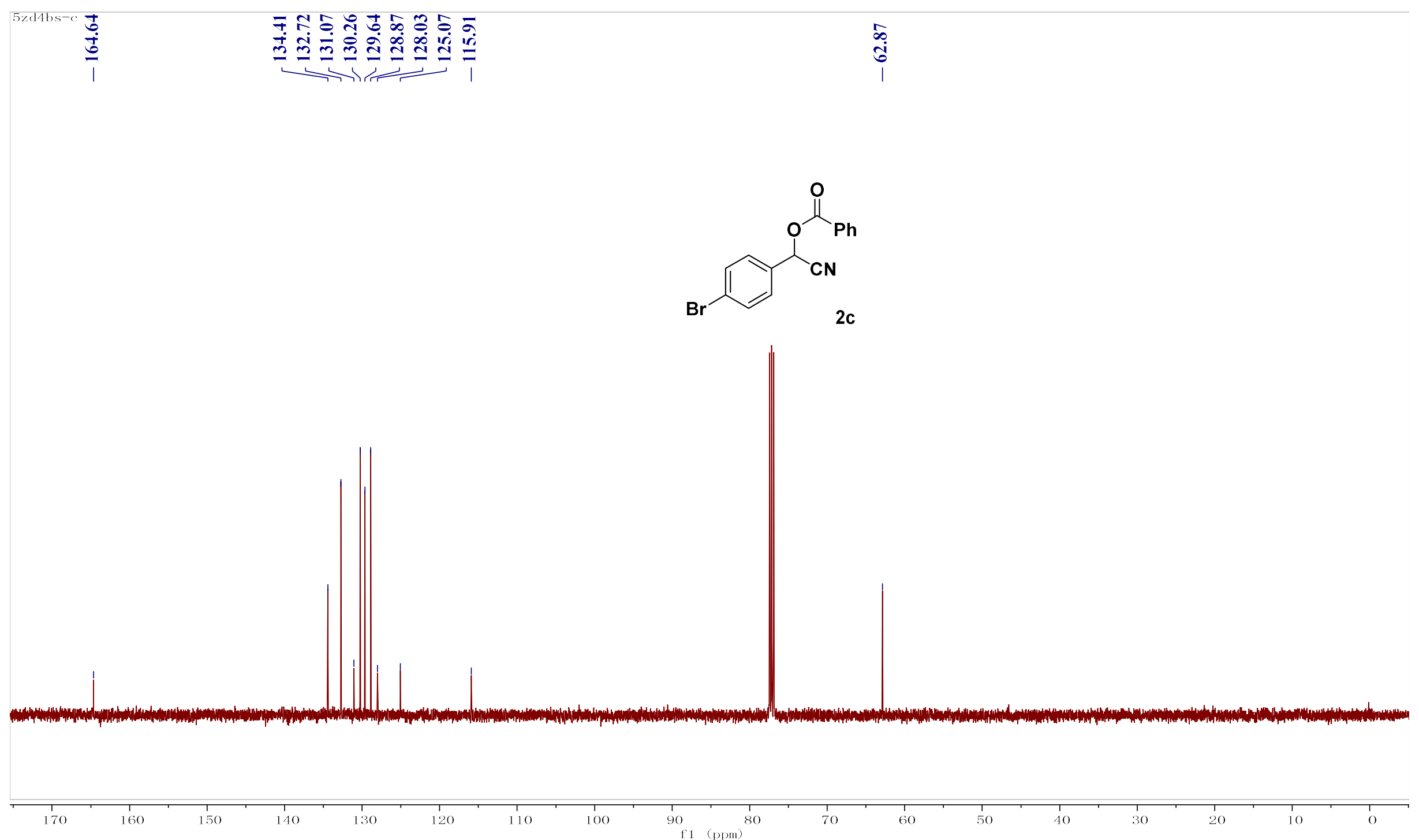

NMR-7 
5xdlbs-h
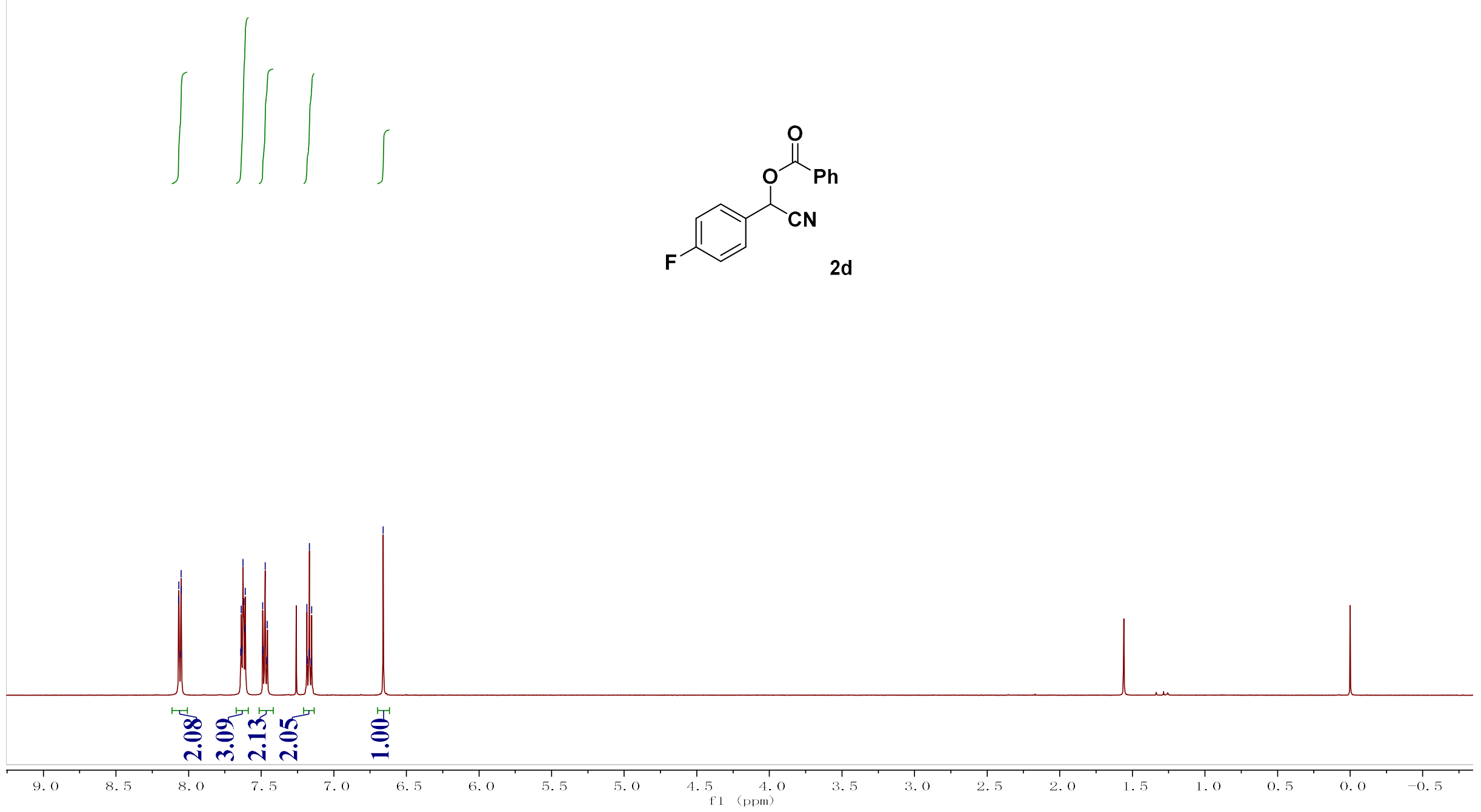

NMR-8 

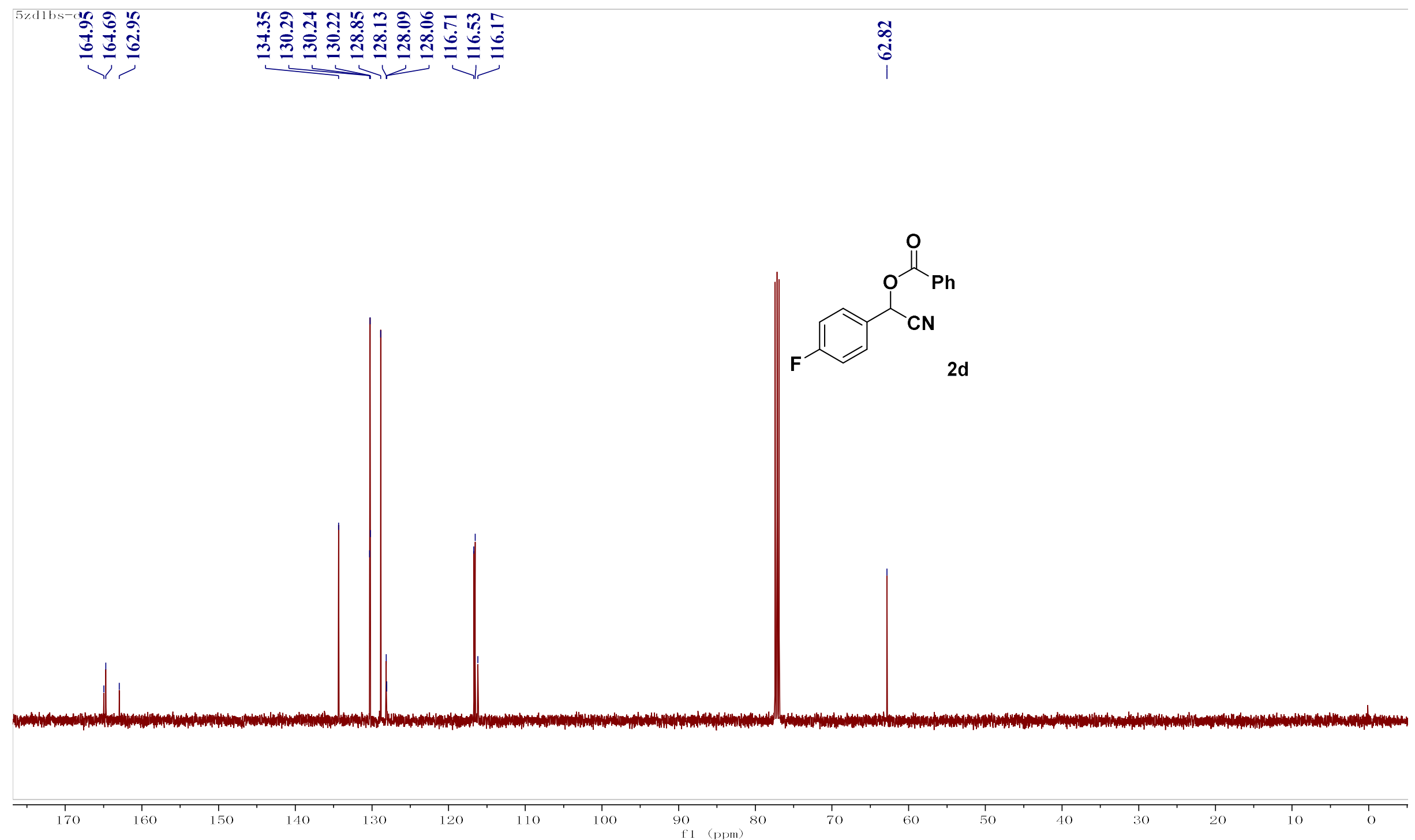

NMR-9 


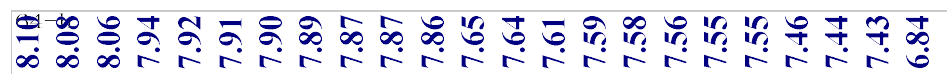
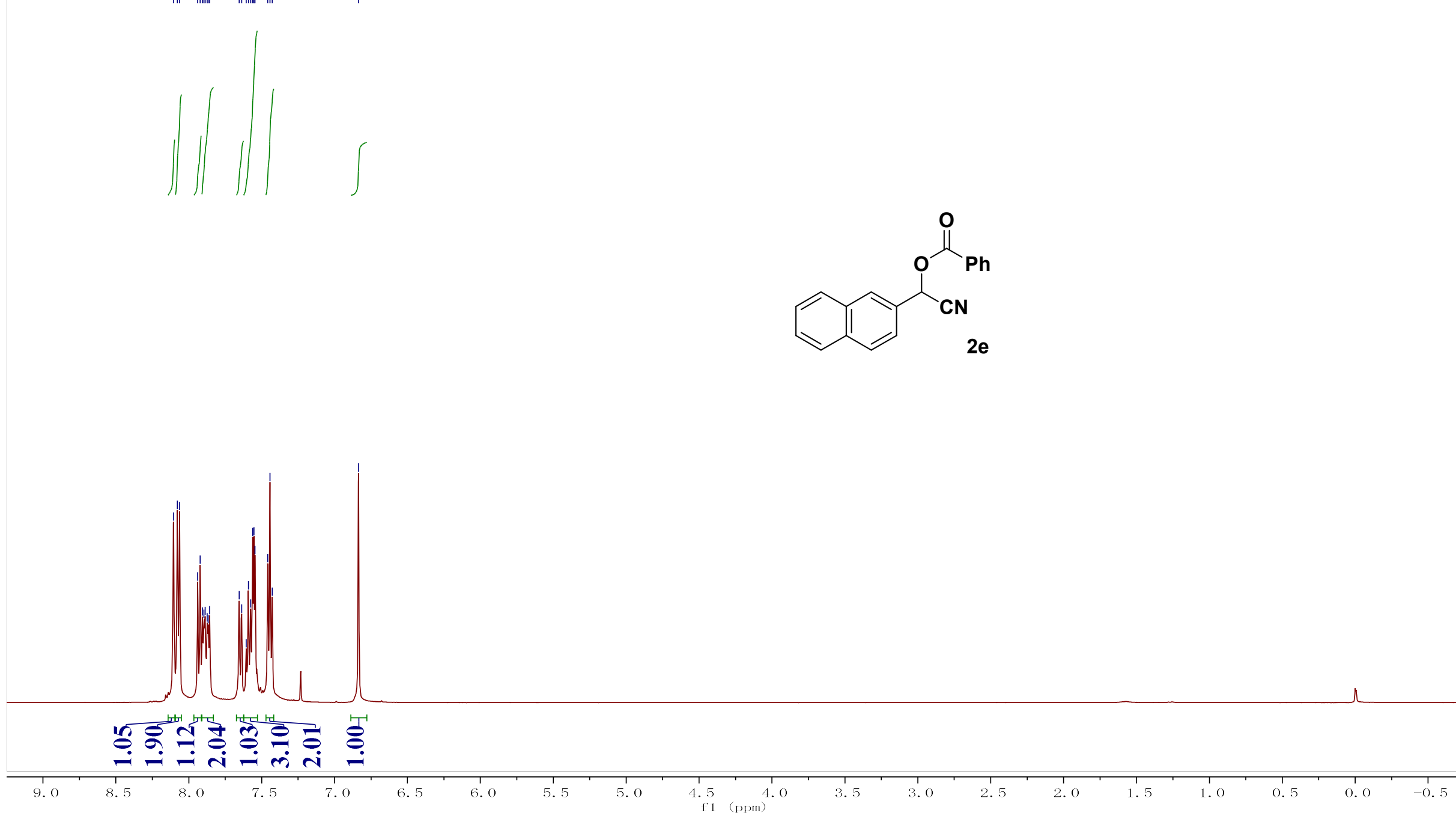

NMR-10 


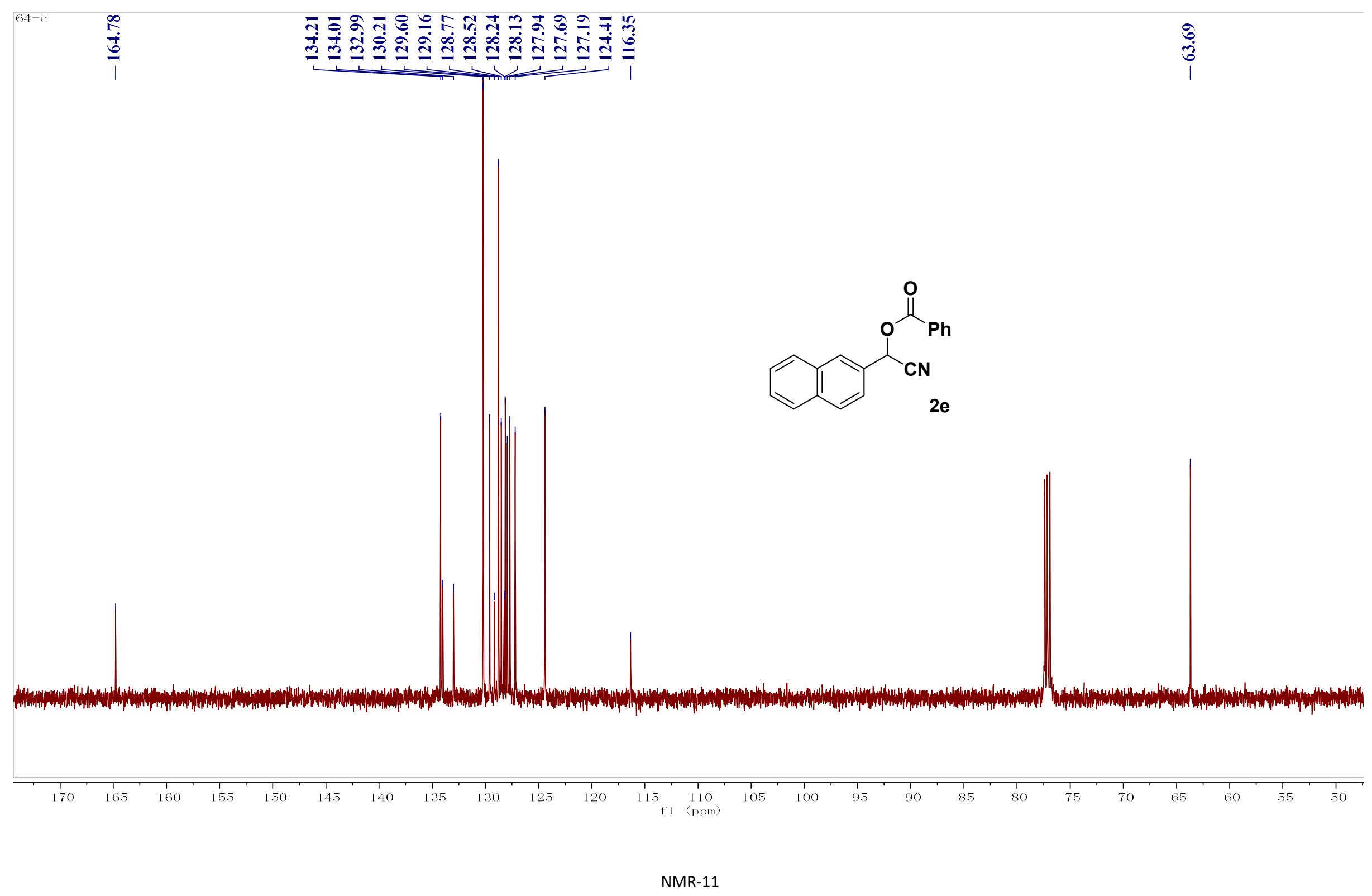




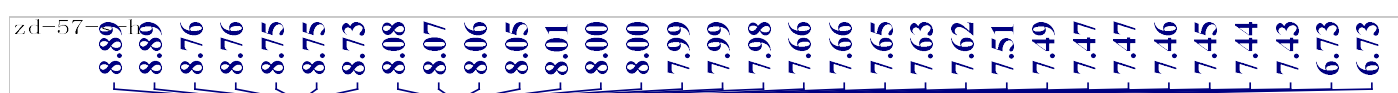
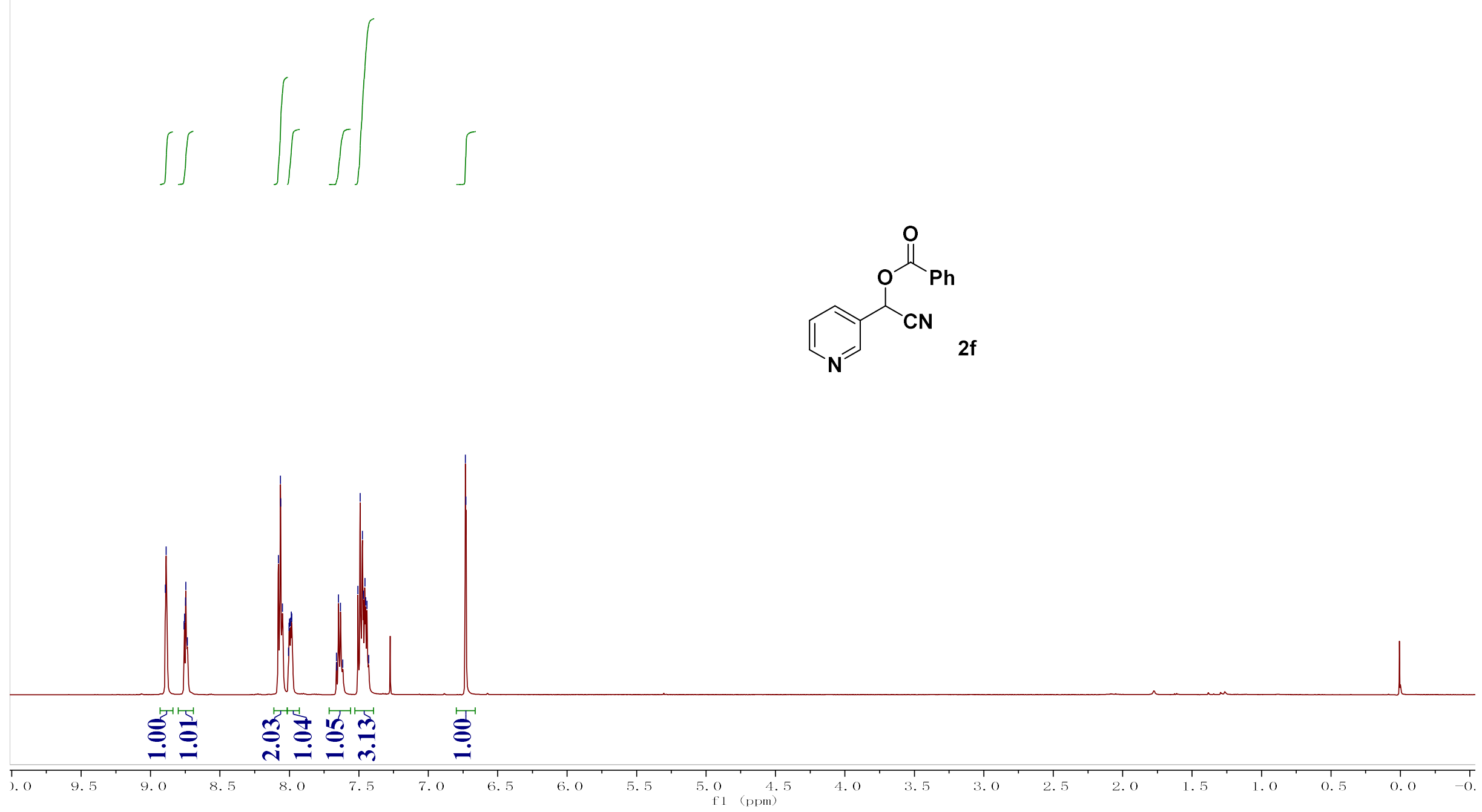

NMR-12 


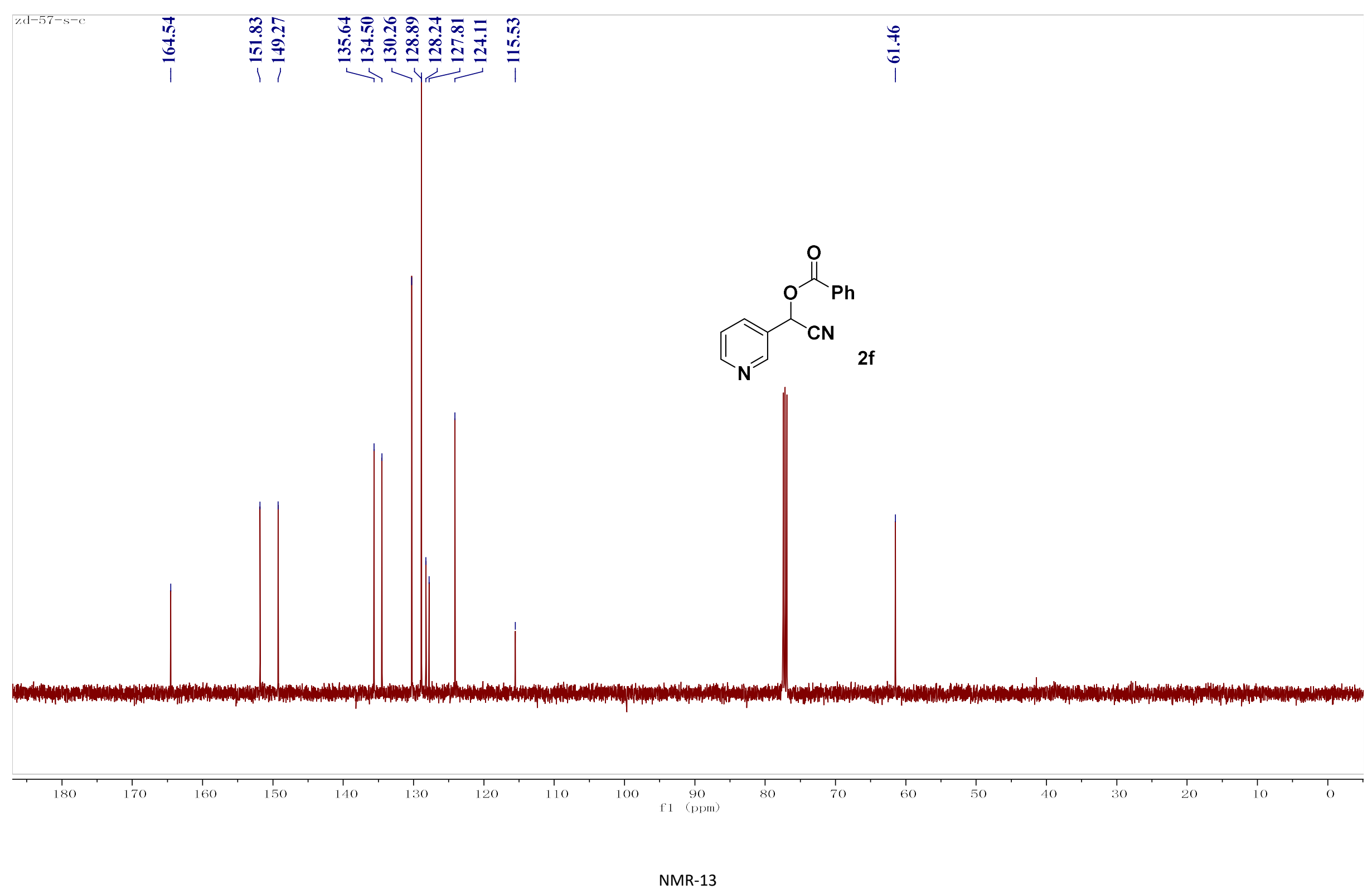




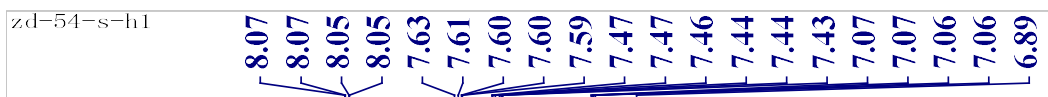
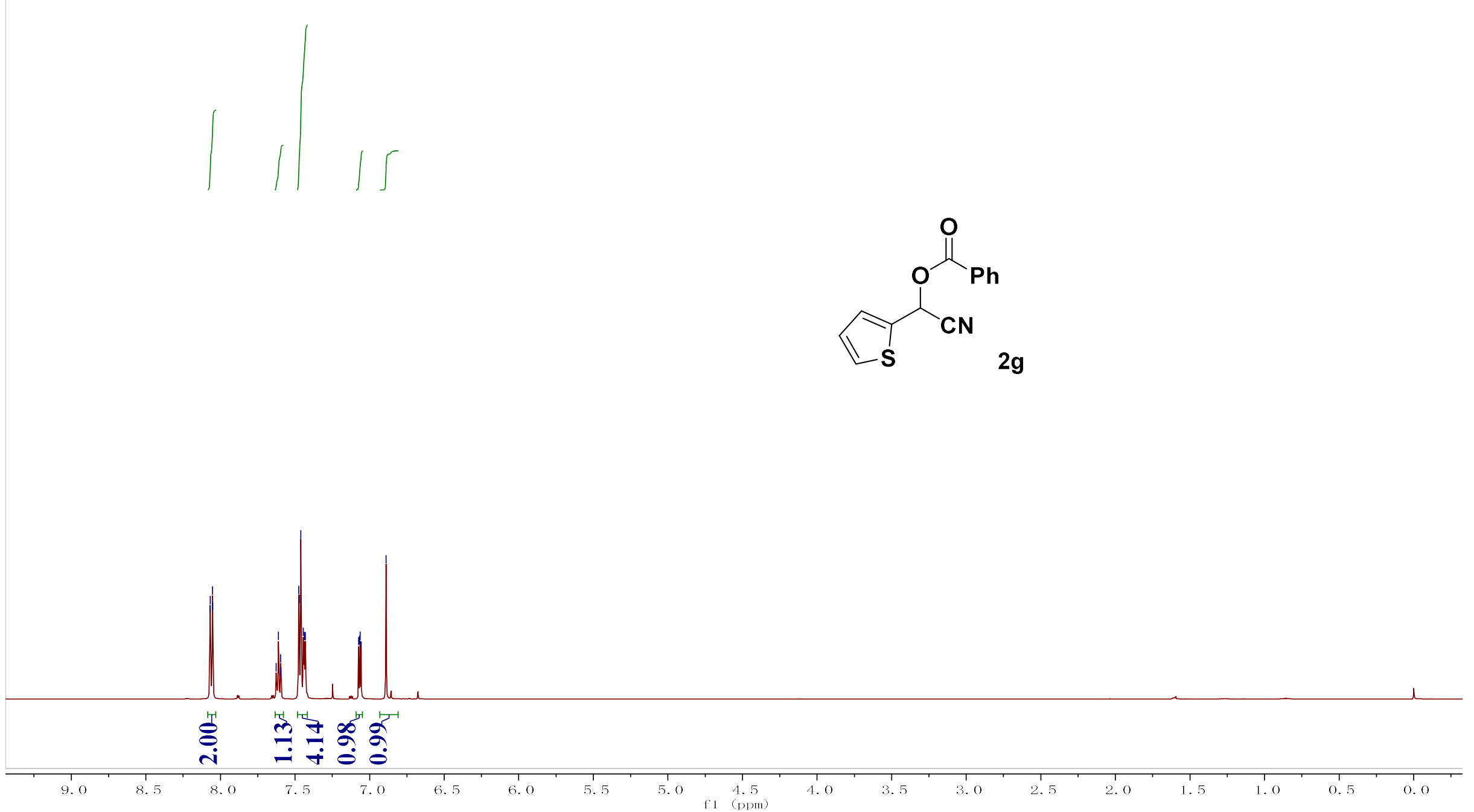

NMR-14 


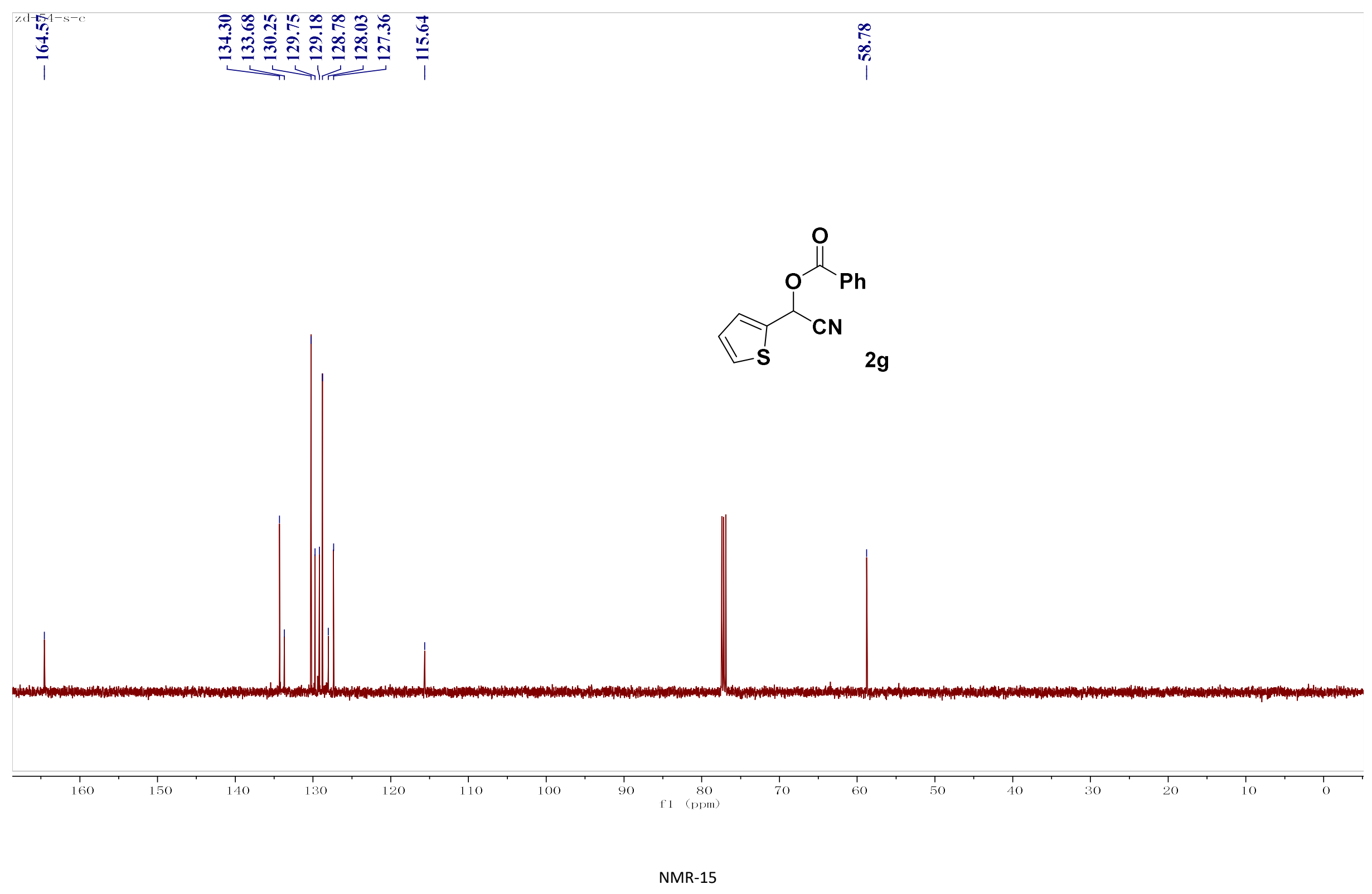




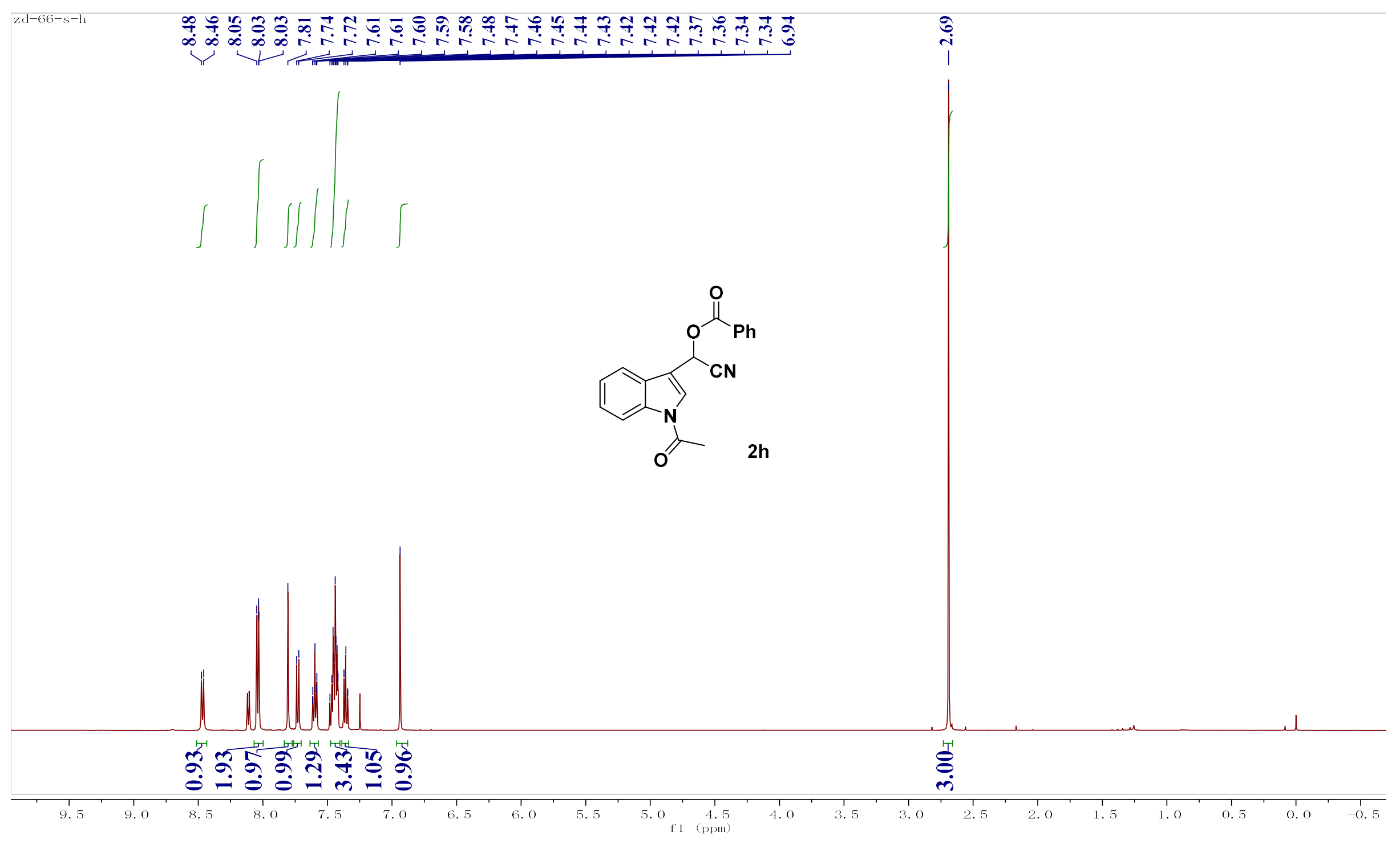

NMR-16 


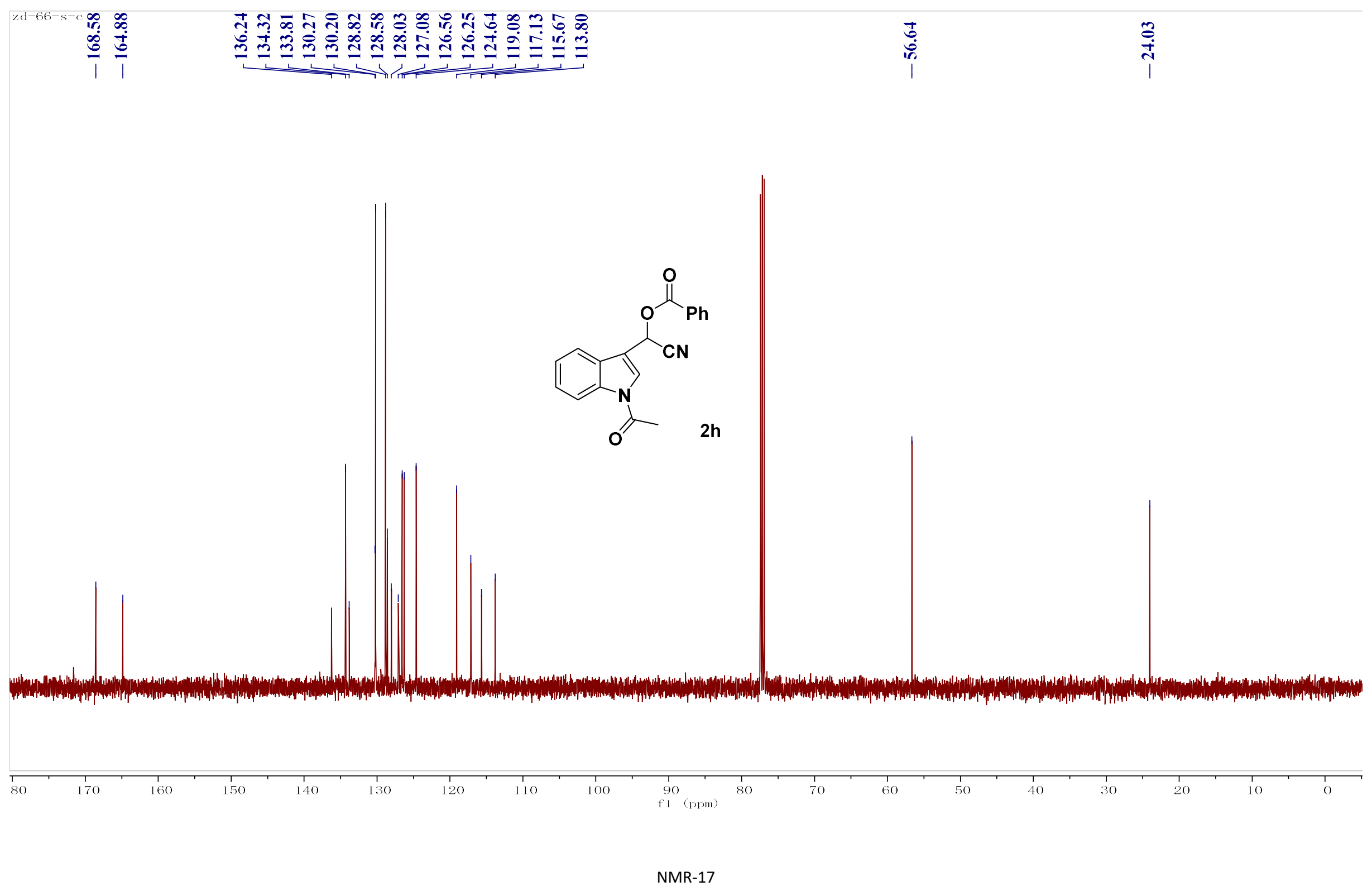




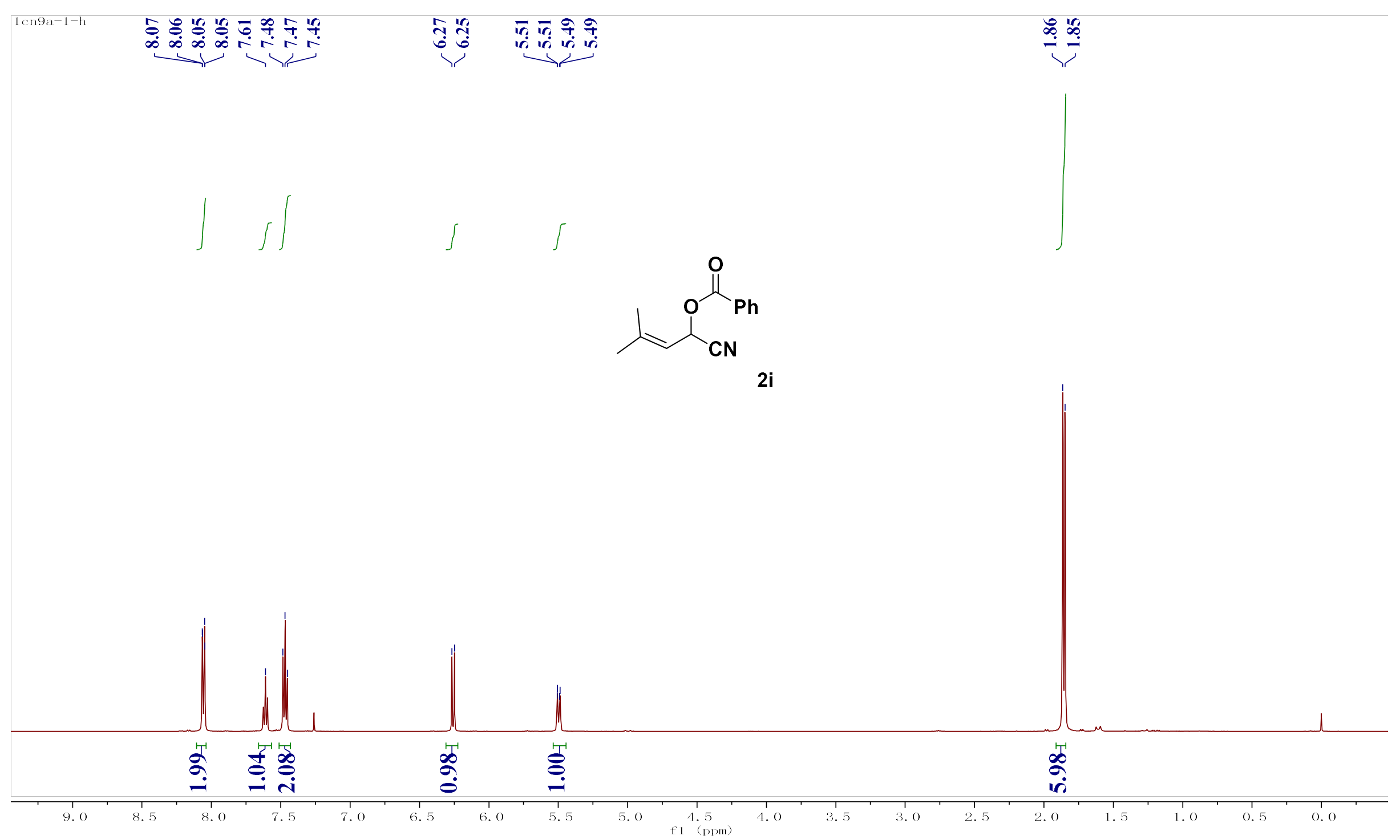

NMR-18 


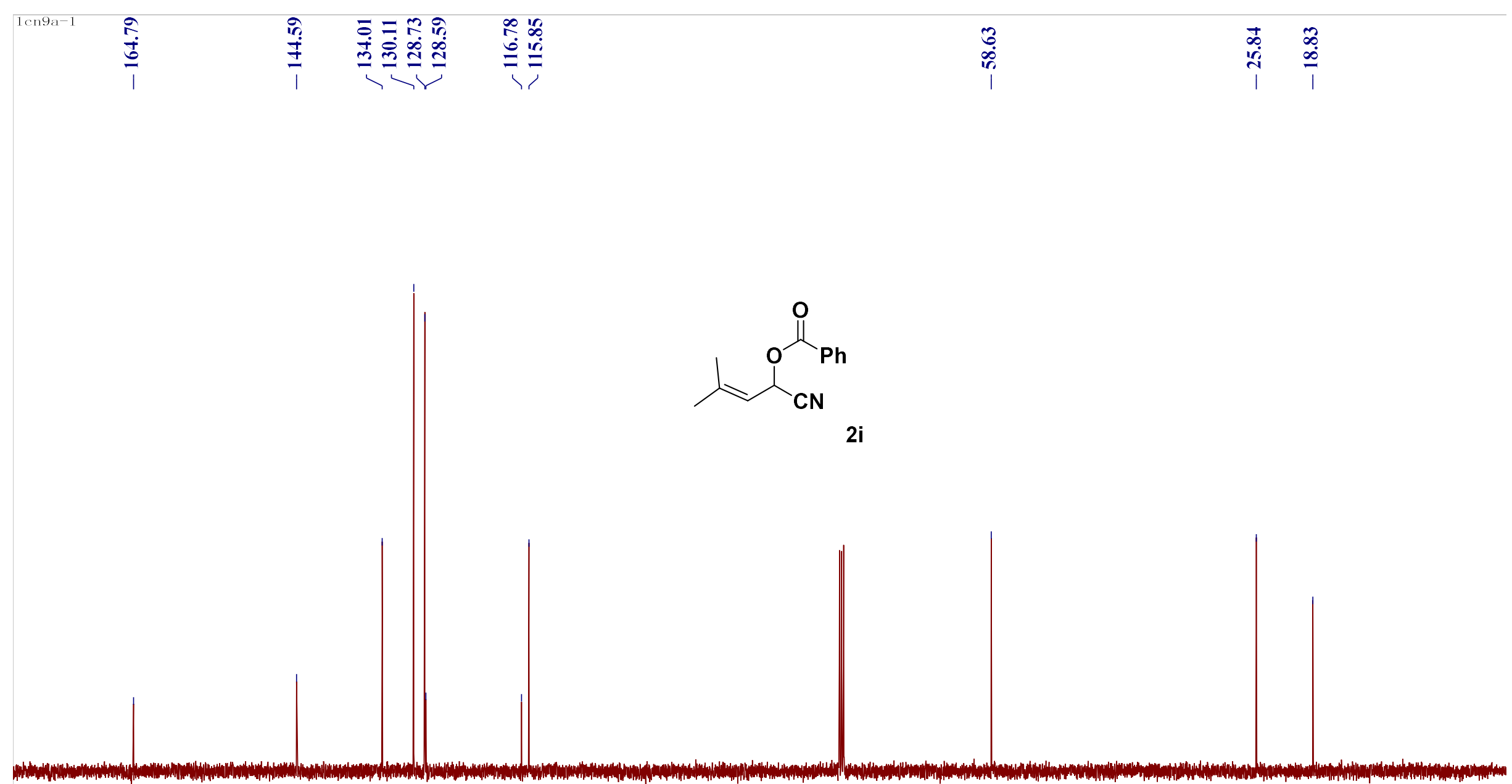




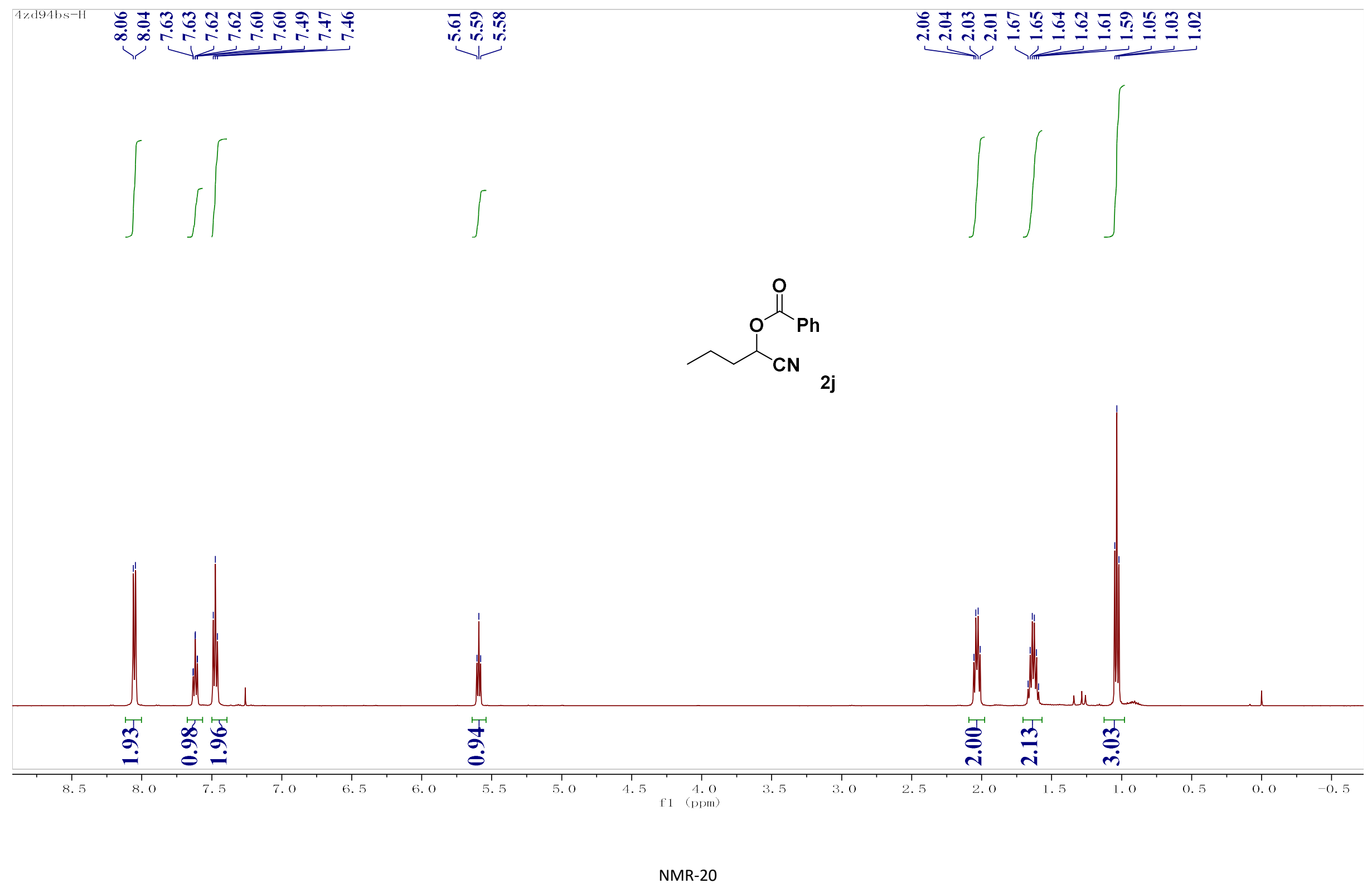




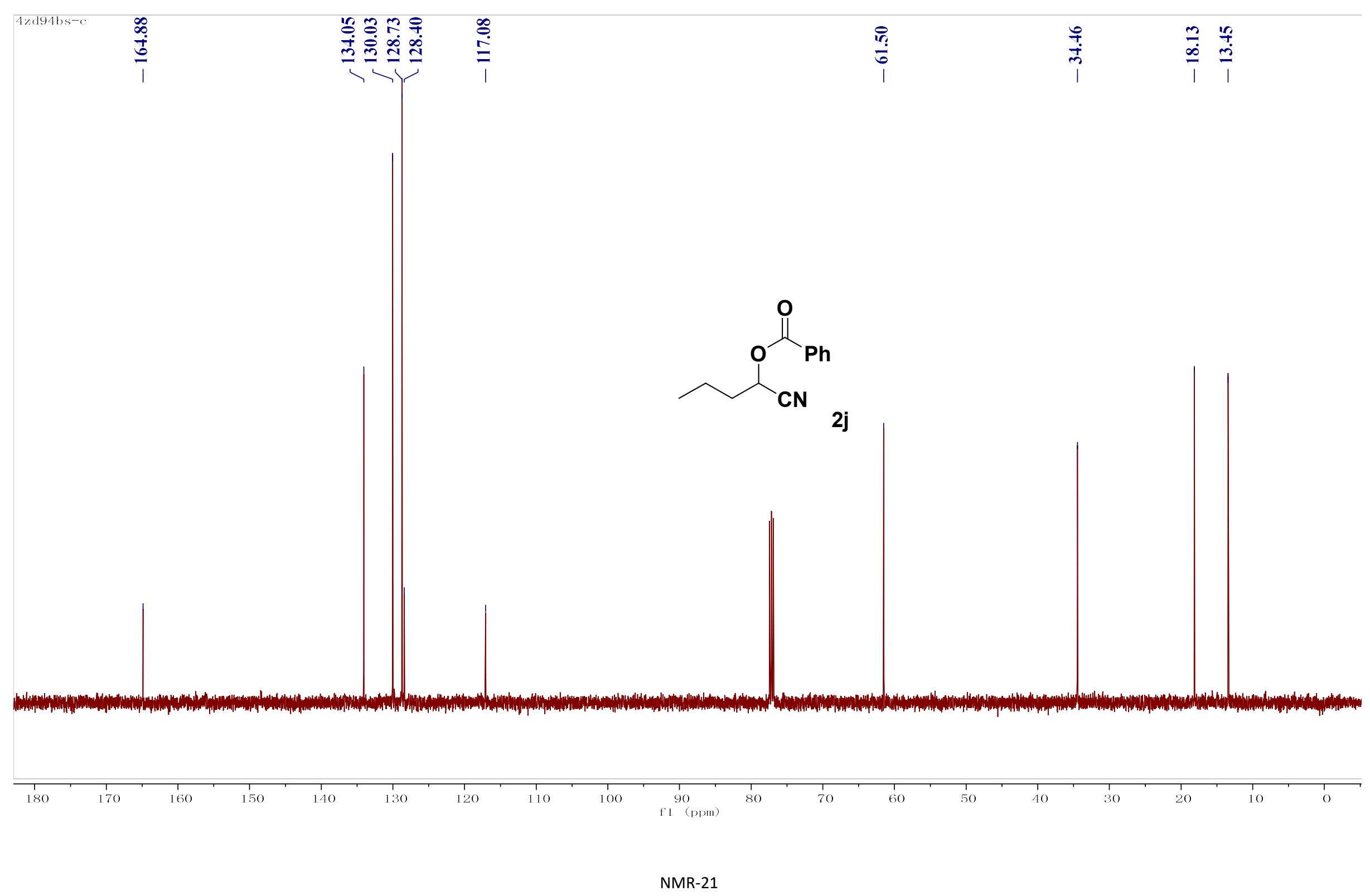




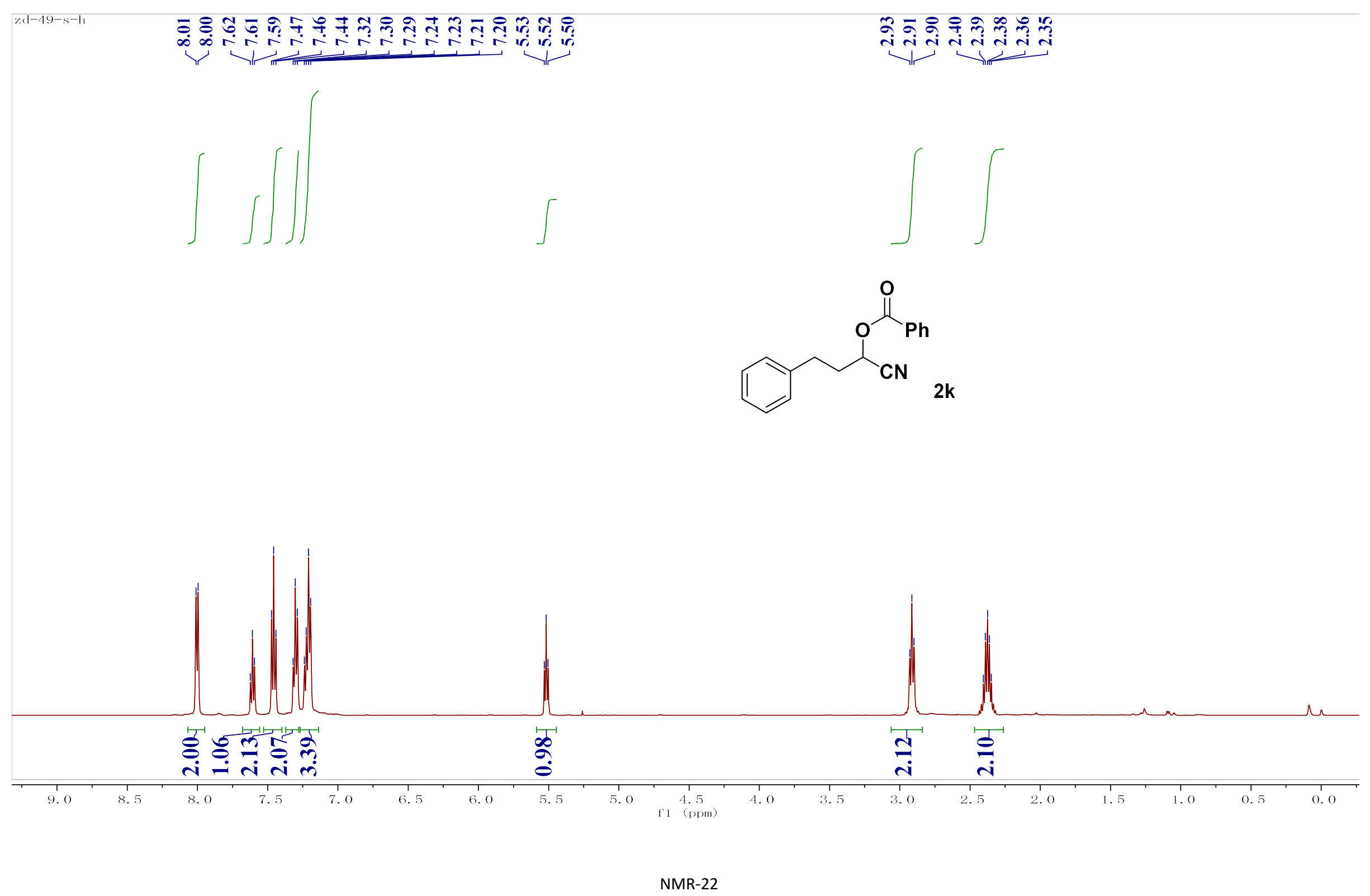




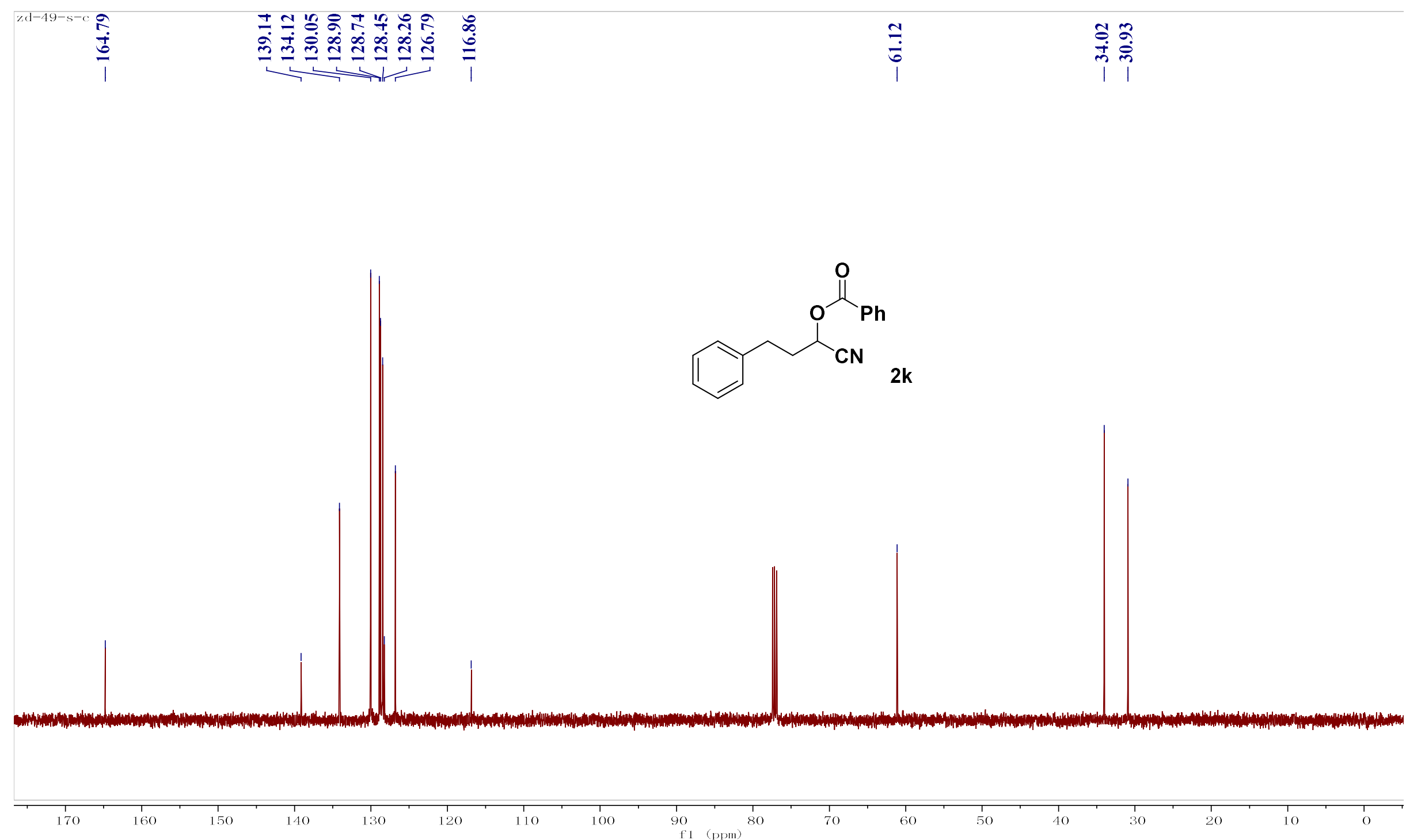




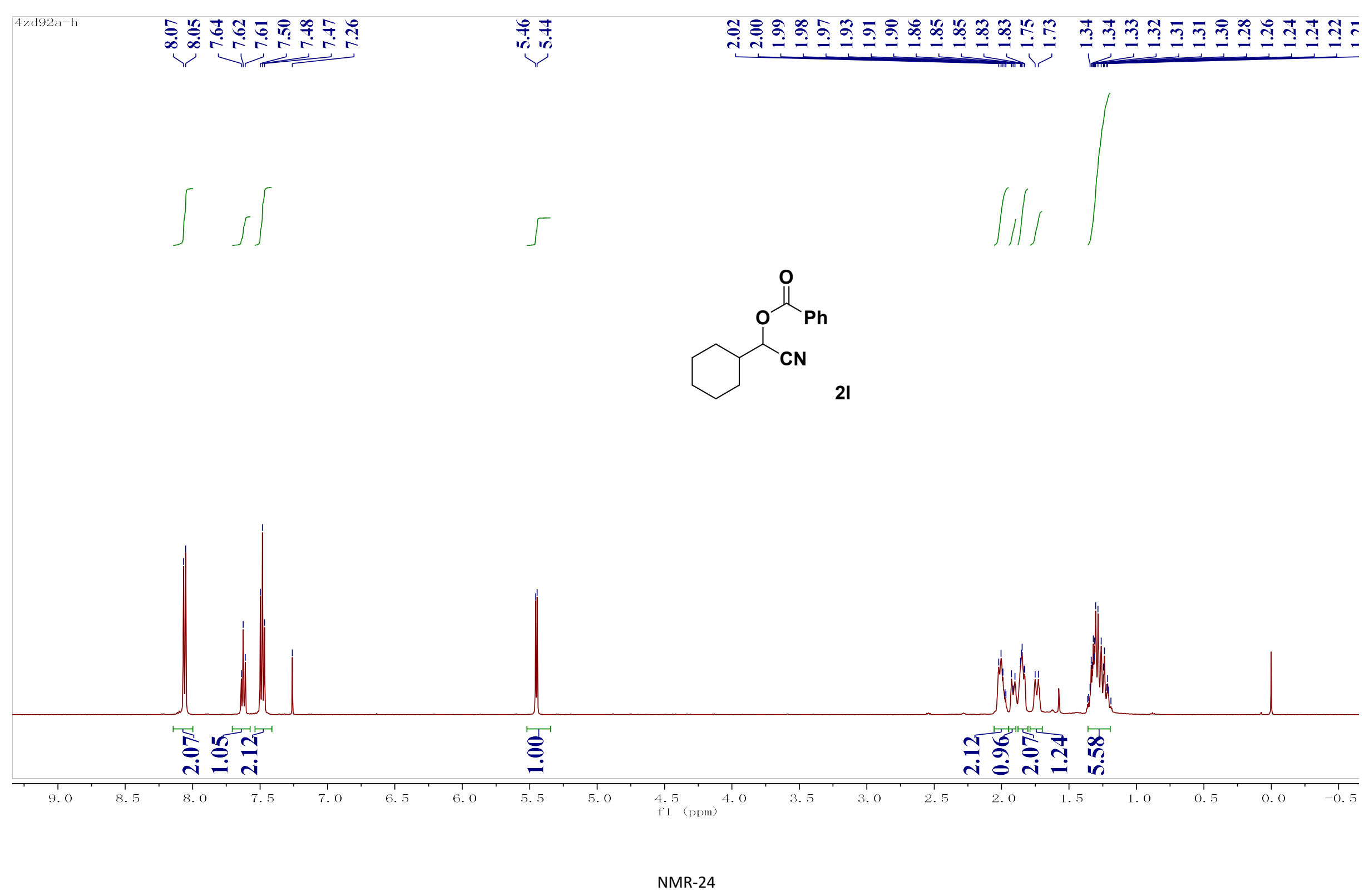




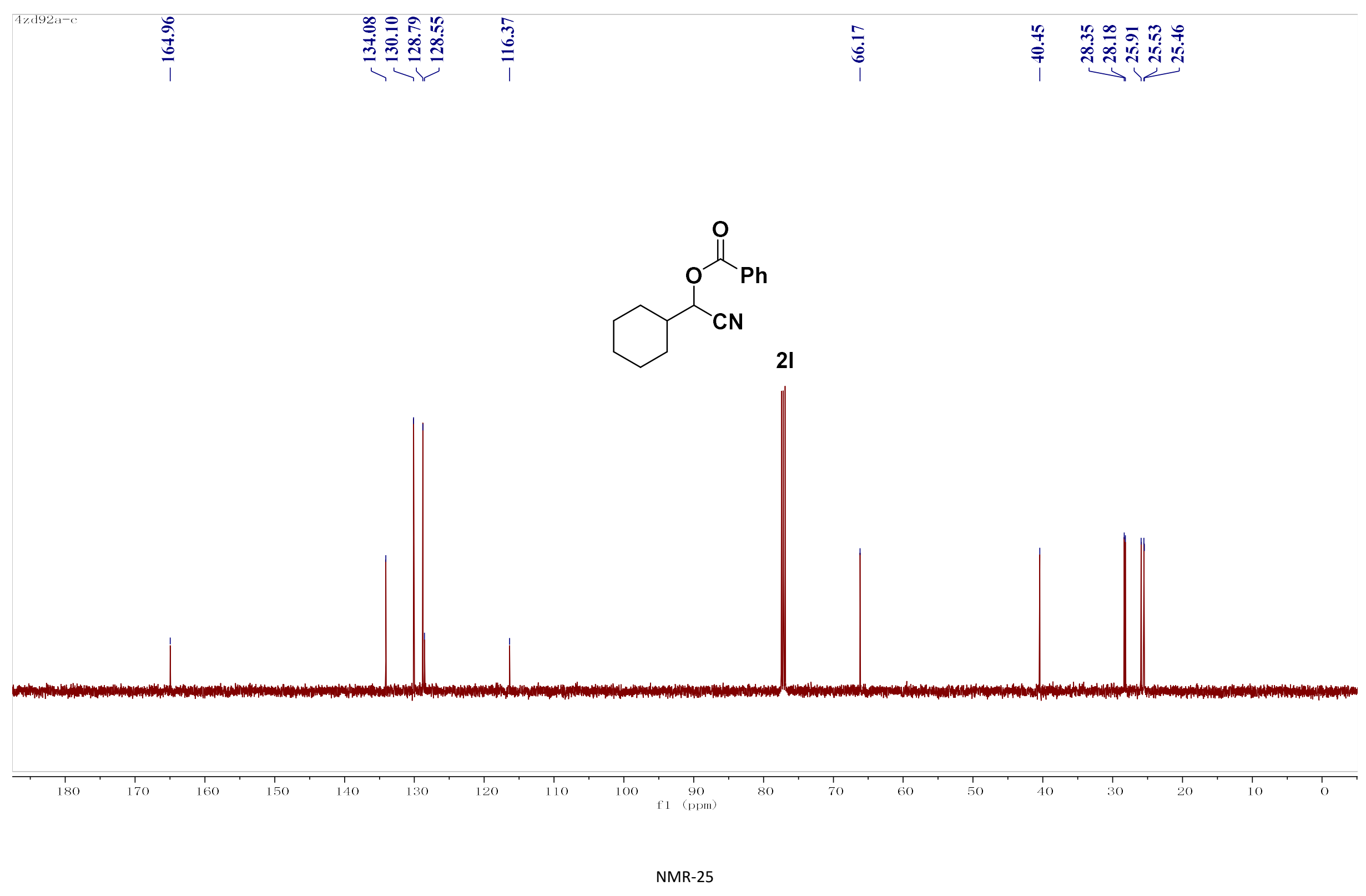




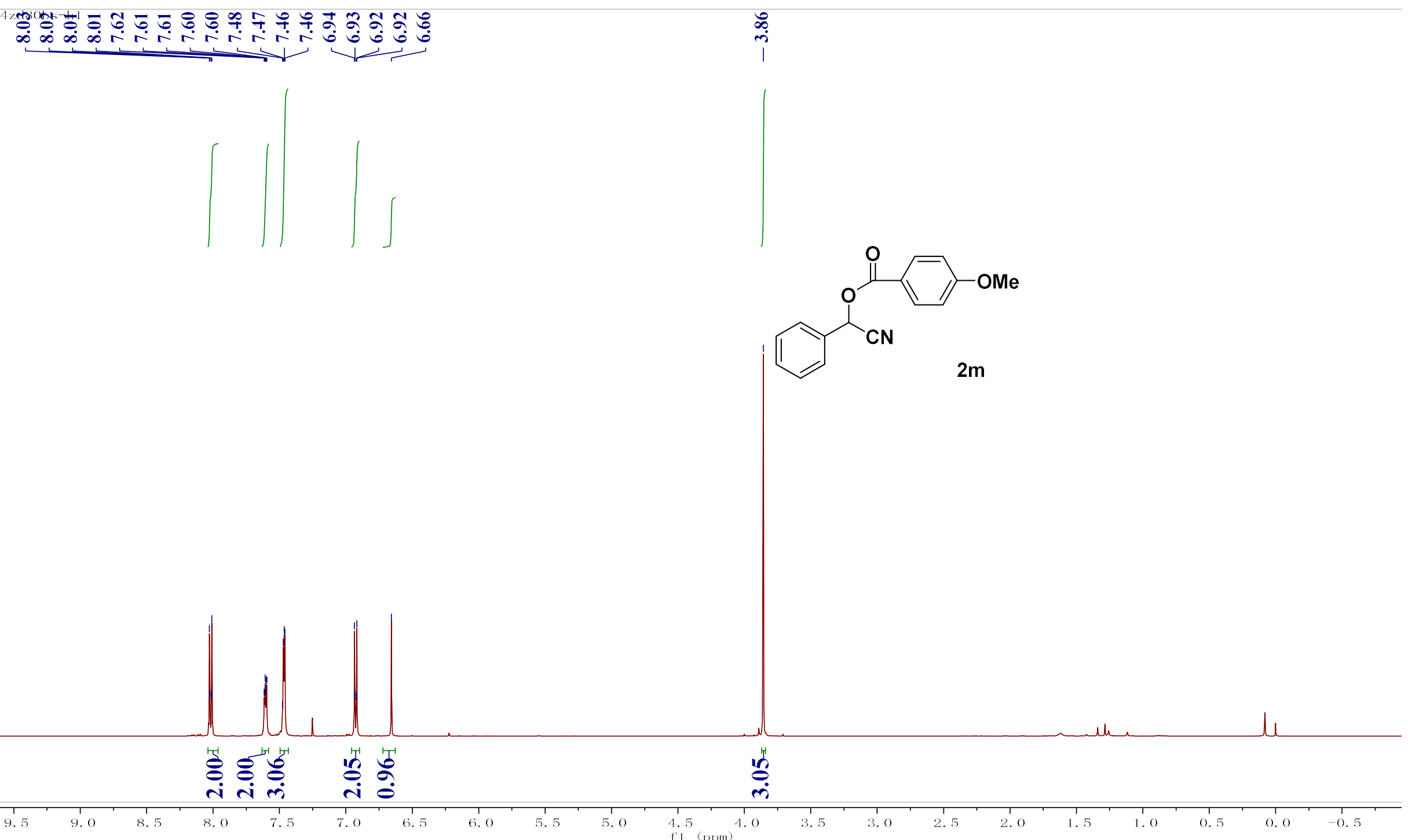

NMR-26 

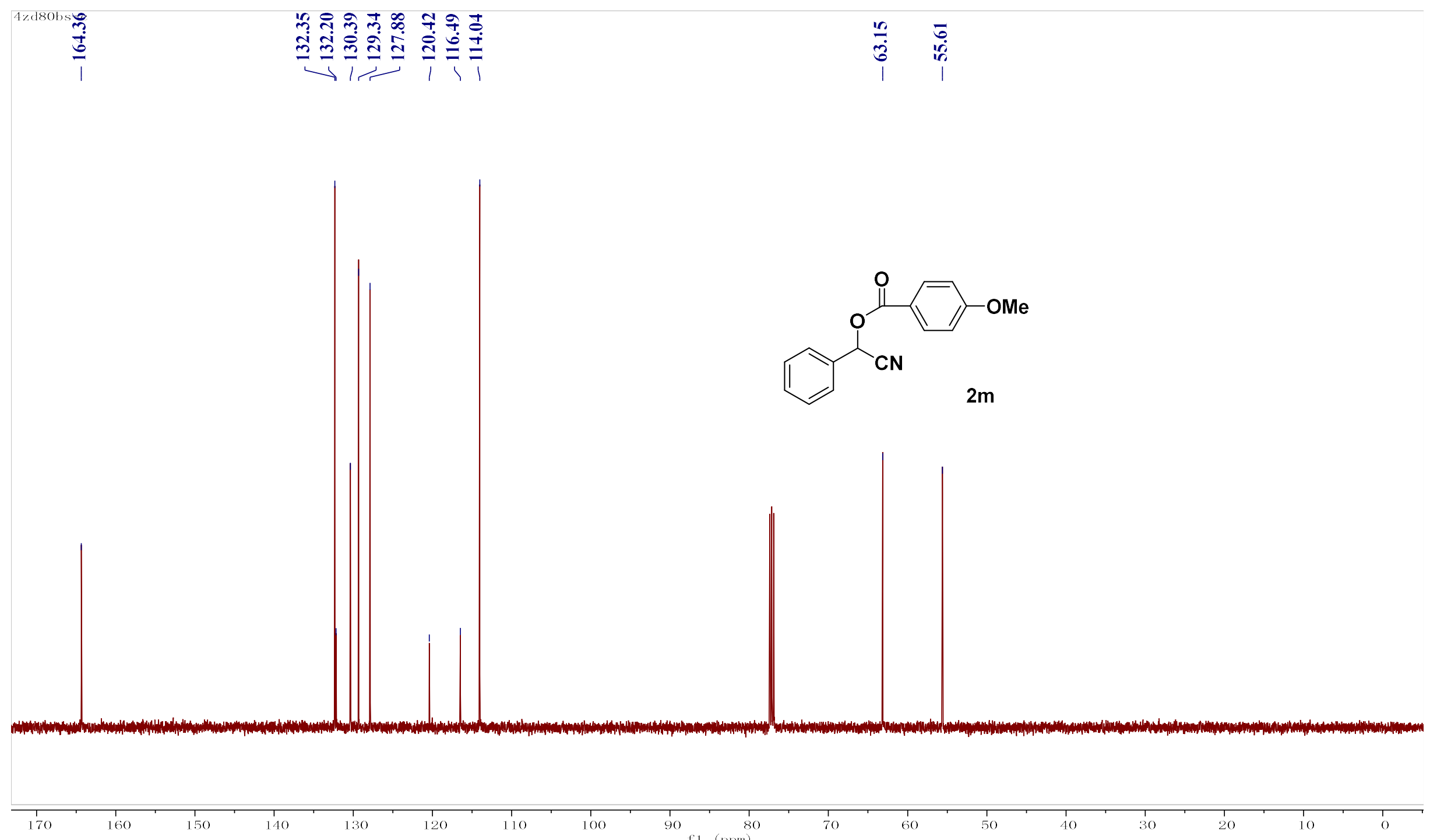

NMR-27 


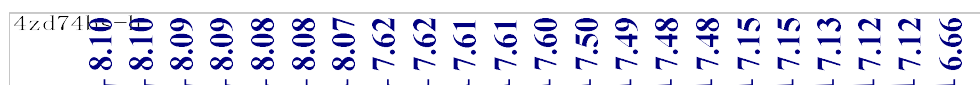
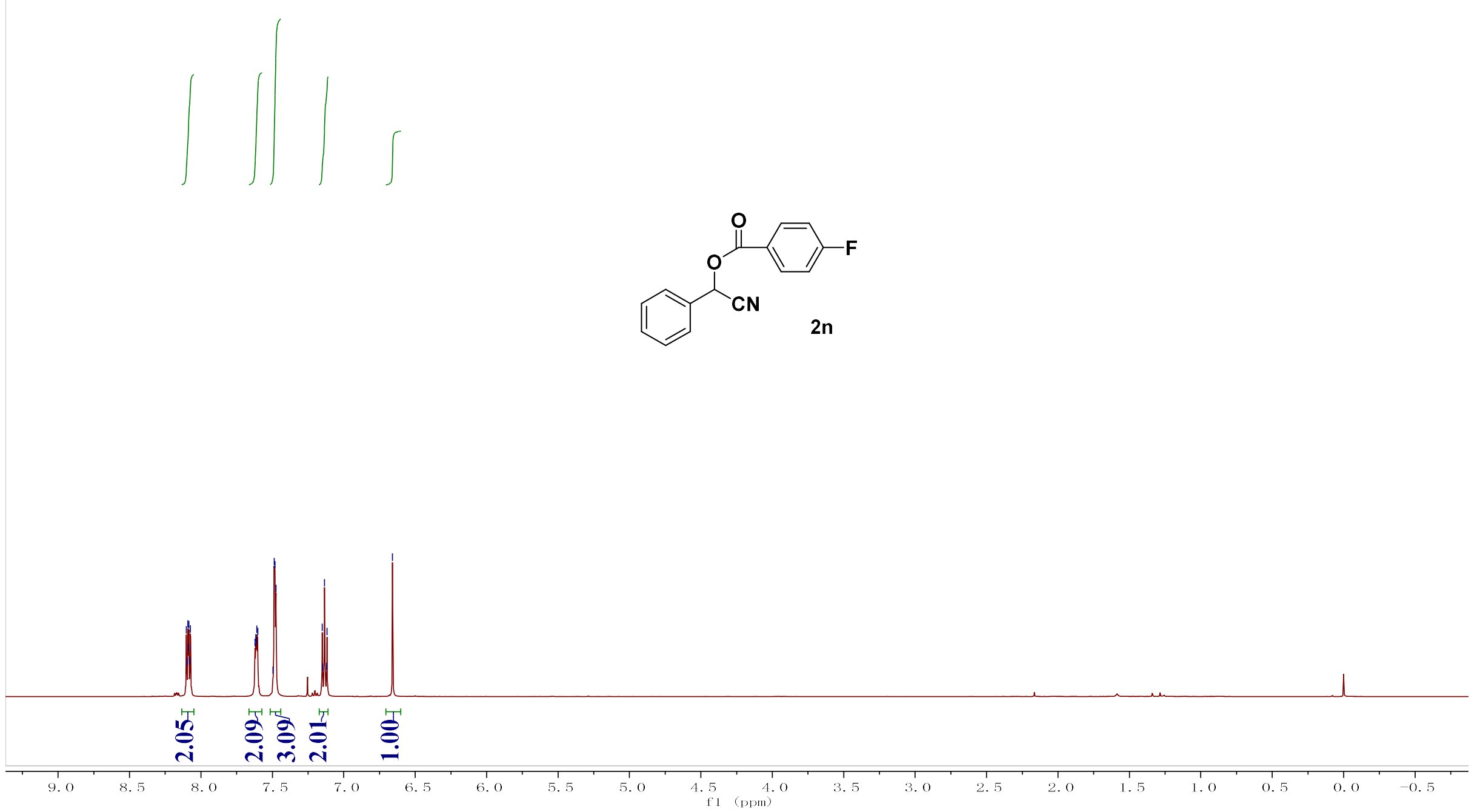

NMR-28 

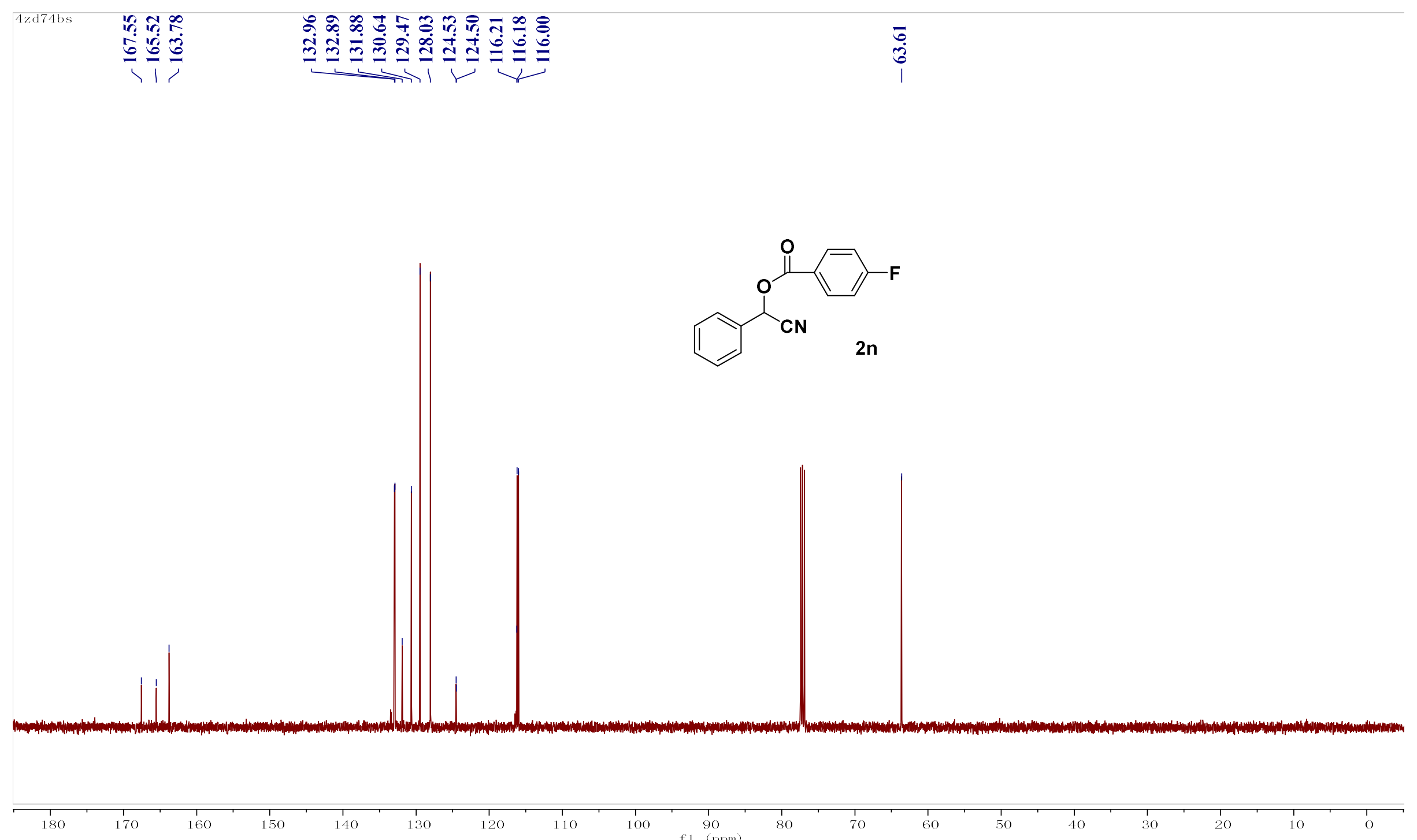

NMR-29 


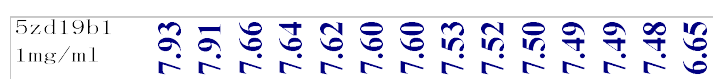
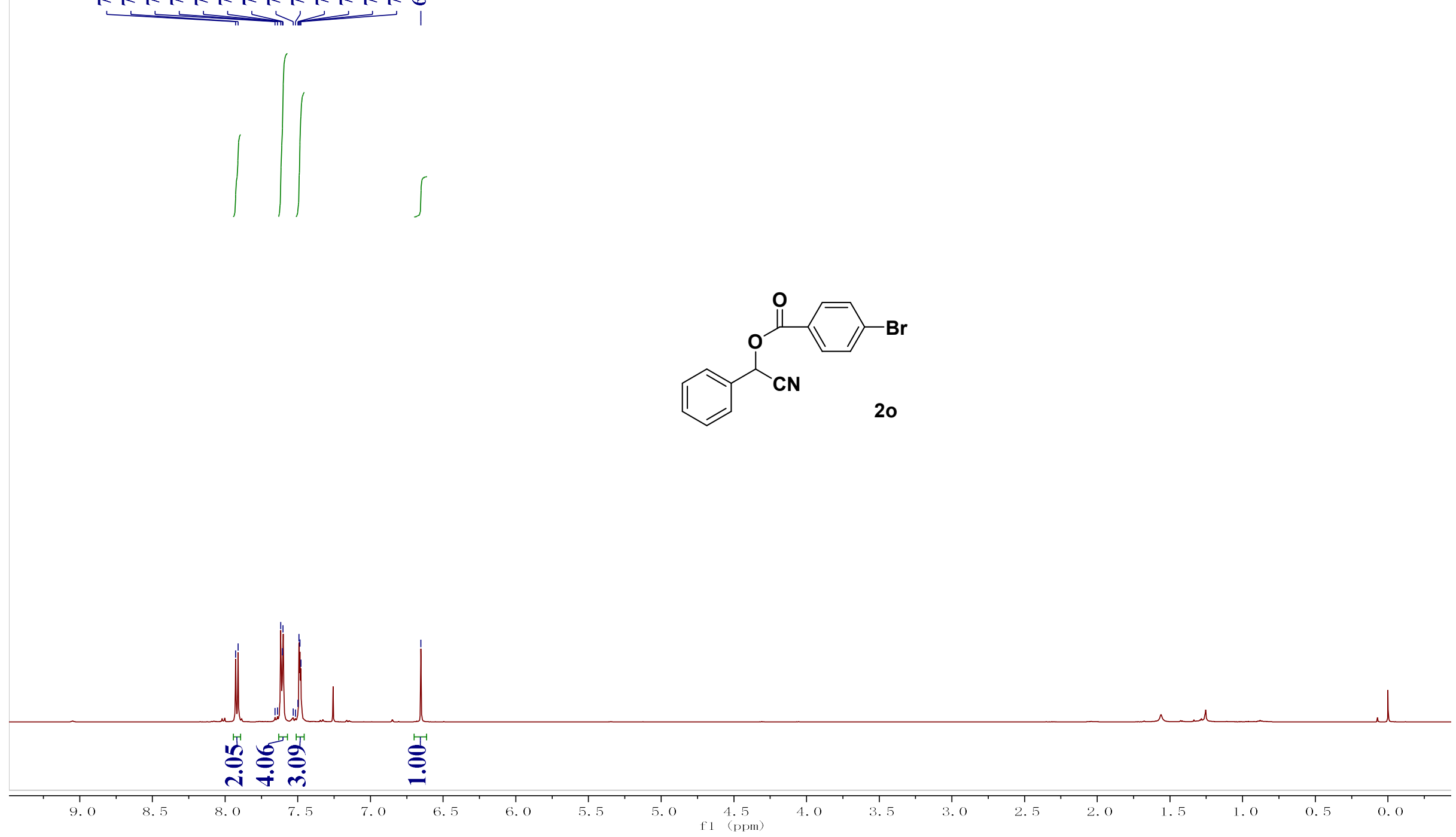

NMR-30 

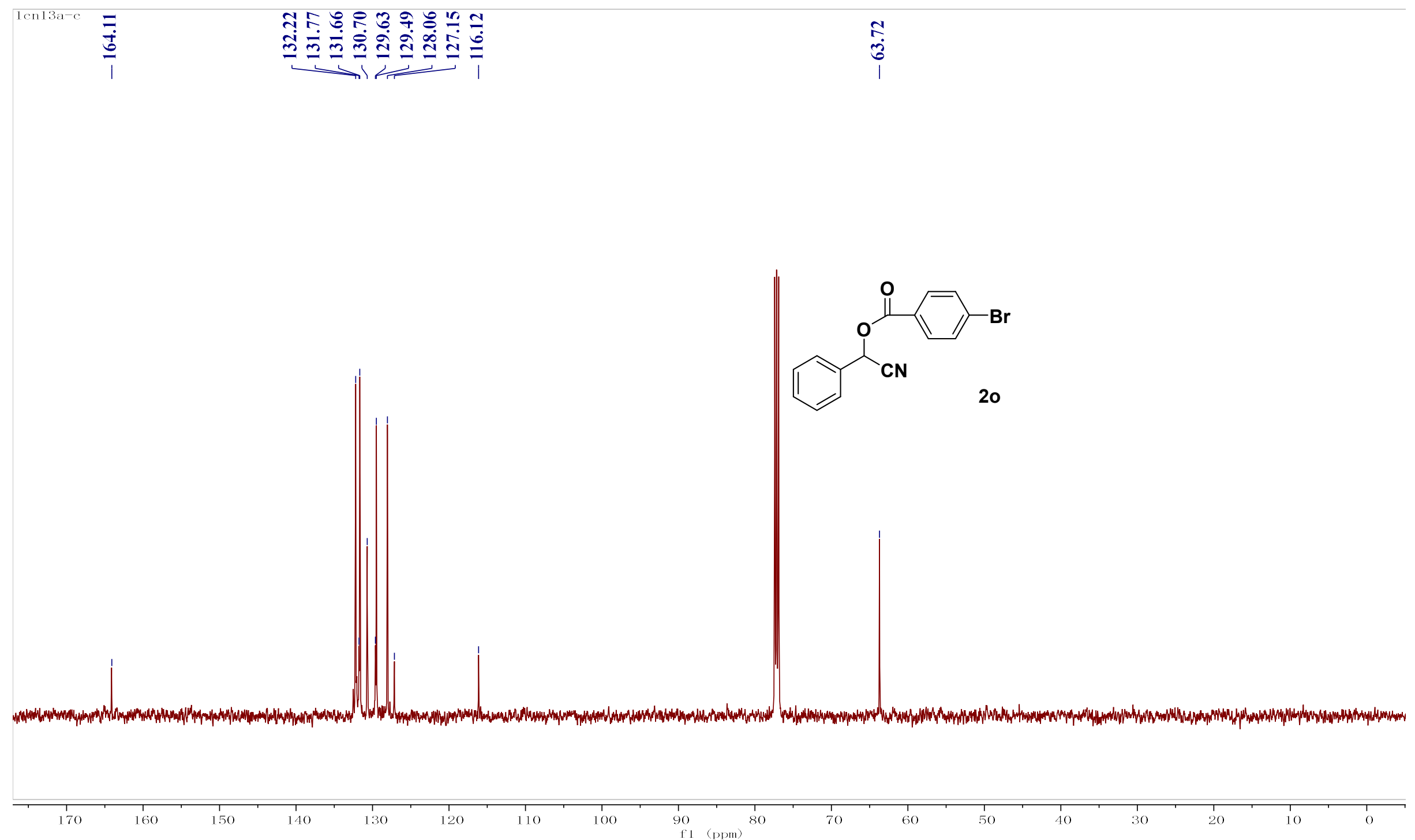
1ent6h-h
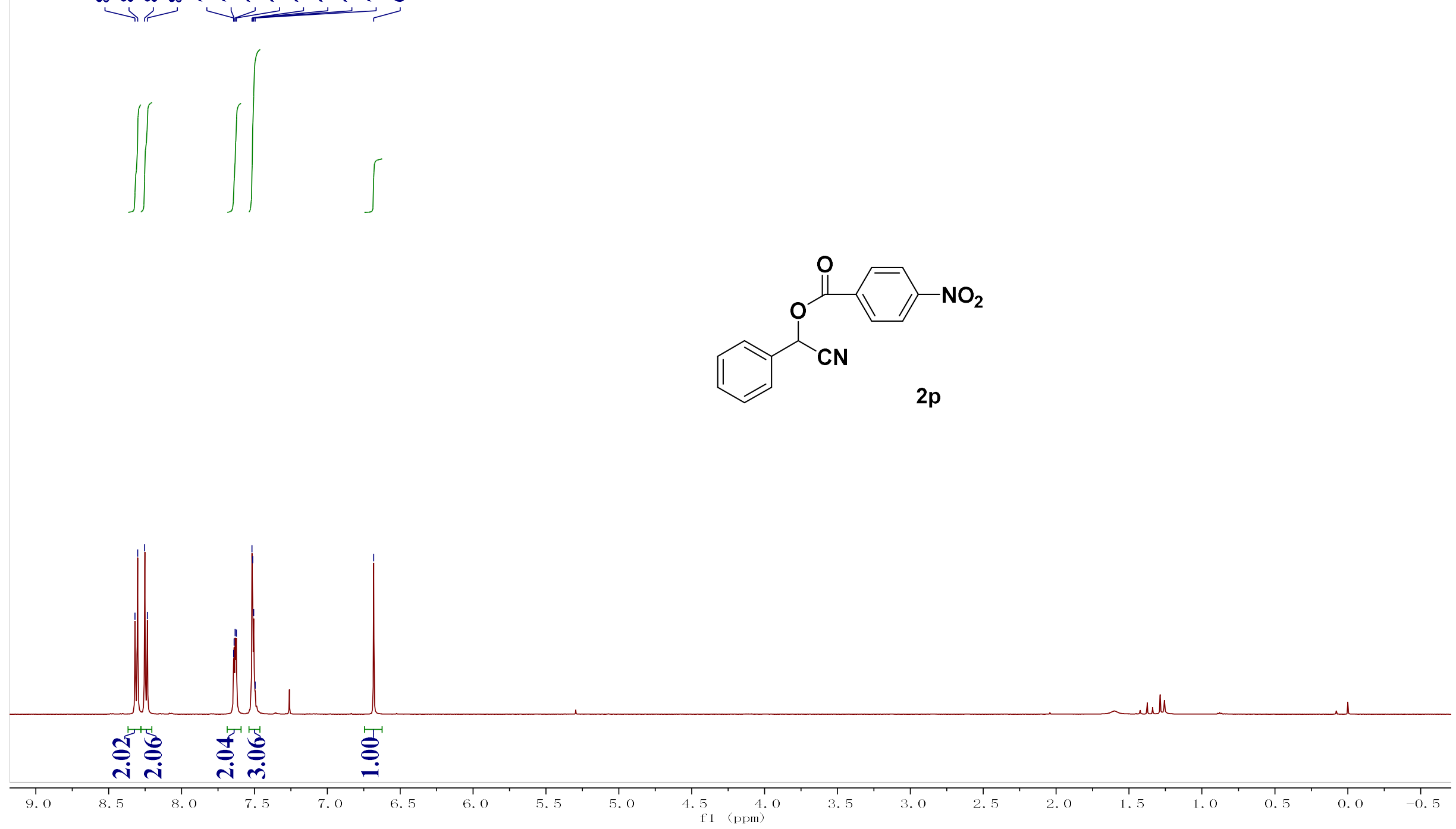

NMR-32 

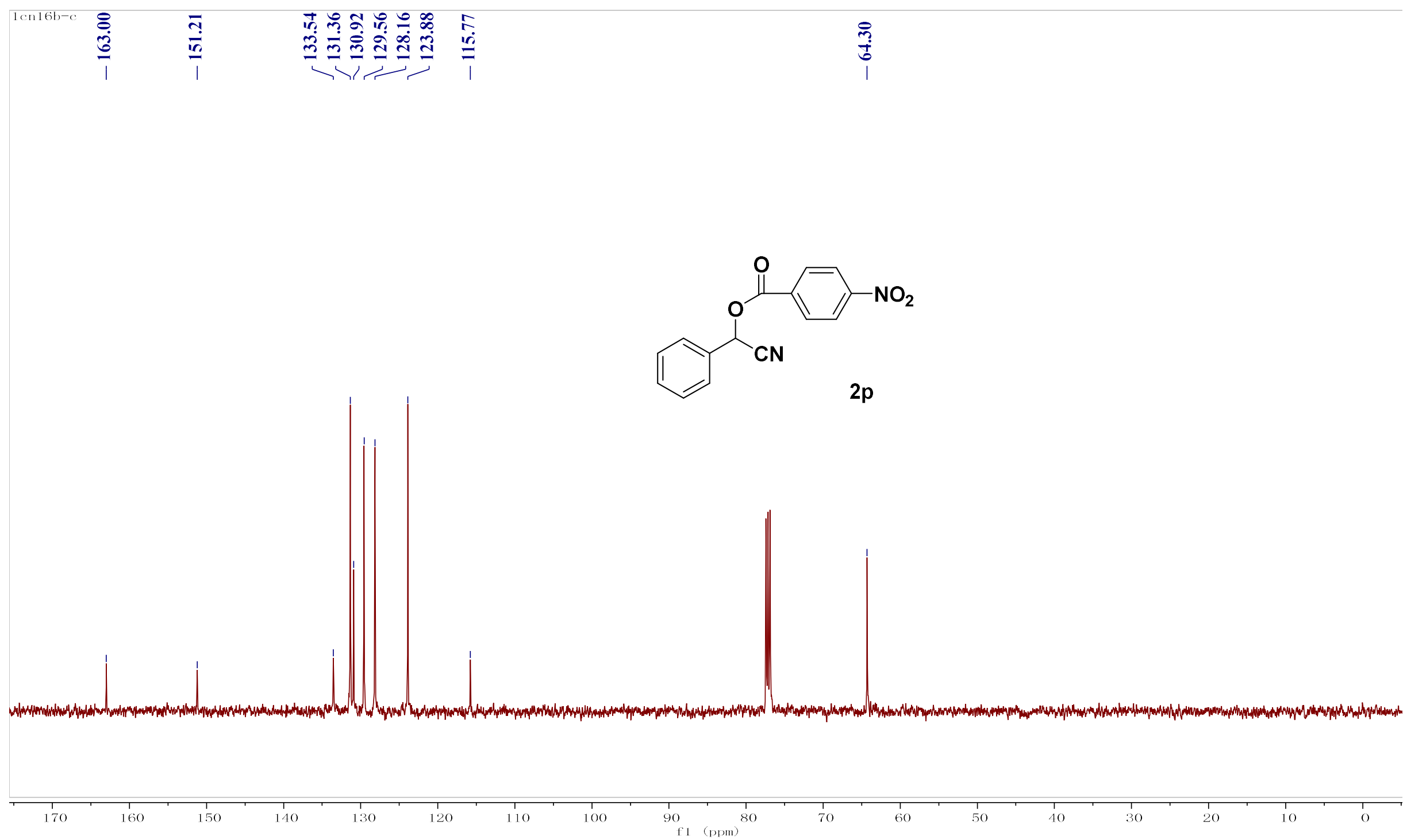


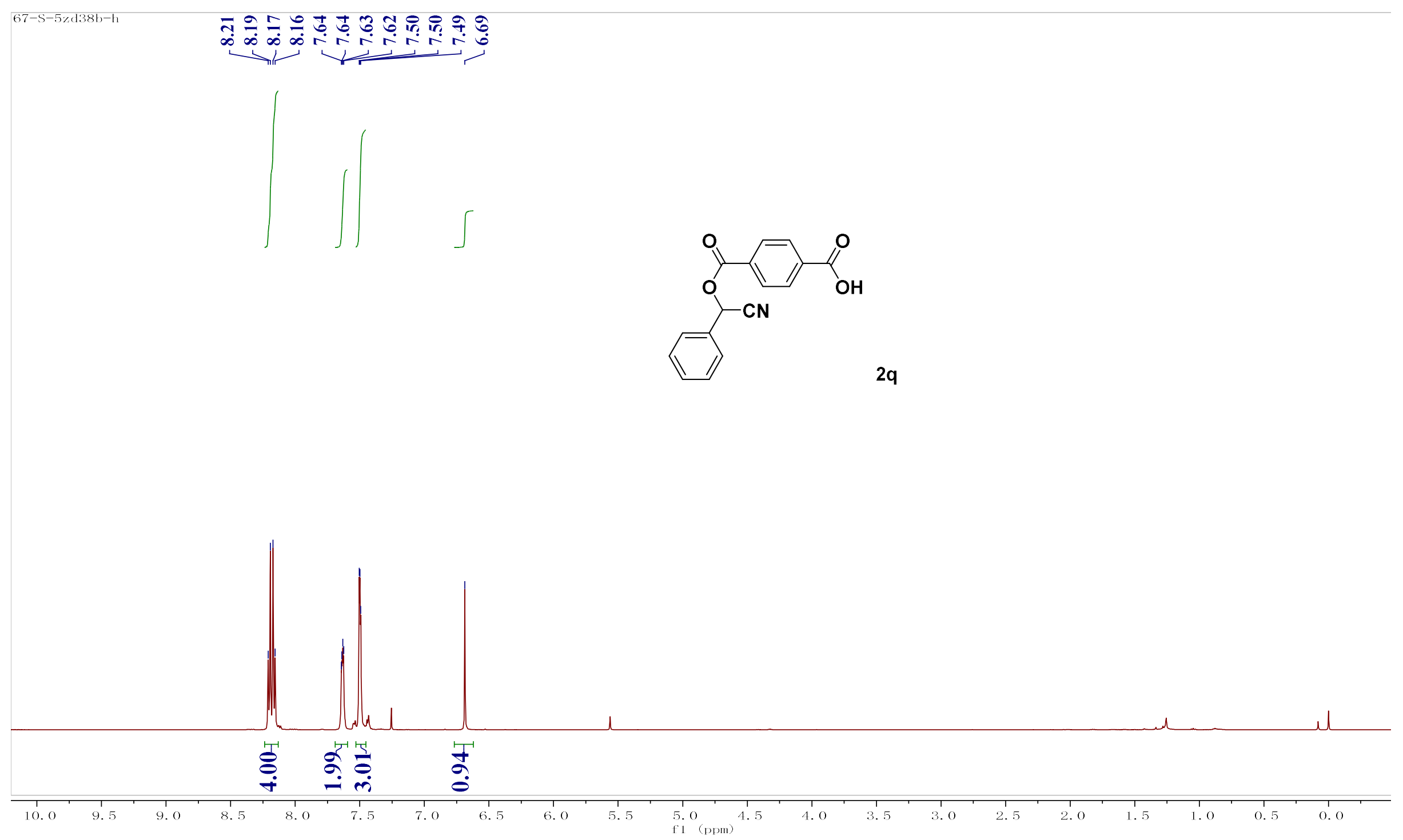

NMR-34 

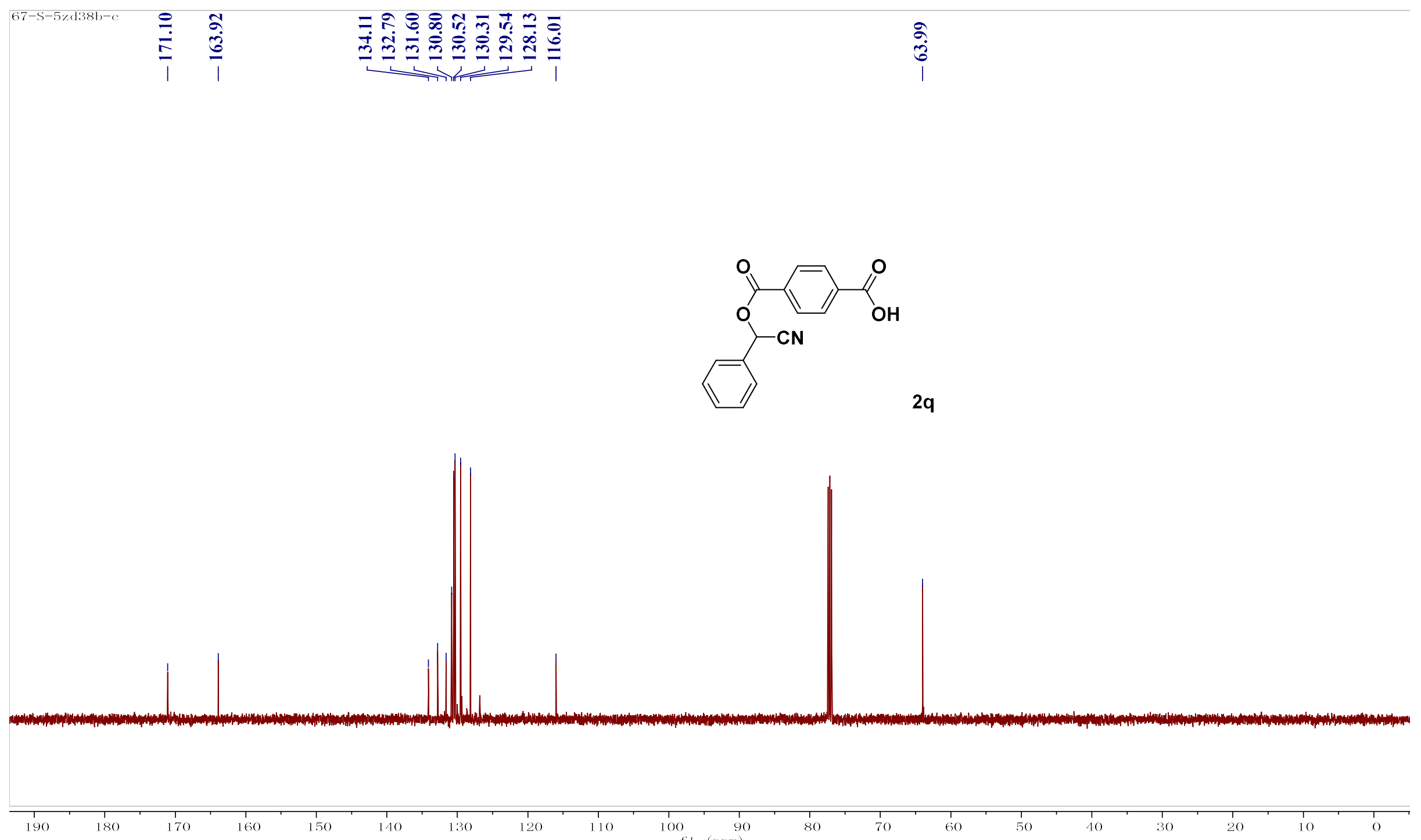


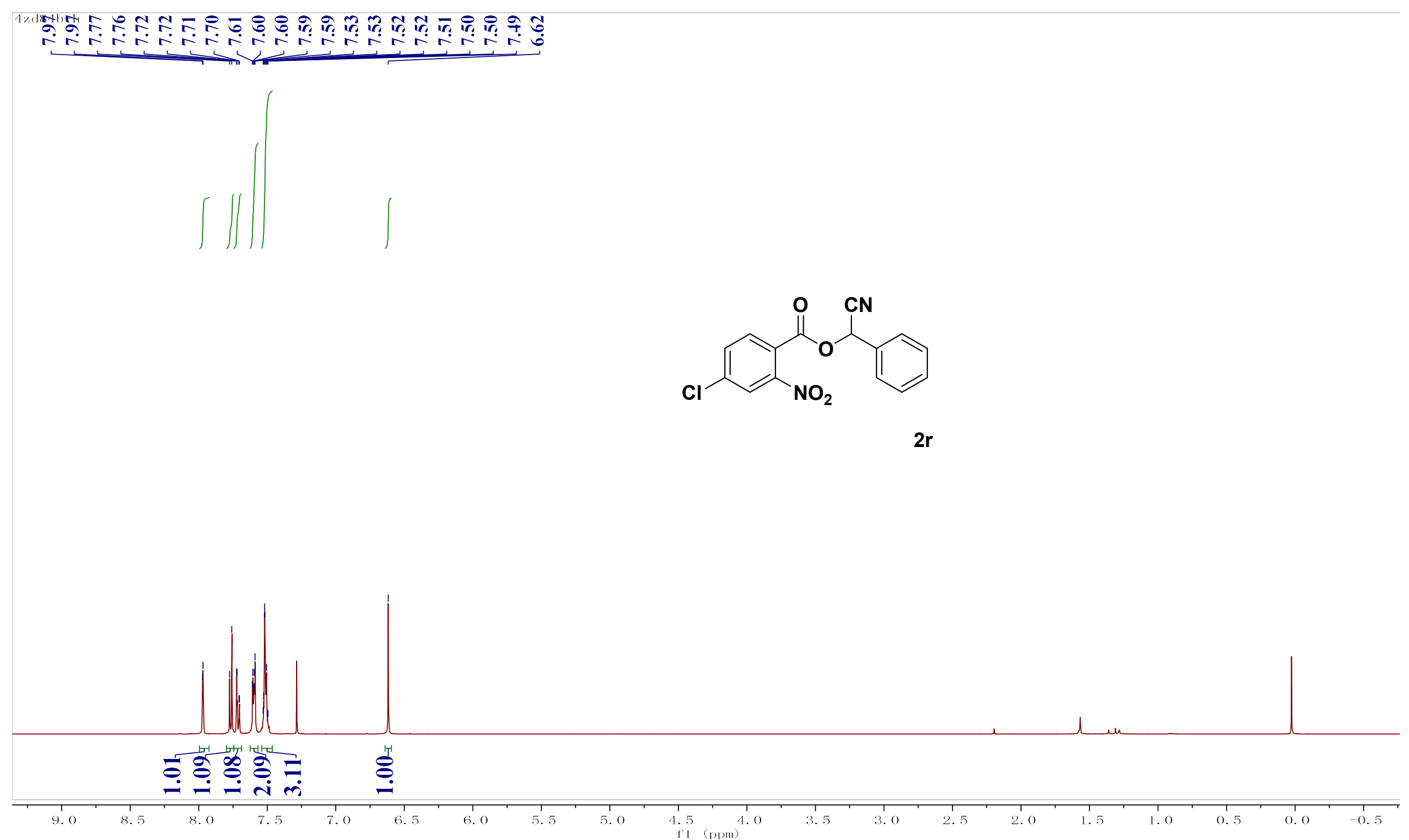

NMR-36 


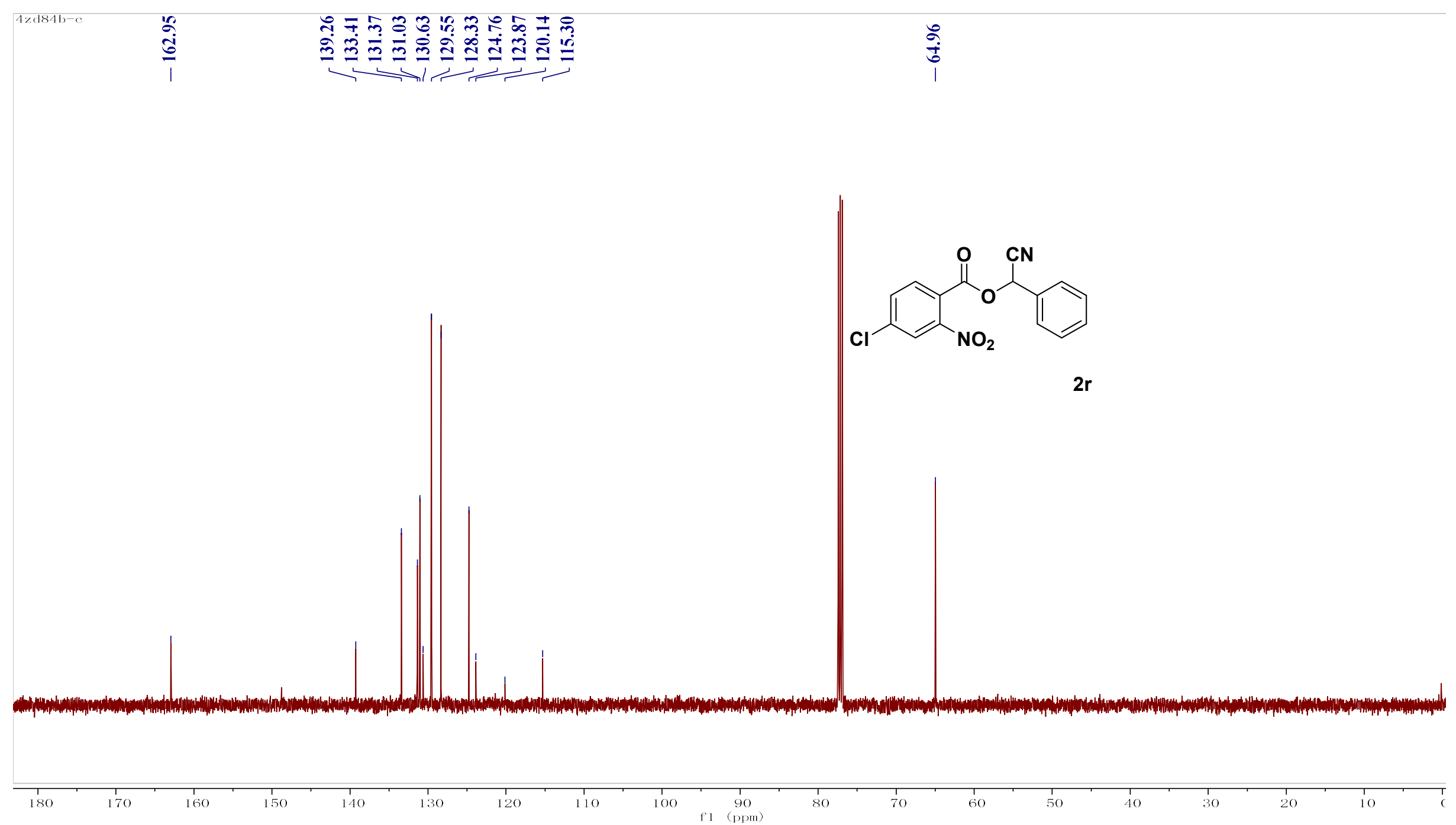

NMR-37 
पर
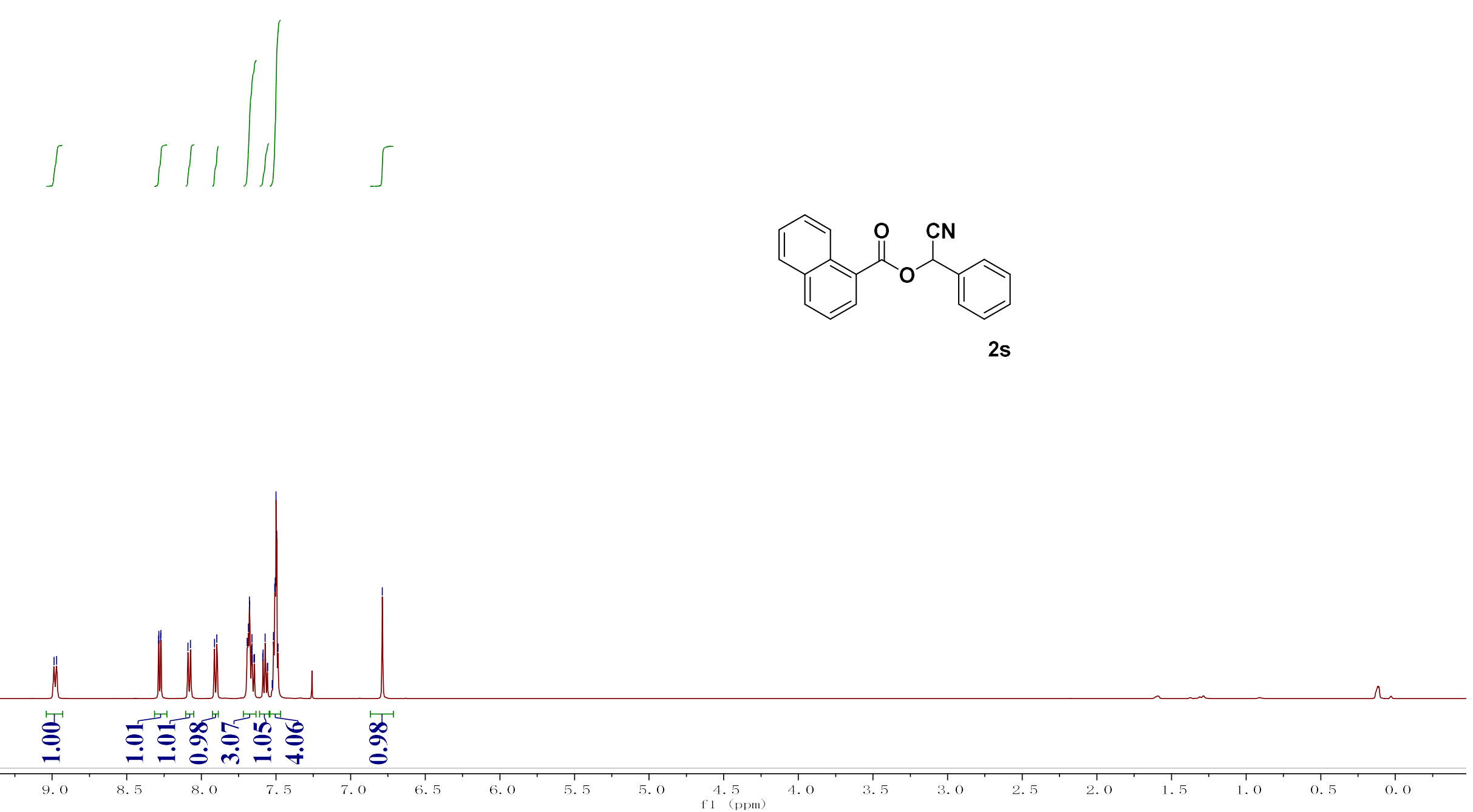

NMR-38 


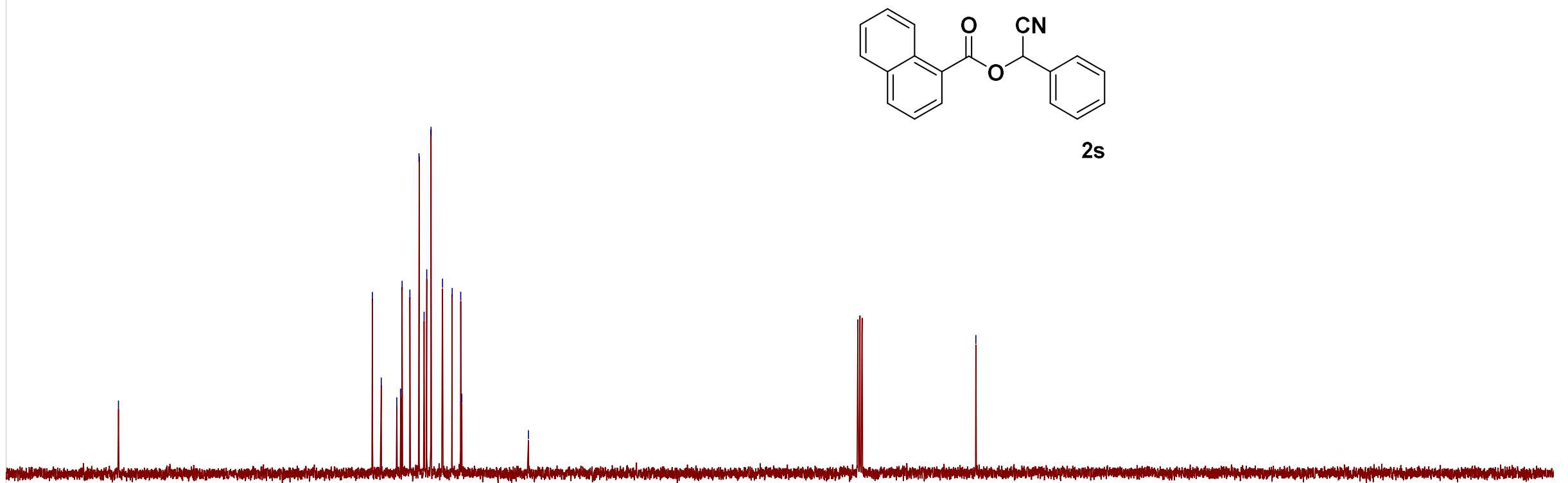




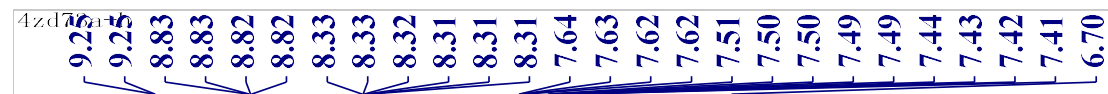
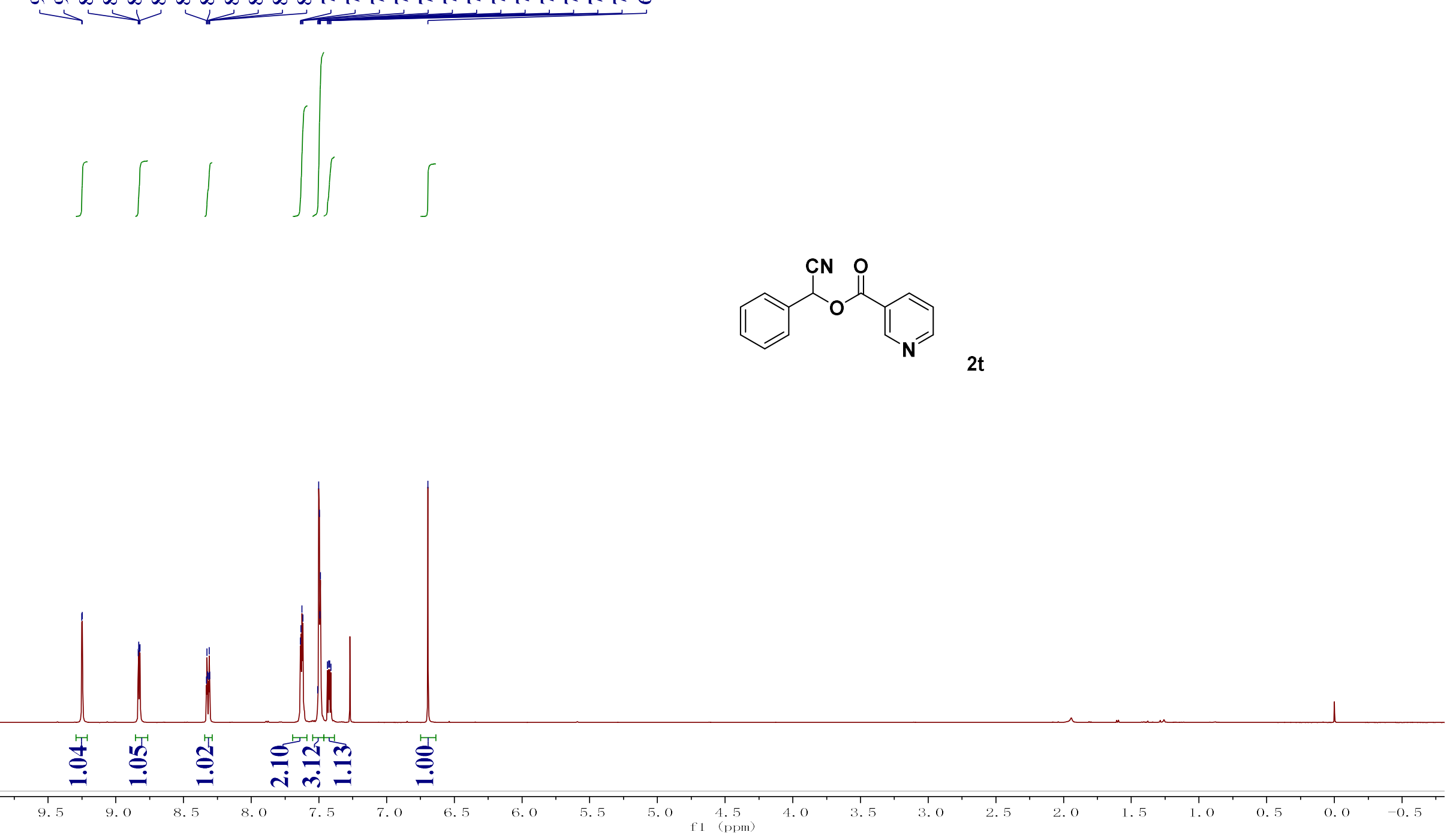

NMR-40 


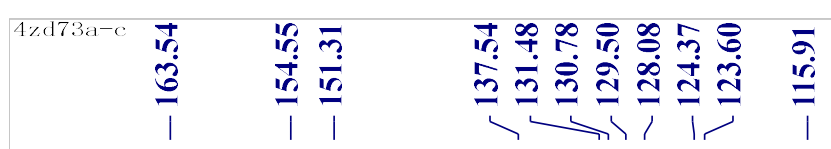
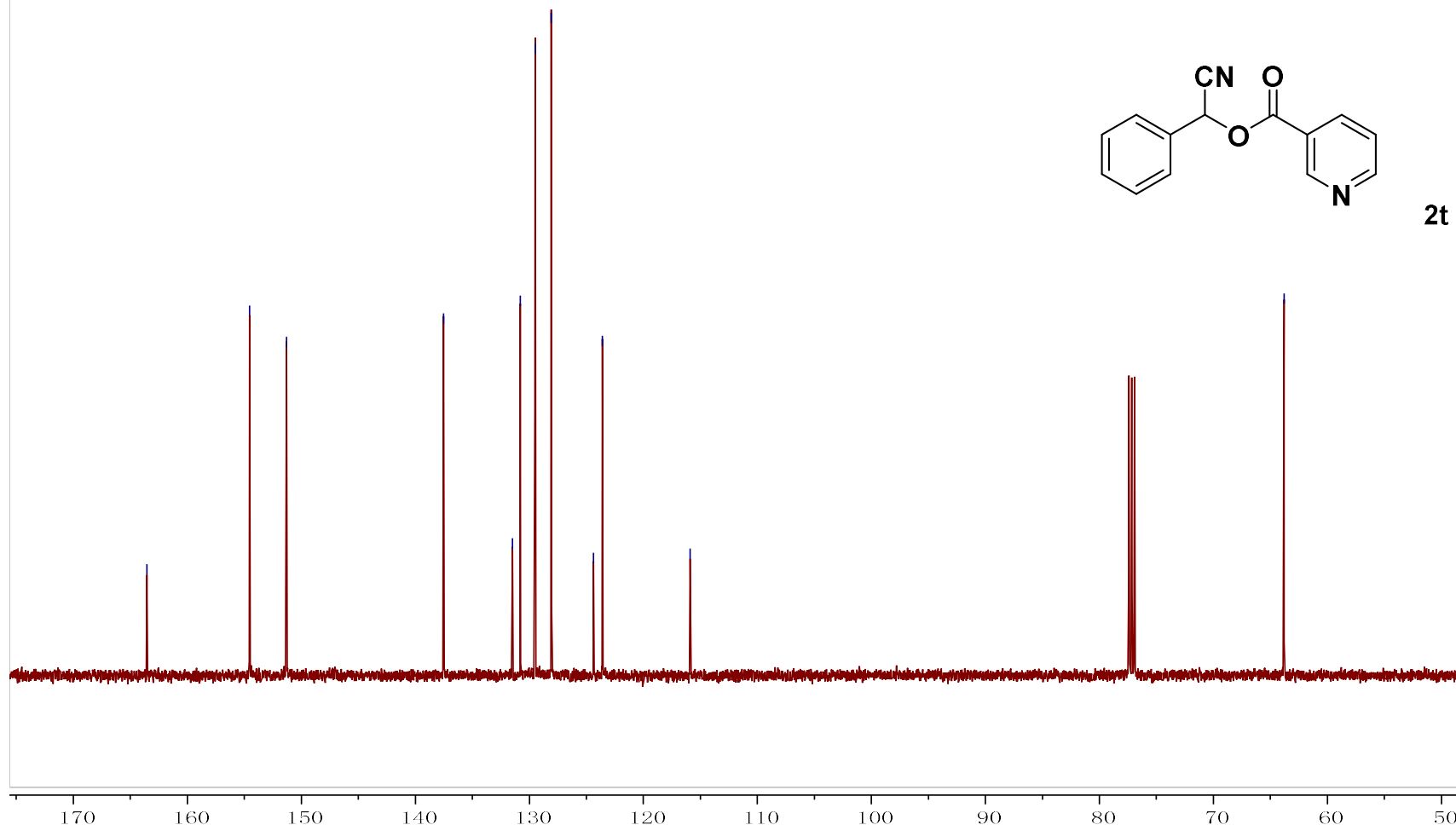

150

140

130

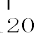

110

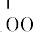

$90 \quad 80$

70

10 


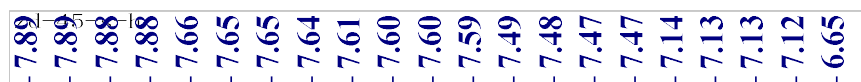
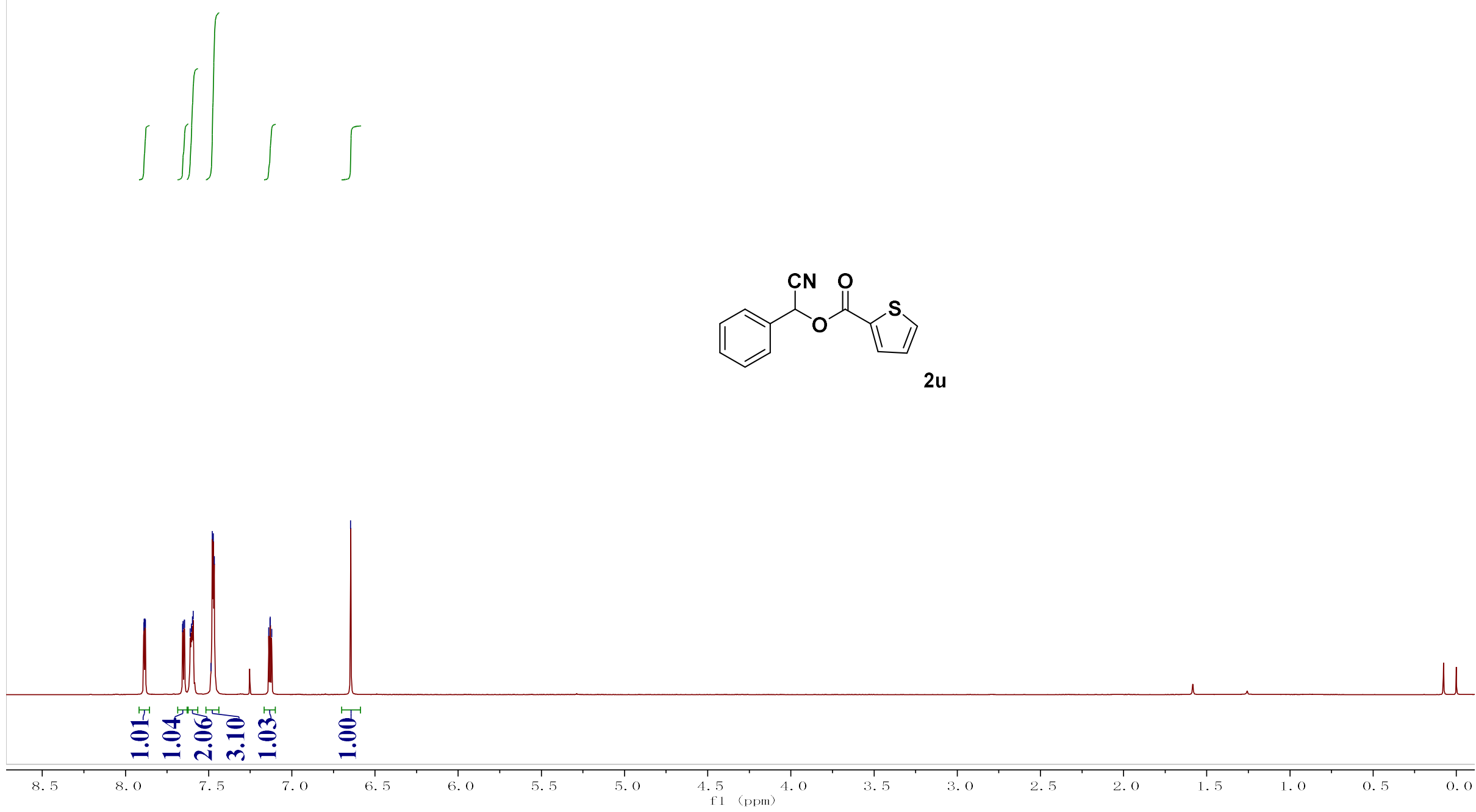

NMR-42 

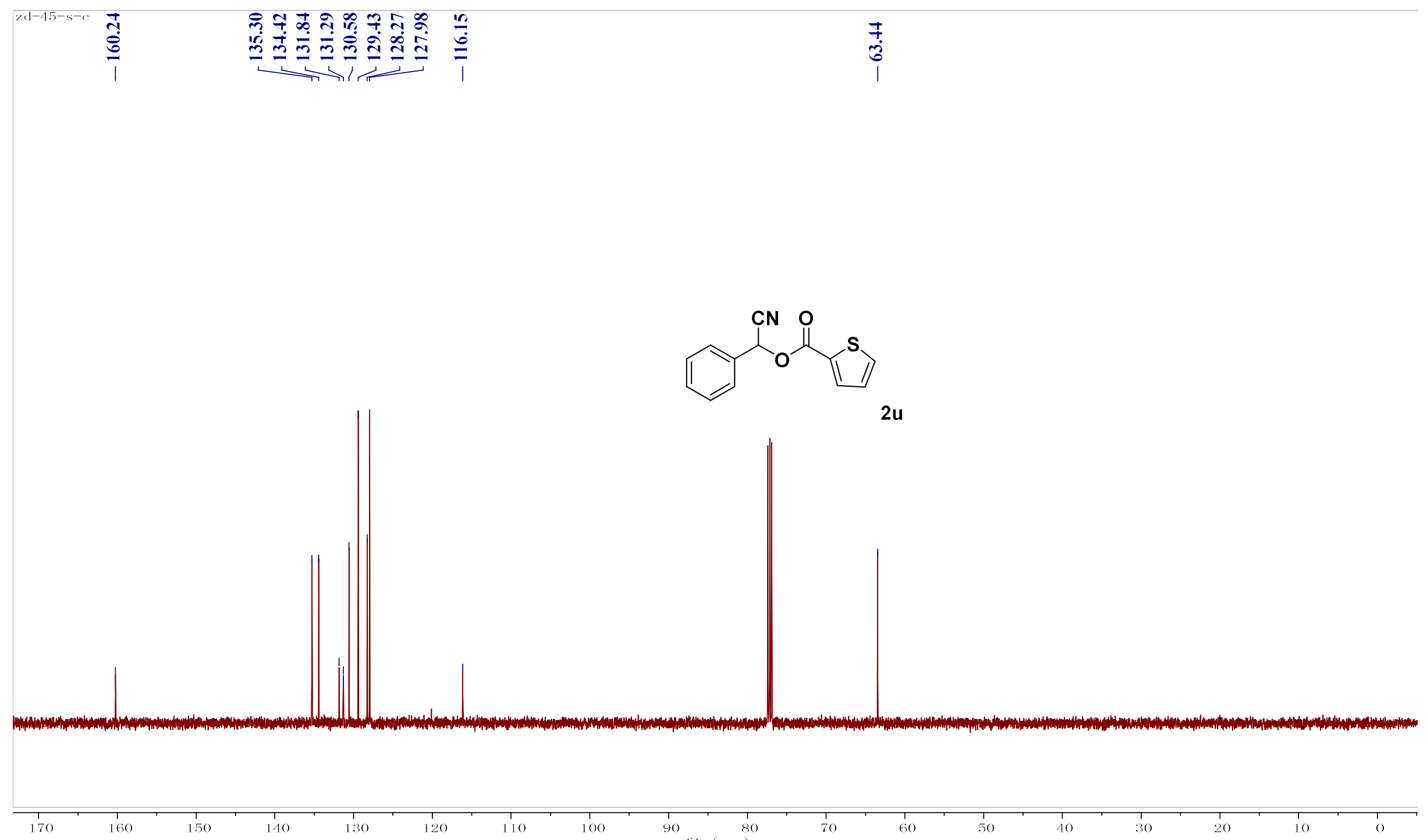


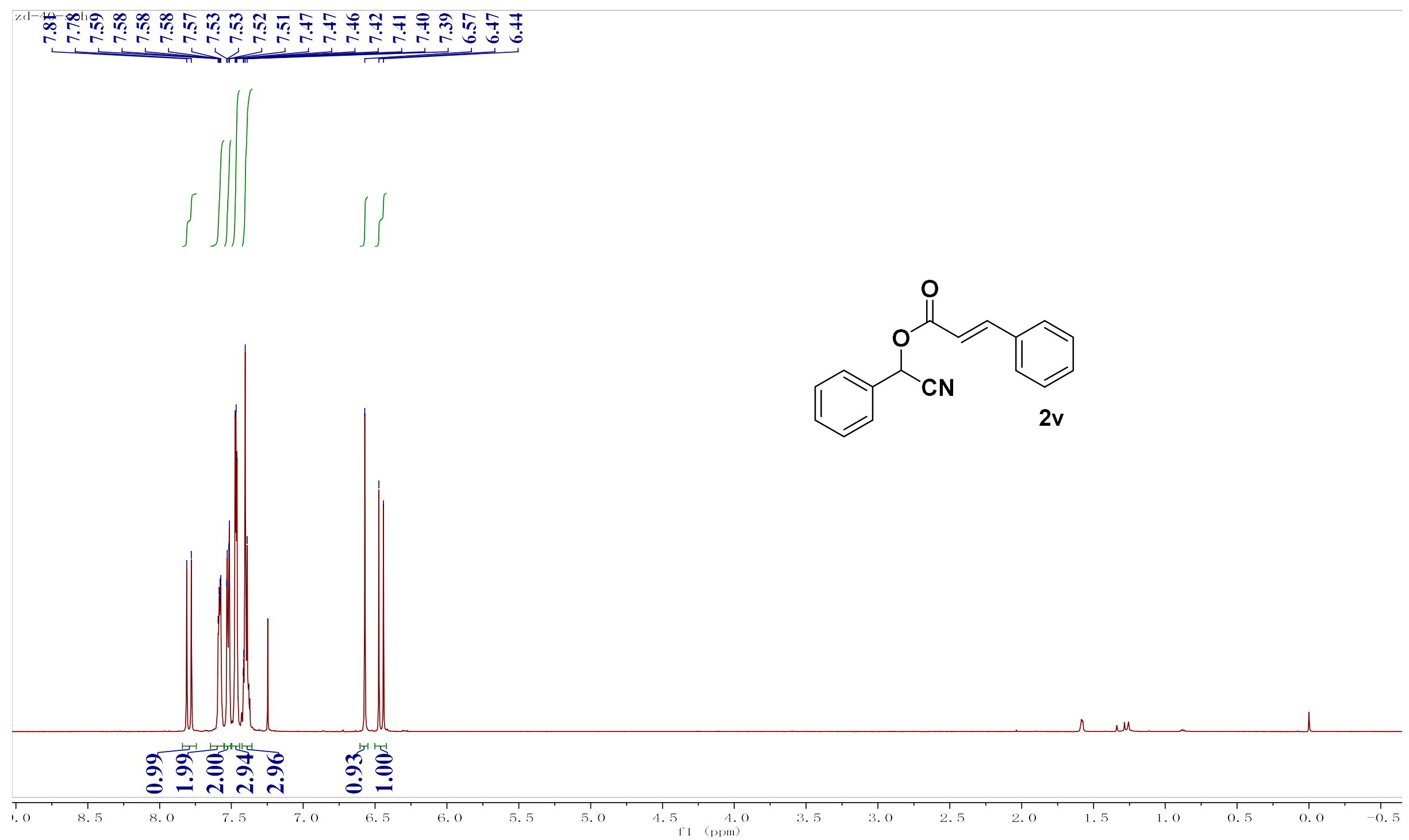

NMR-44 

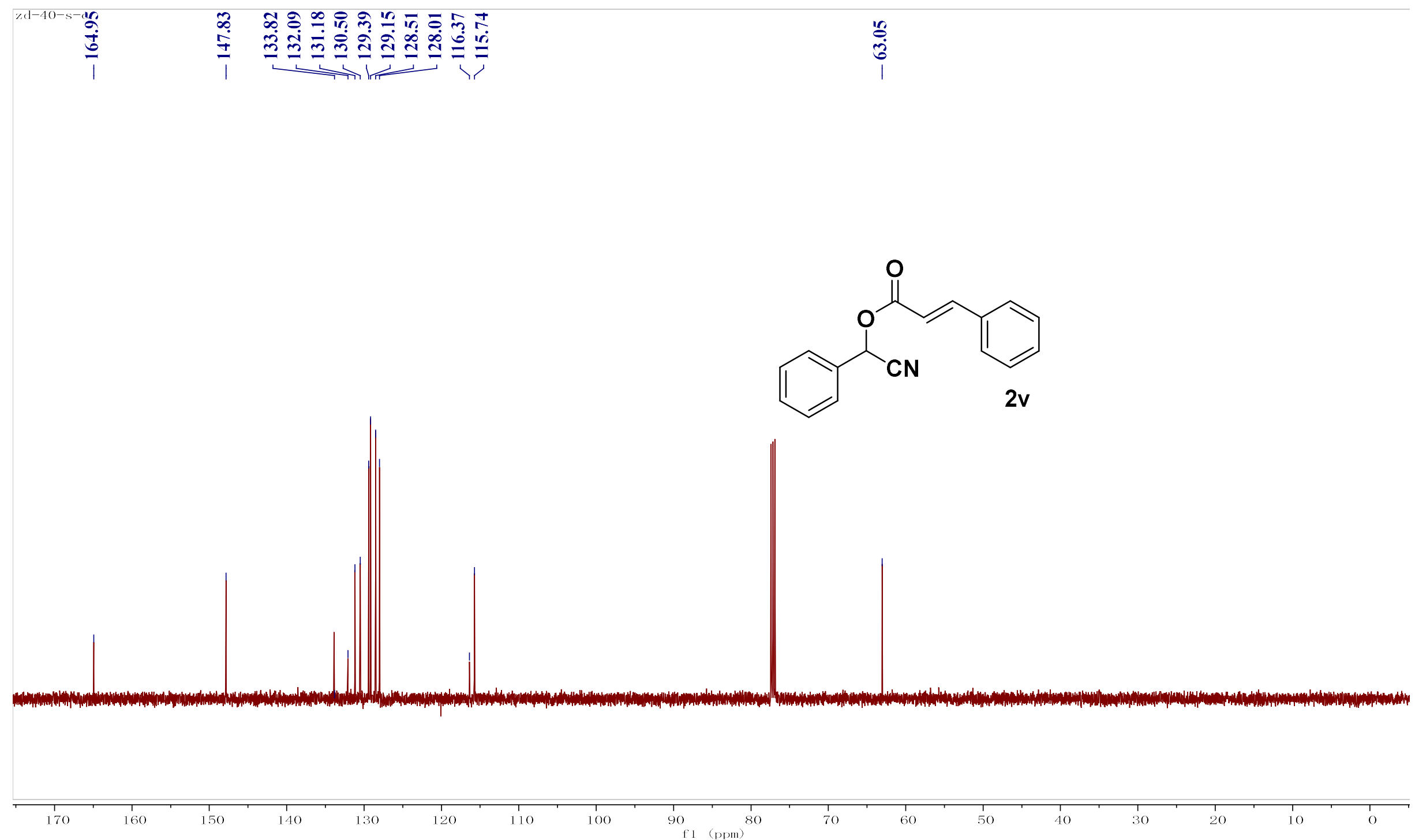

NMR-45 


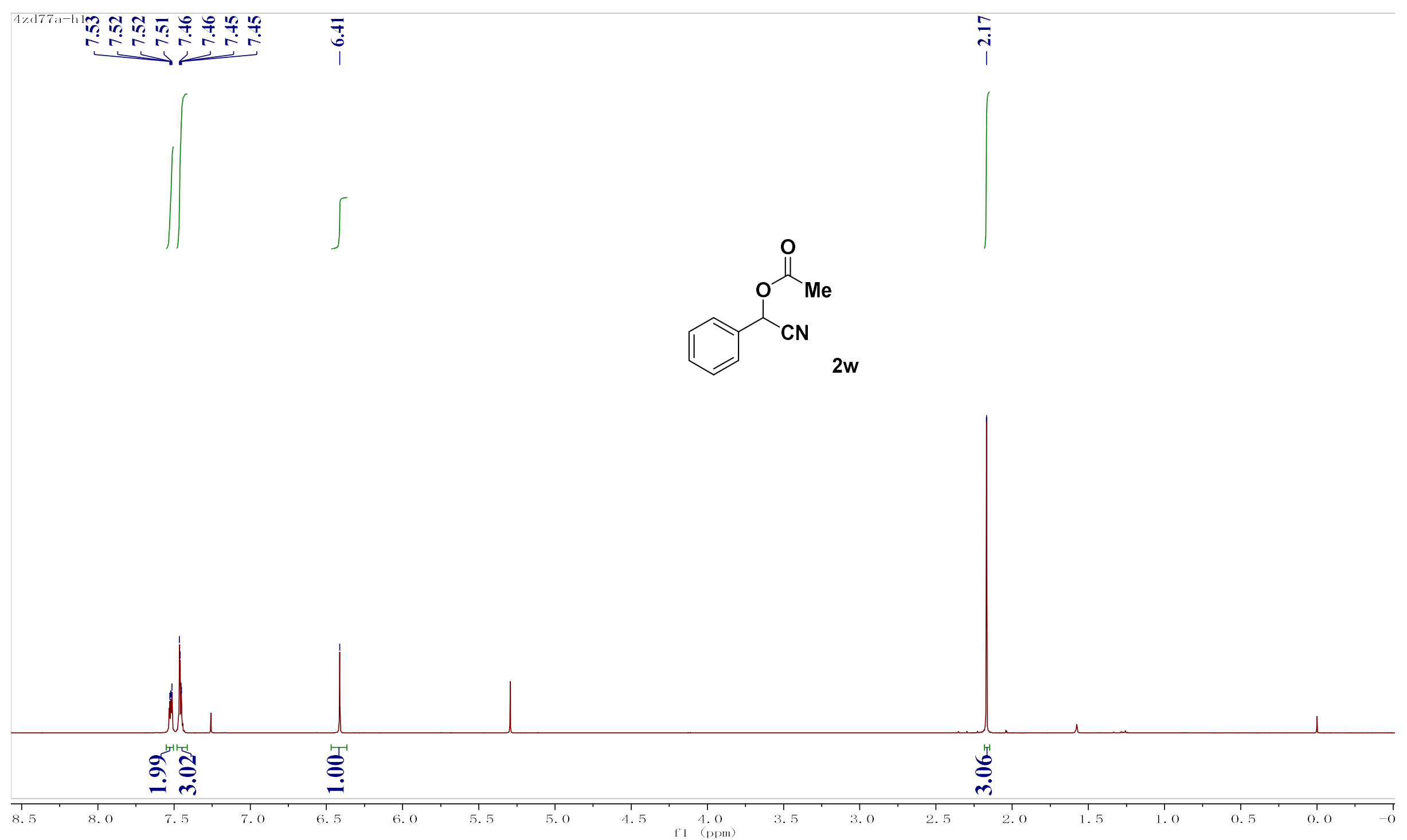

NMR-46 


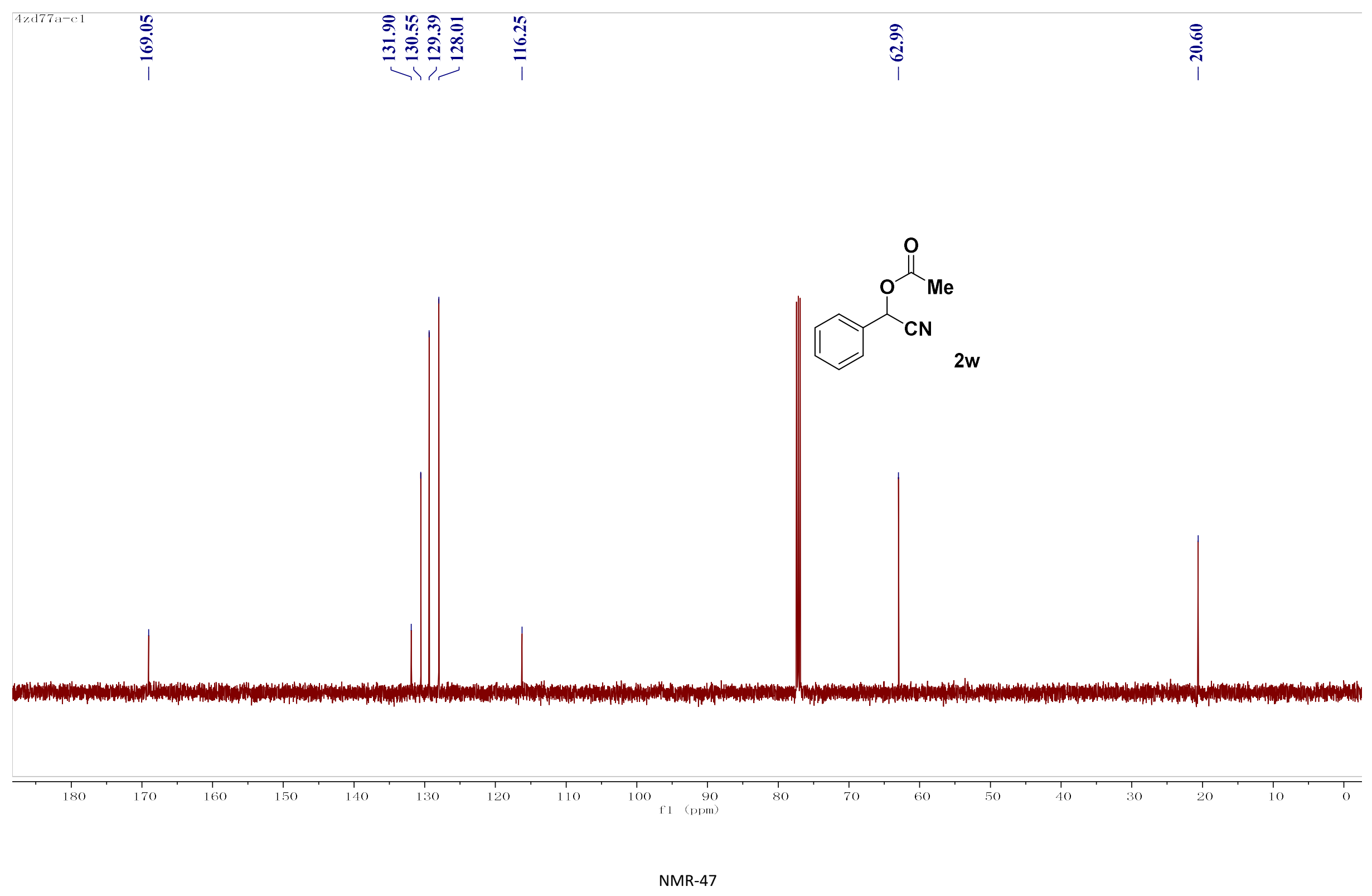




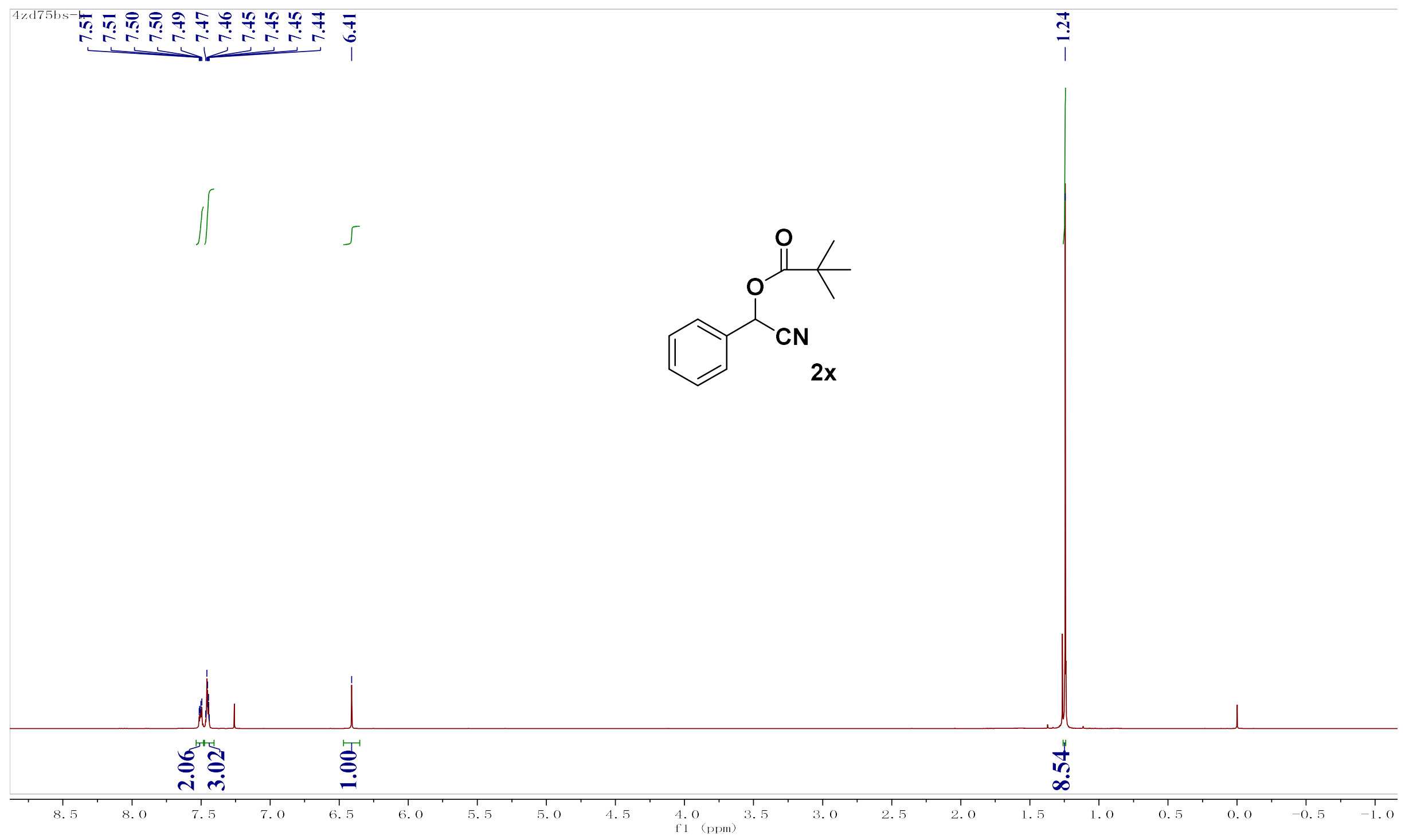

NMR-48 


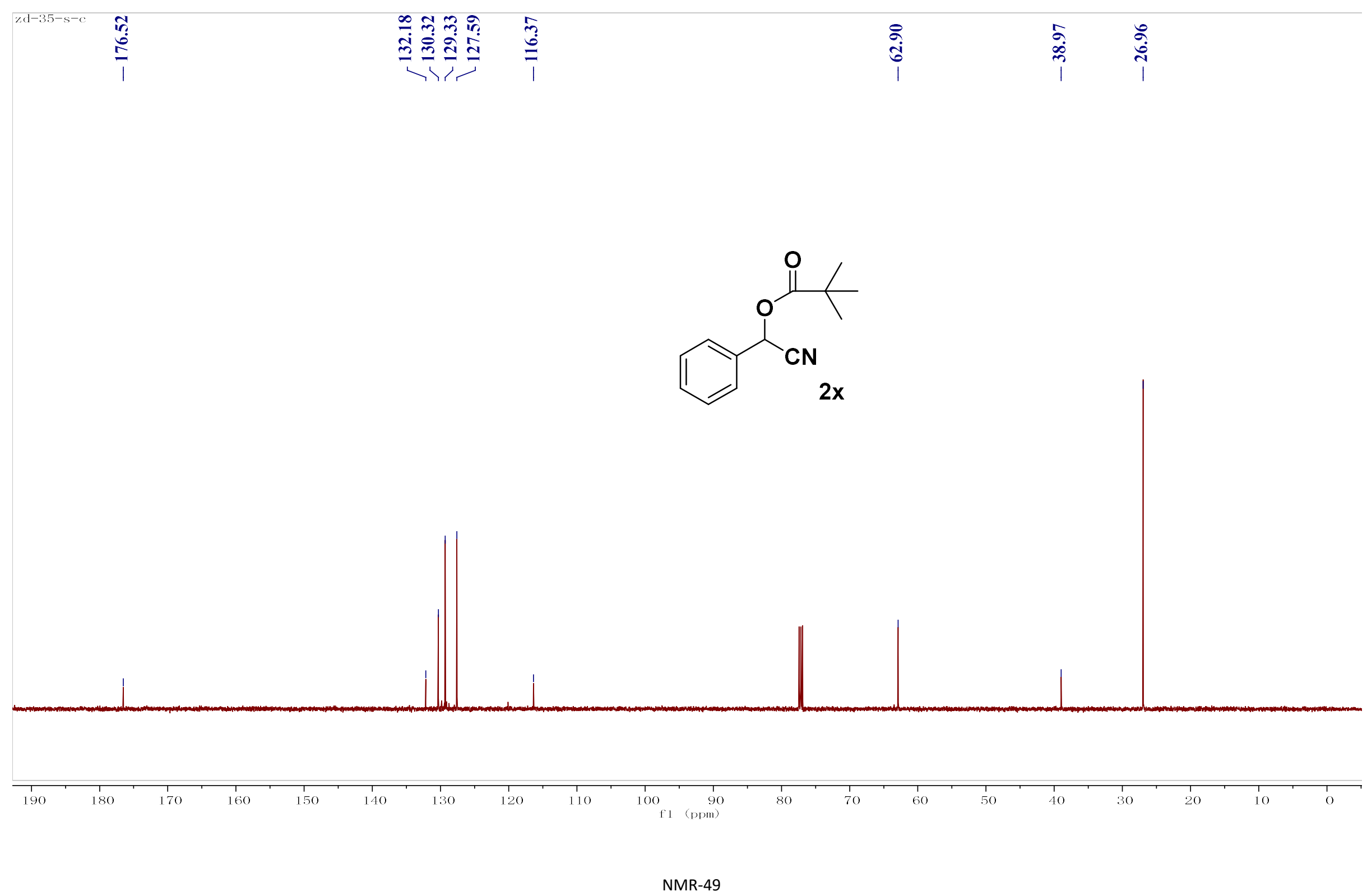




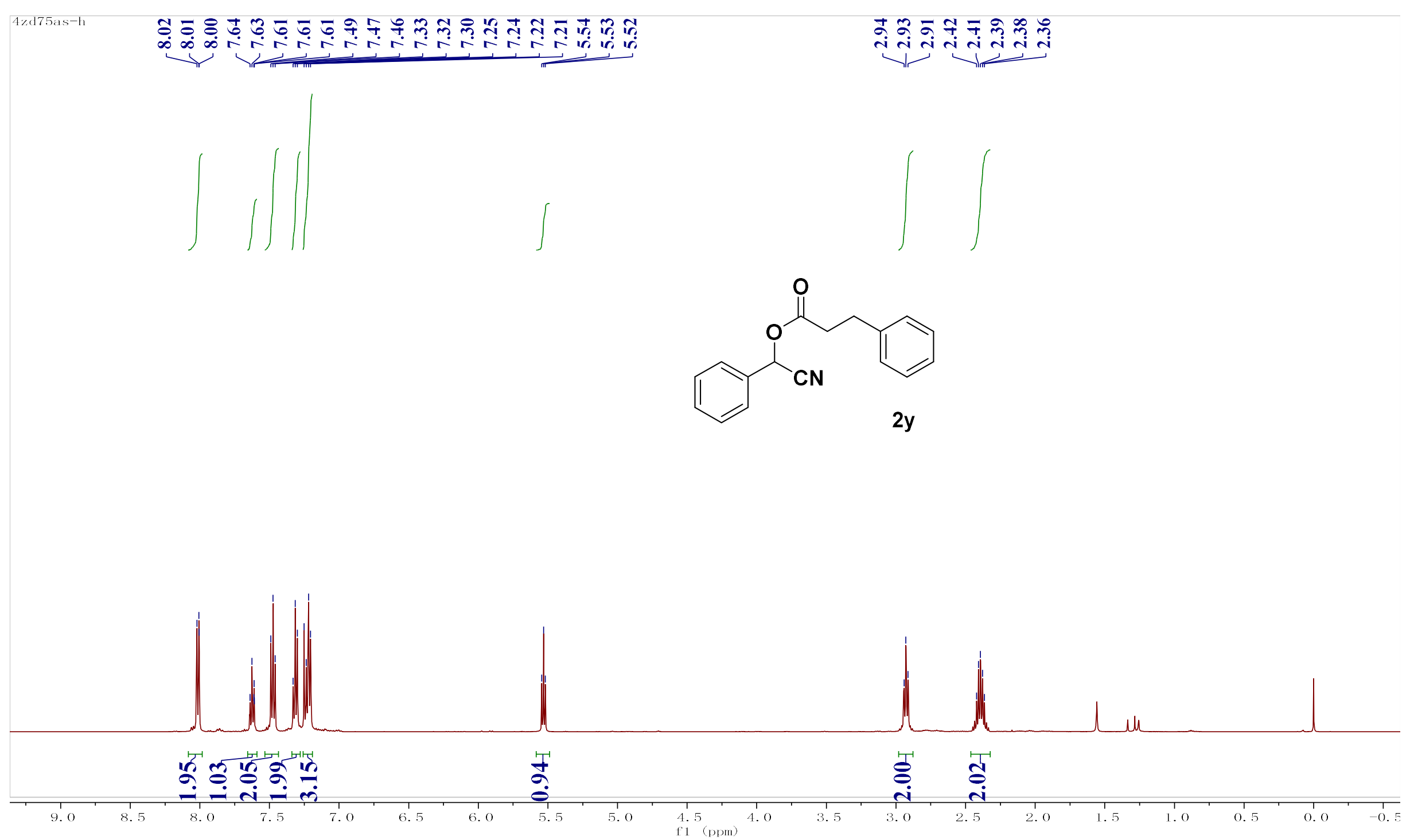

NMR-50 

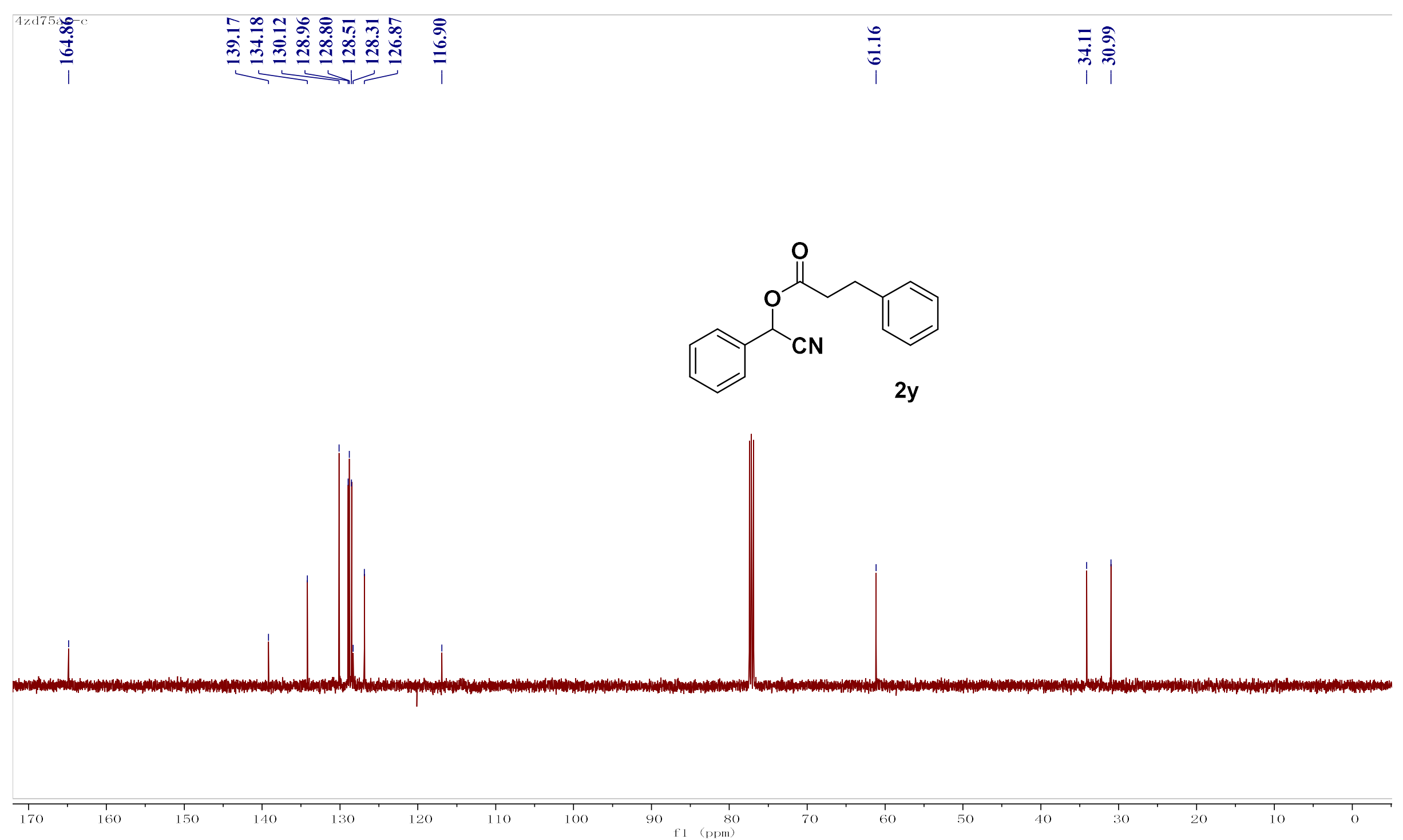

NMR-51 

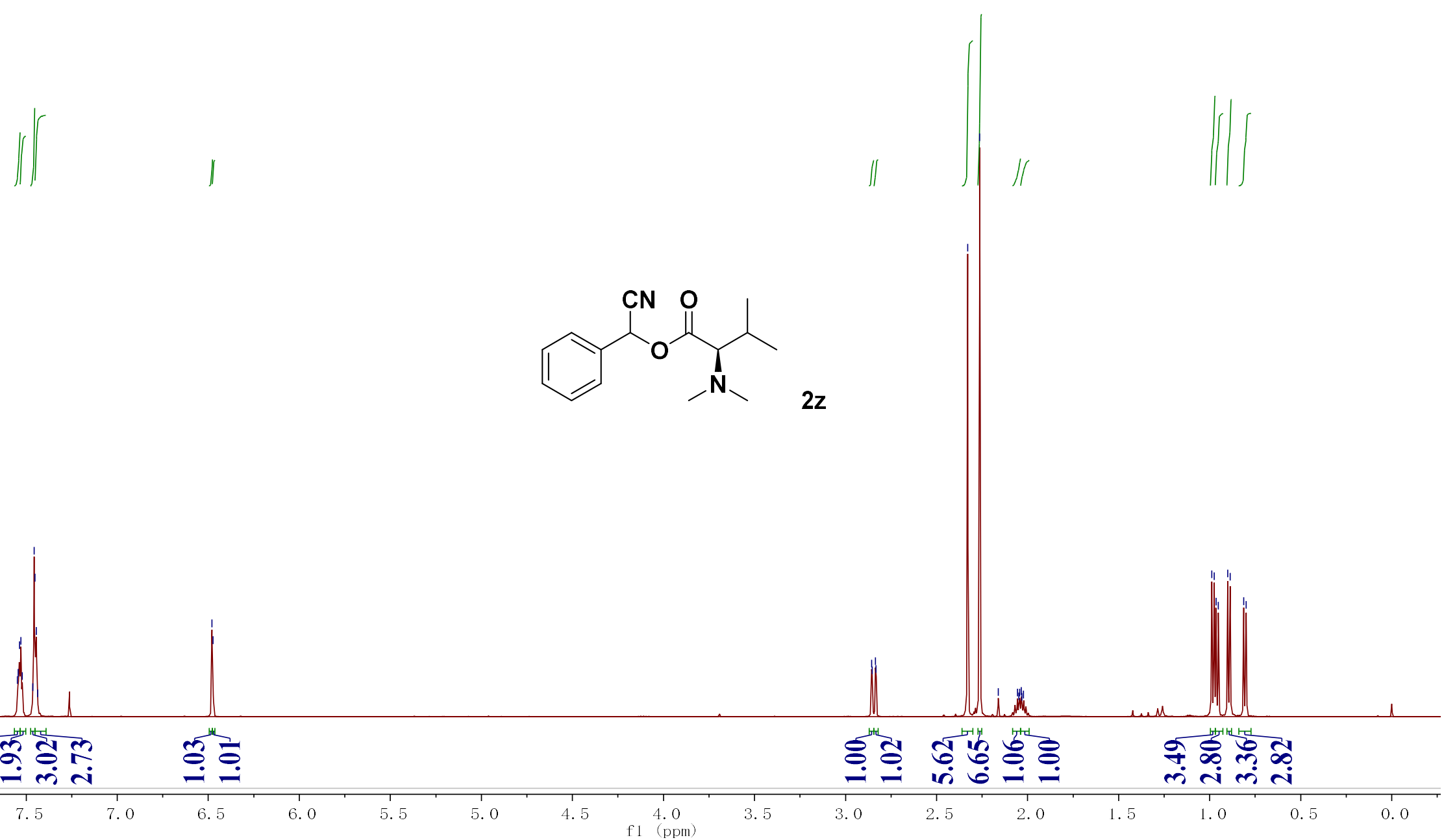

NMR-52 


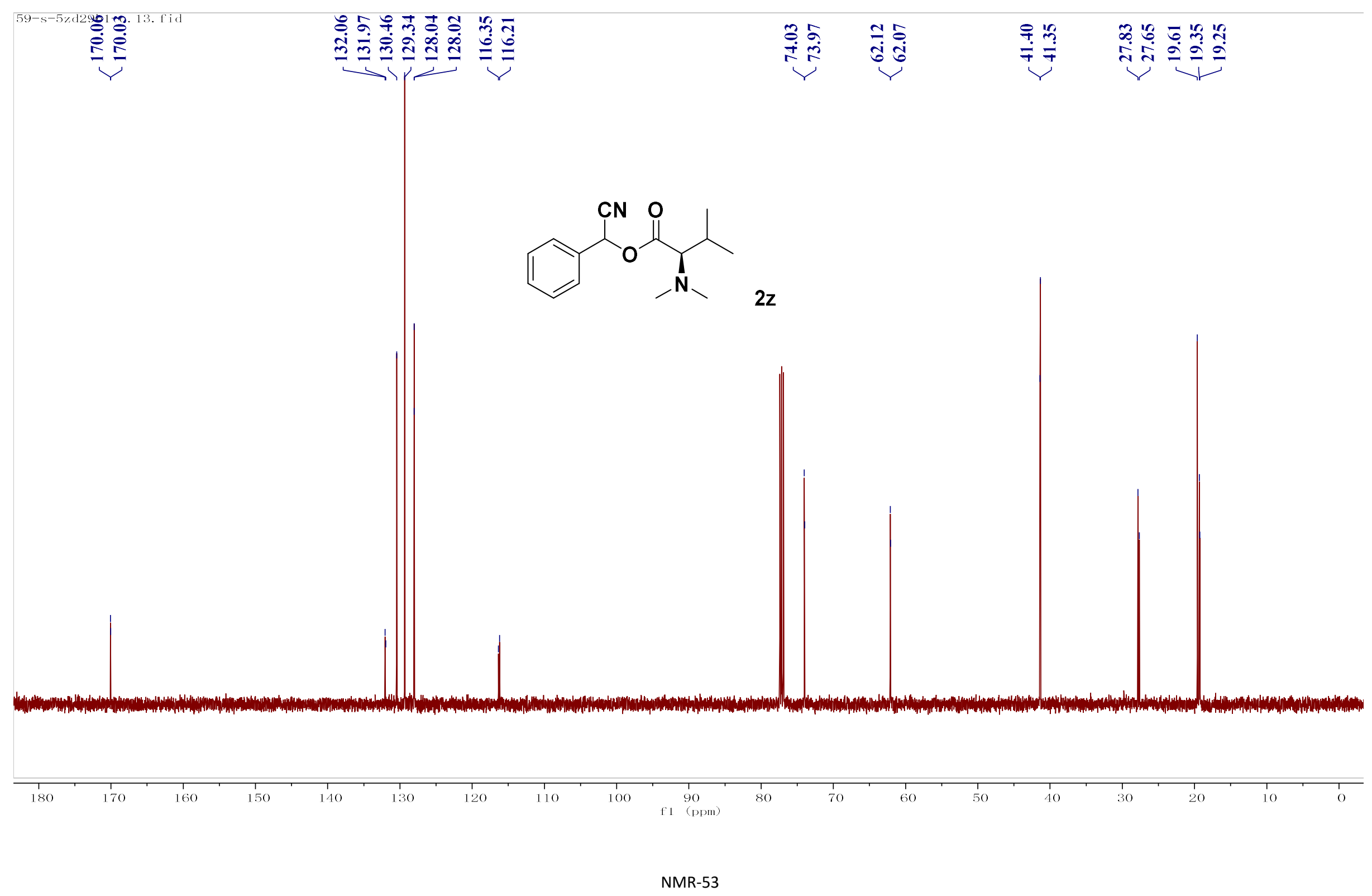




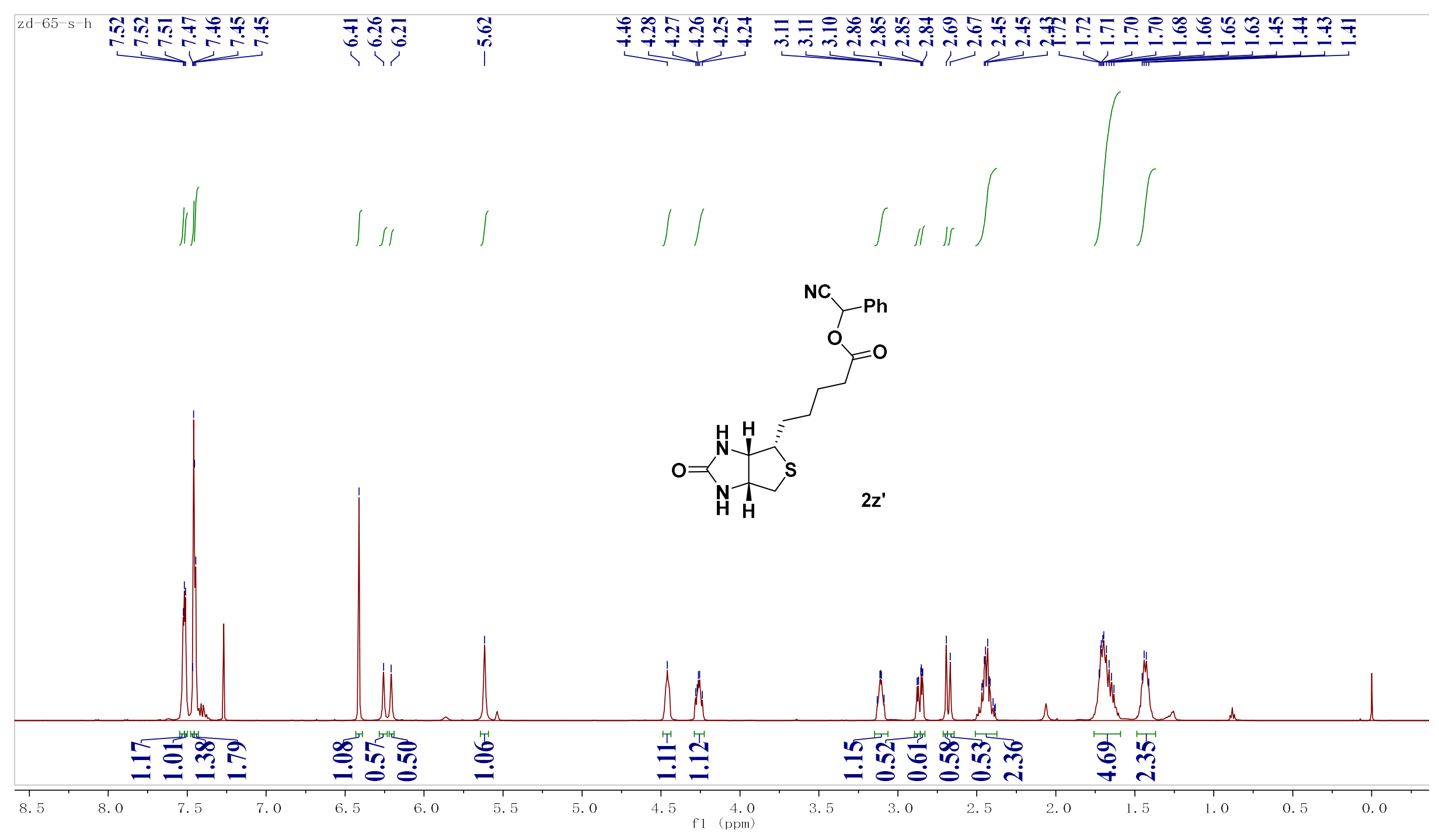

NMR-54 

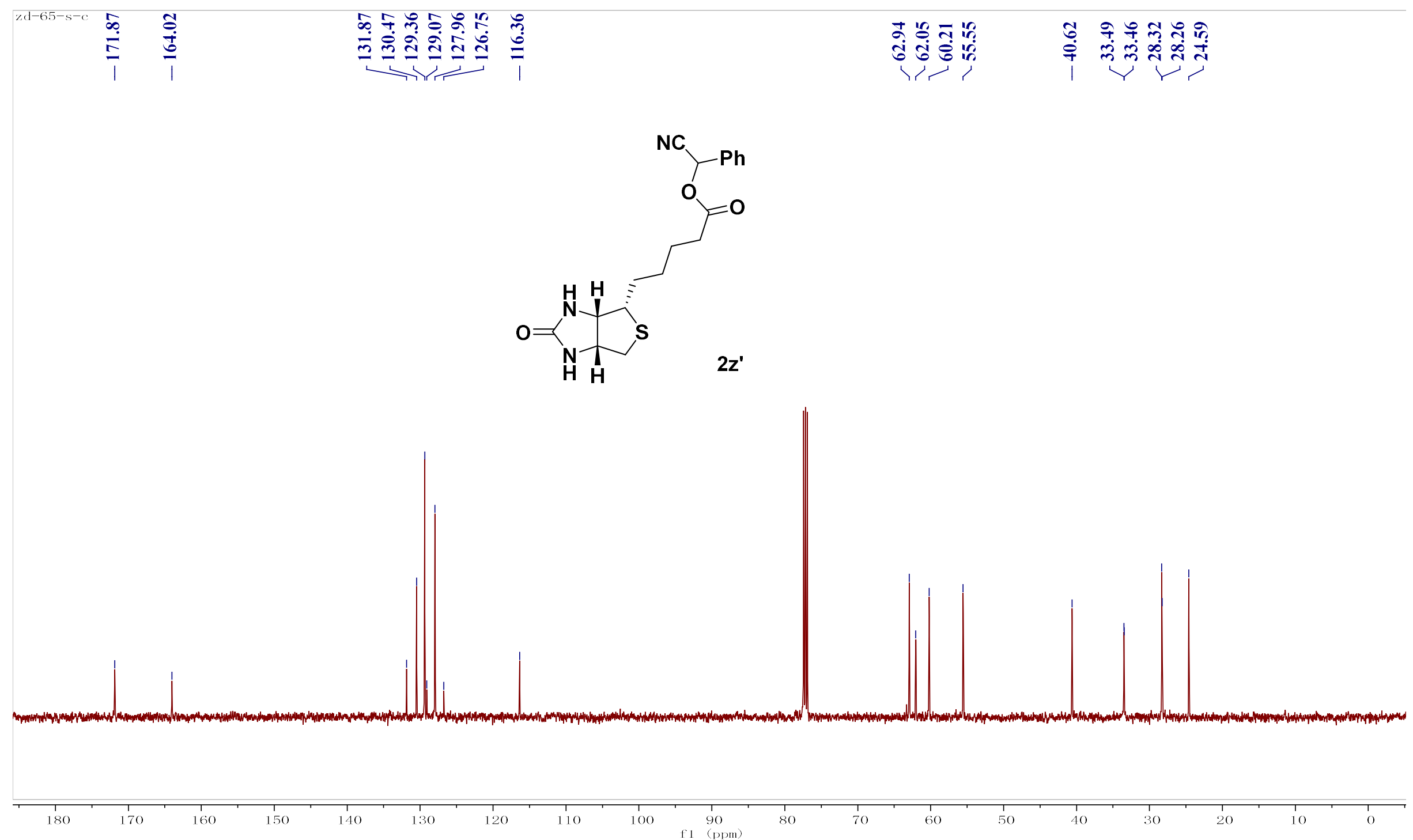


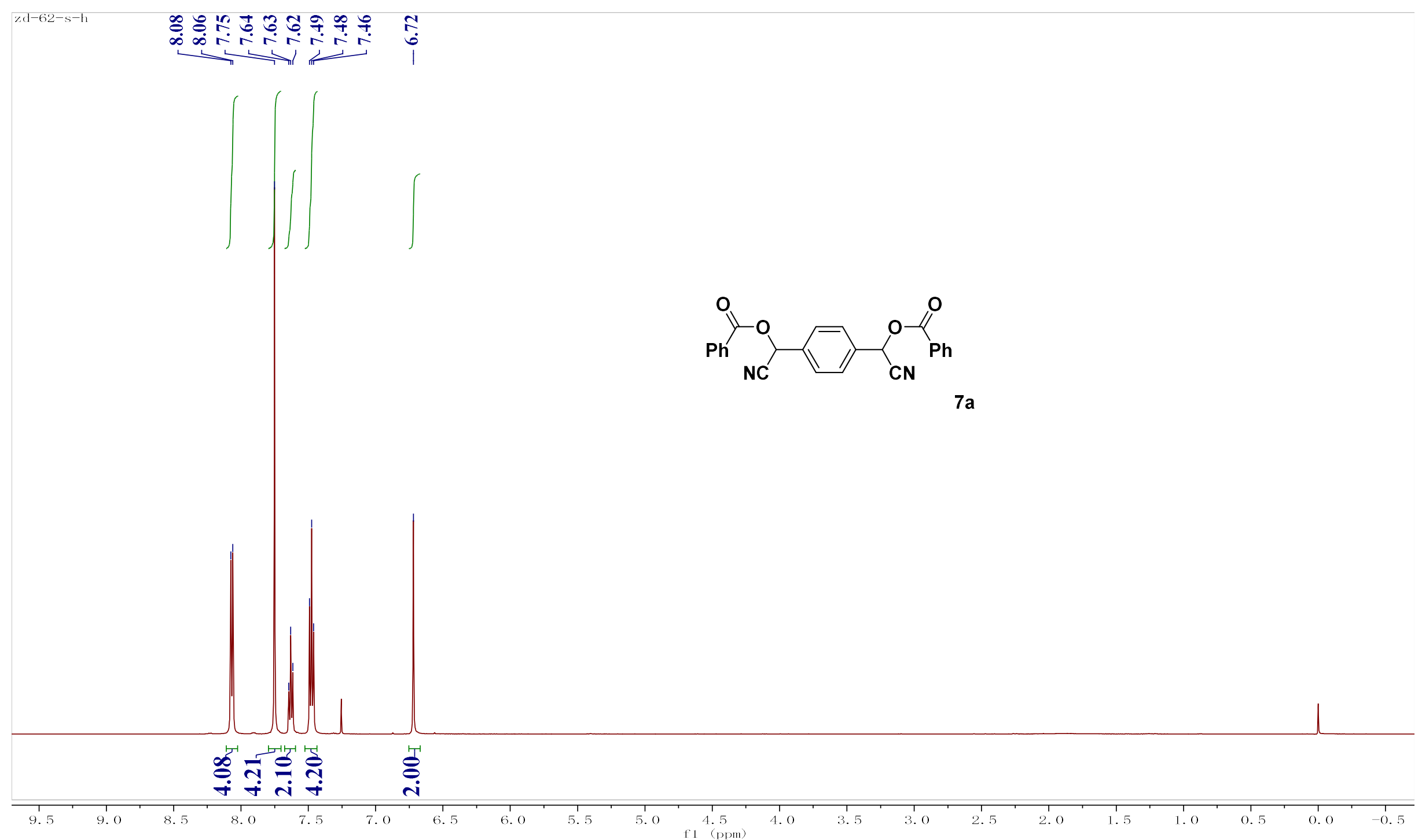

NMR-56 


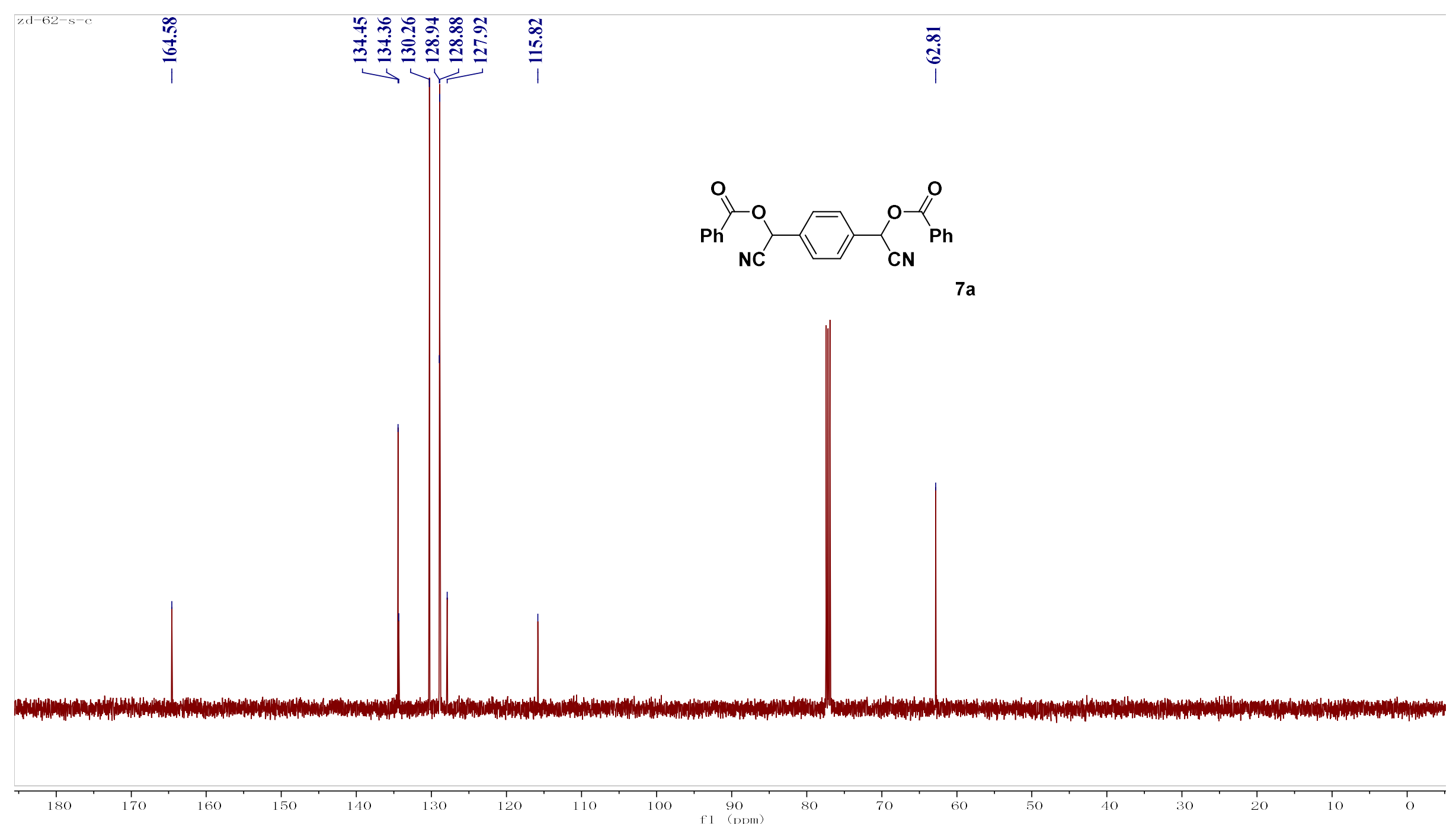

NMR-57 


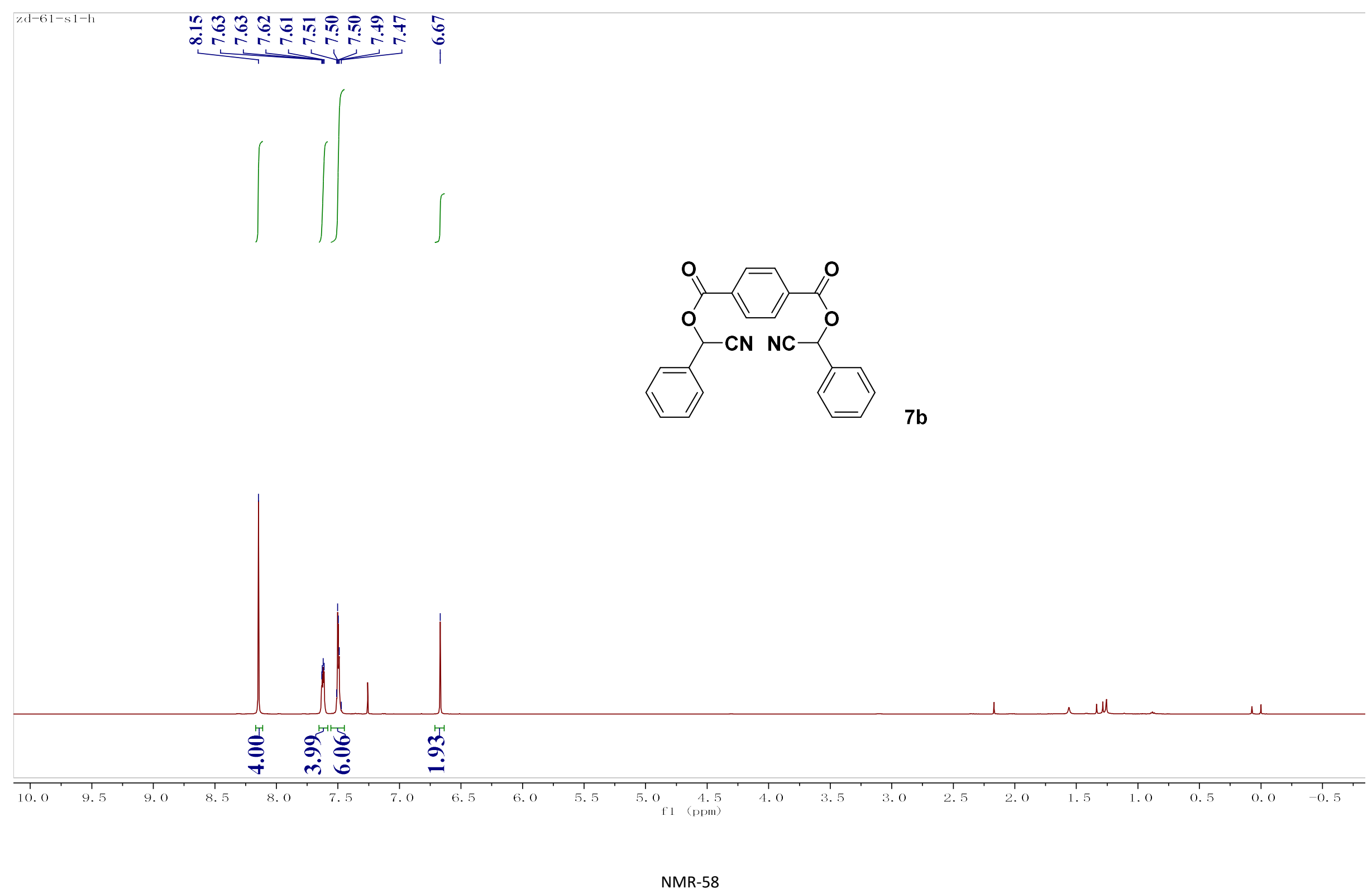




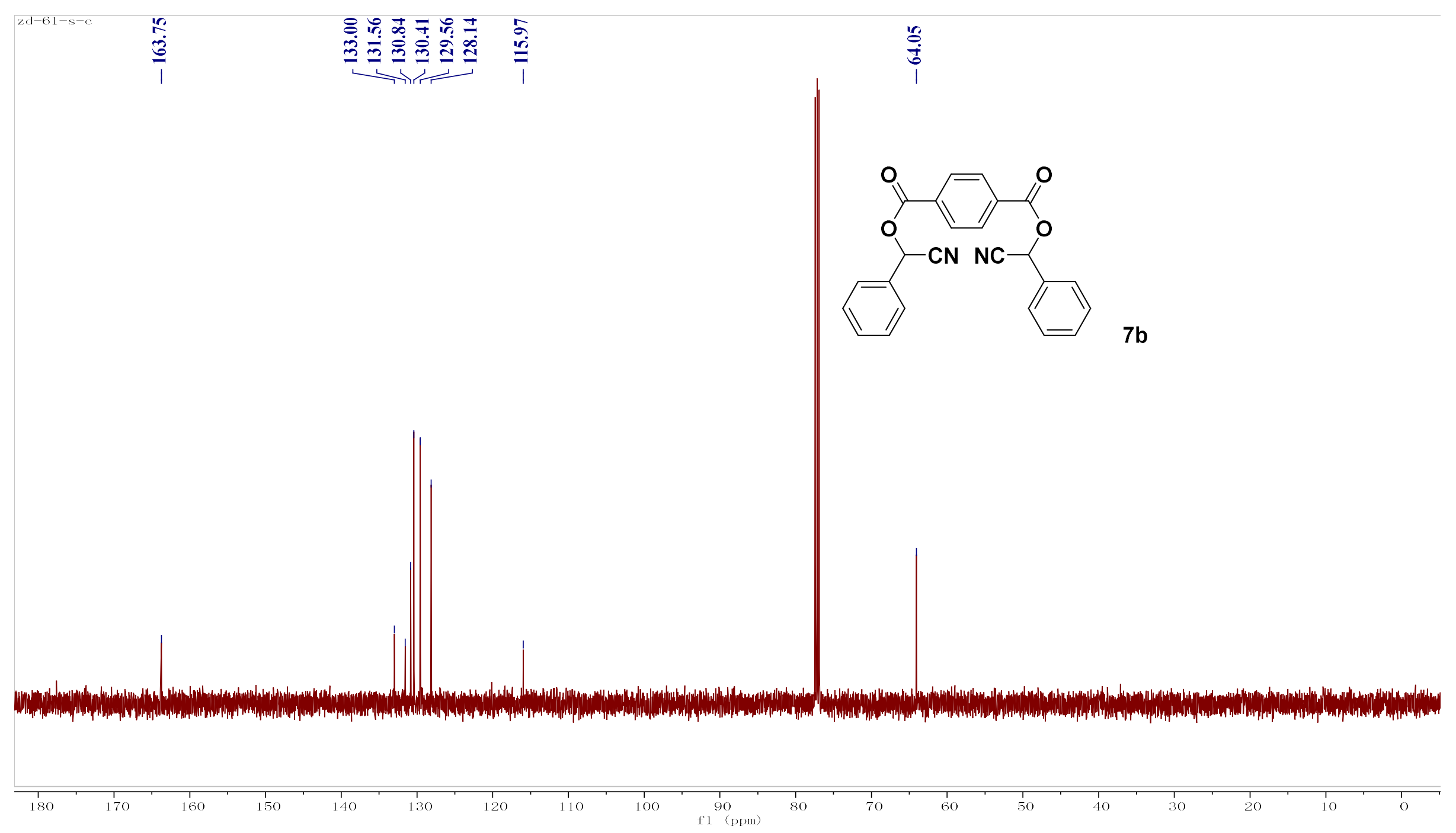

NMR-59 


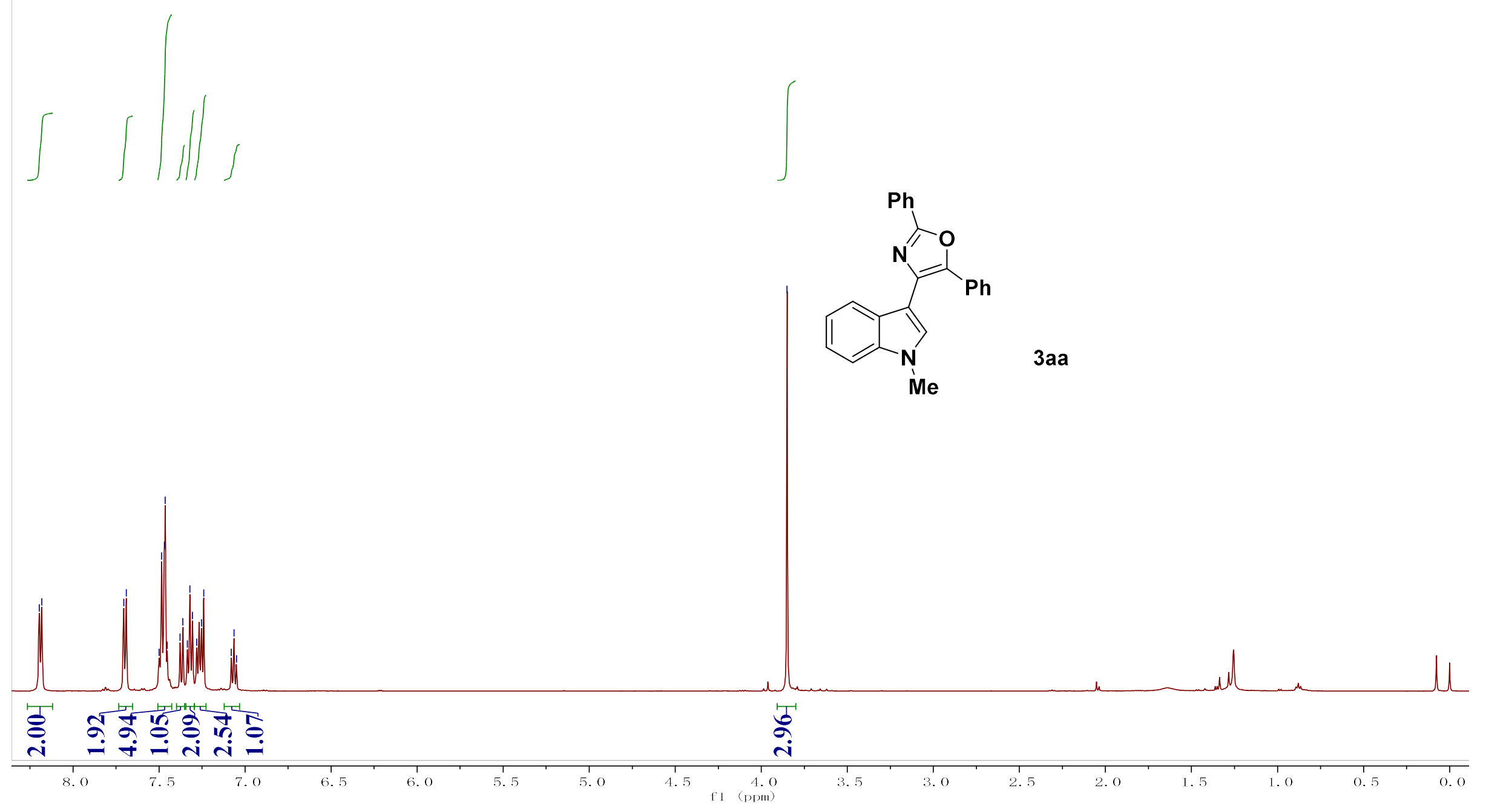

NMR-60 


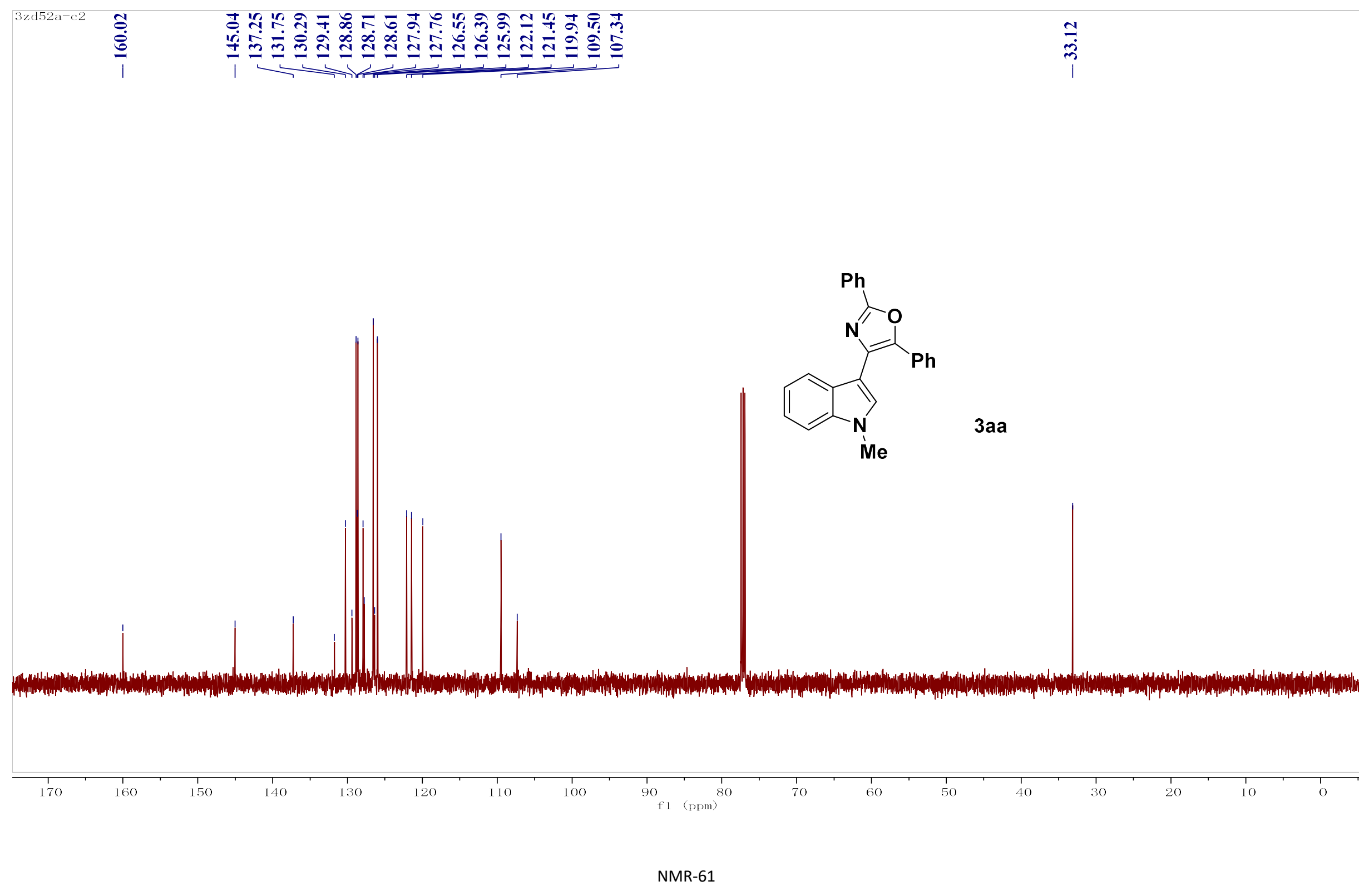




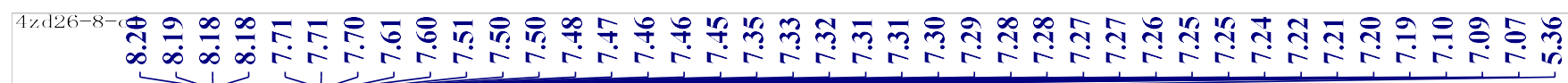
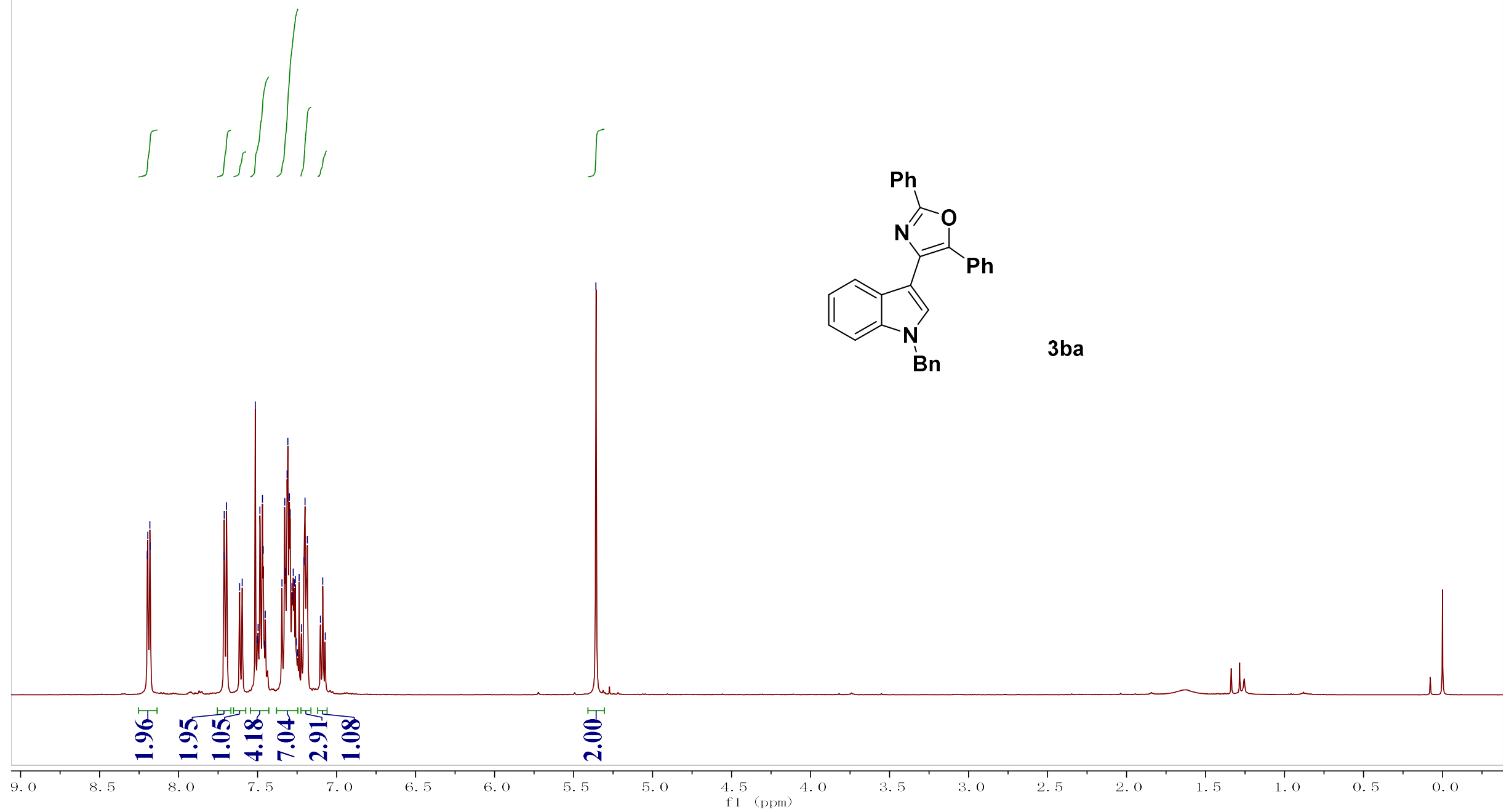

NMR-62 


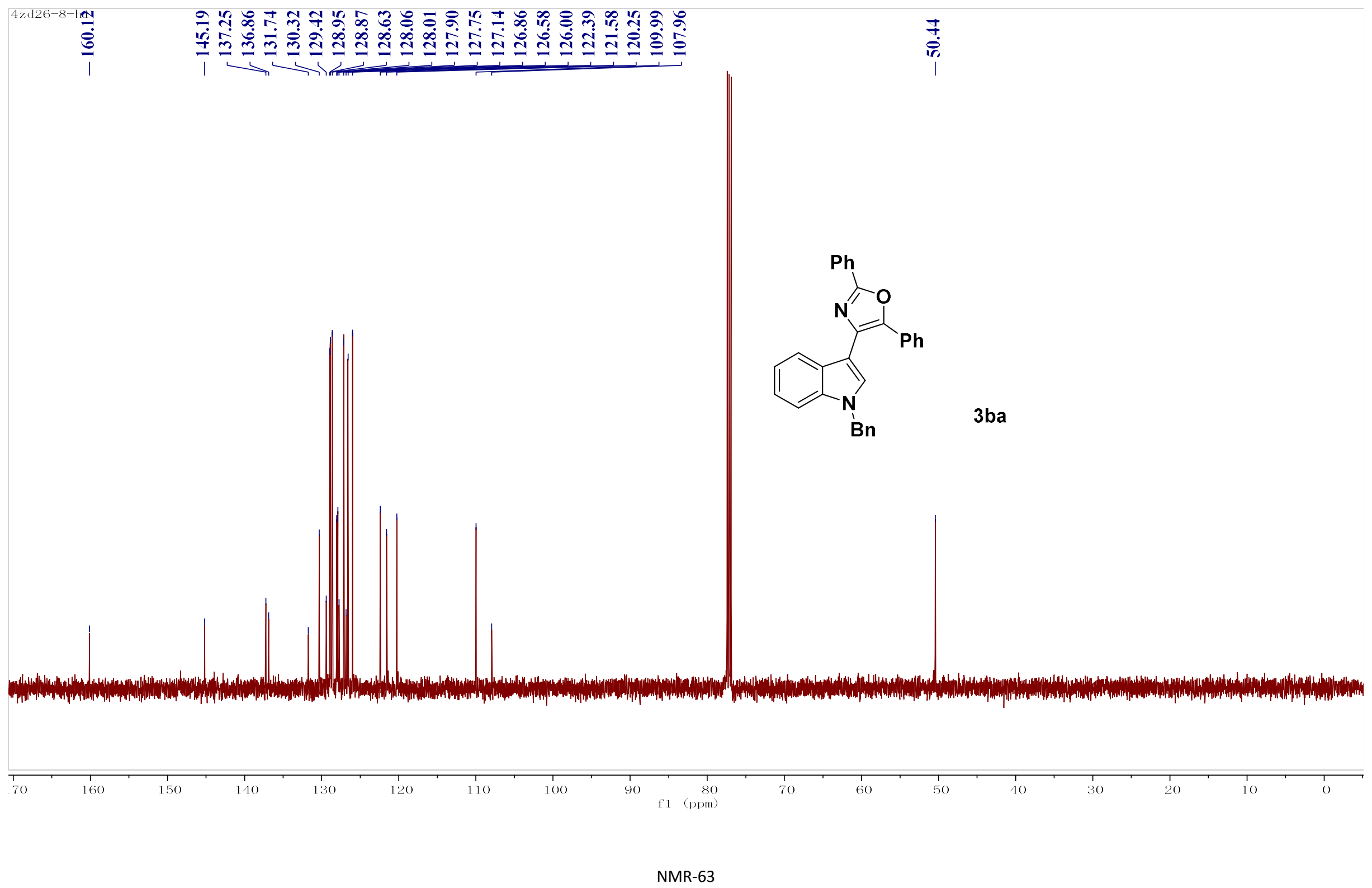




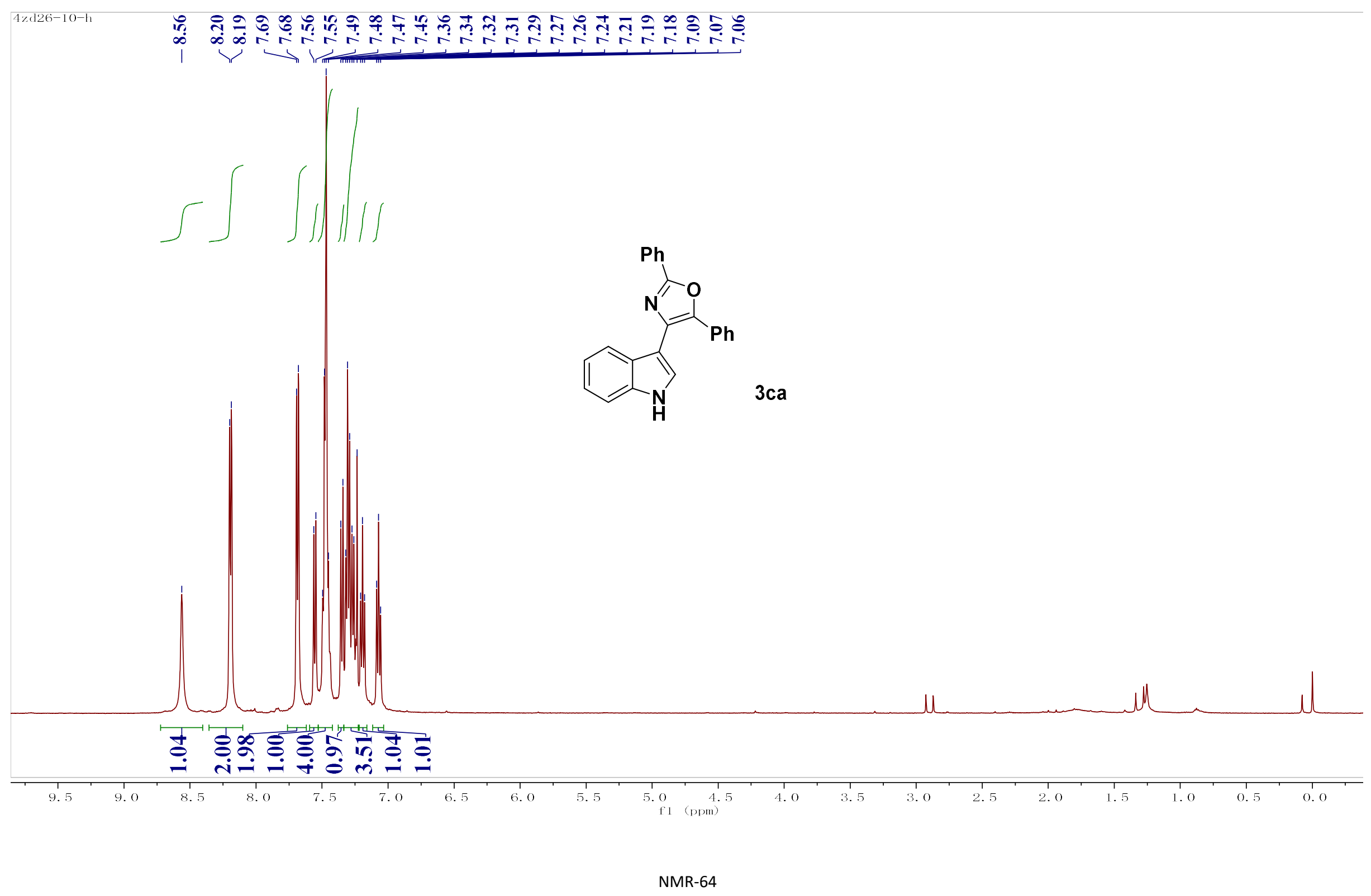




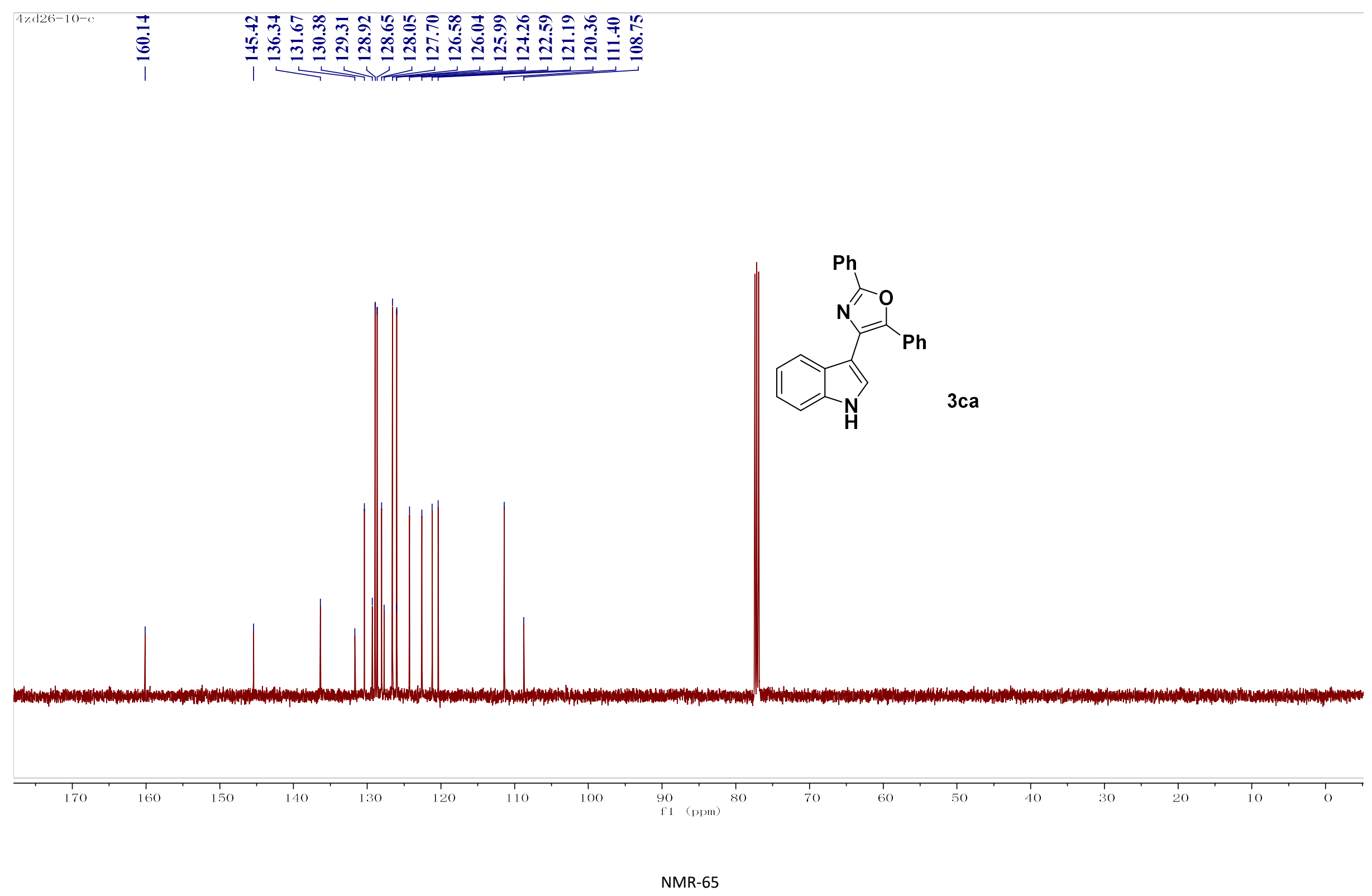




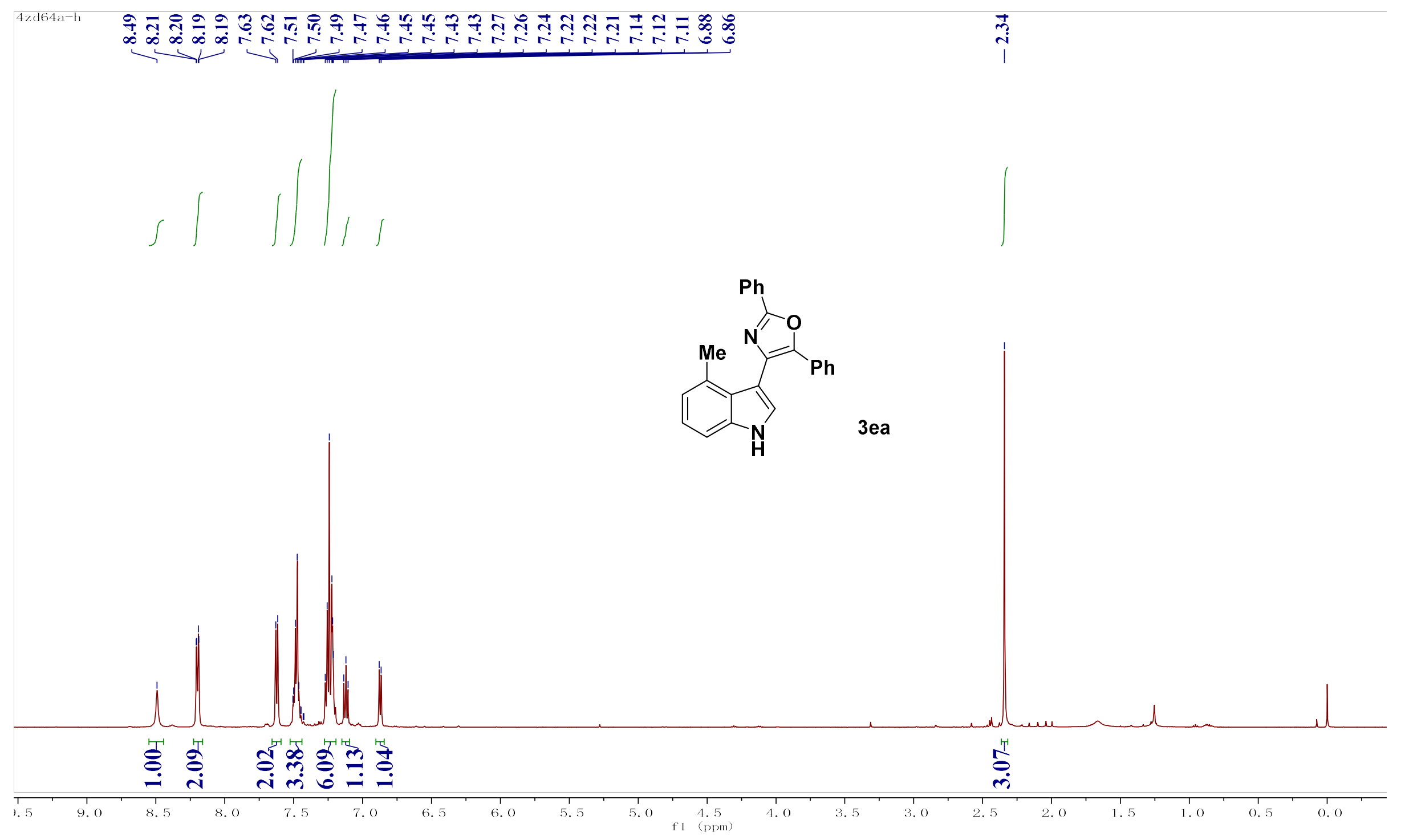

NMR-66 


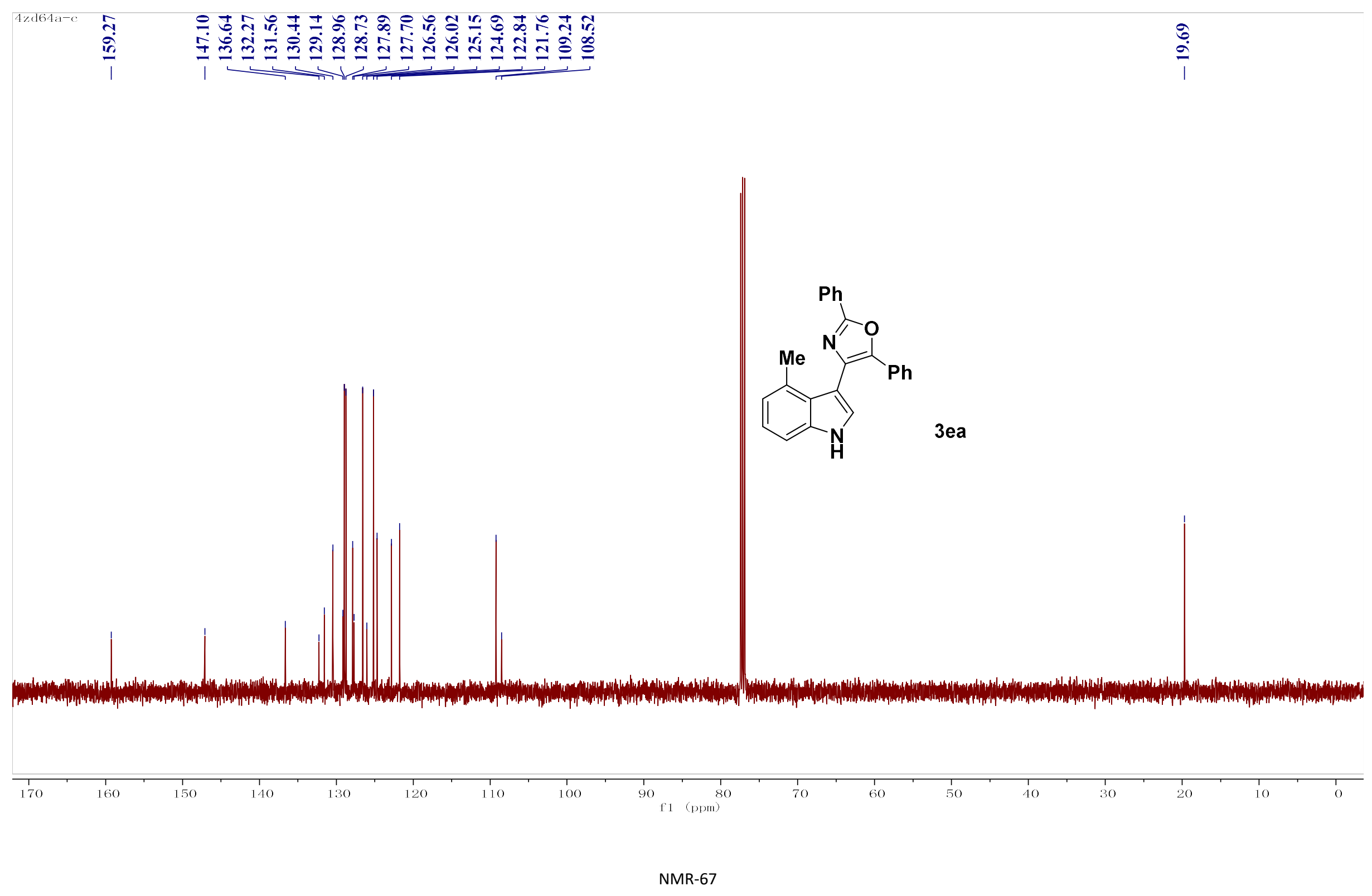




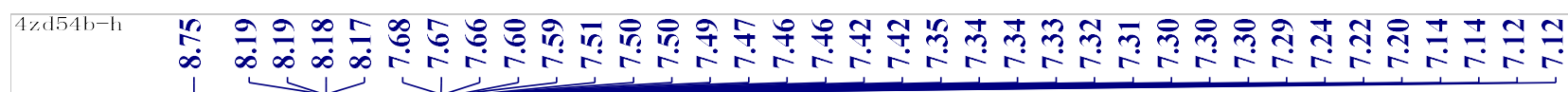

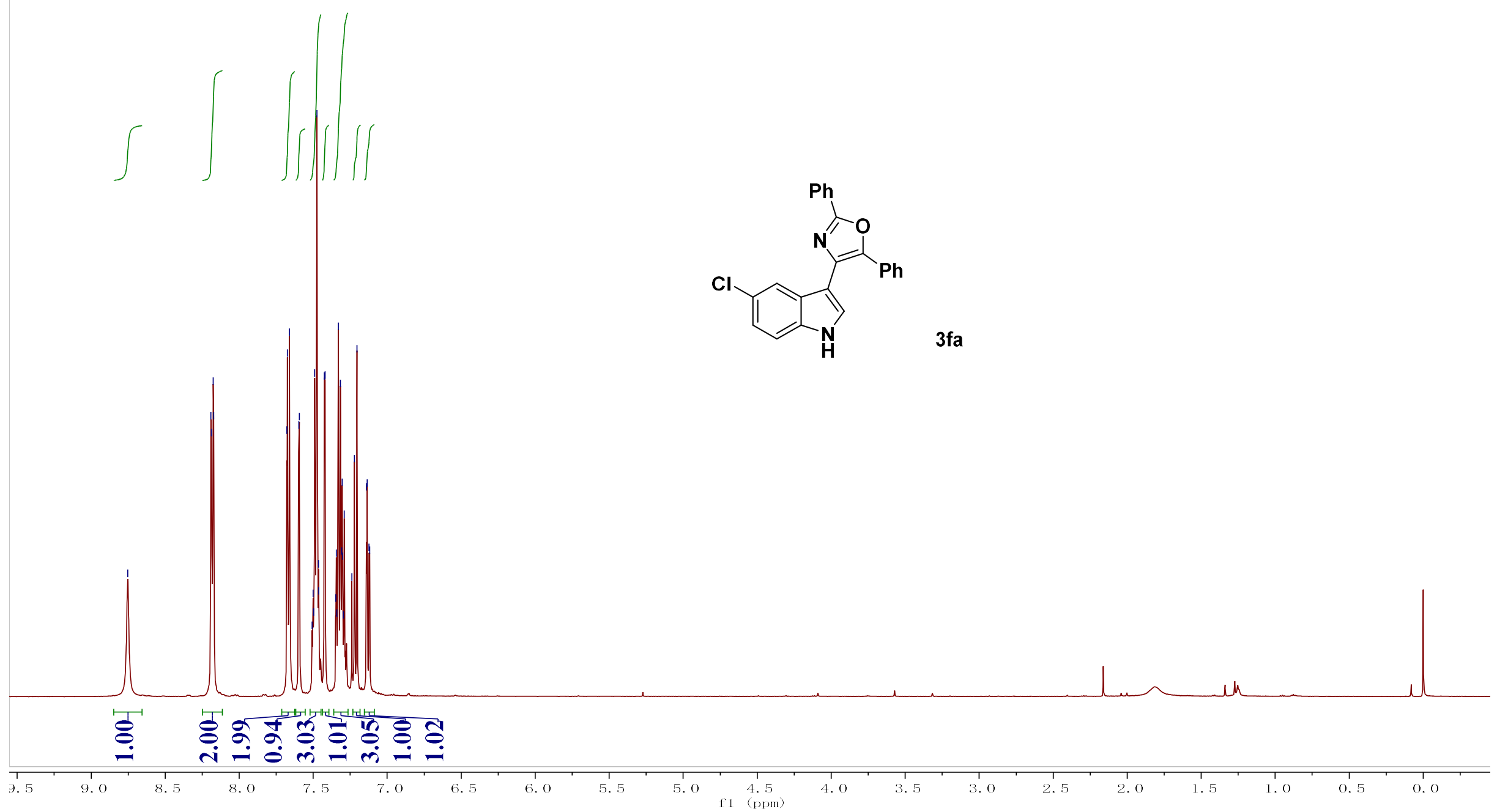

NMR-68 


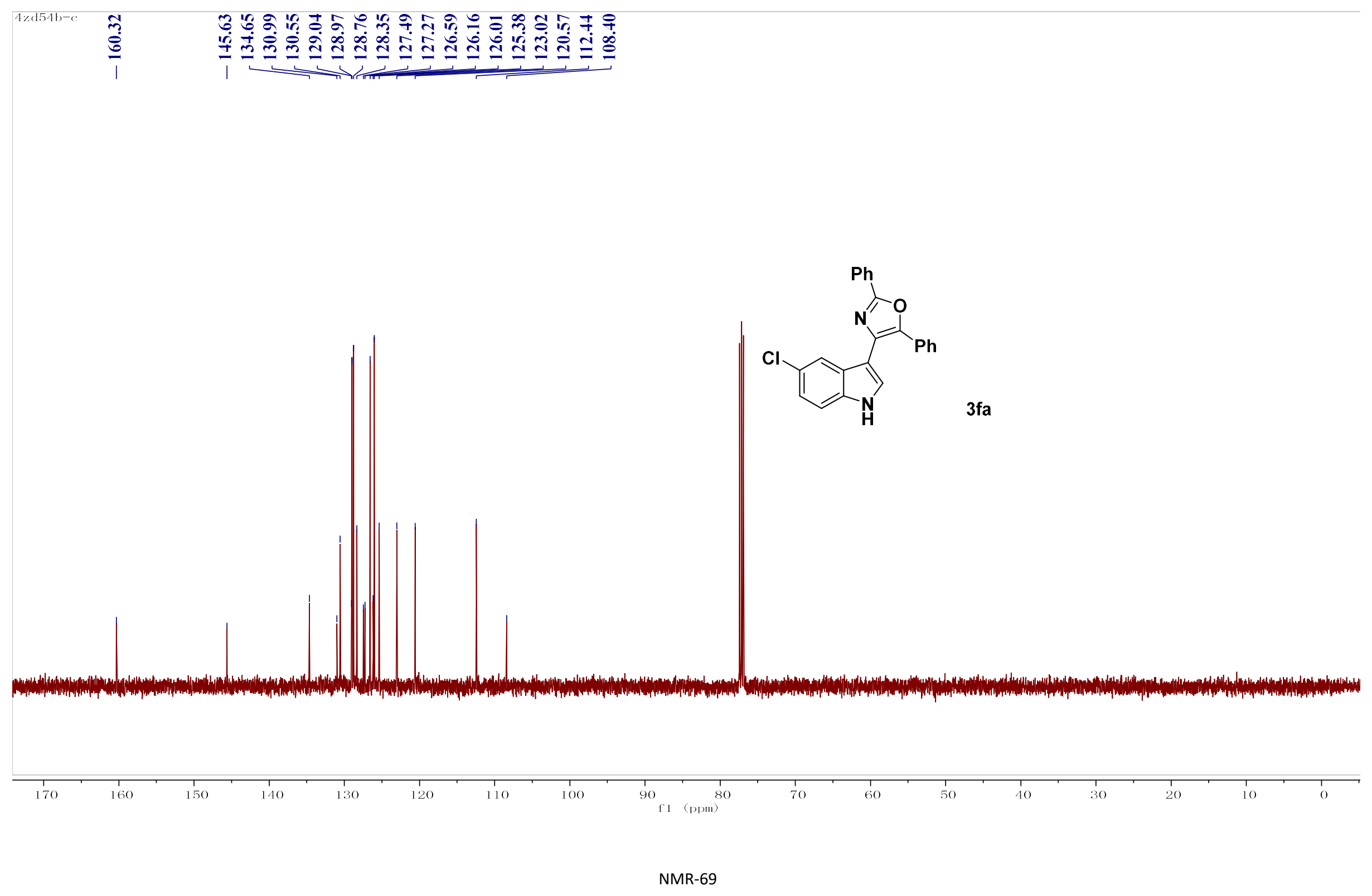


$\iiint \int /$

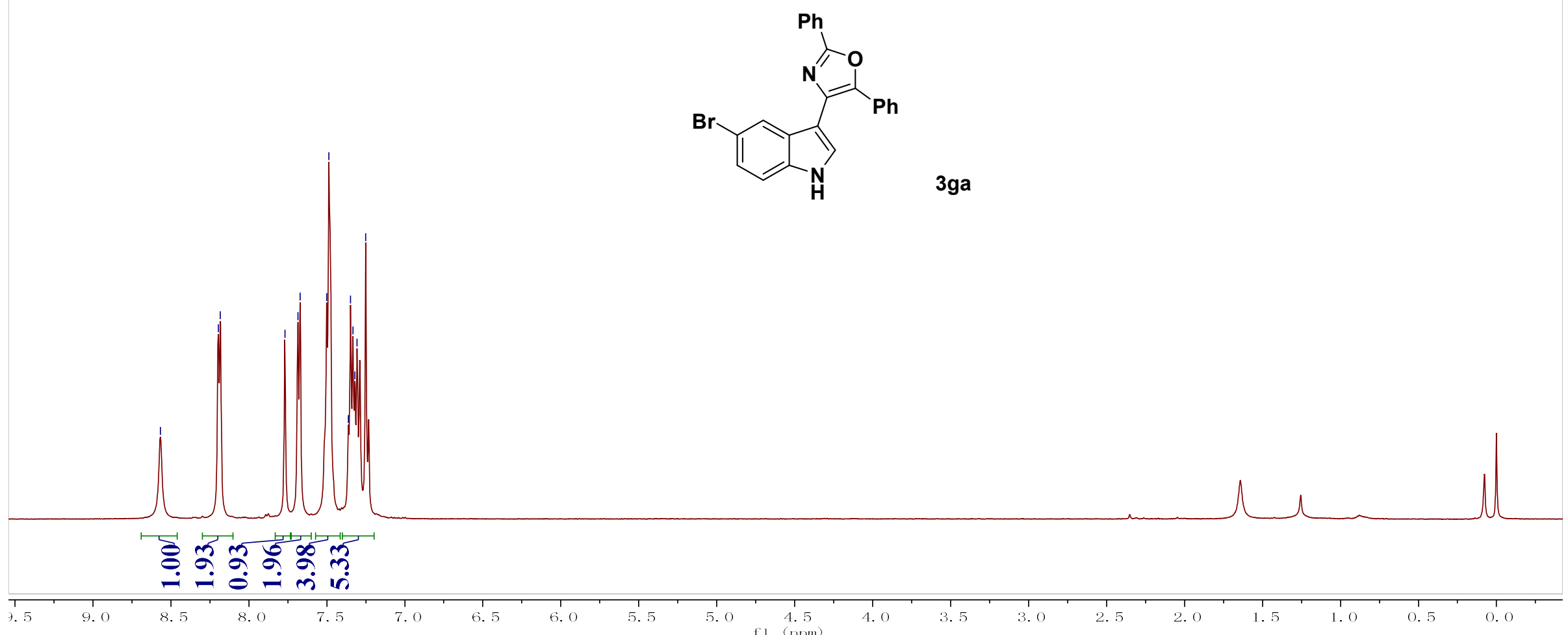




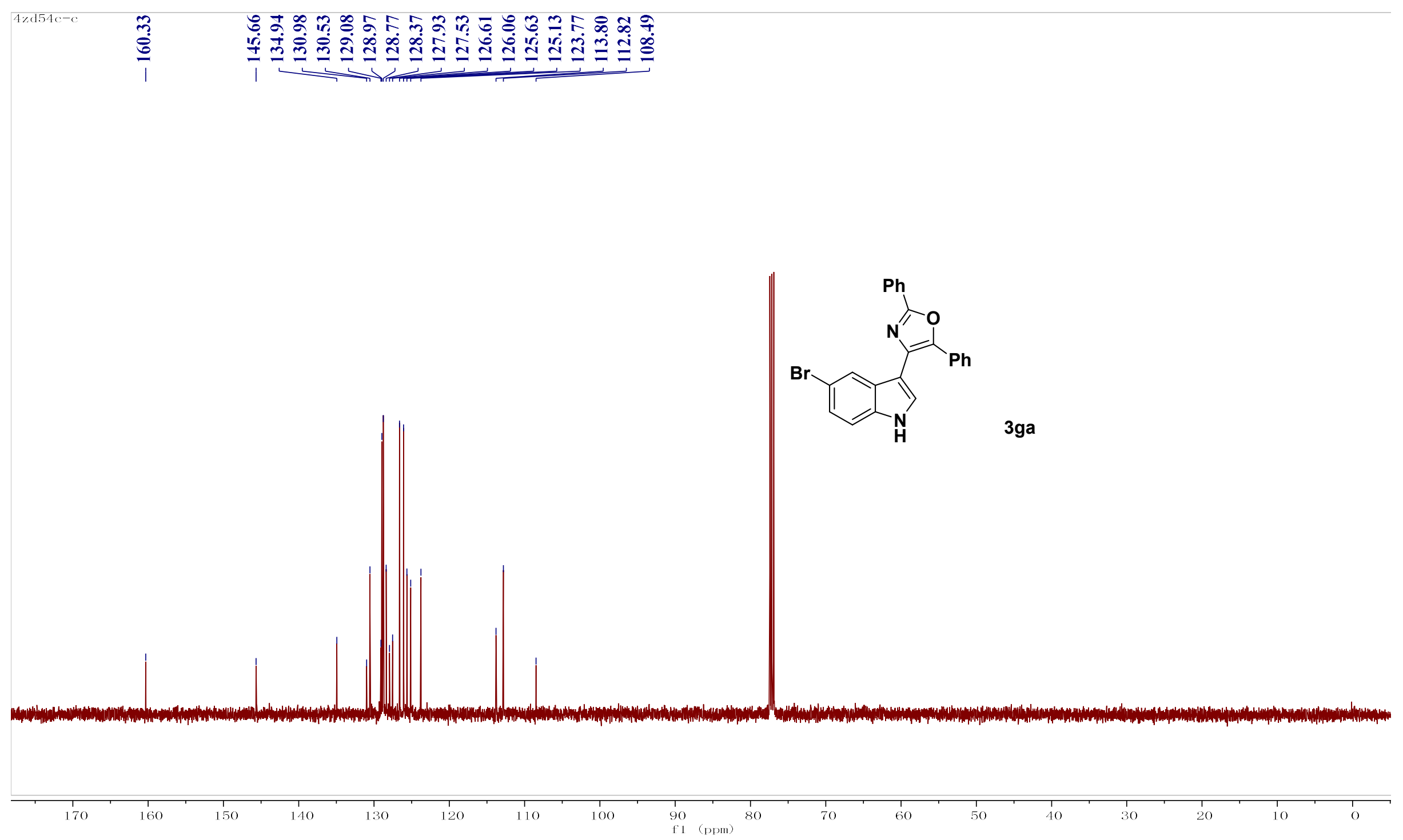

NMR-71 


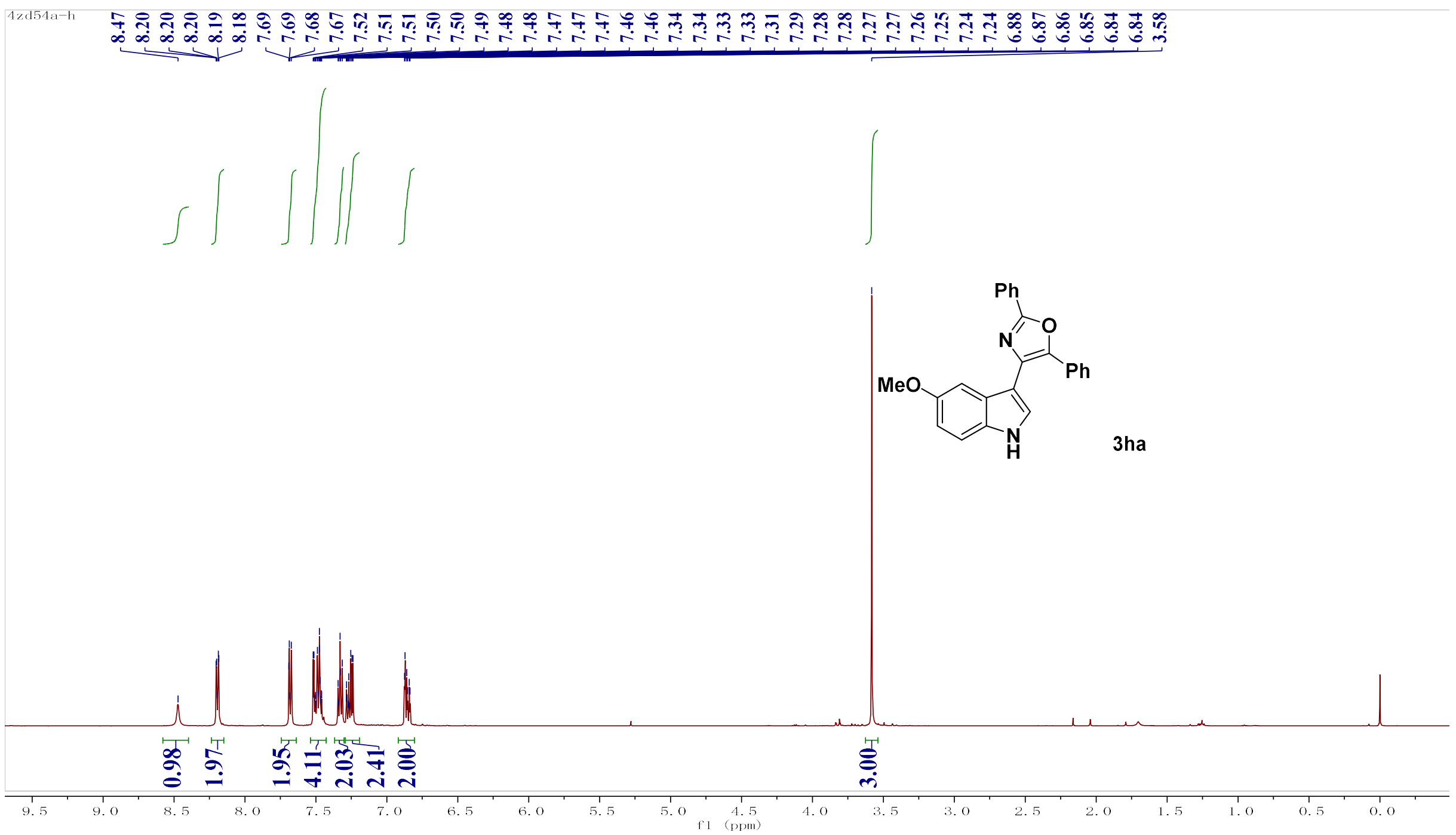

NMR-72 


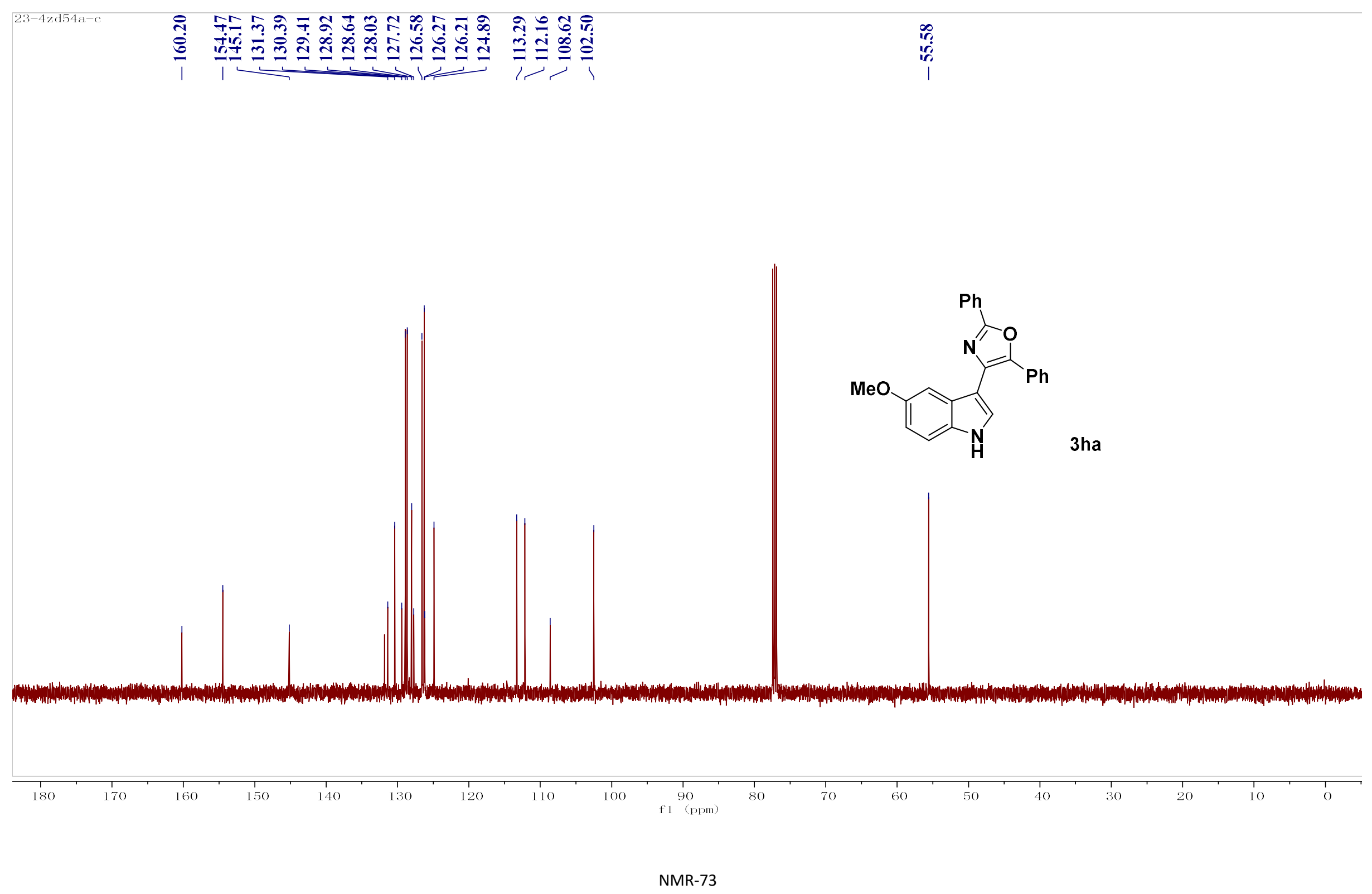




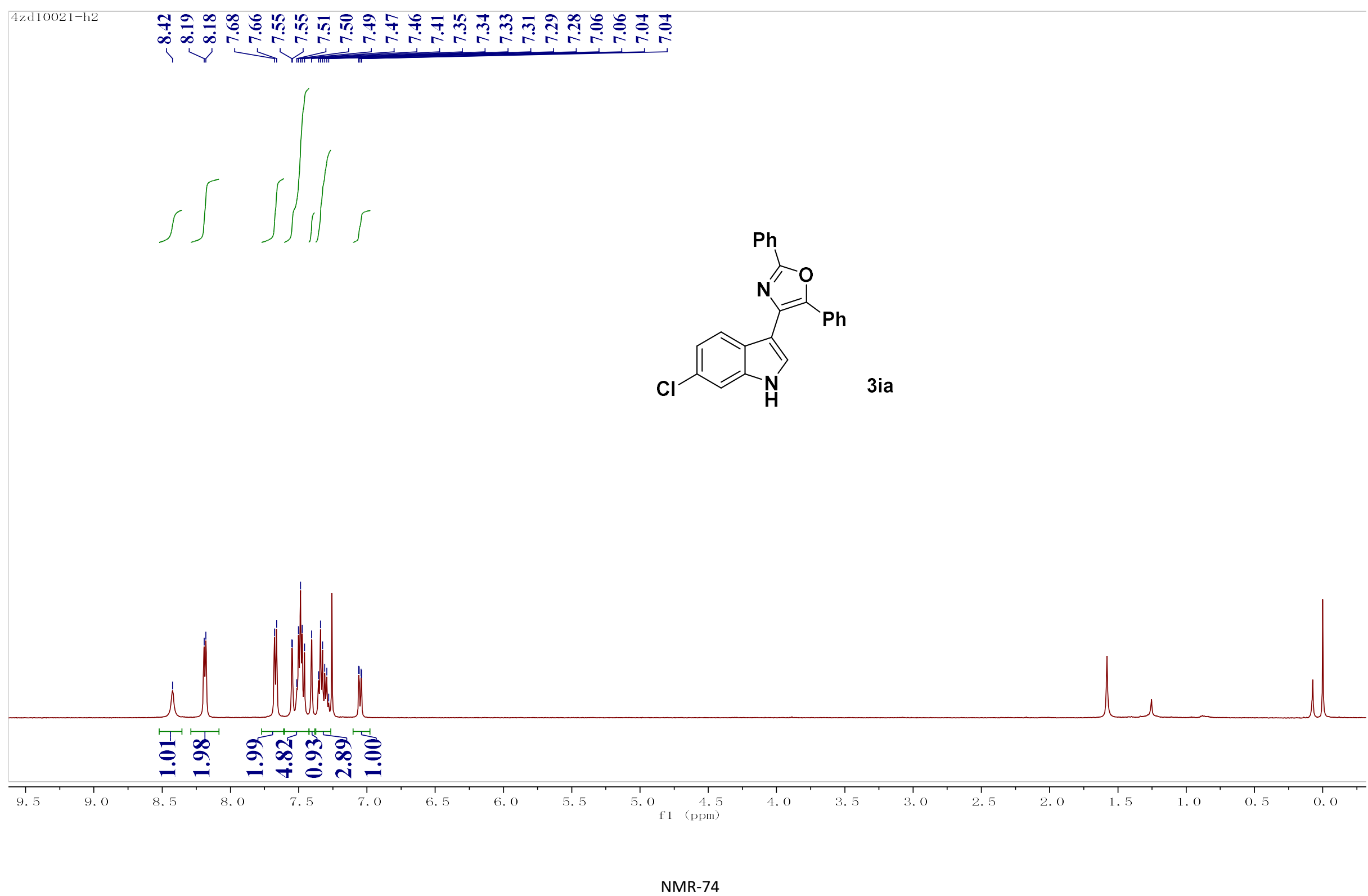




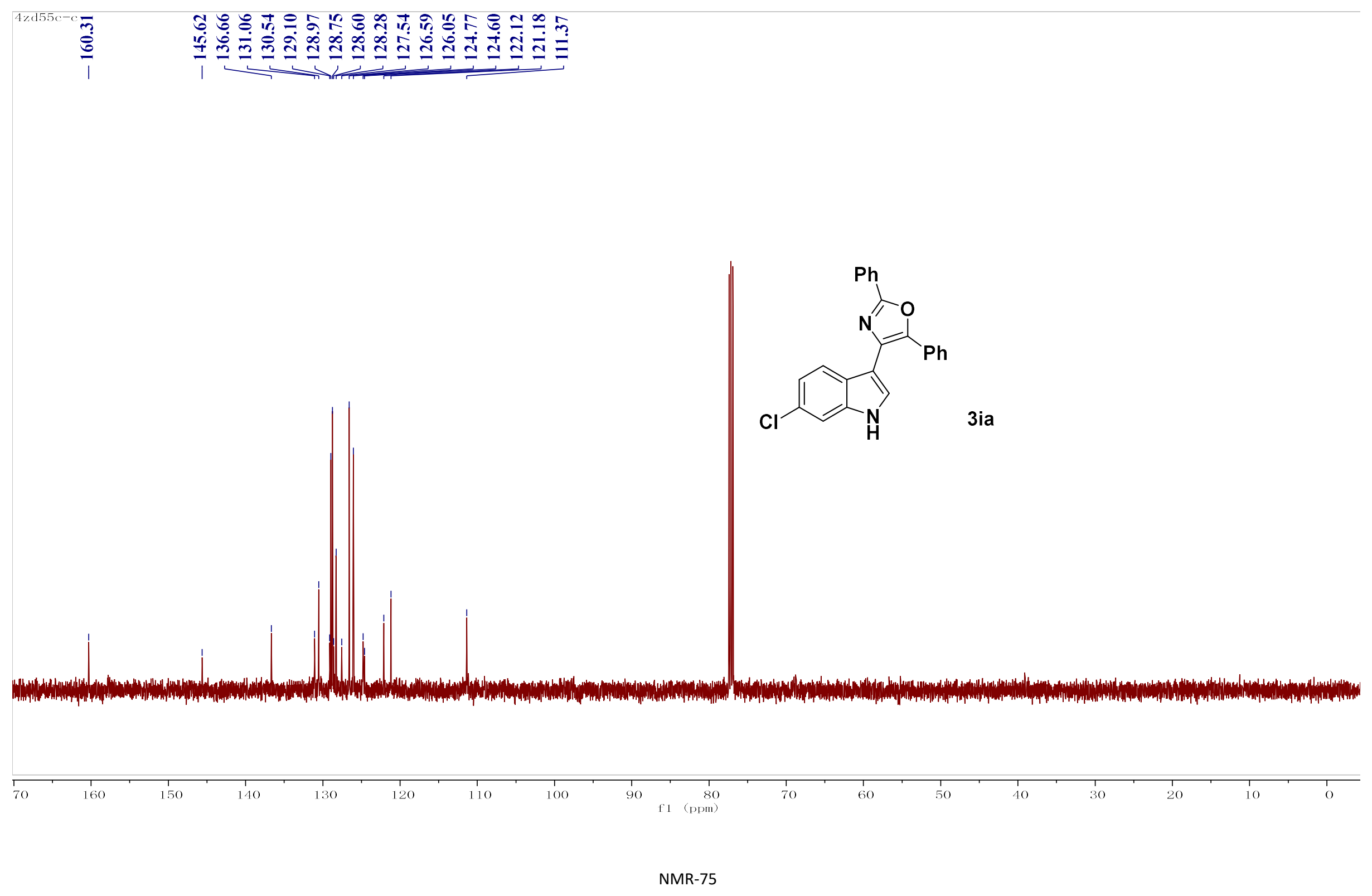




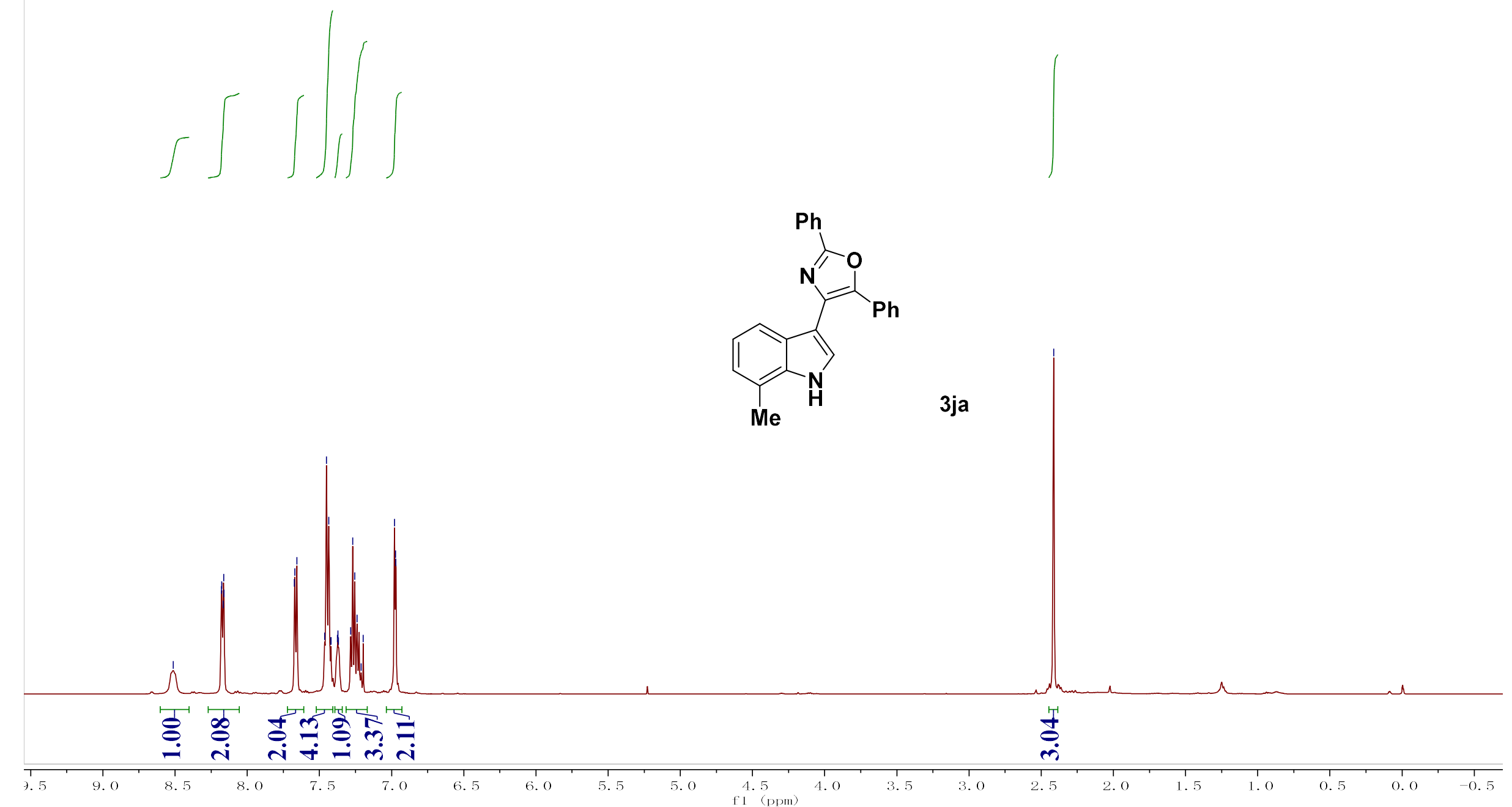

NMR-76 


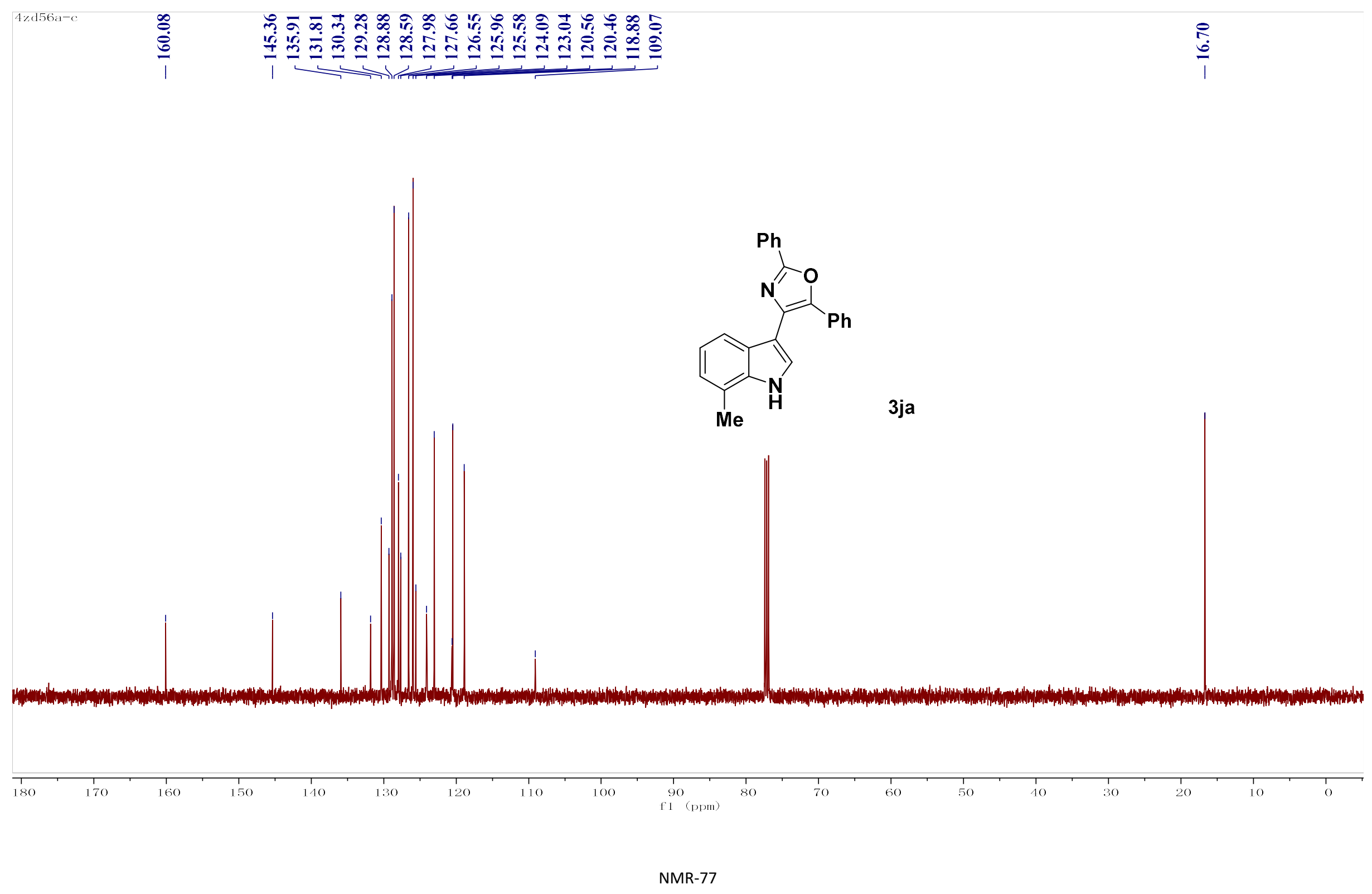




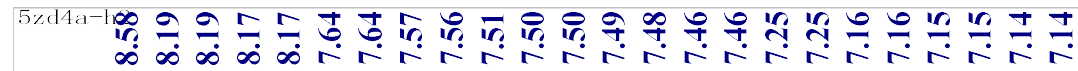
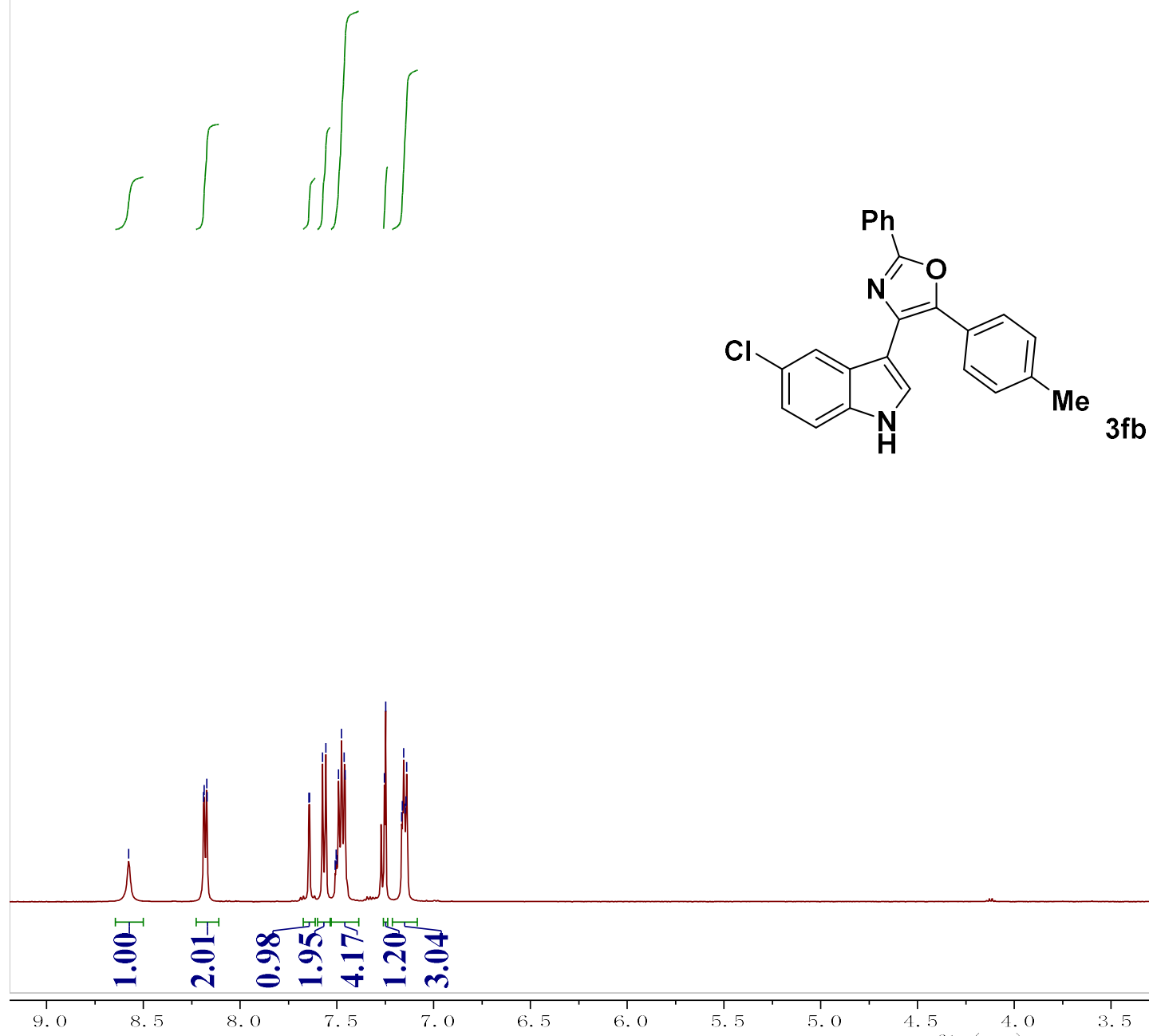


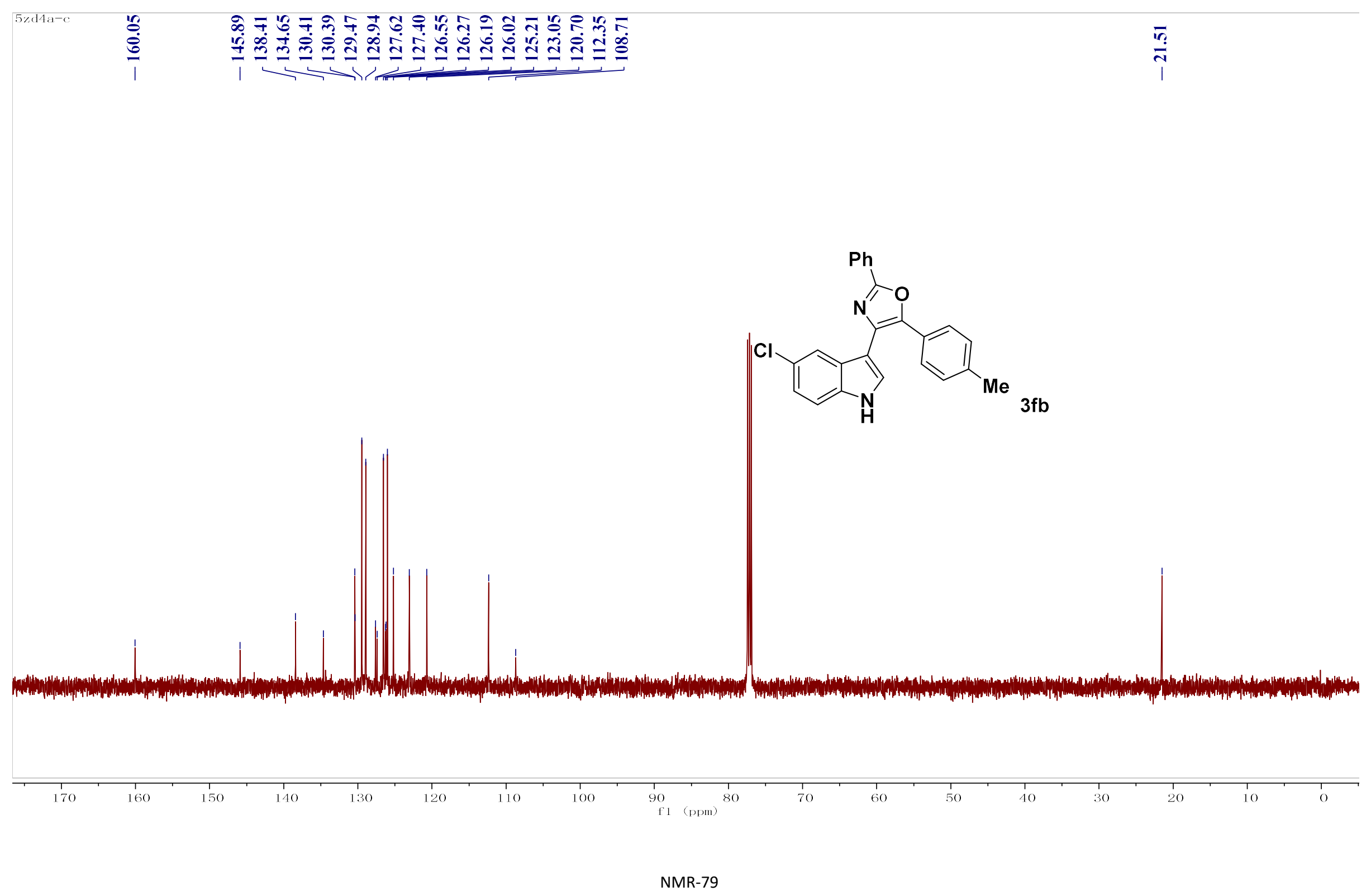




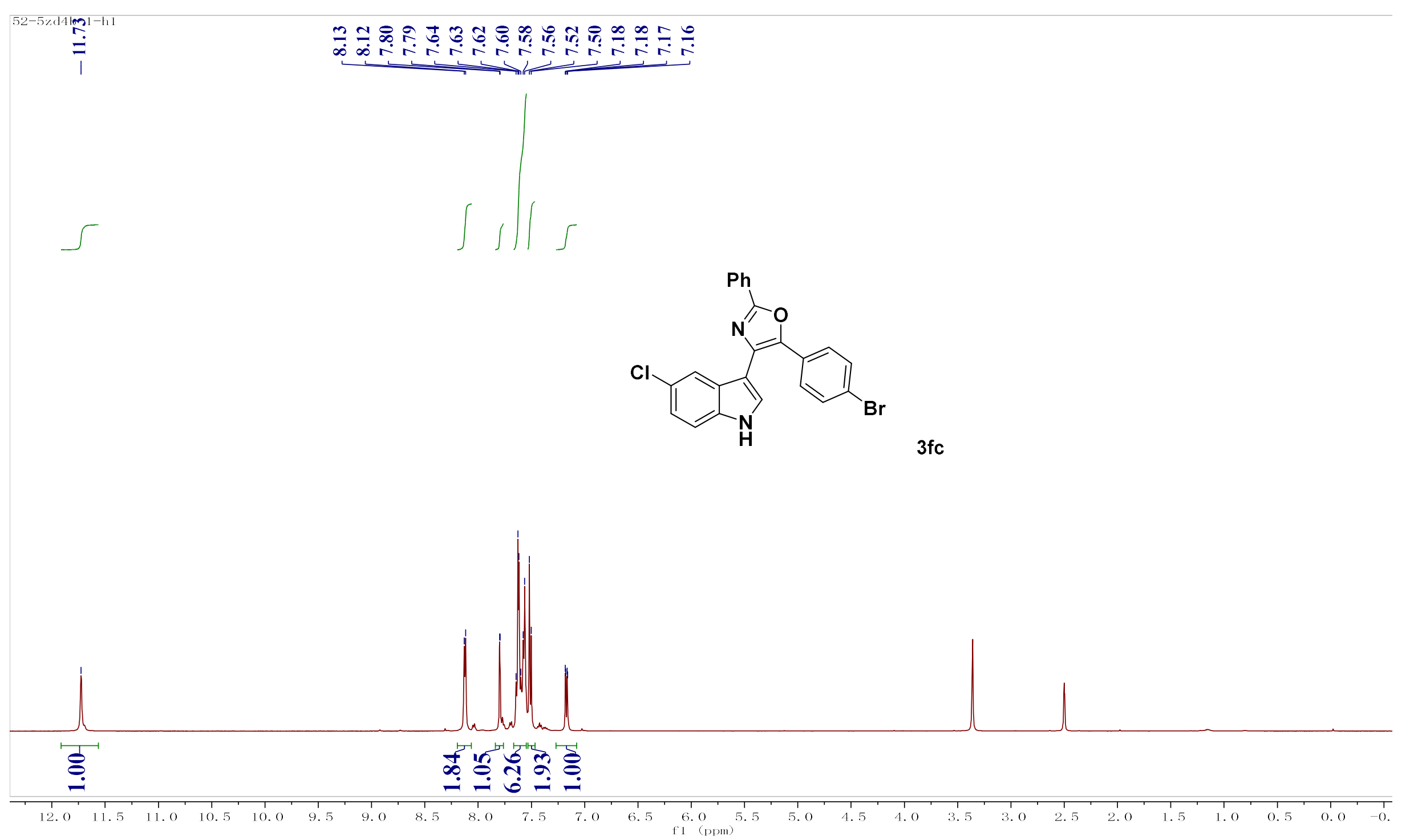

NMR-80 


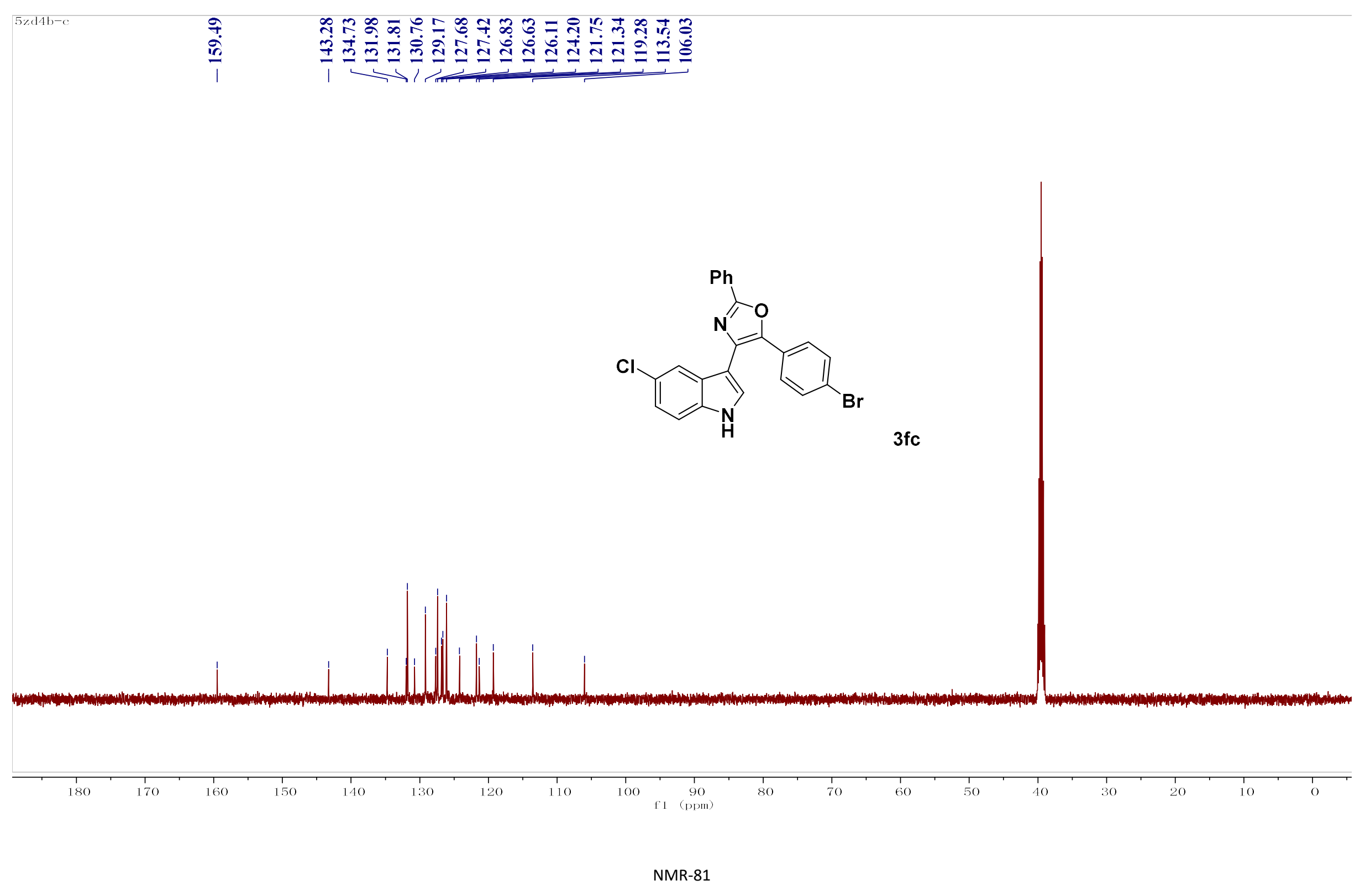




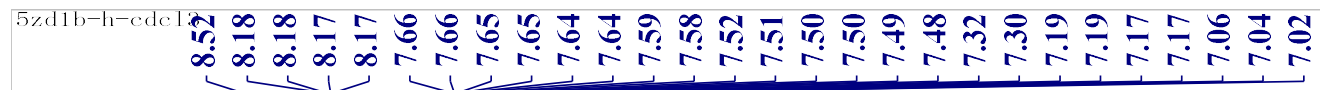
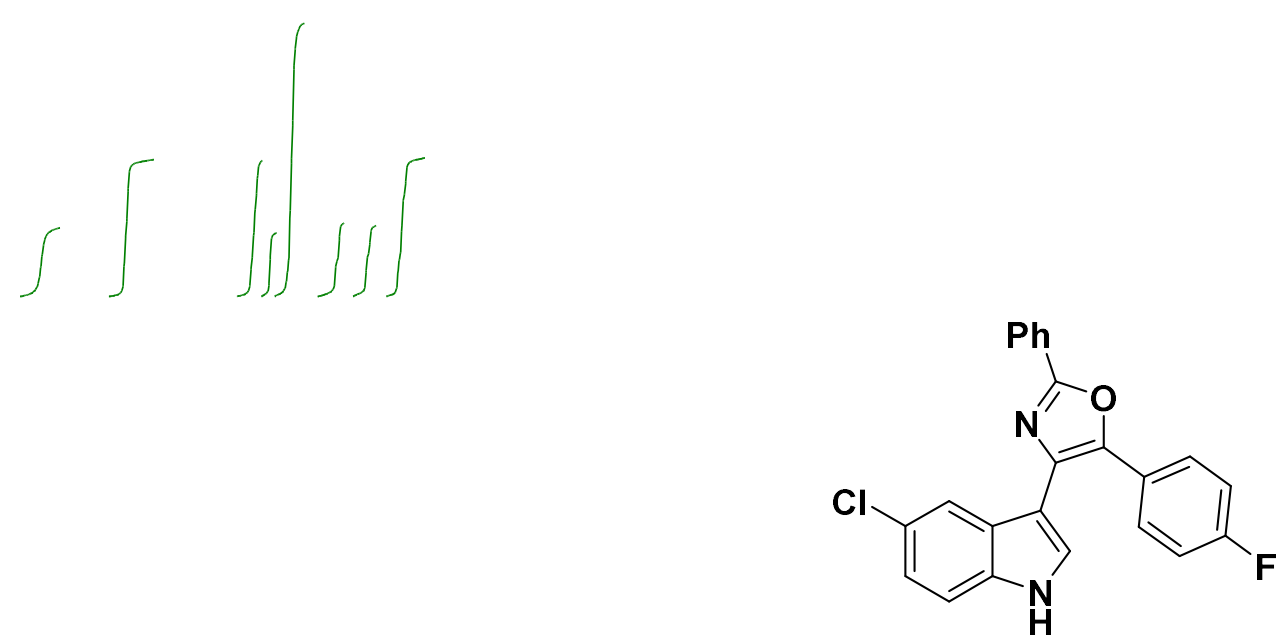

$3 \mathrm{fd}$

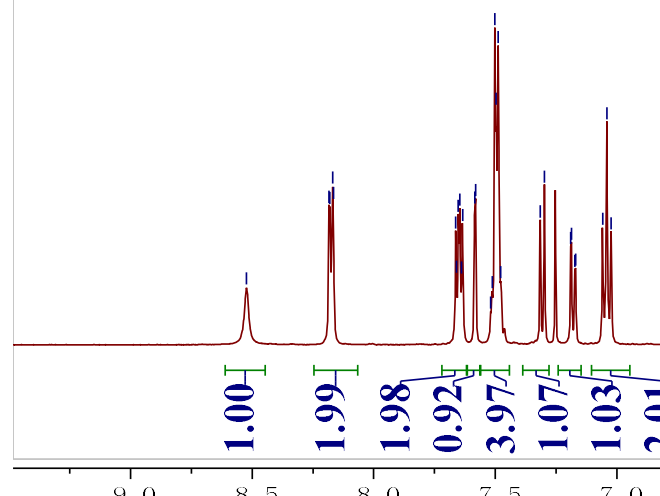

NMR-82 


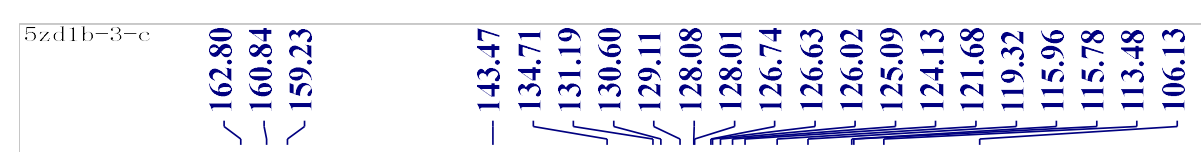

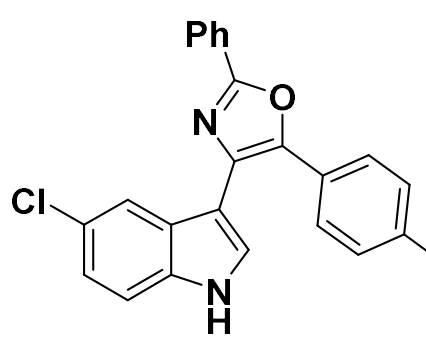

$3 \mathrm{fd}$

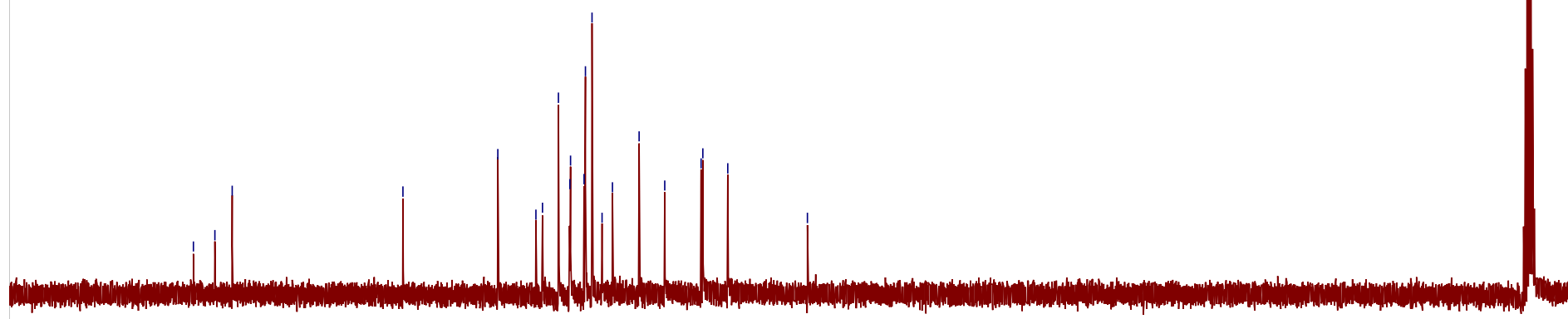

$170 \quad 160$

150

140

$130 \quad 120$

110

$\mathrm{fl}^{90}(\mathrm{ppm})$

NMR-83 


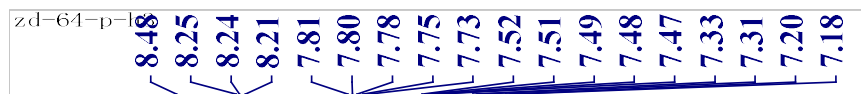

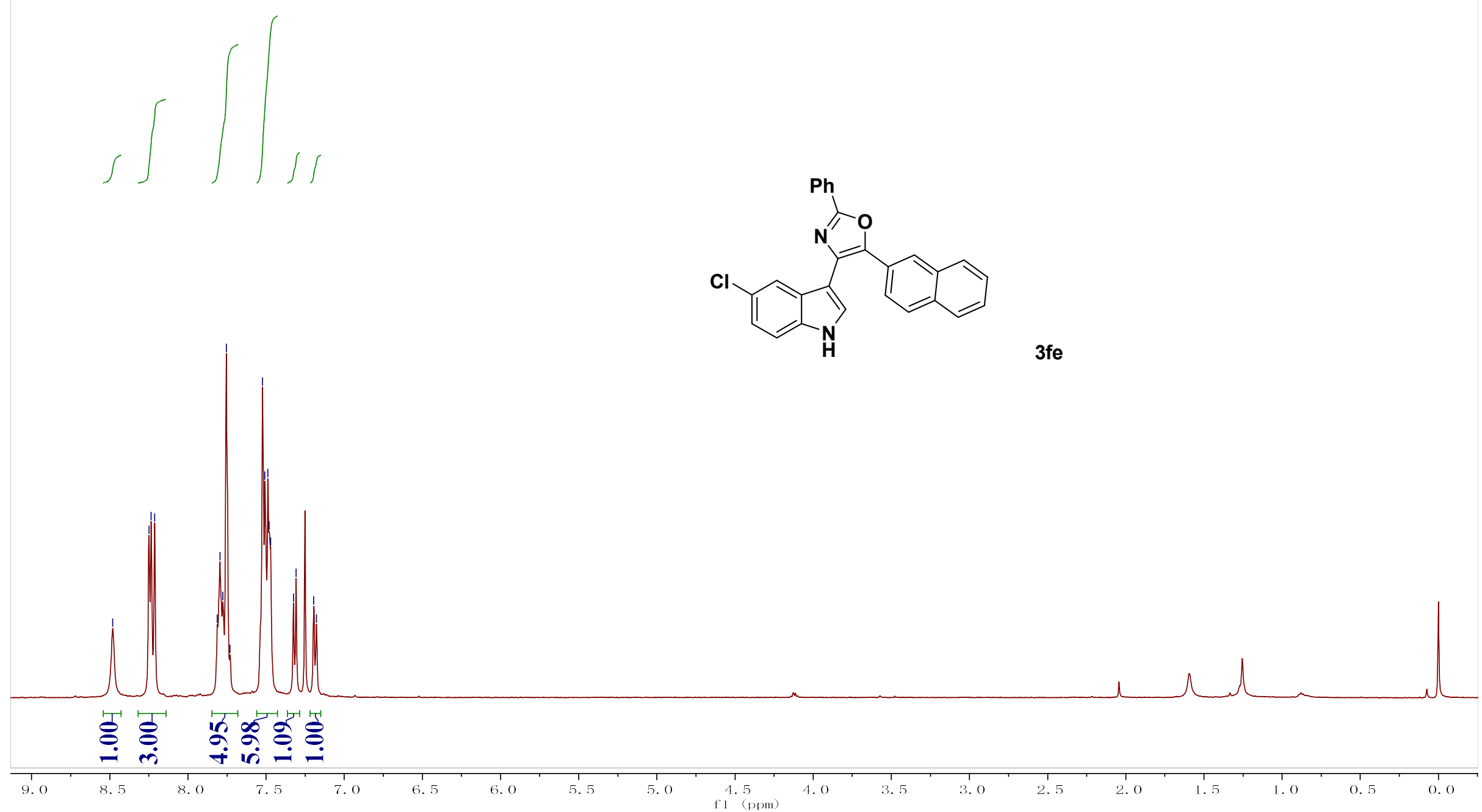

NMR-84 

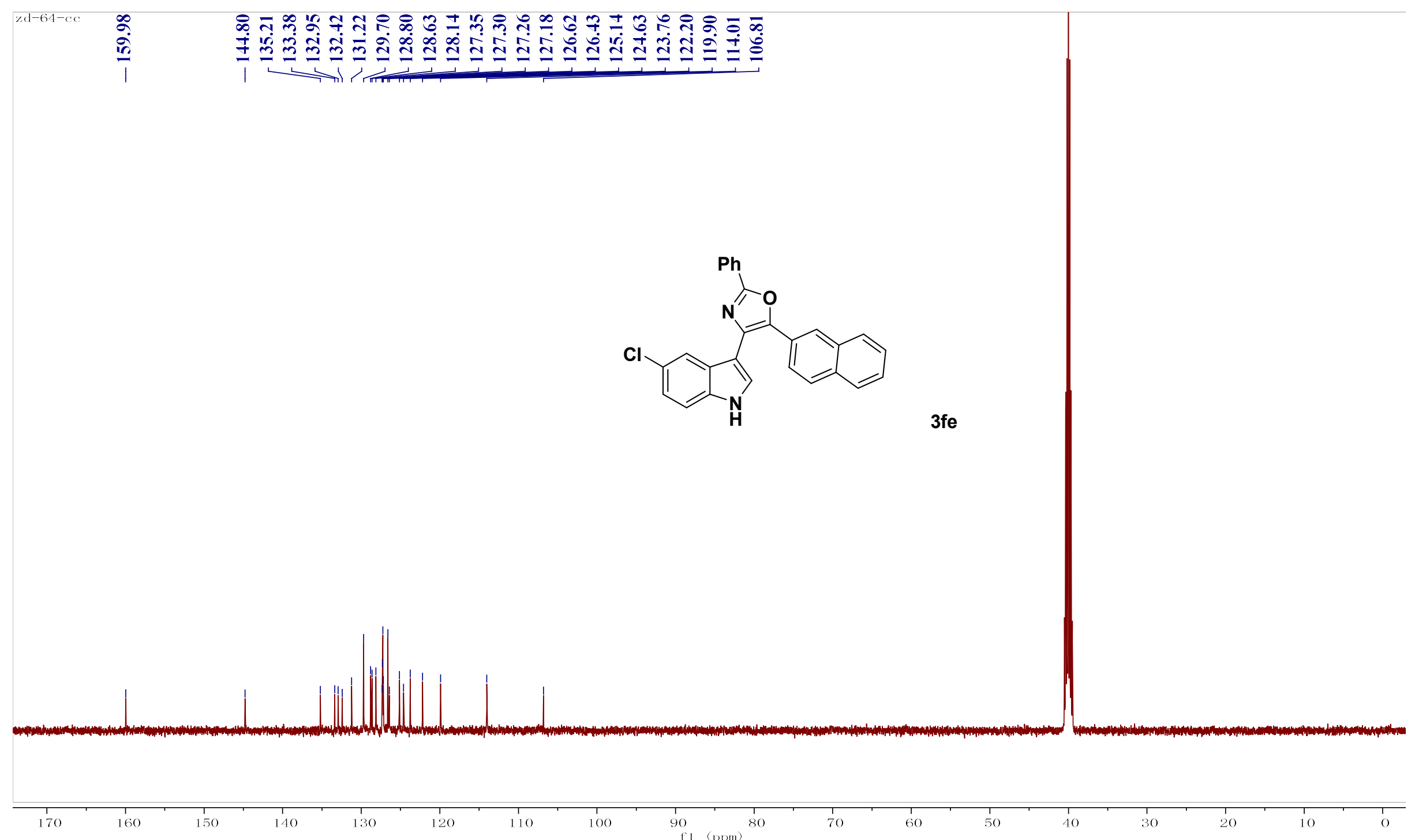

NMR-85 


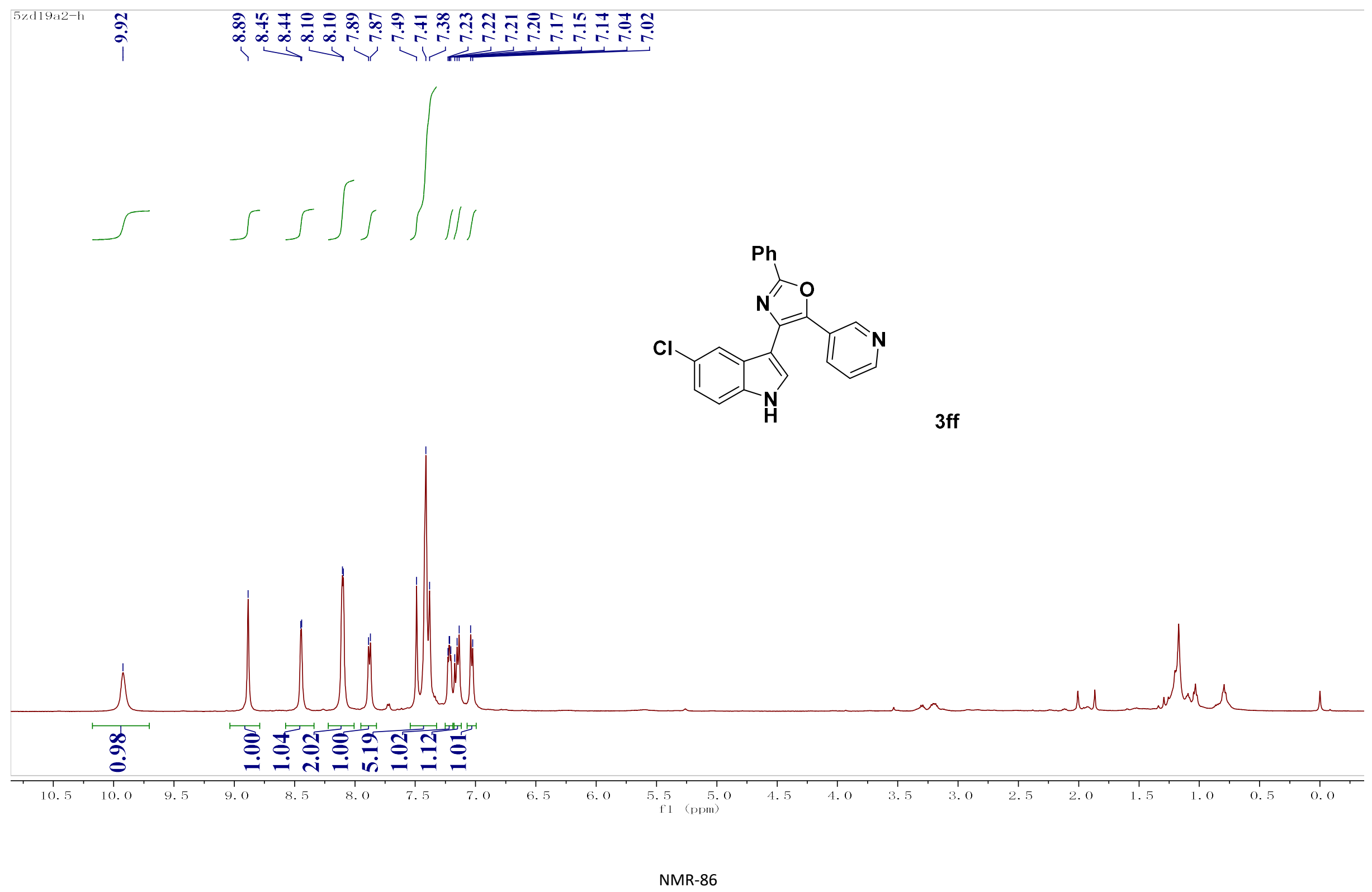




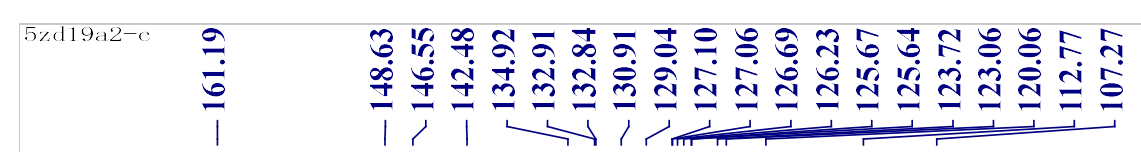
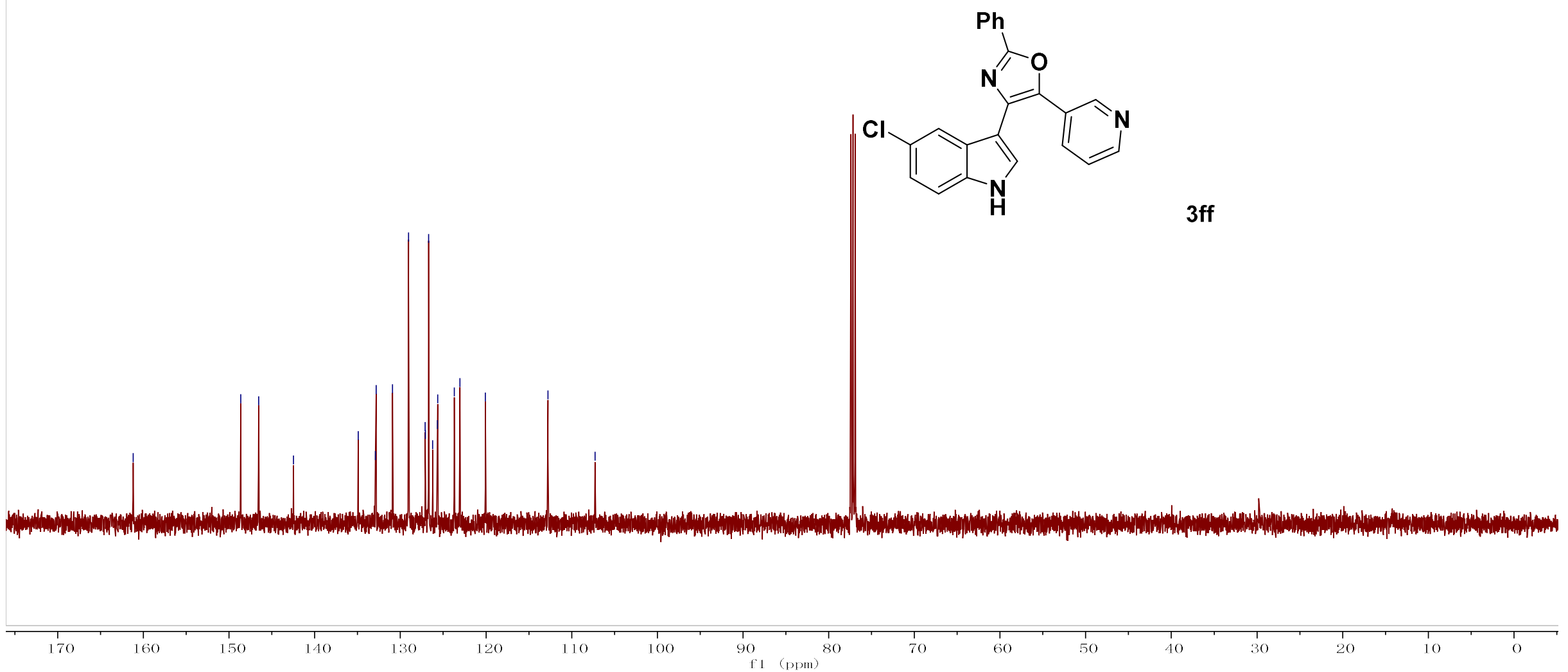

NMR-87 

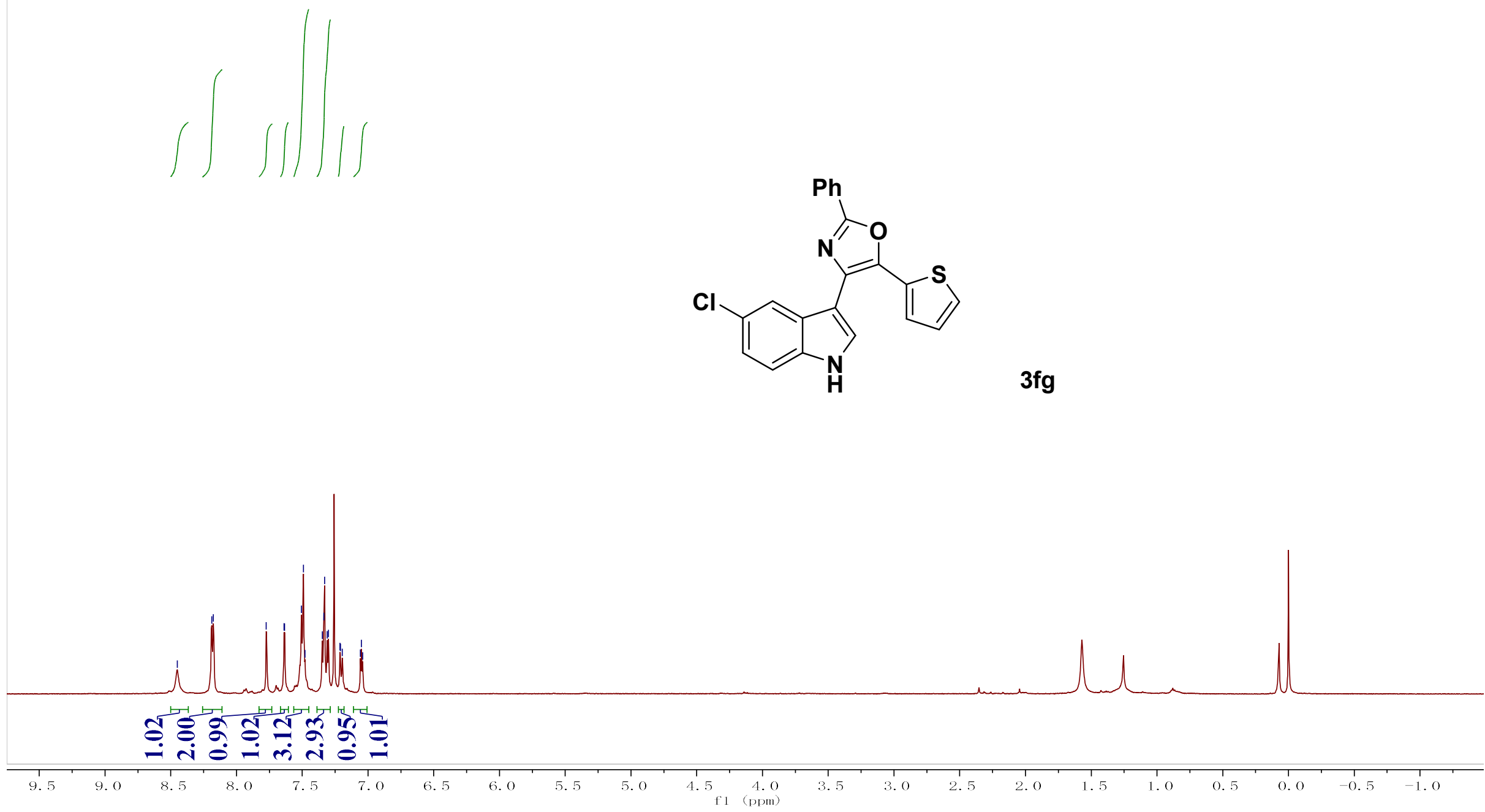

NMR-88 


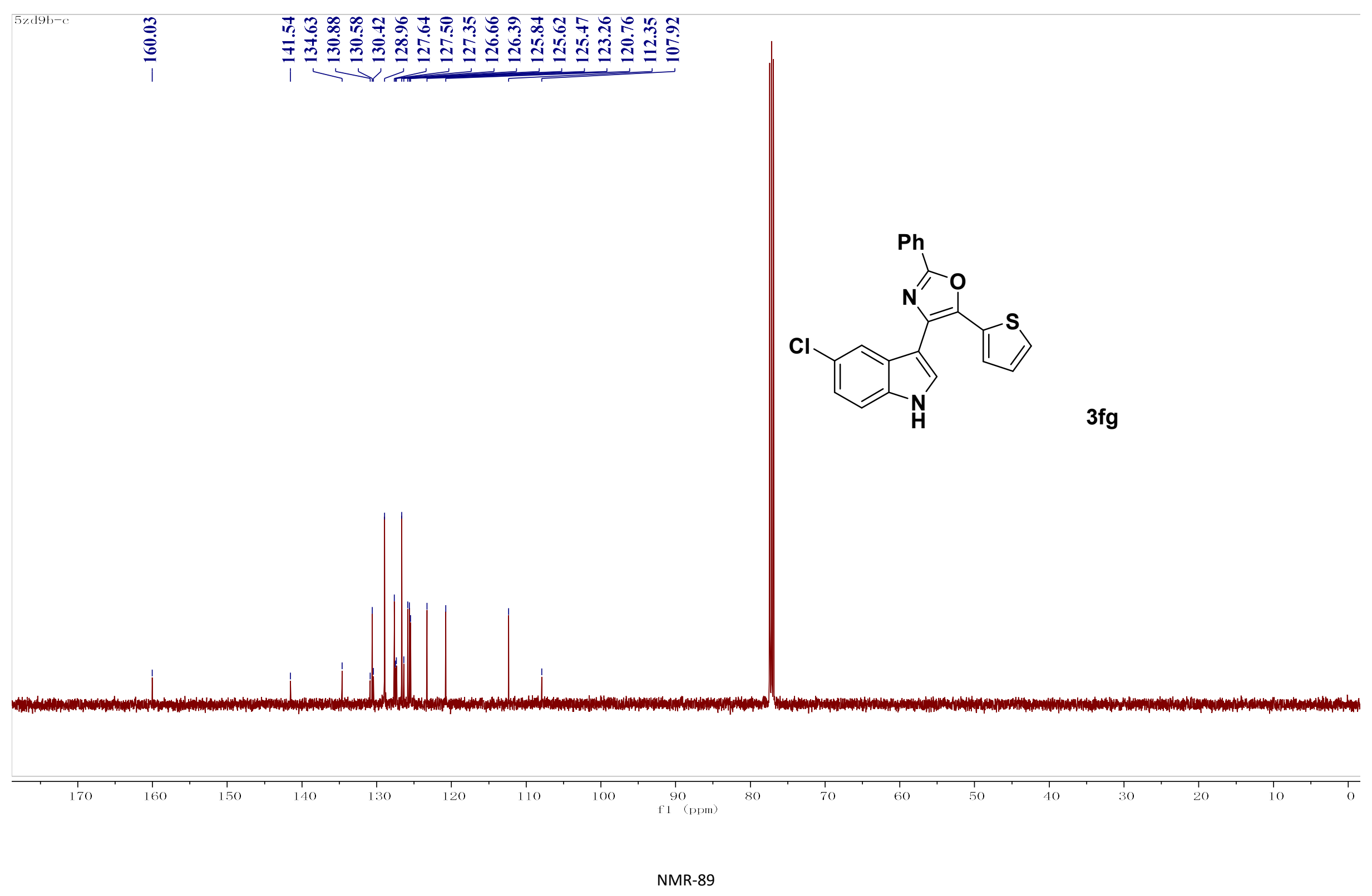




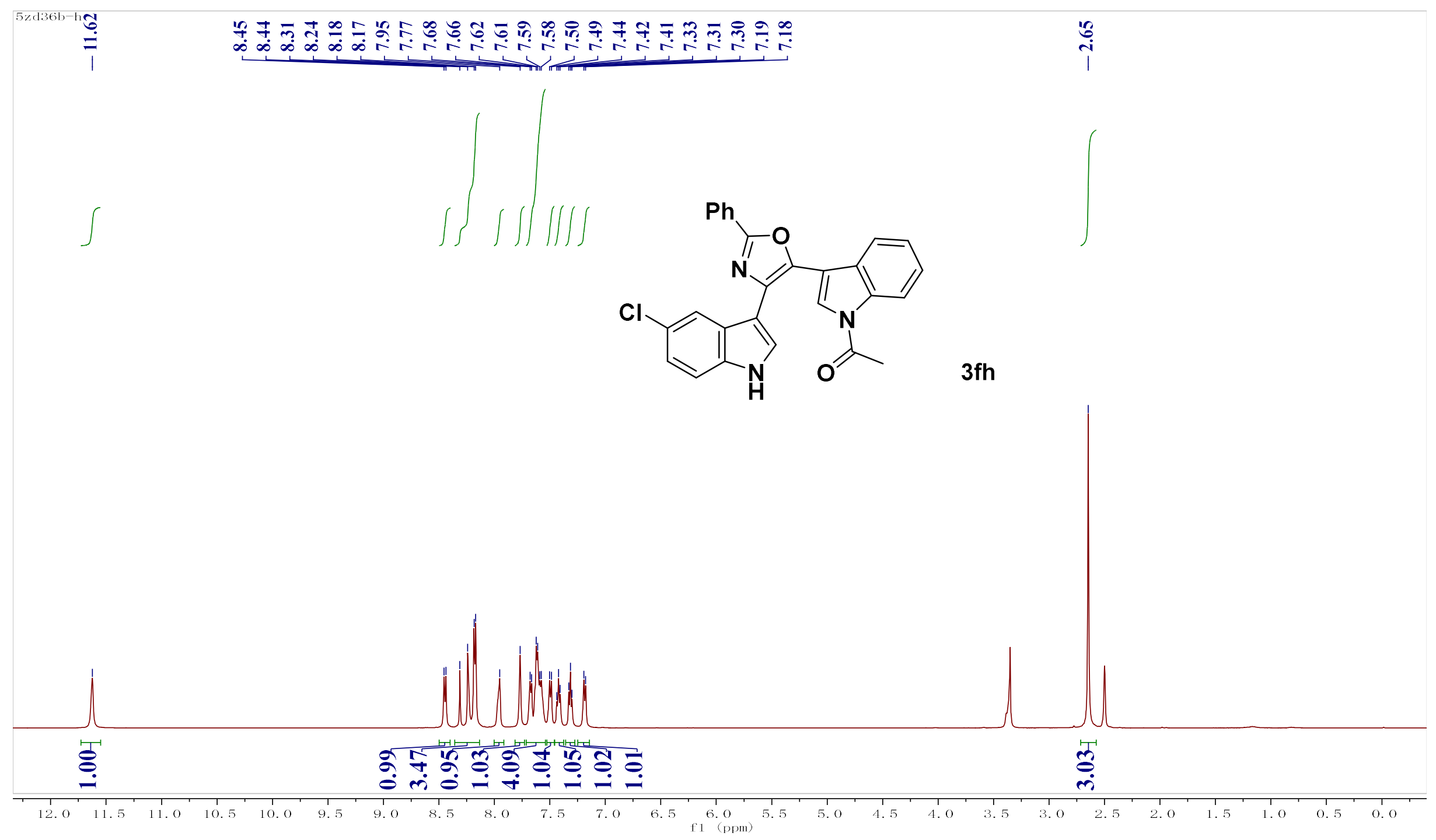

NMR-90 

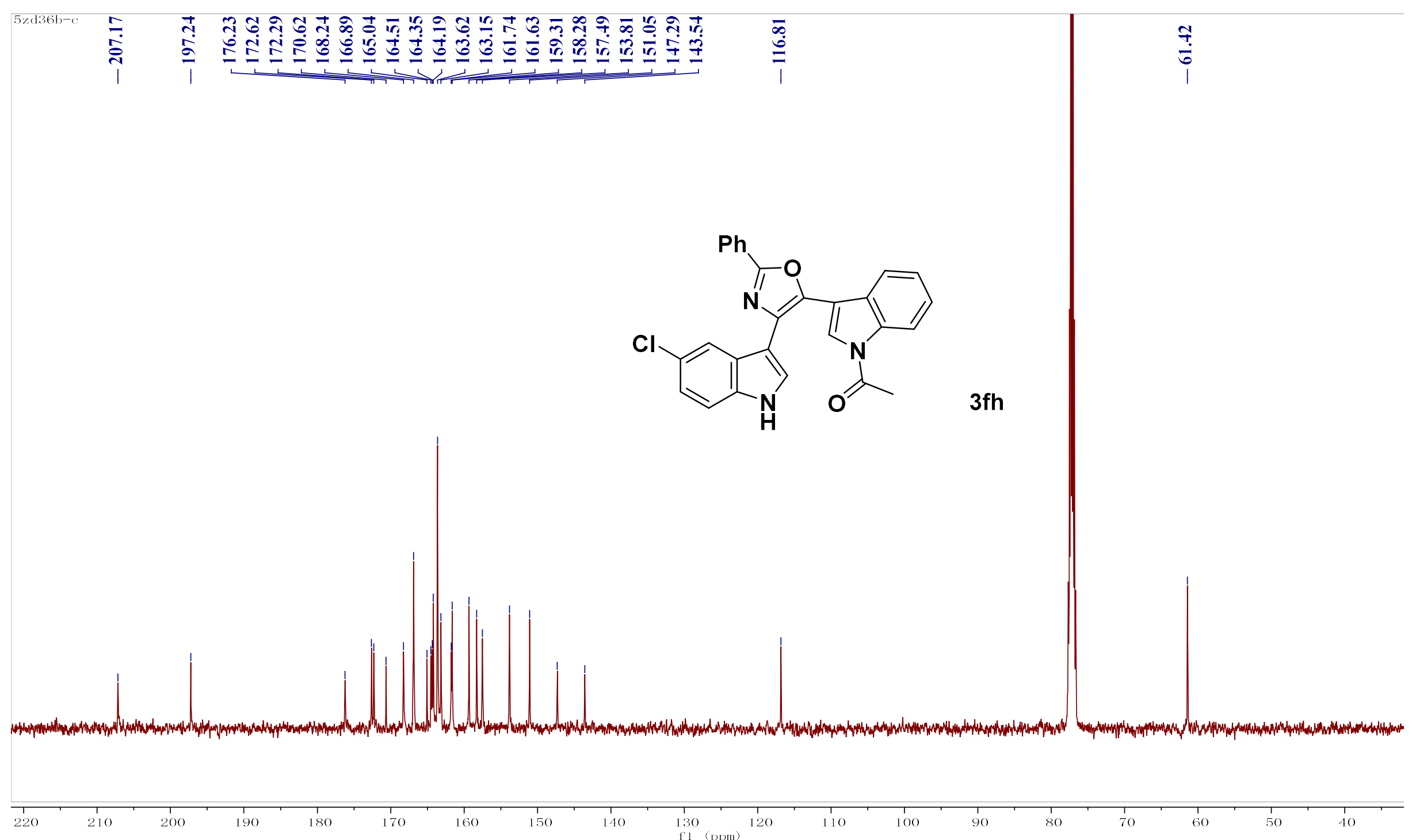

NMR-91 
5zd37e-h

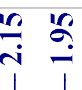
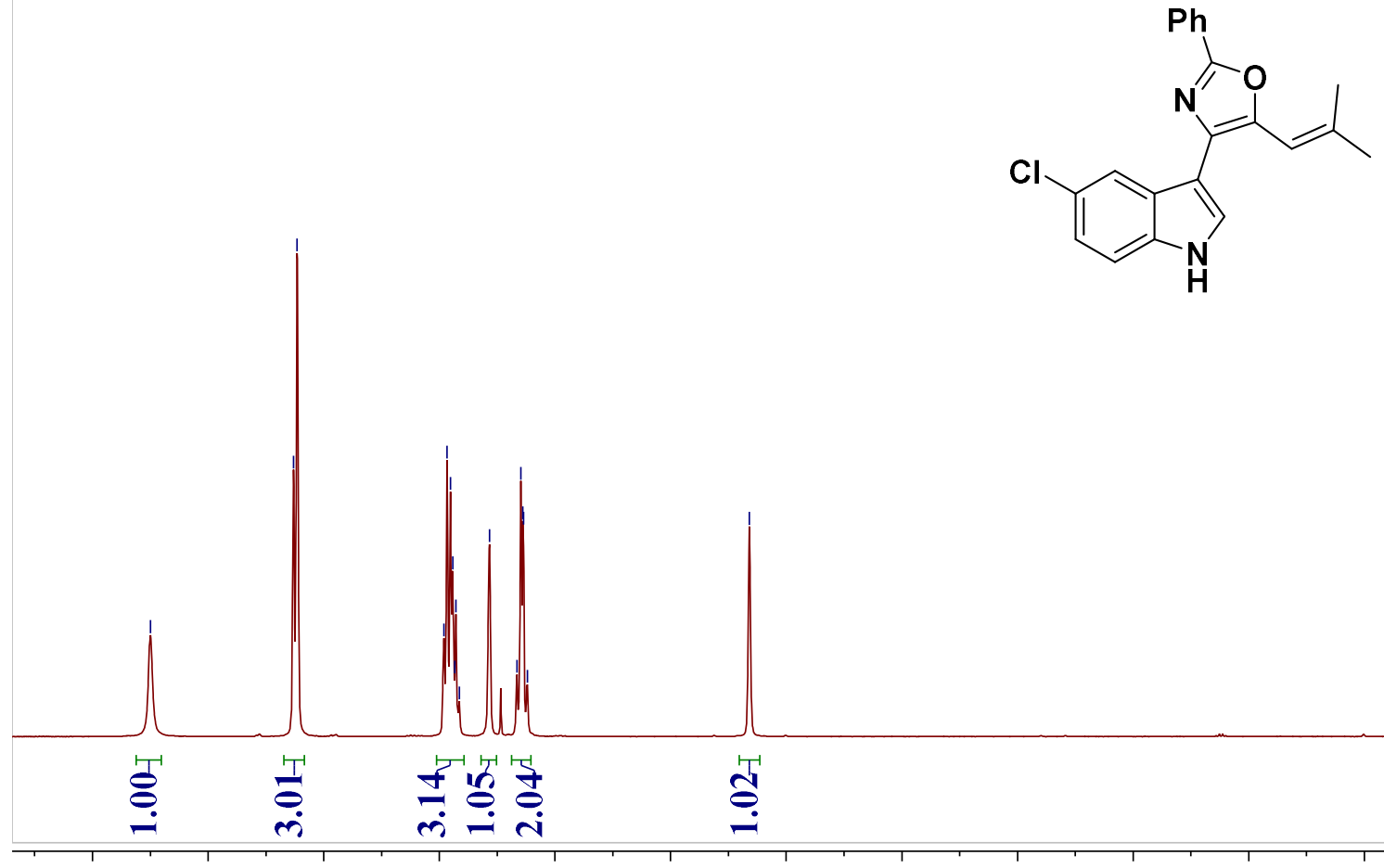

$3 f i$

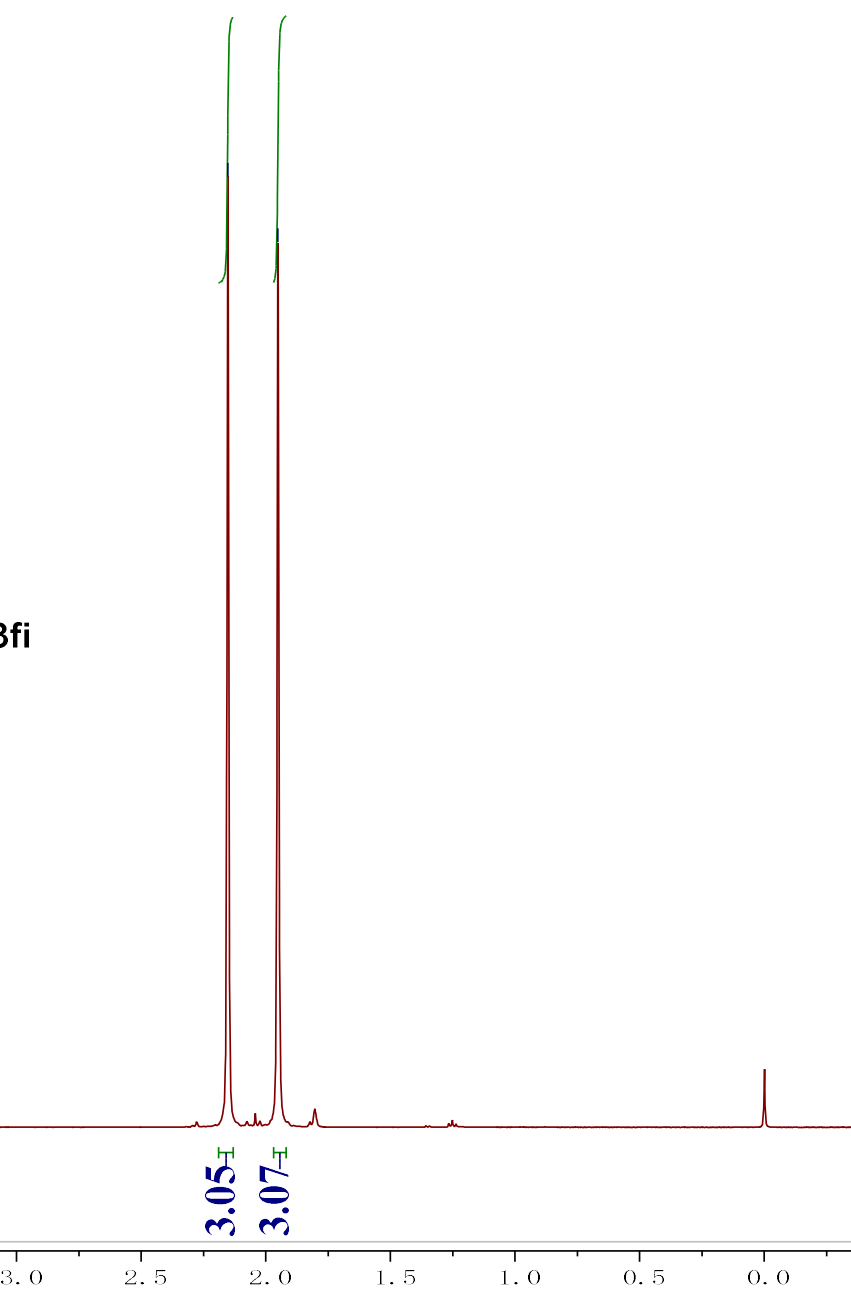

NMR-92 

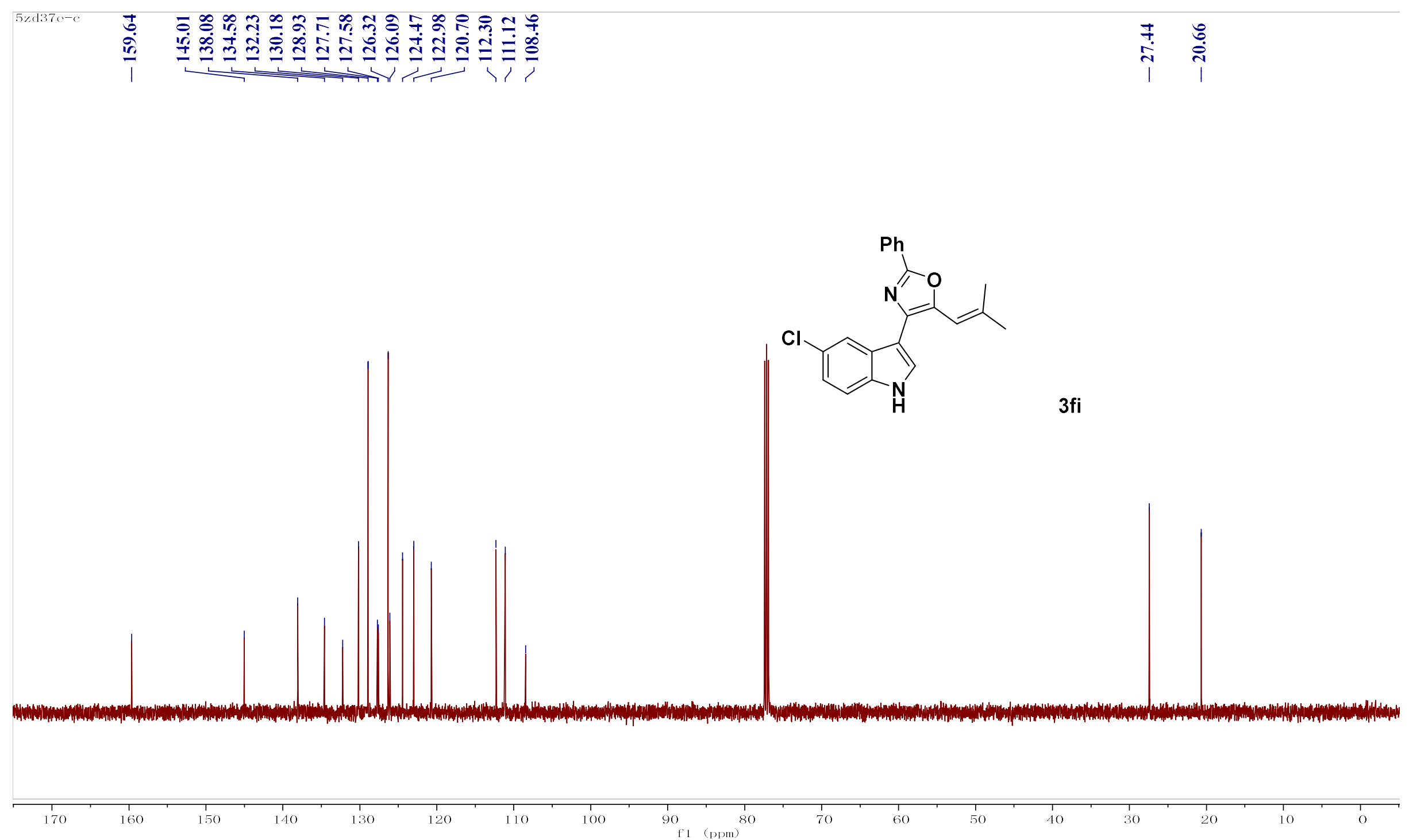


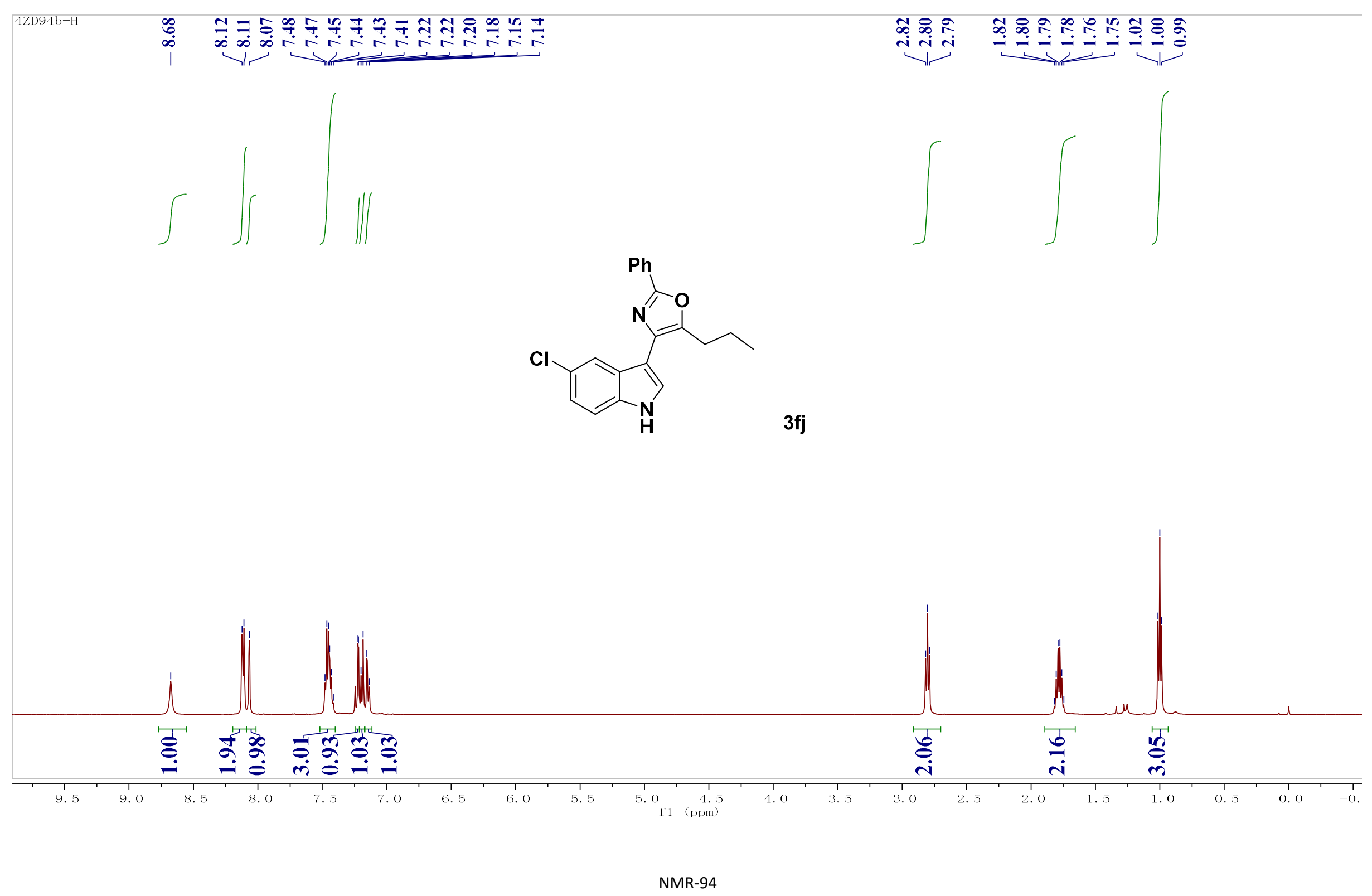




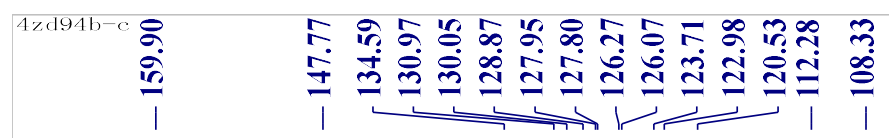

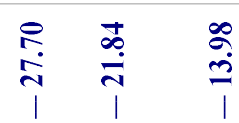

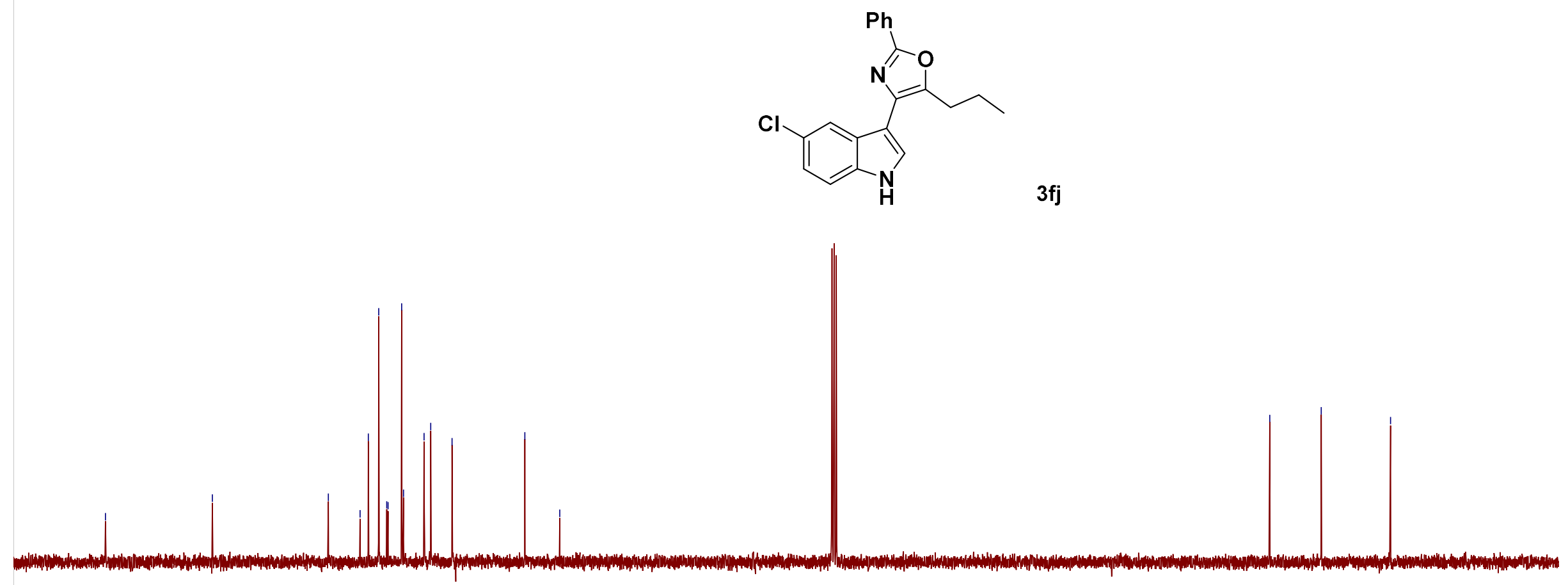

$150 \div \quad 140$ 130 120 110 100 8
$f 1 \quad(p p m)$ 


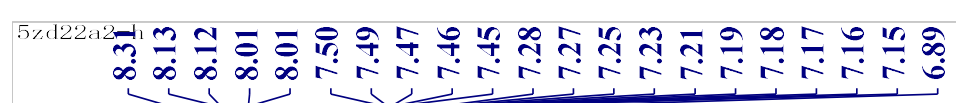
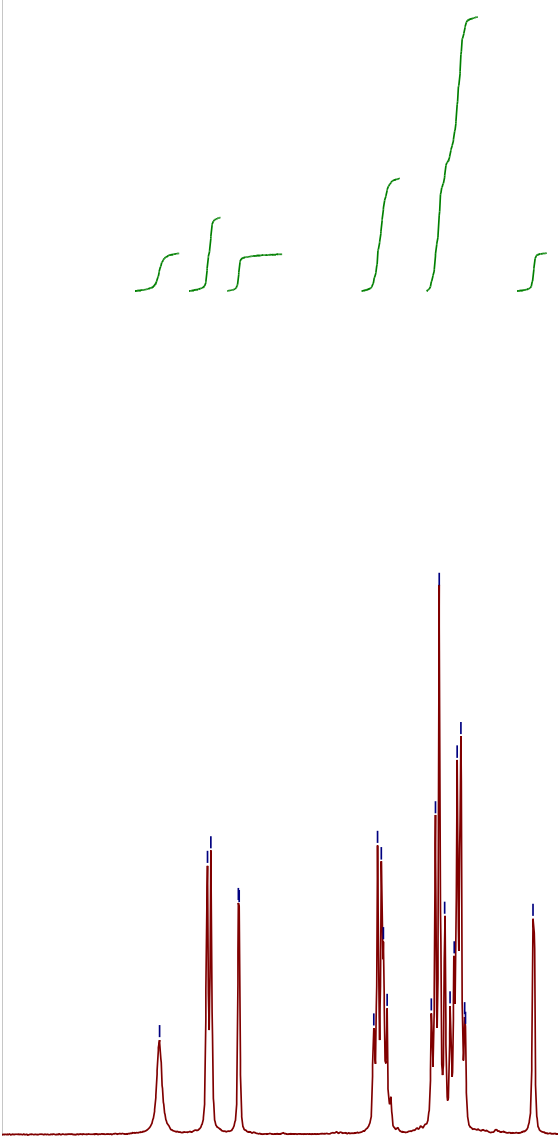

言紫然

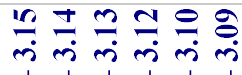
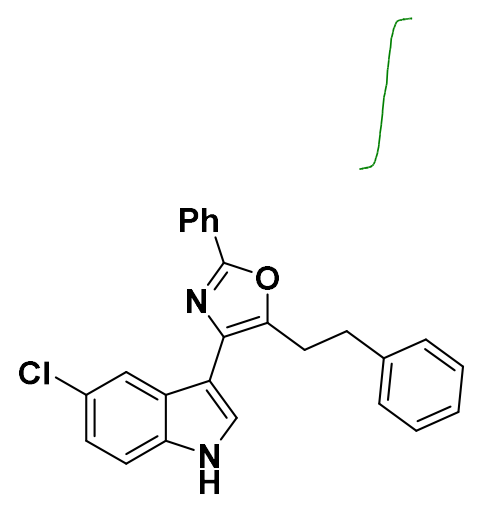

$3 \mathrm{fk}$

NMR-96 


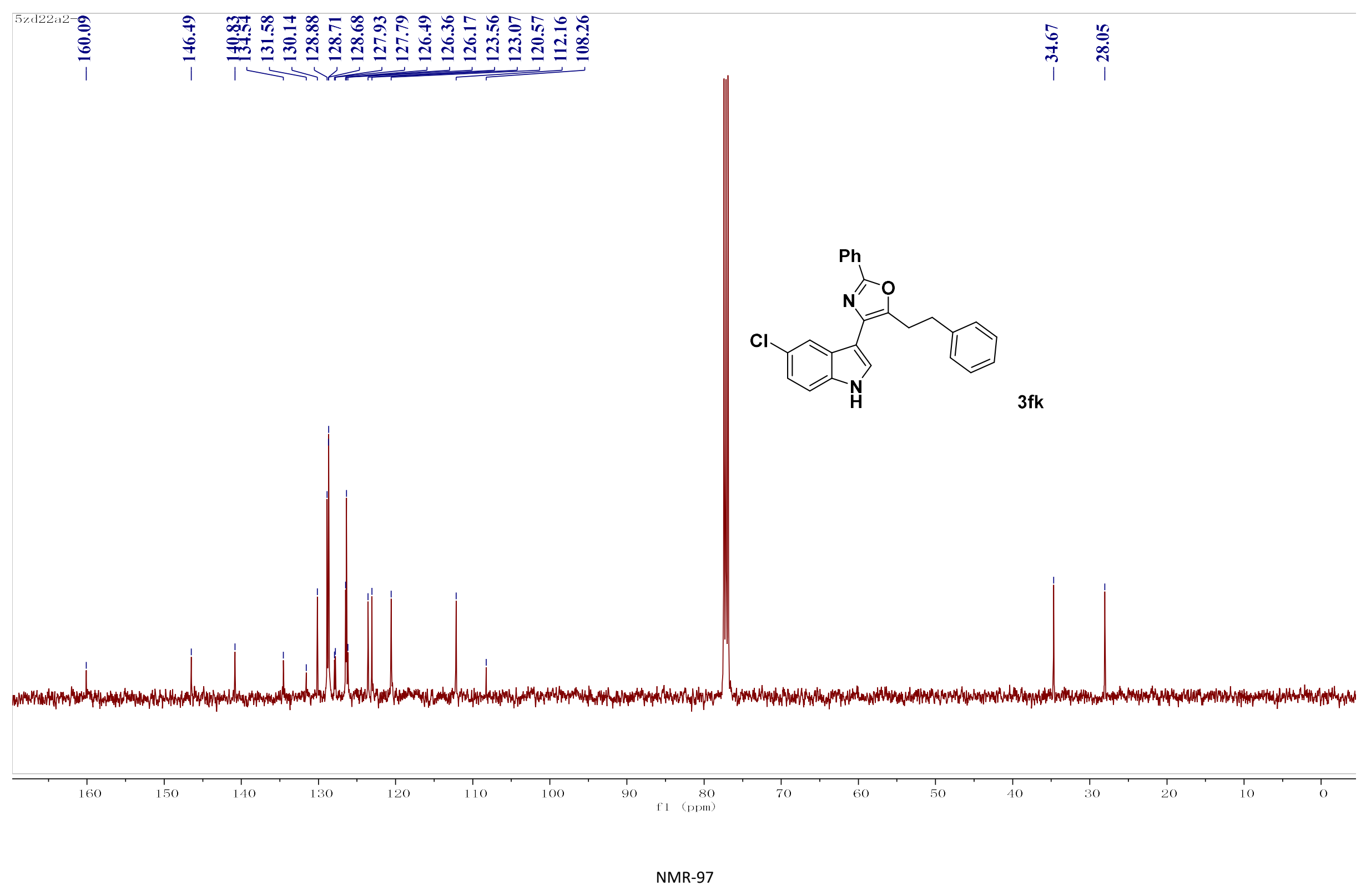




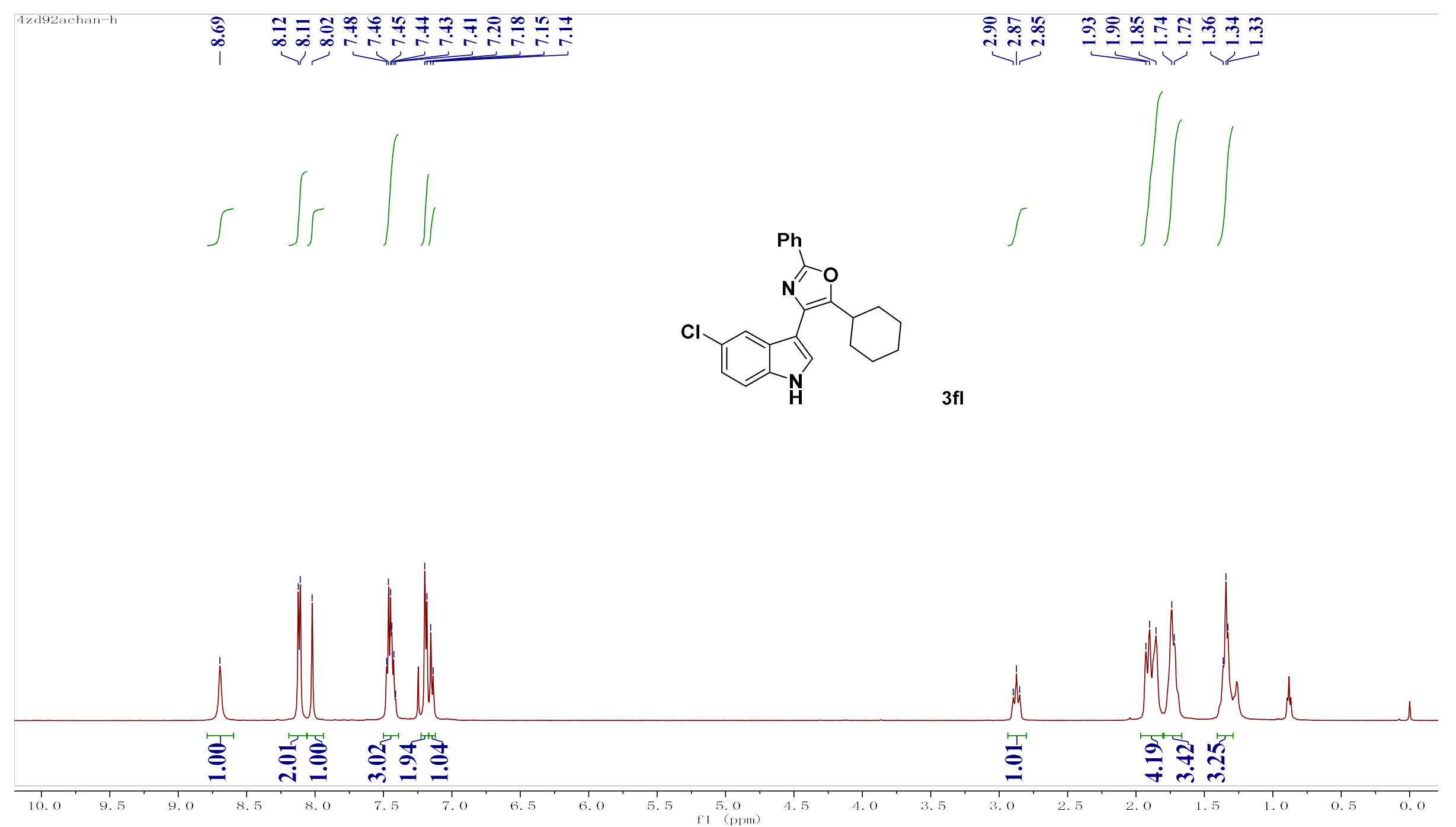

NMR-98 

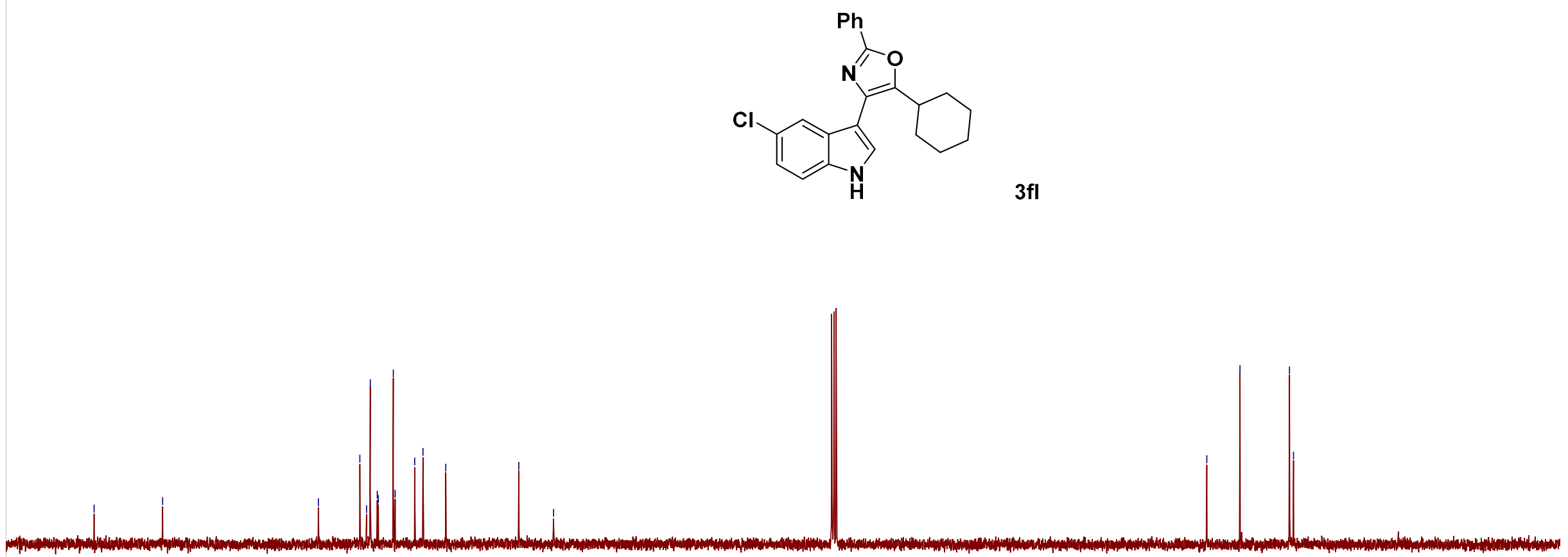


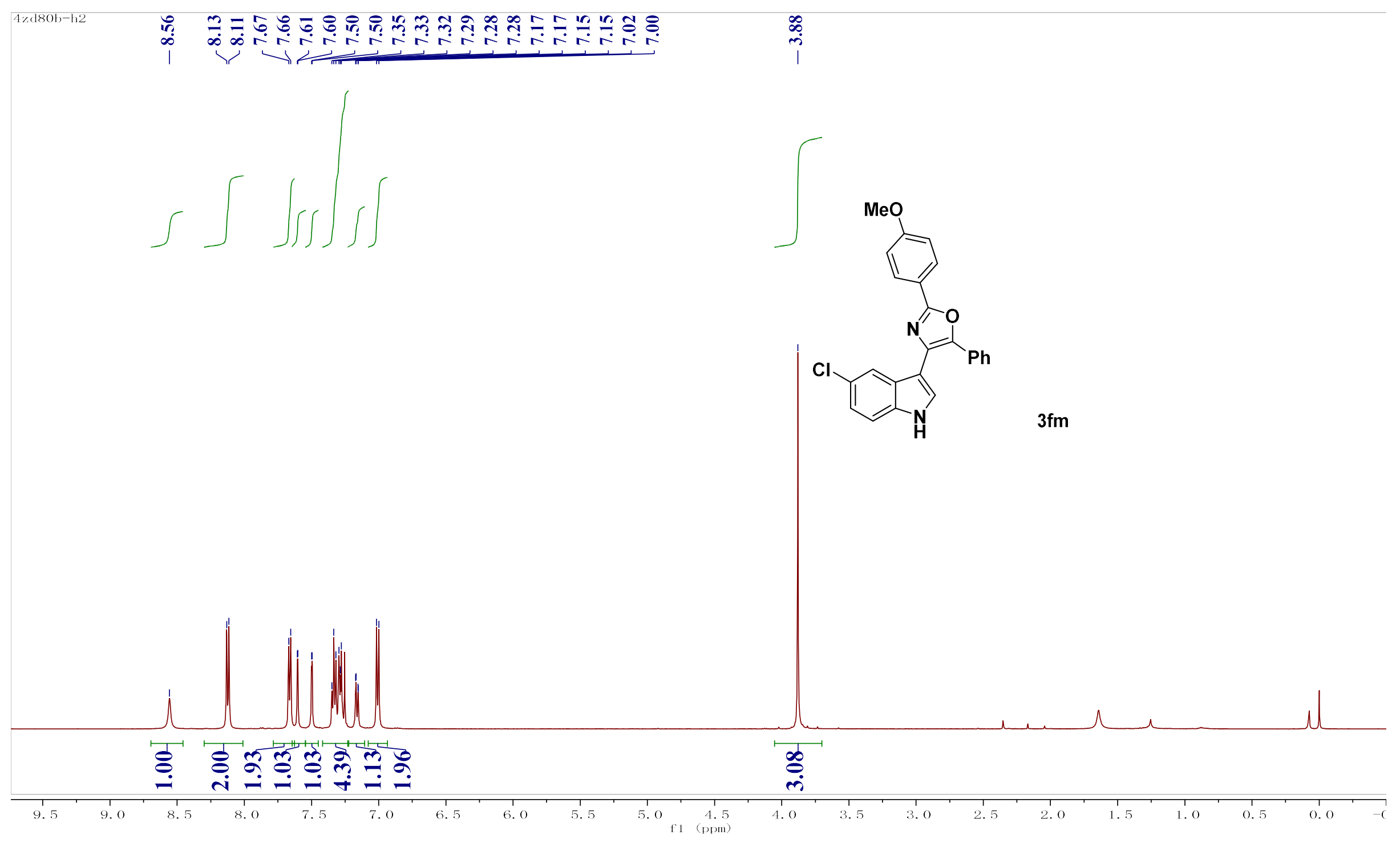

NMR-100 


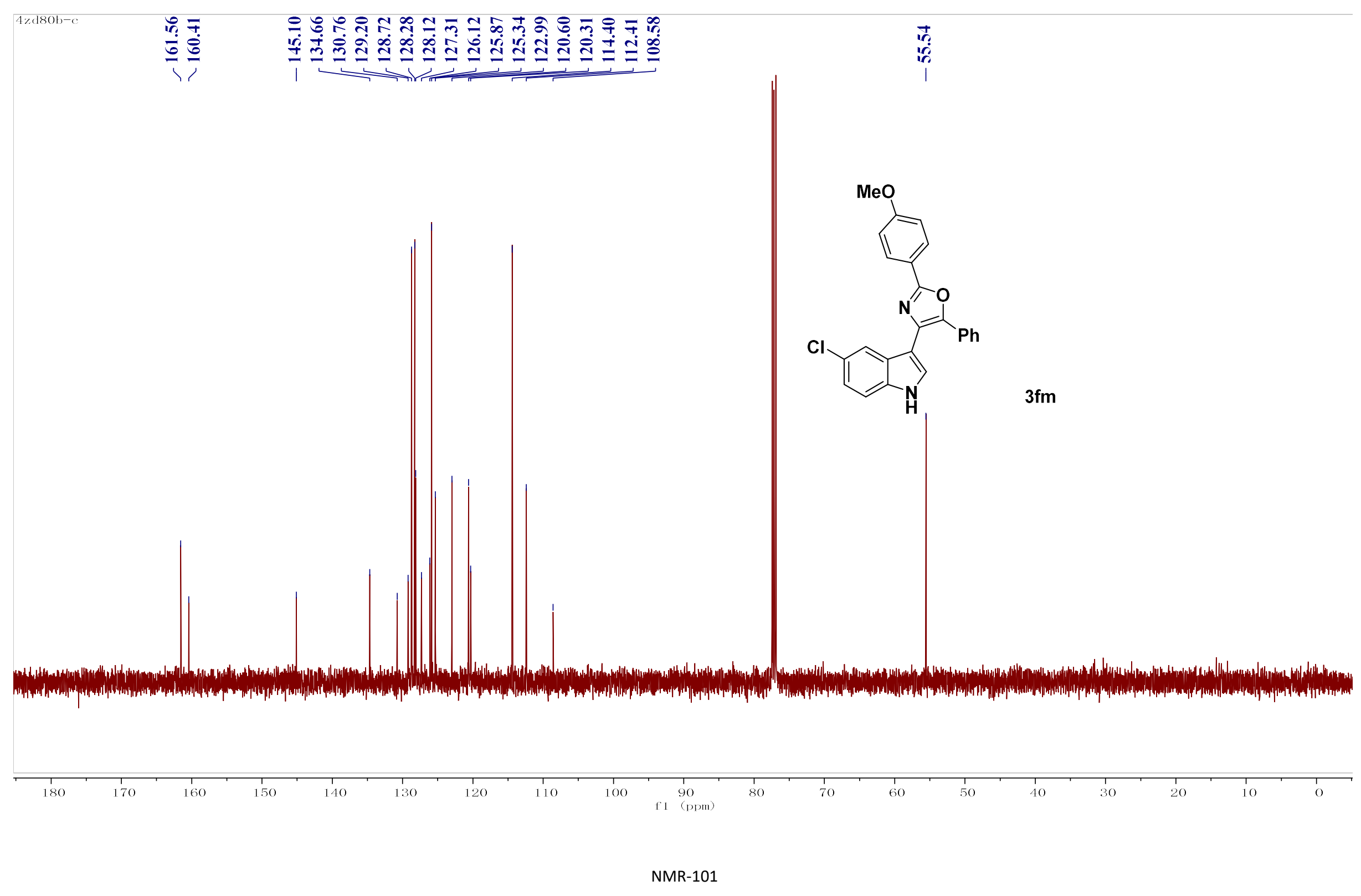




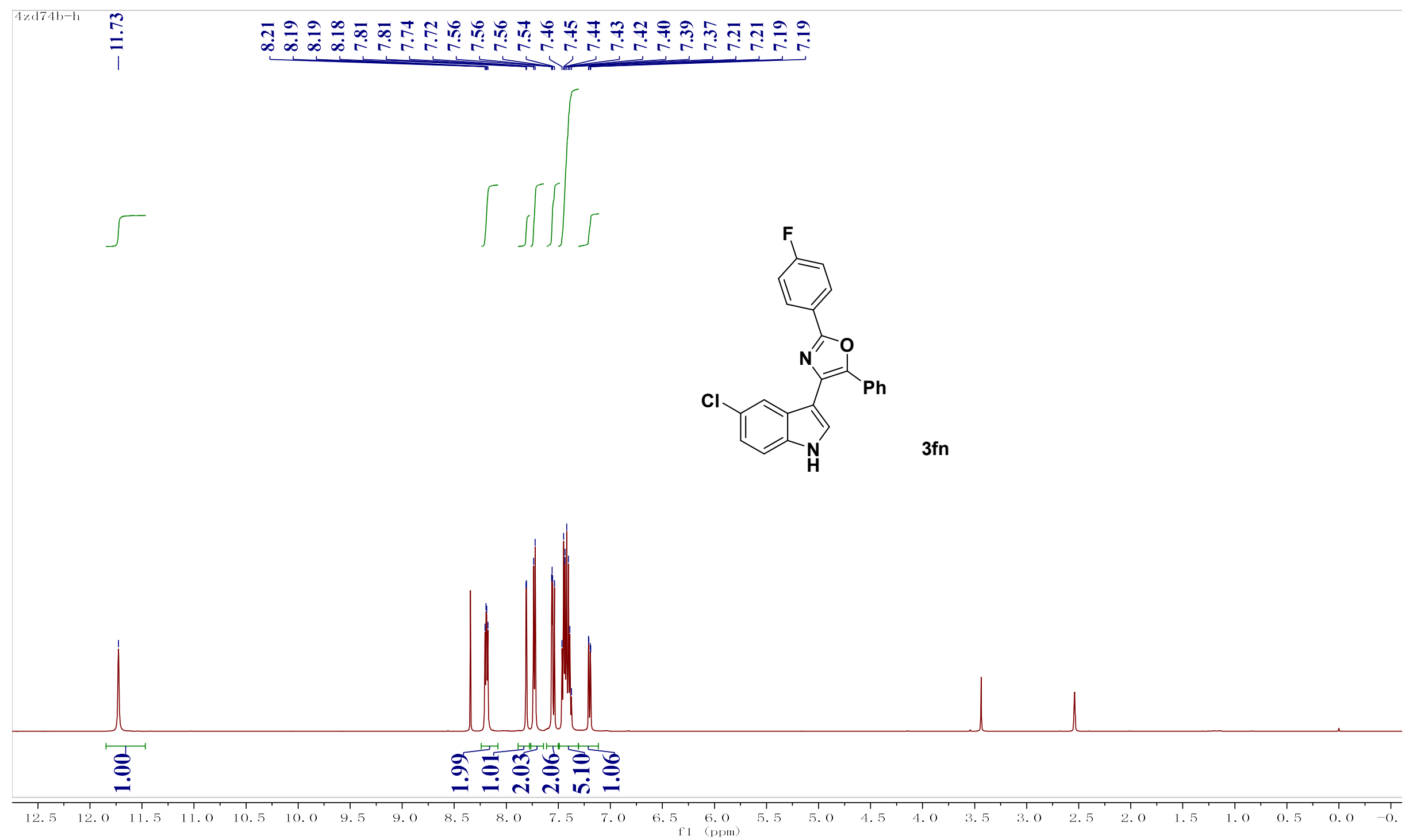

NMR-102 


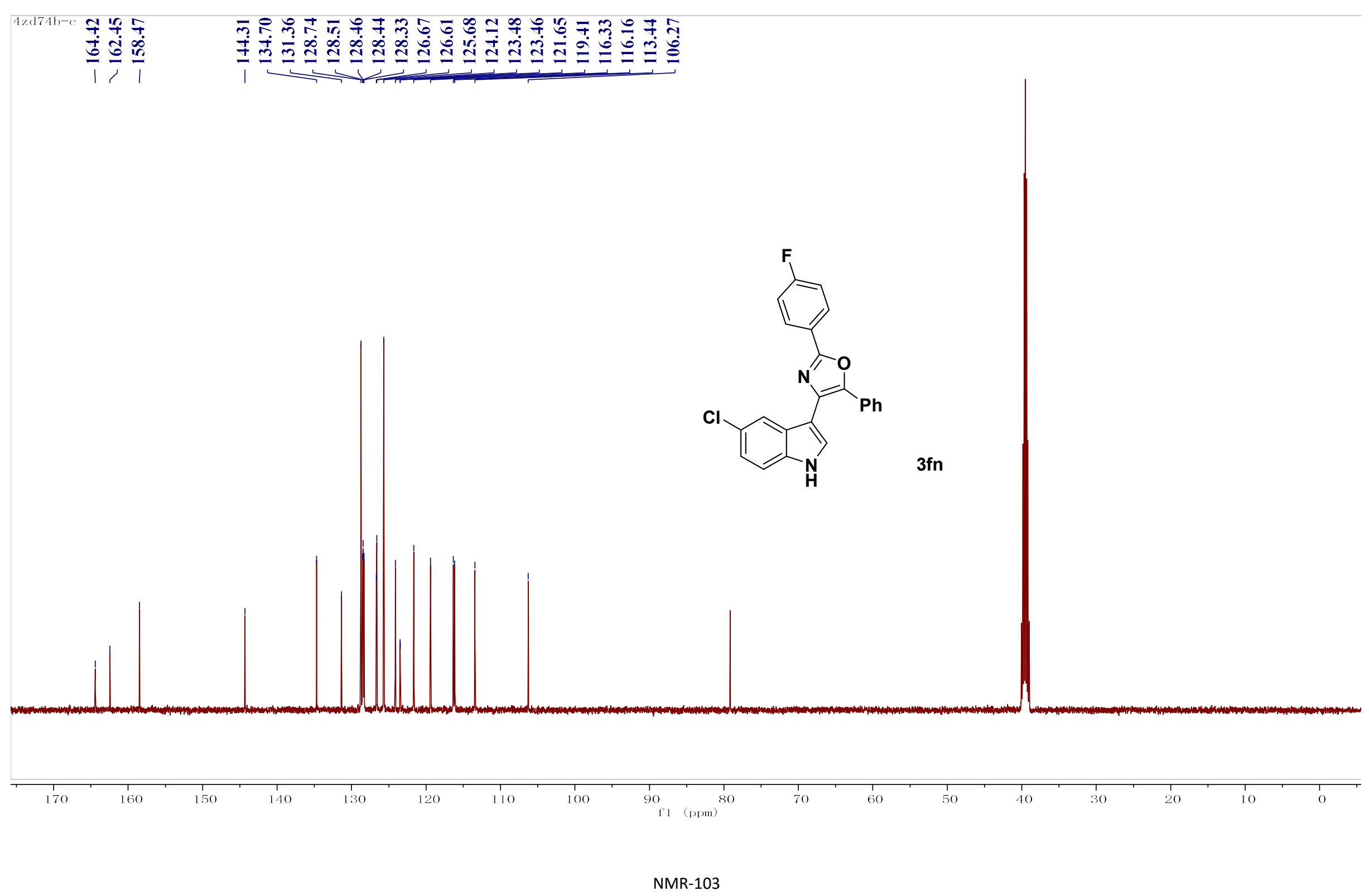




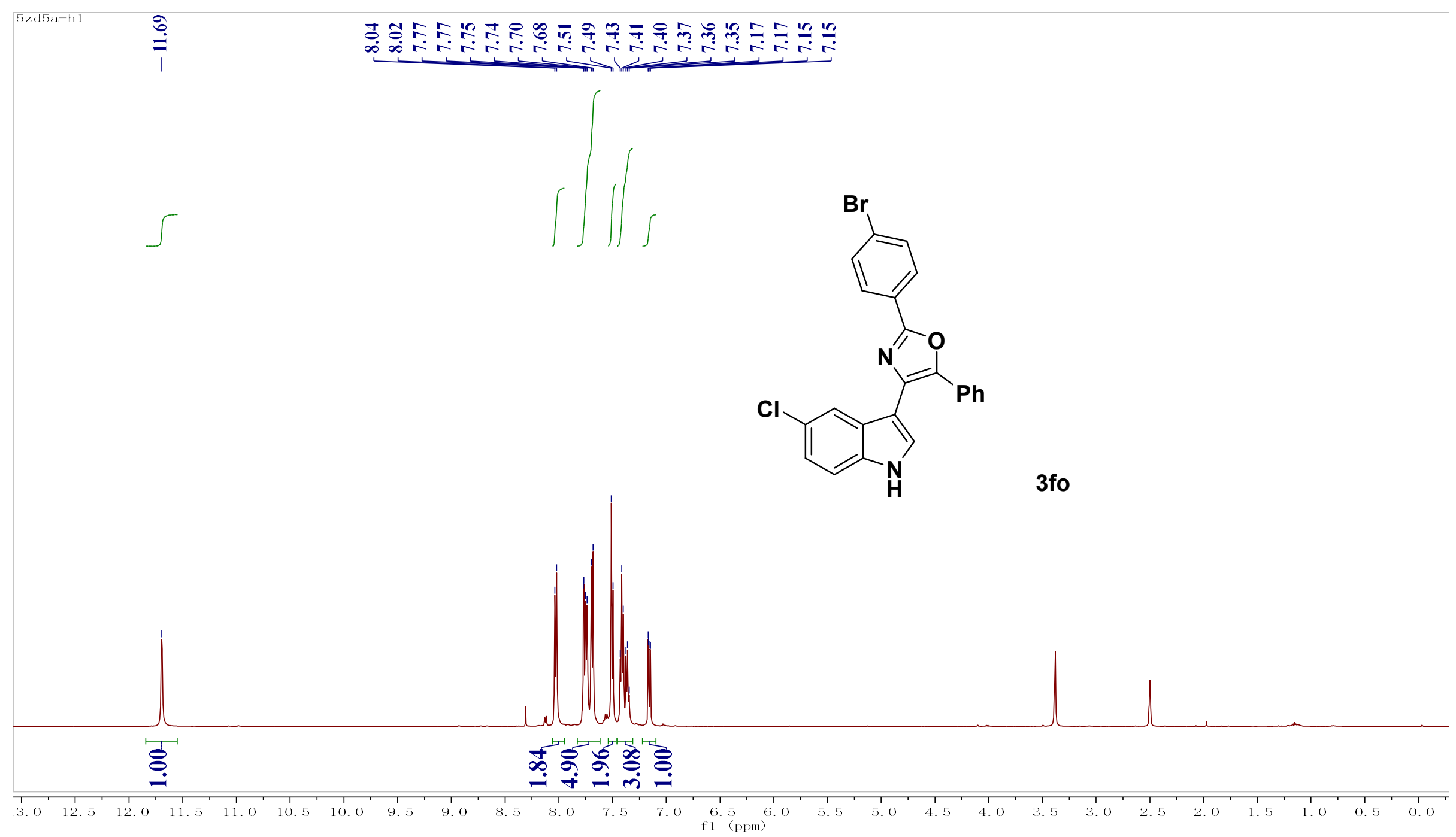

NMR-104 


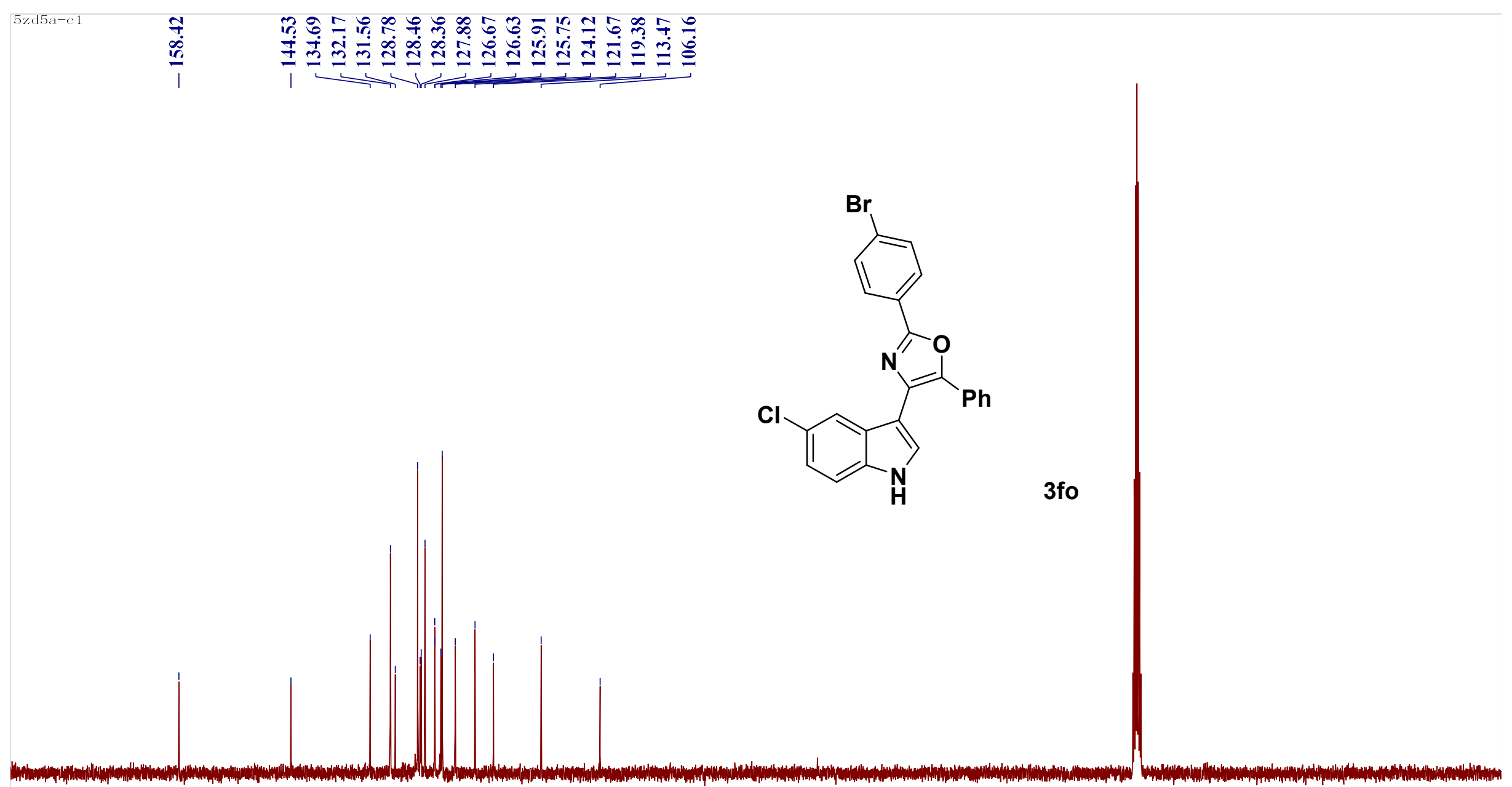




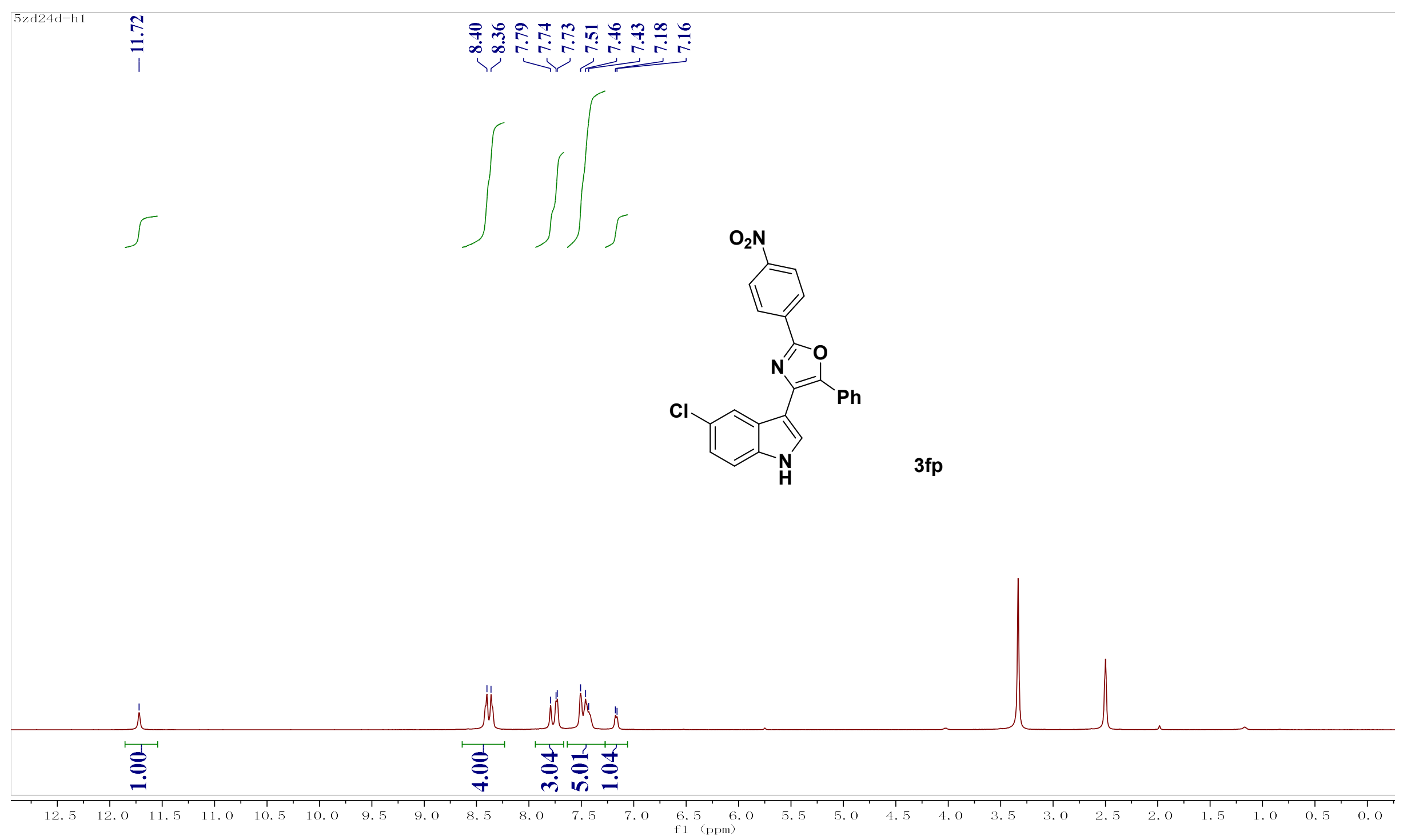

NMR-106 

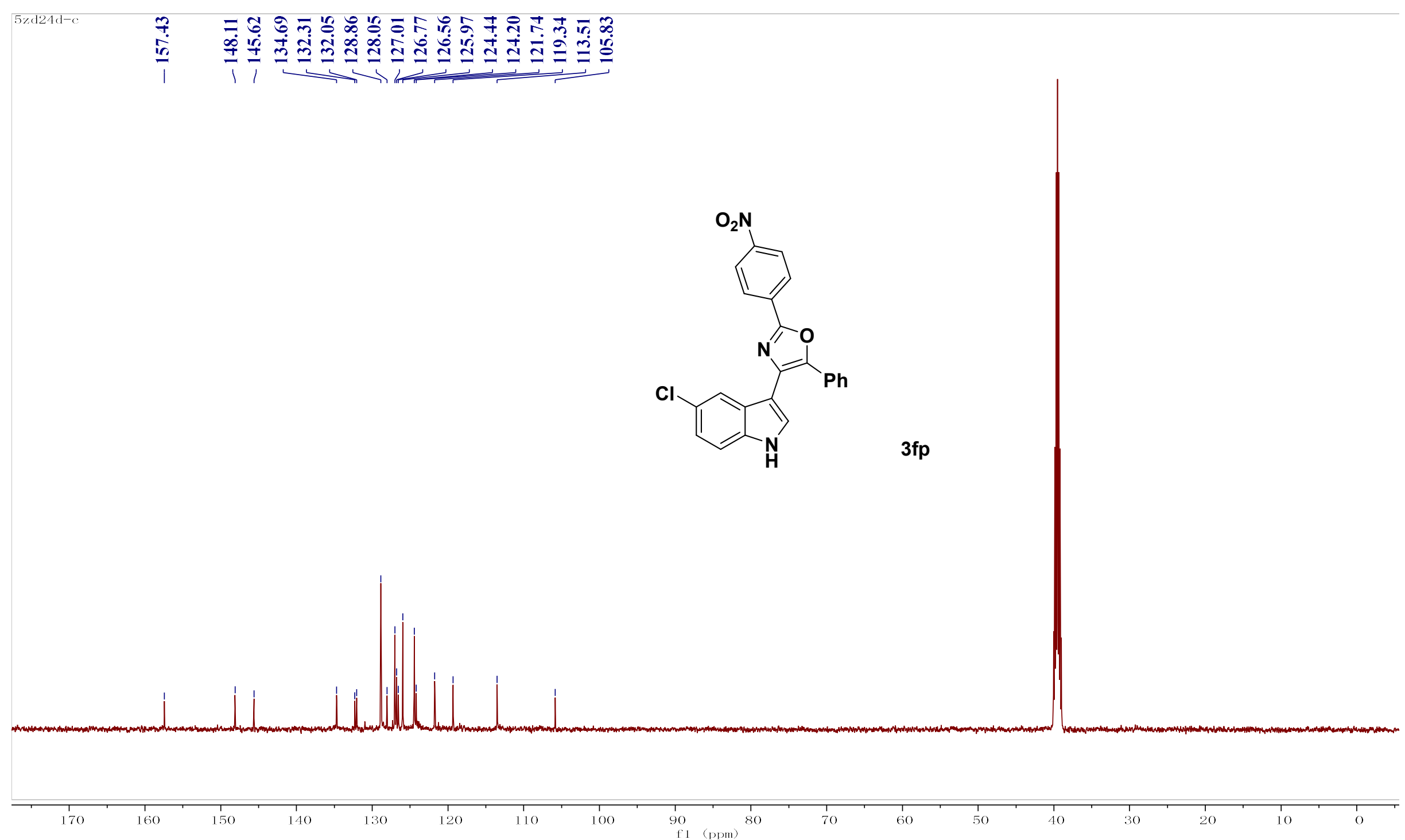

NMR-107 


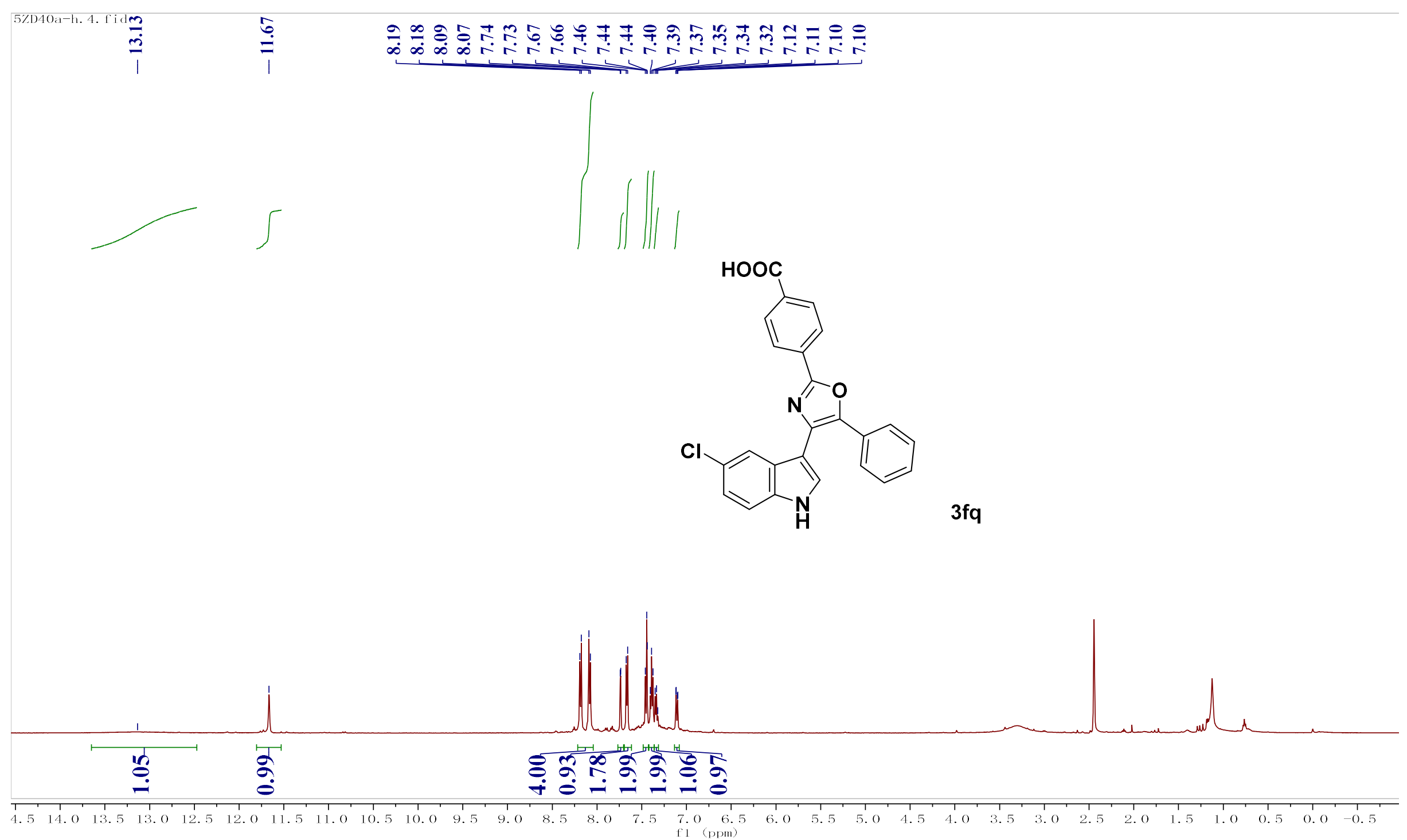

NMR-108 


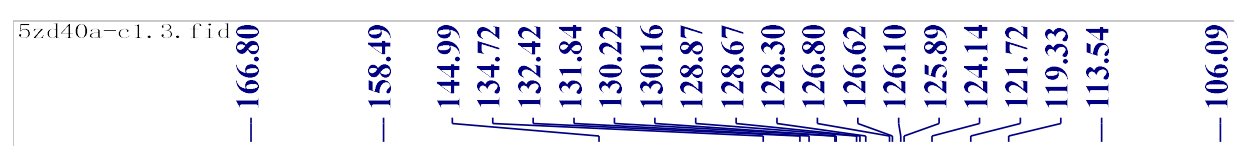
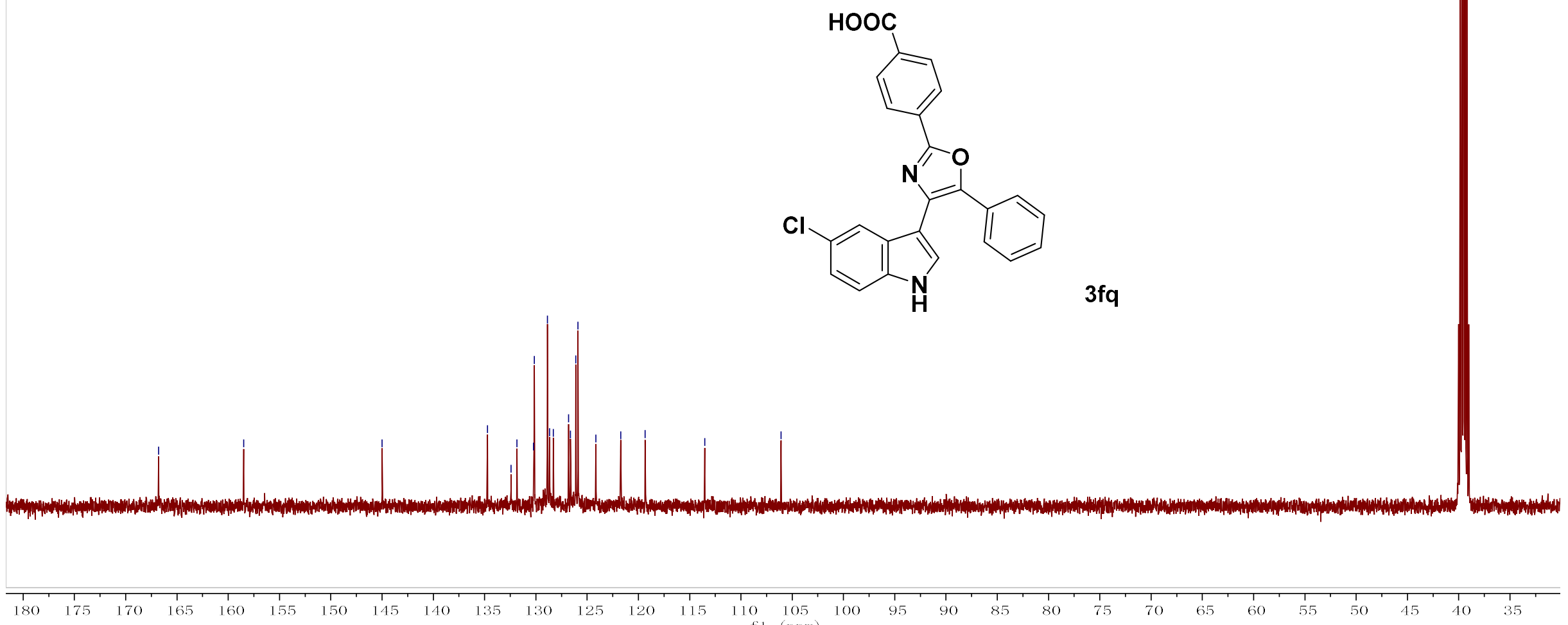


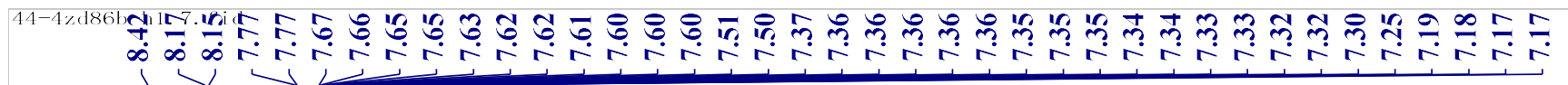
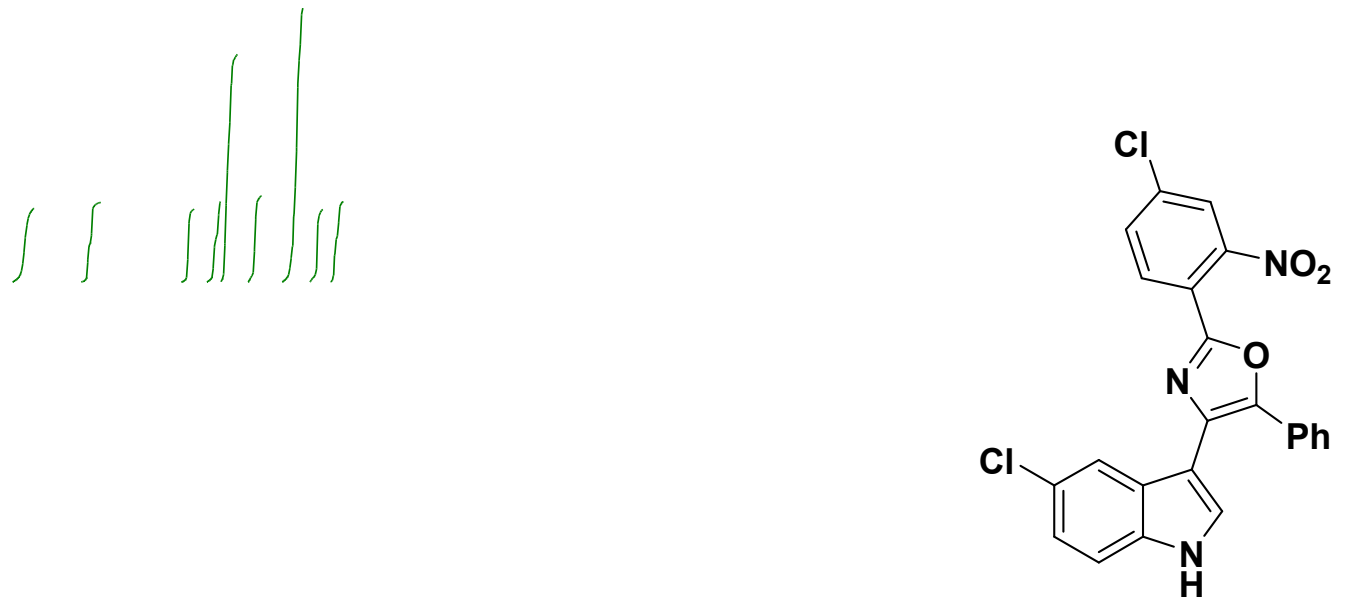

$3 f r$

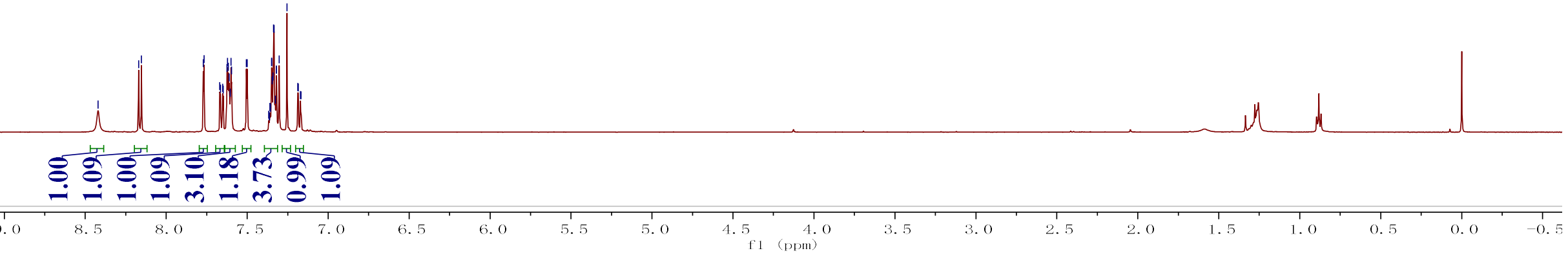

NMR-110 


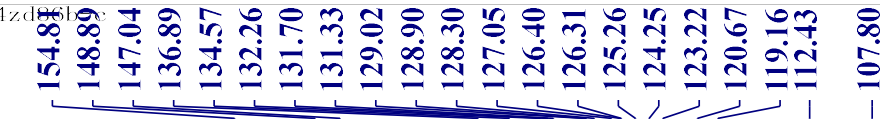

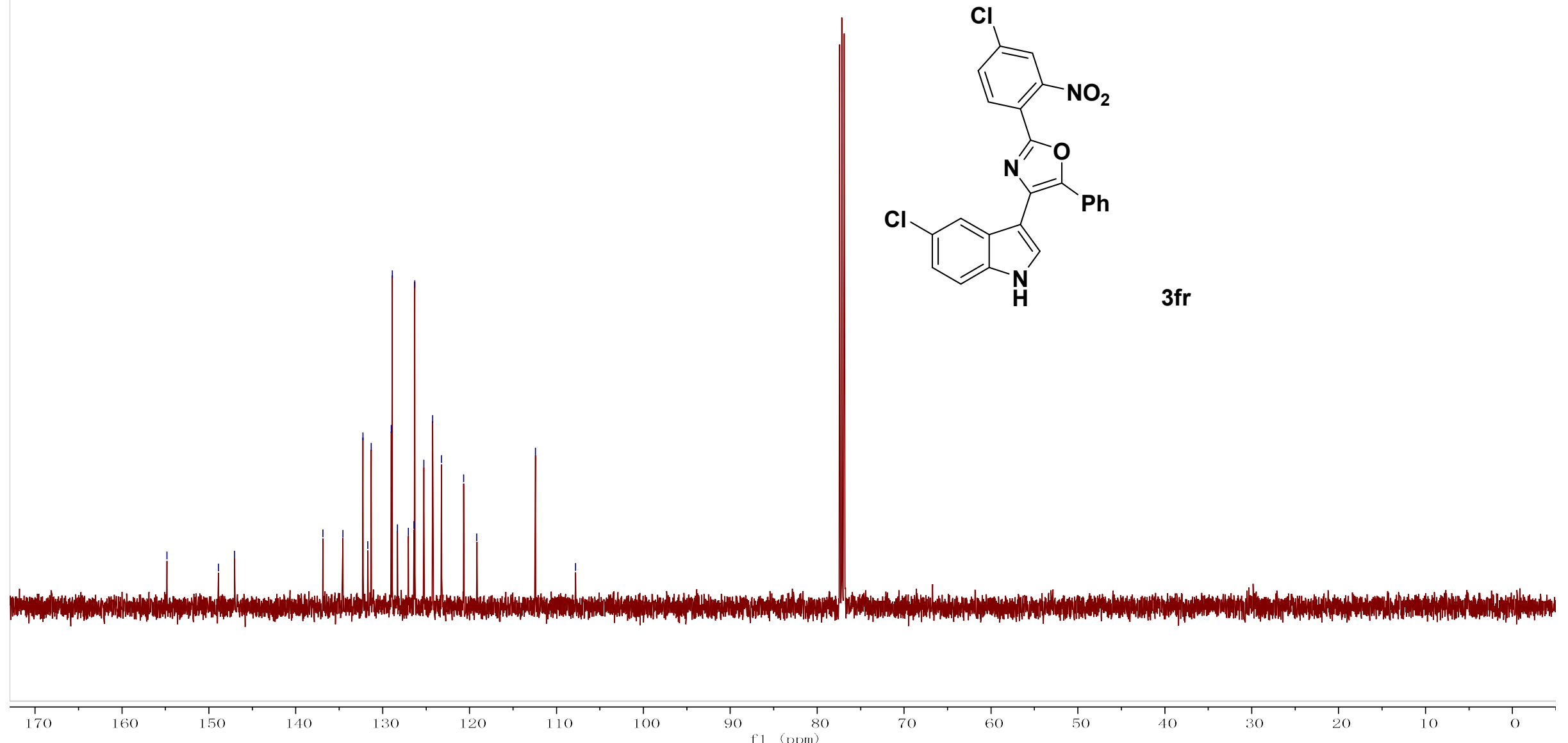

NMR-111 


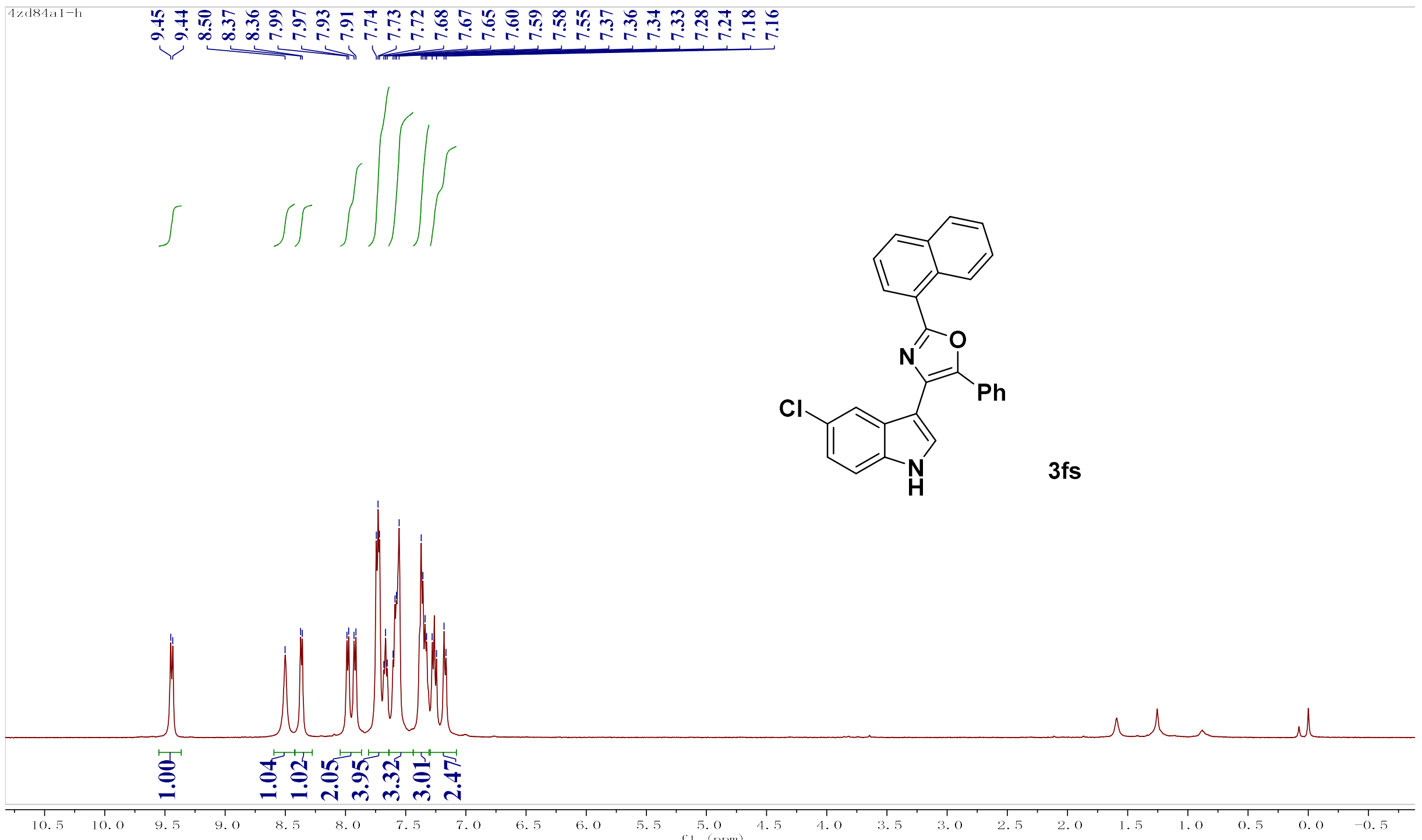



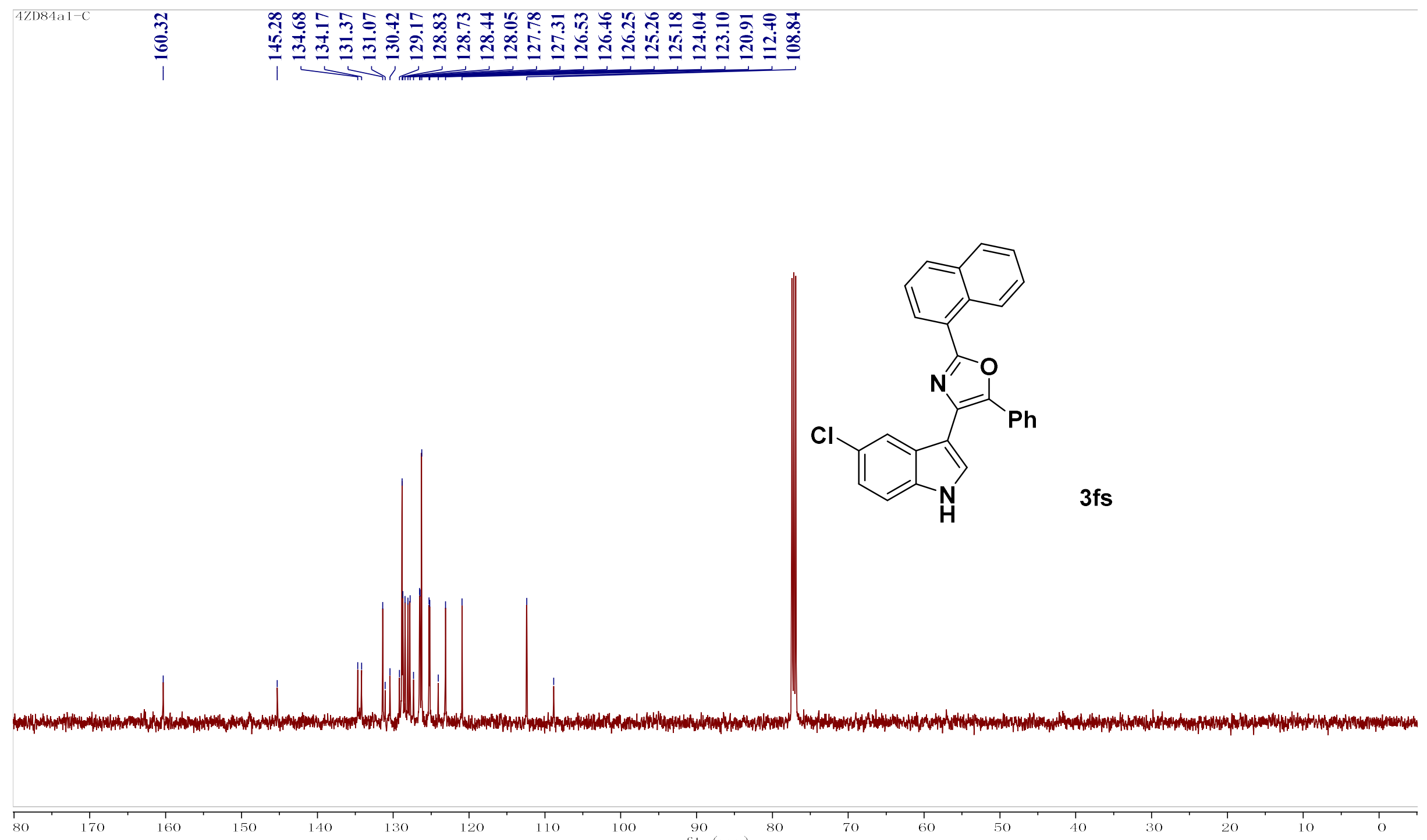


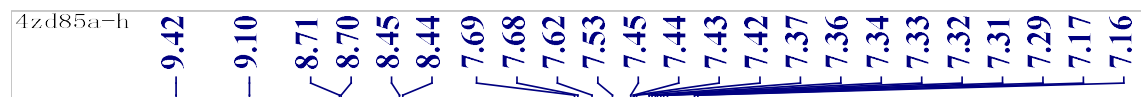
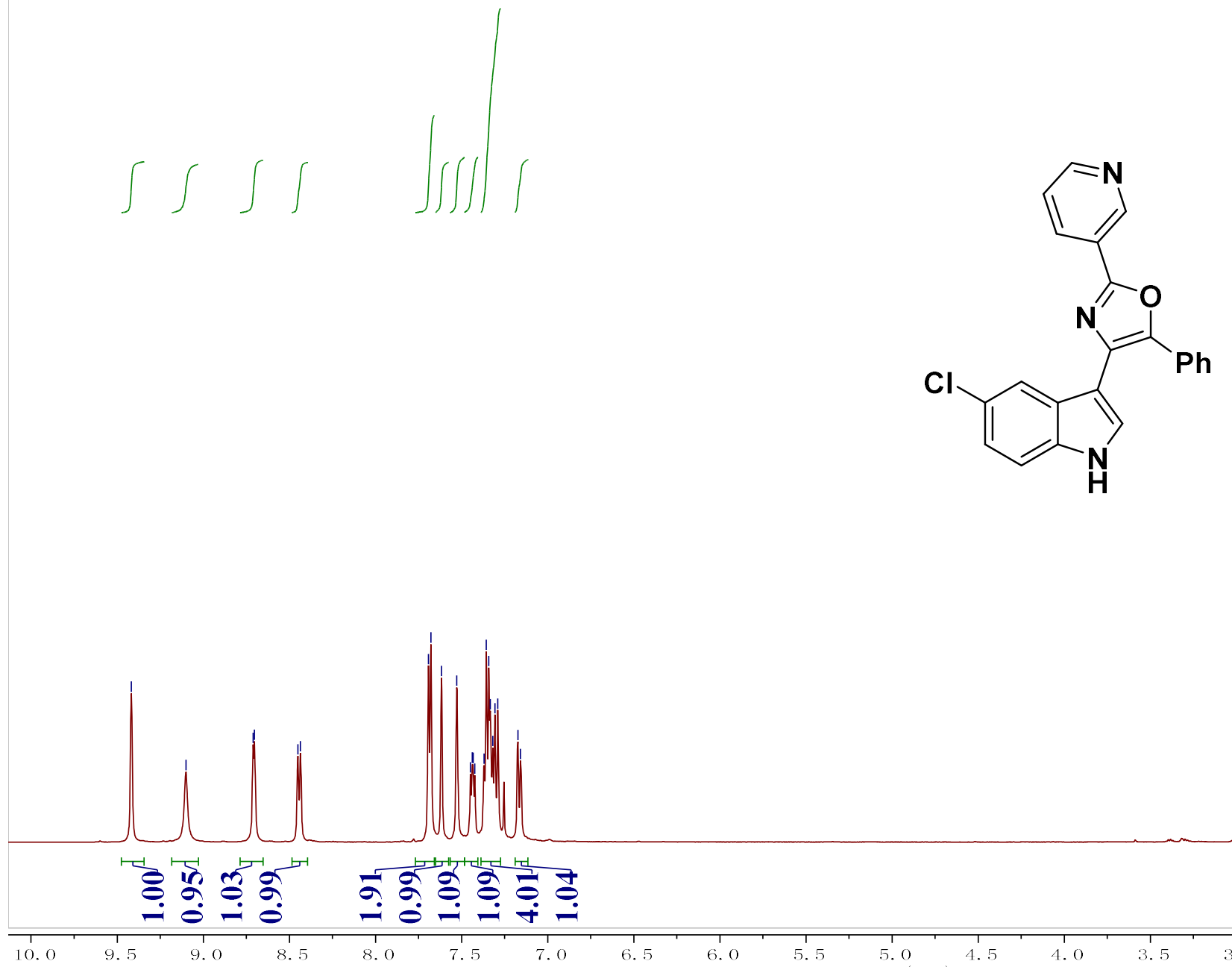

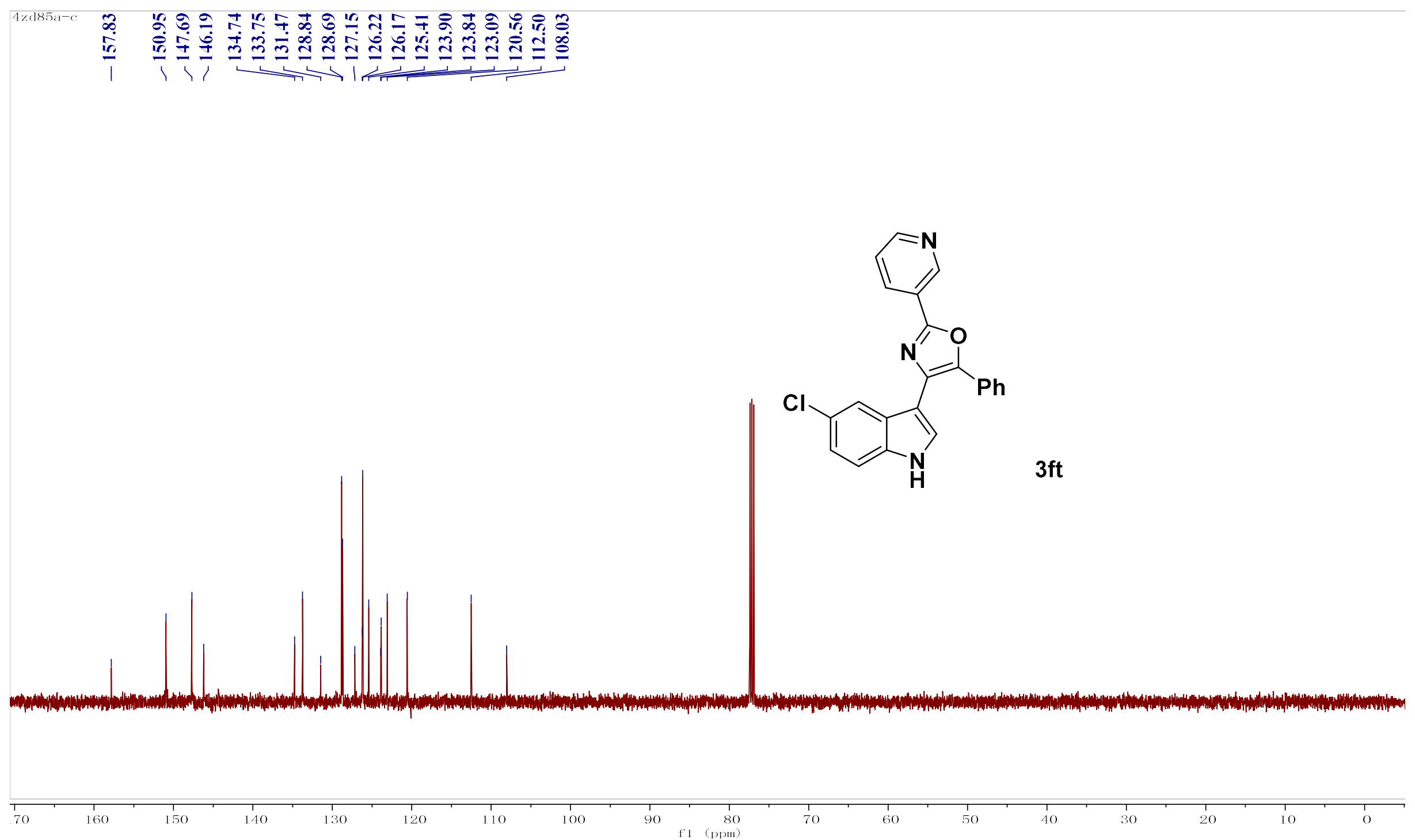


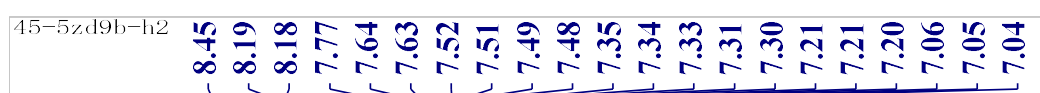
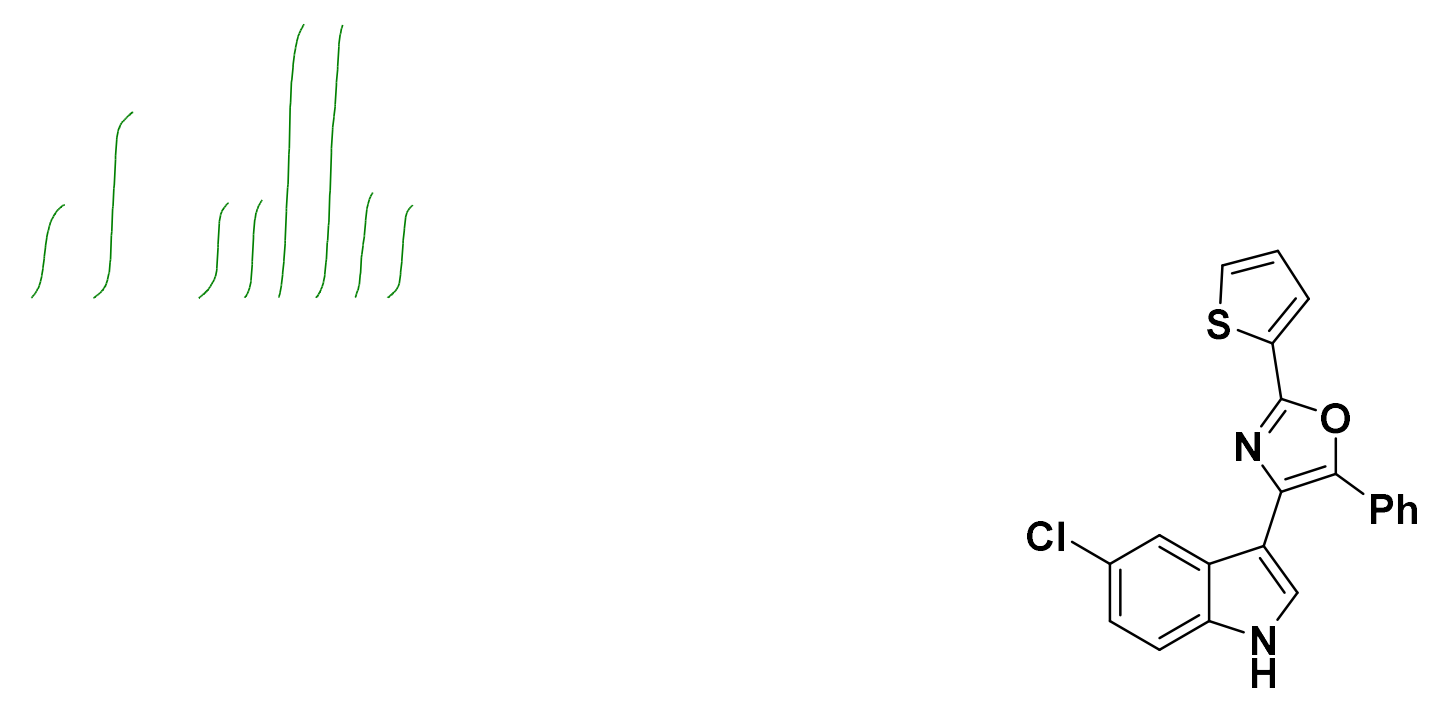

$3 f u$

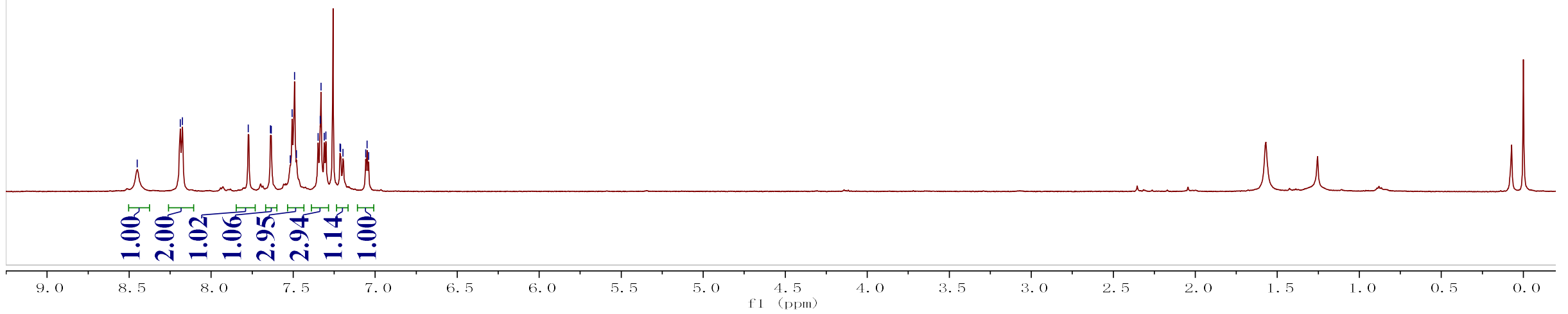

NMR-116 

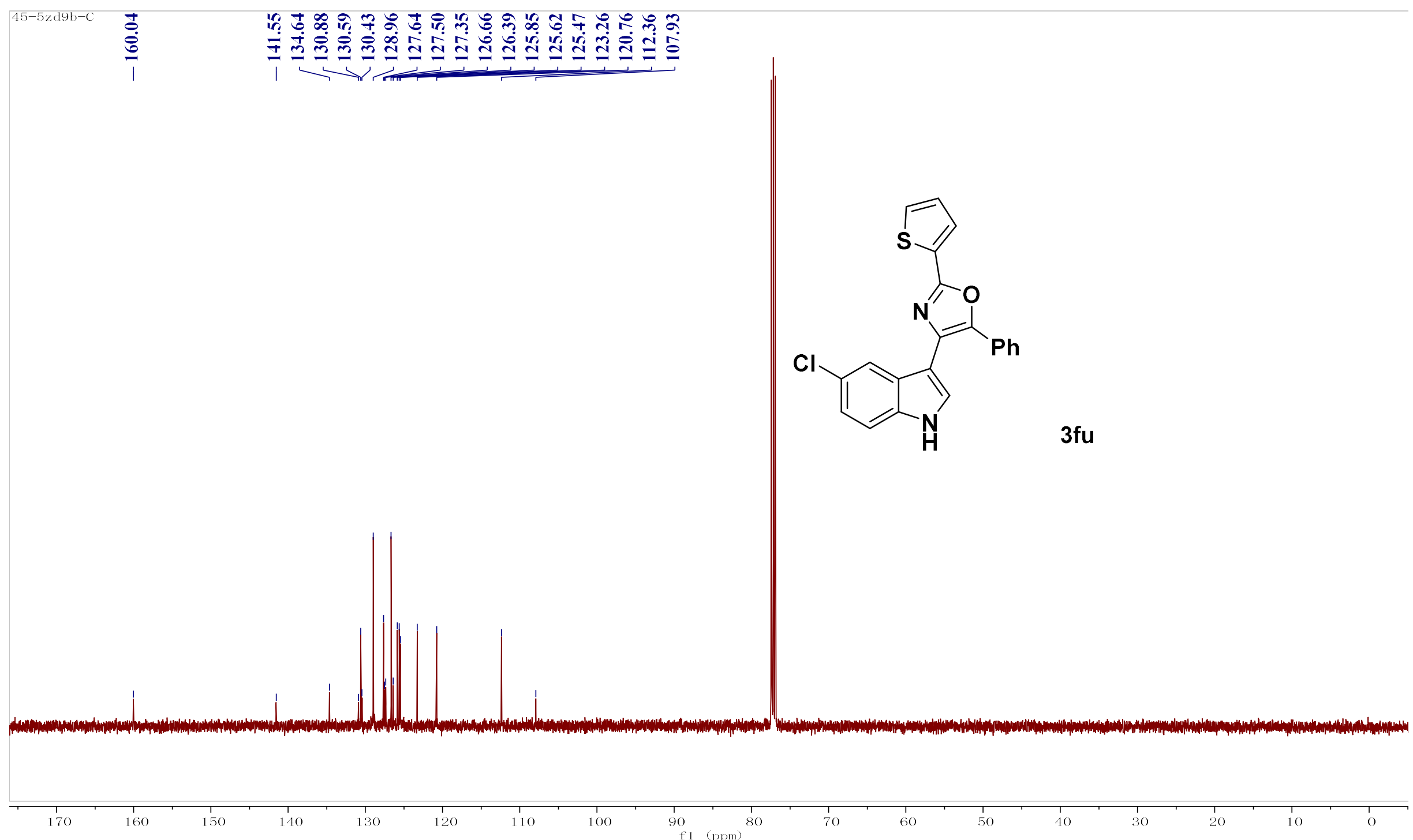

NMR-117 


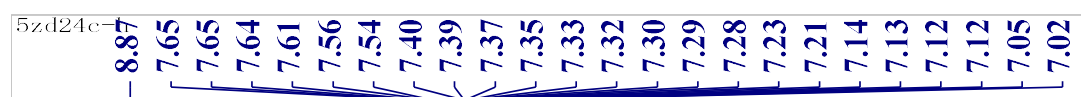

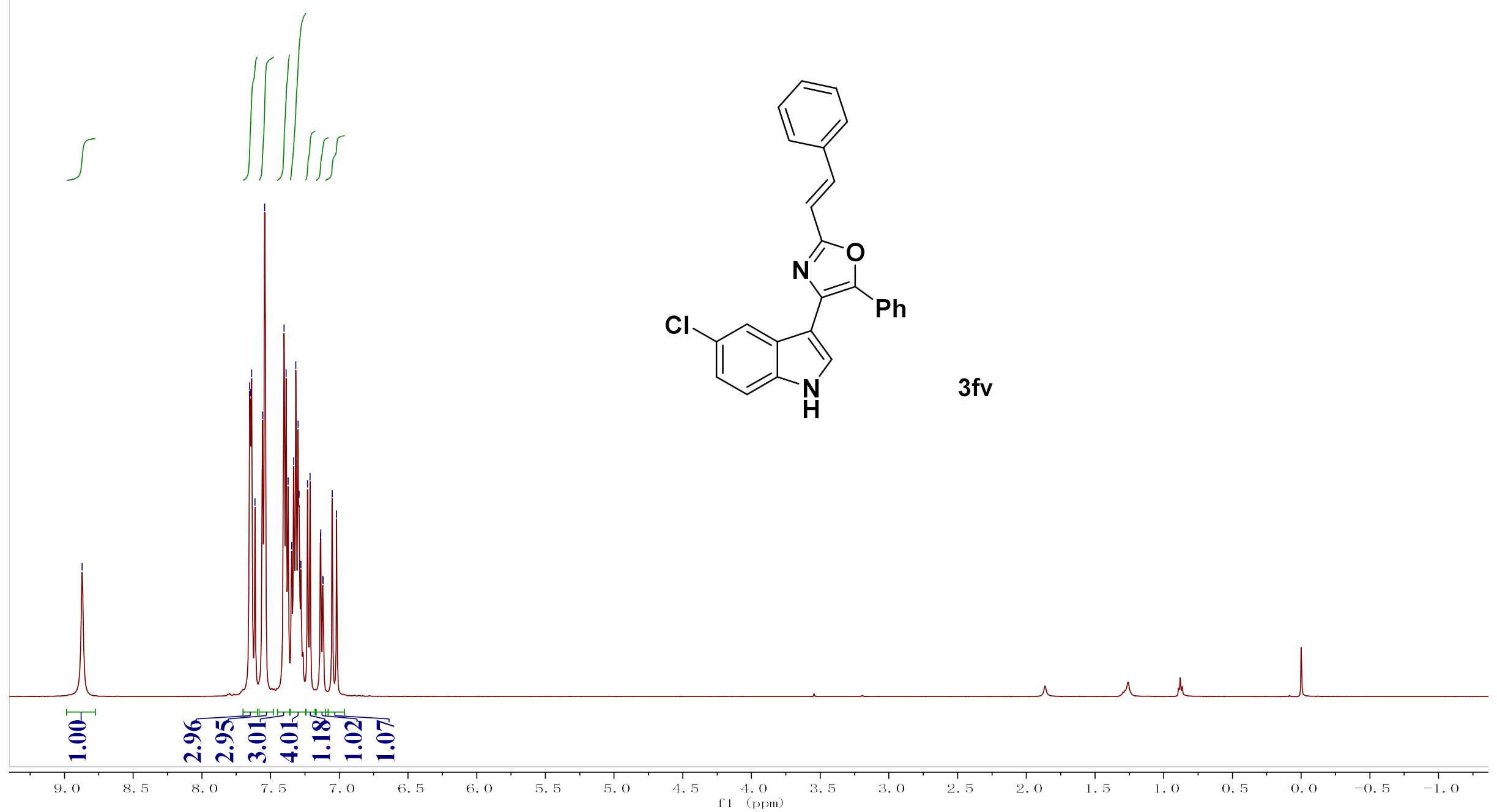

NMR-118 

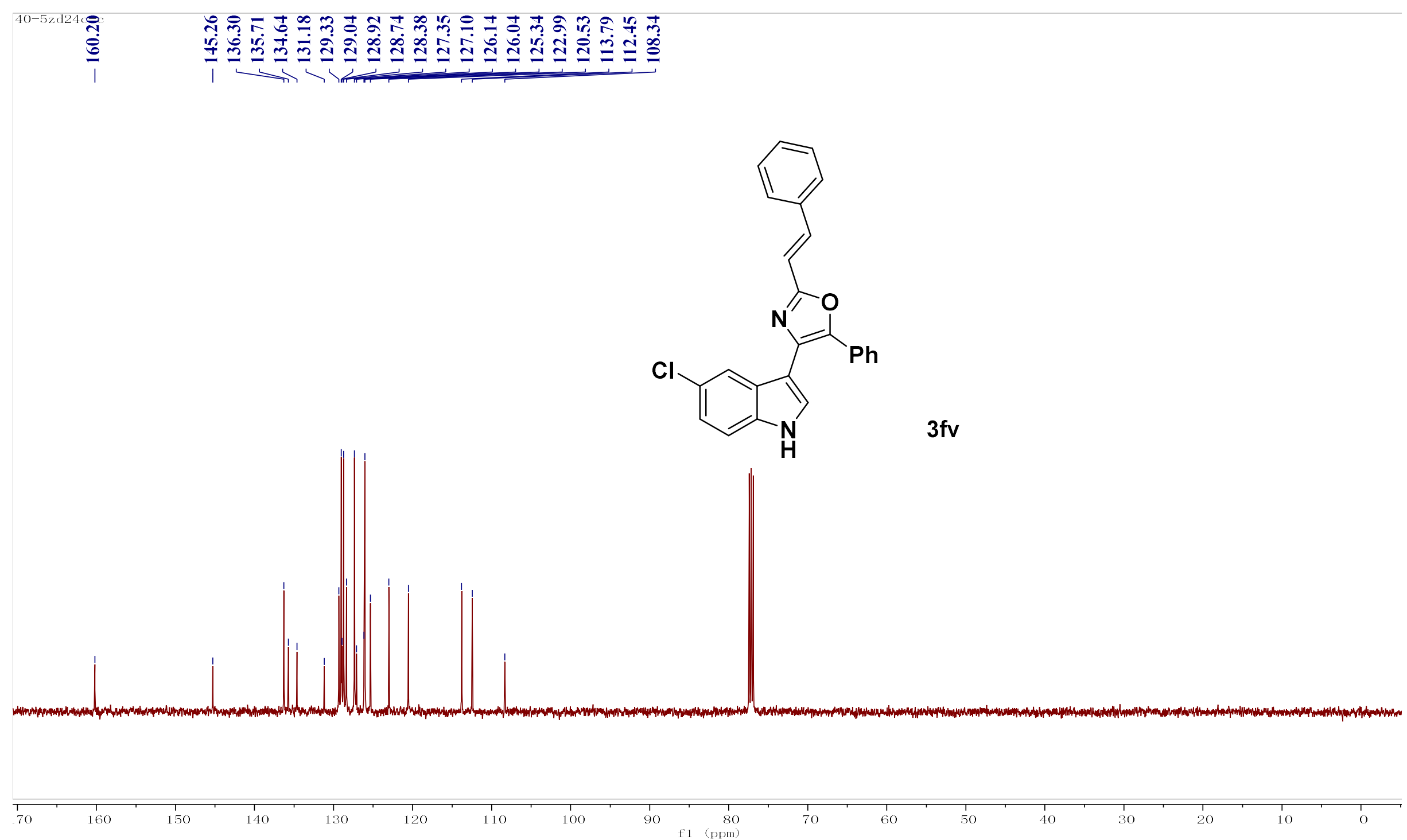

NMR-119 


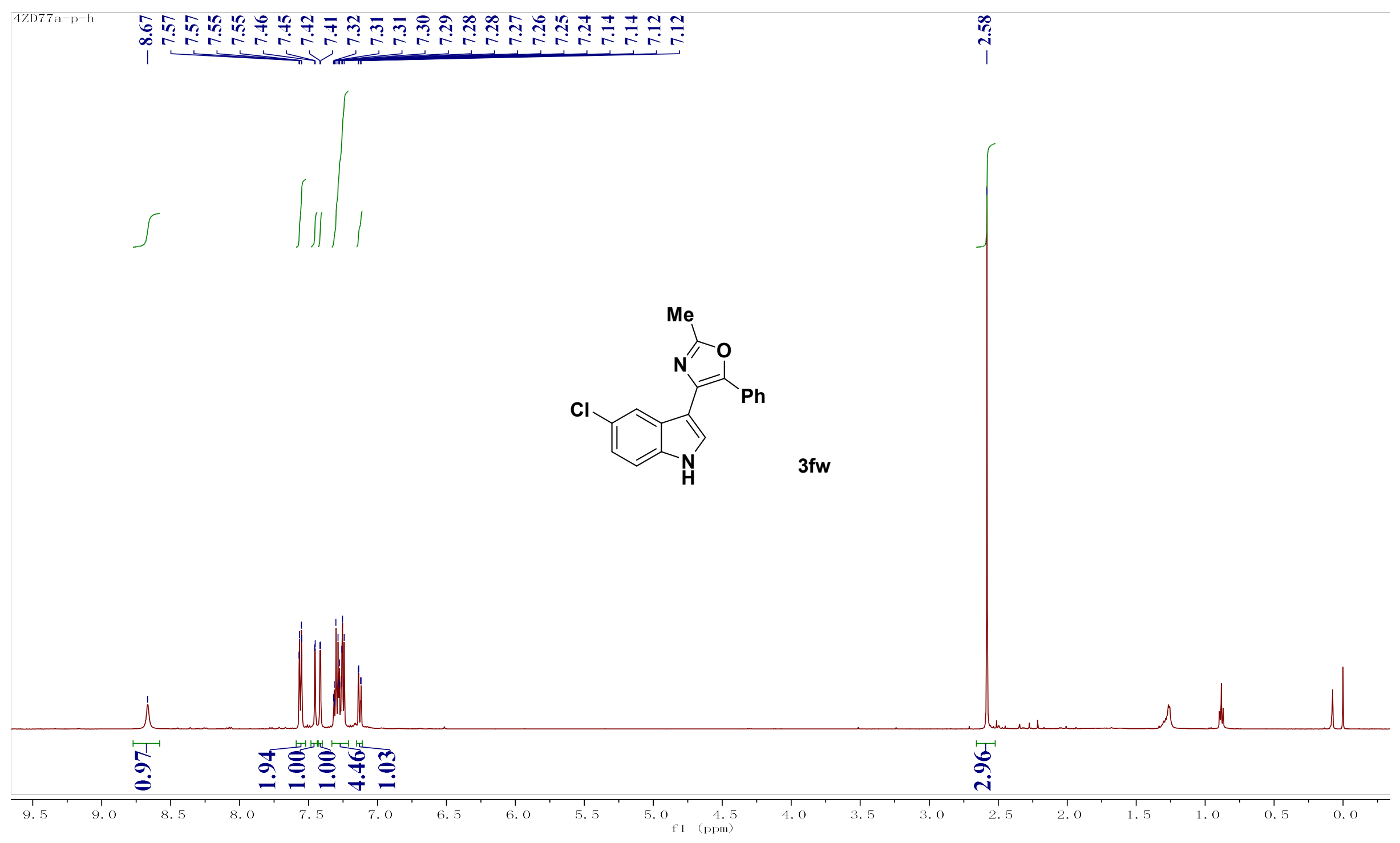

NMR-120 

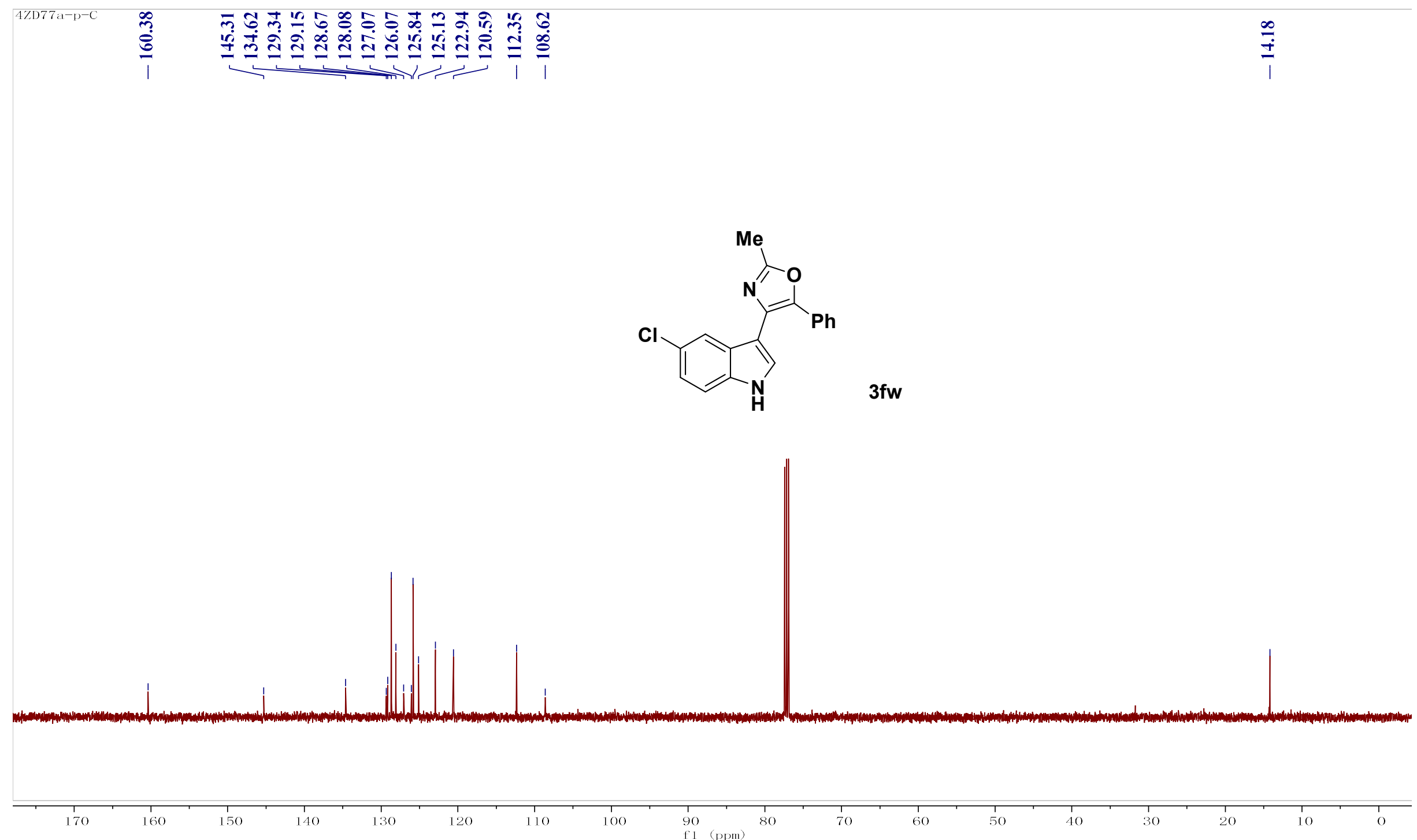


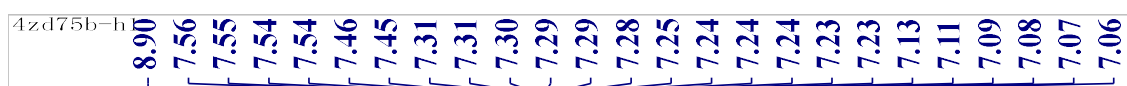
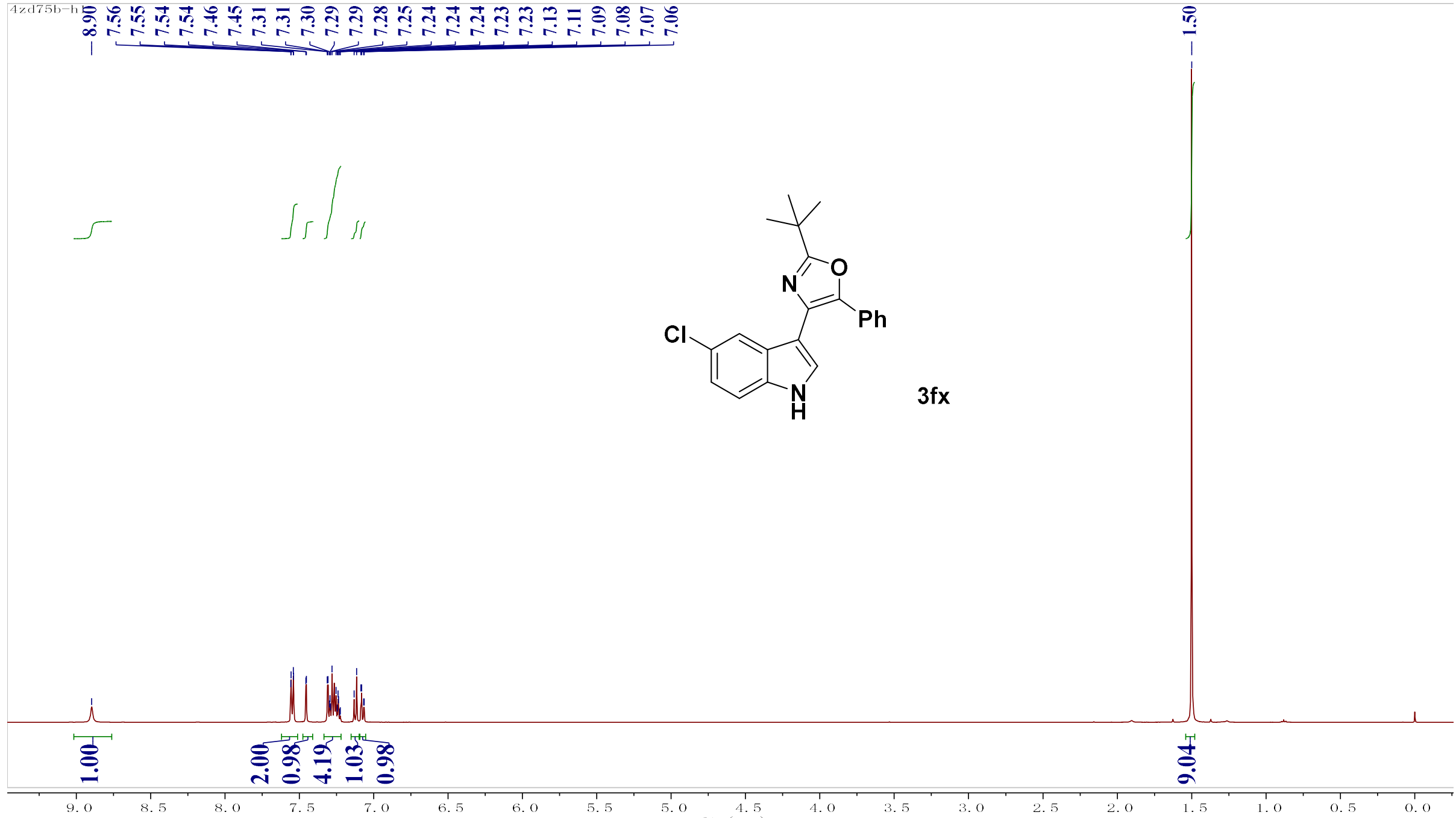

$3 f x$

NMR-122 


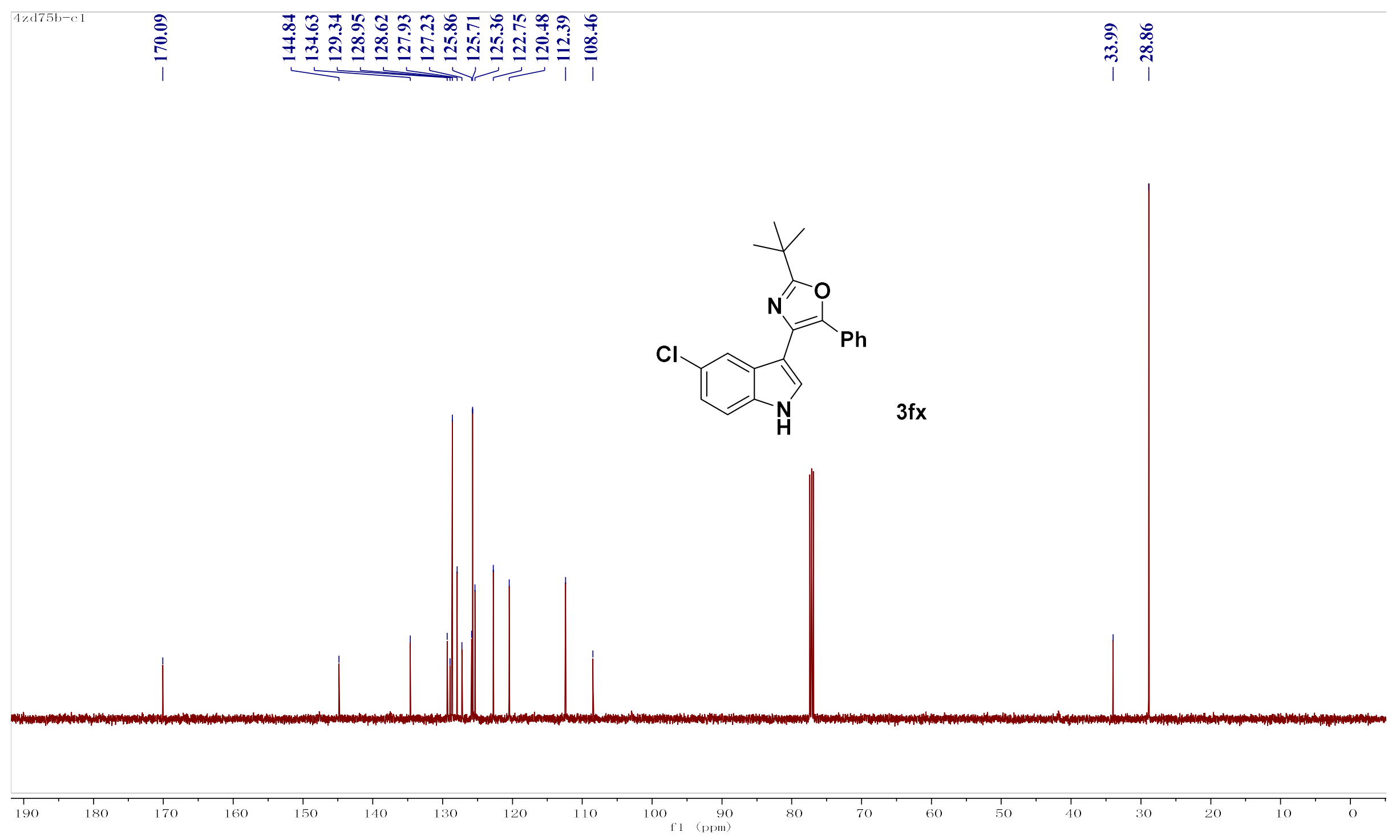




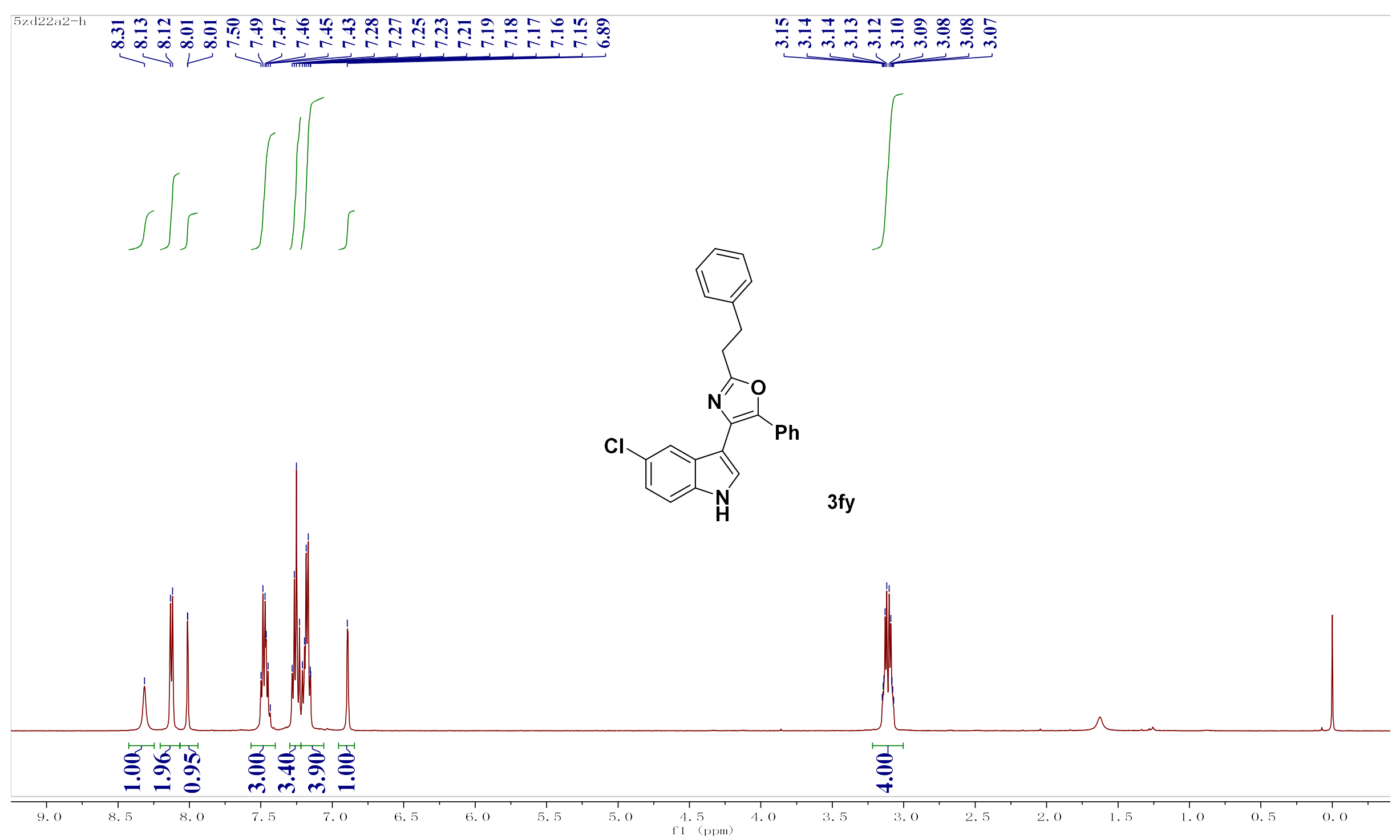

NMR-124 

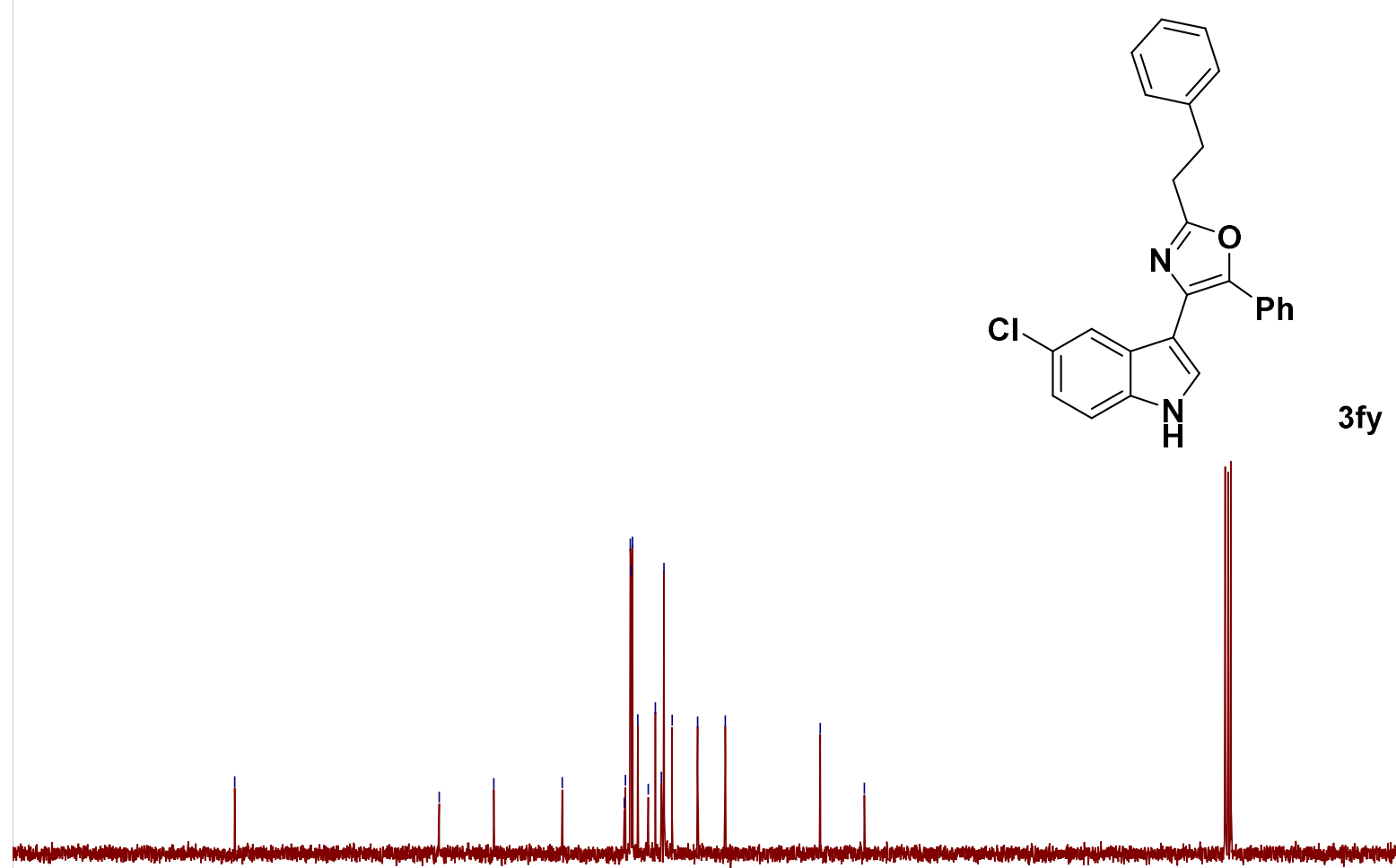


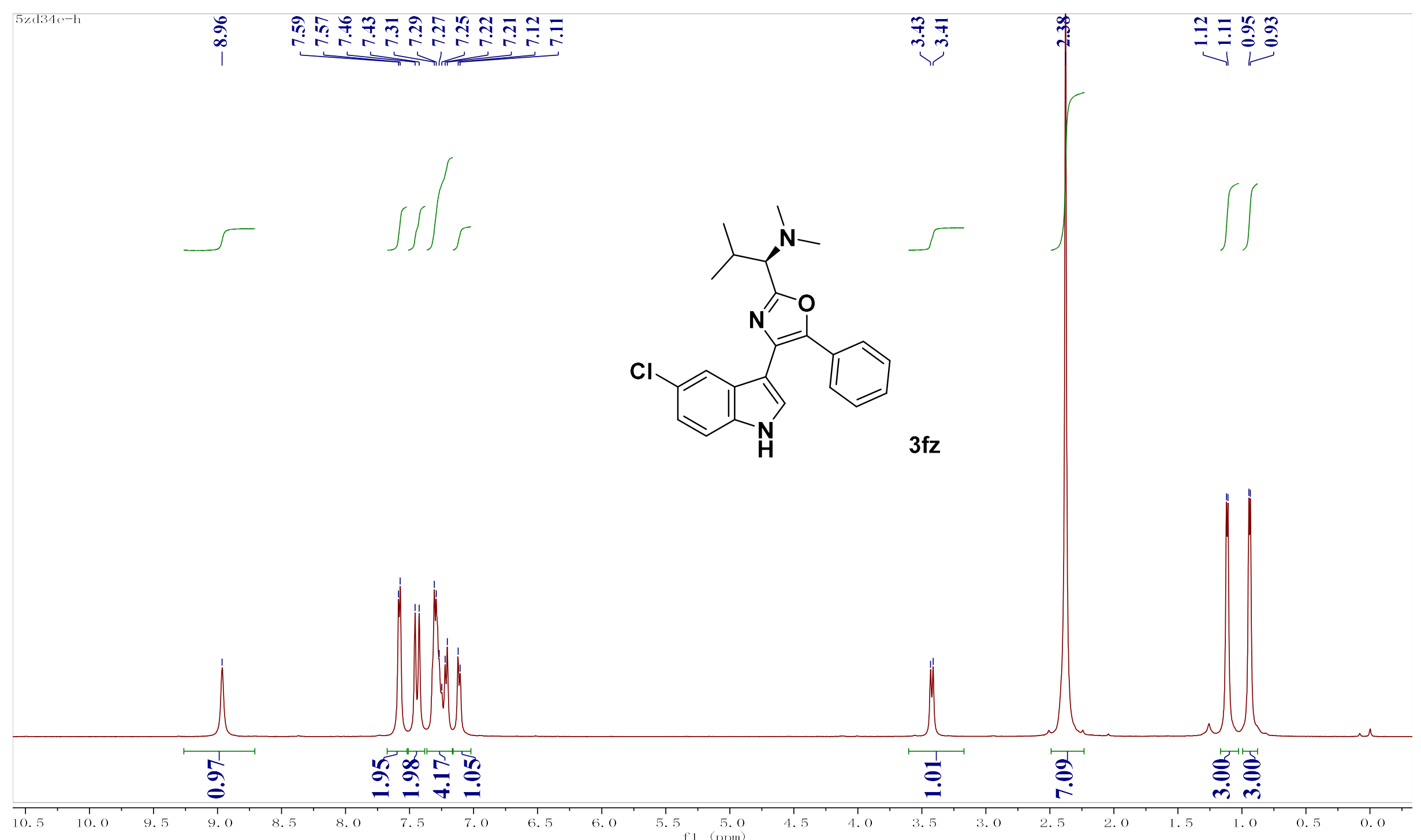

NMR-126 

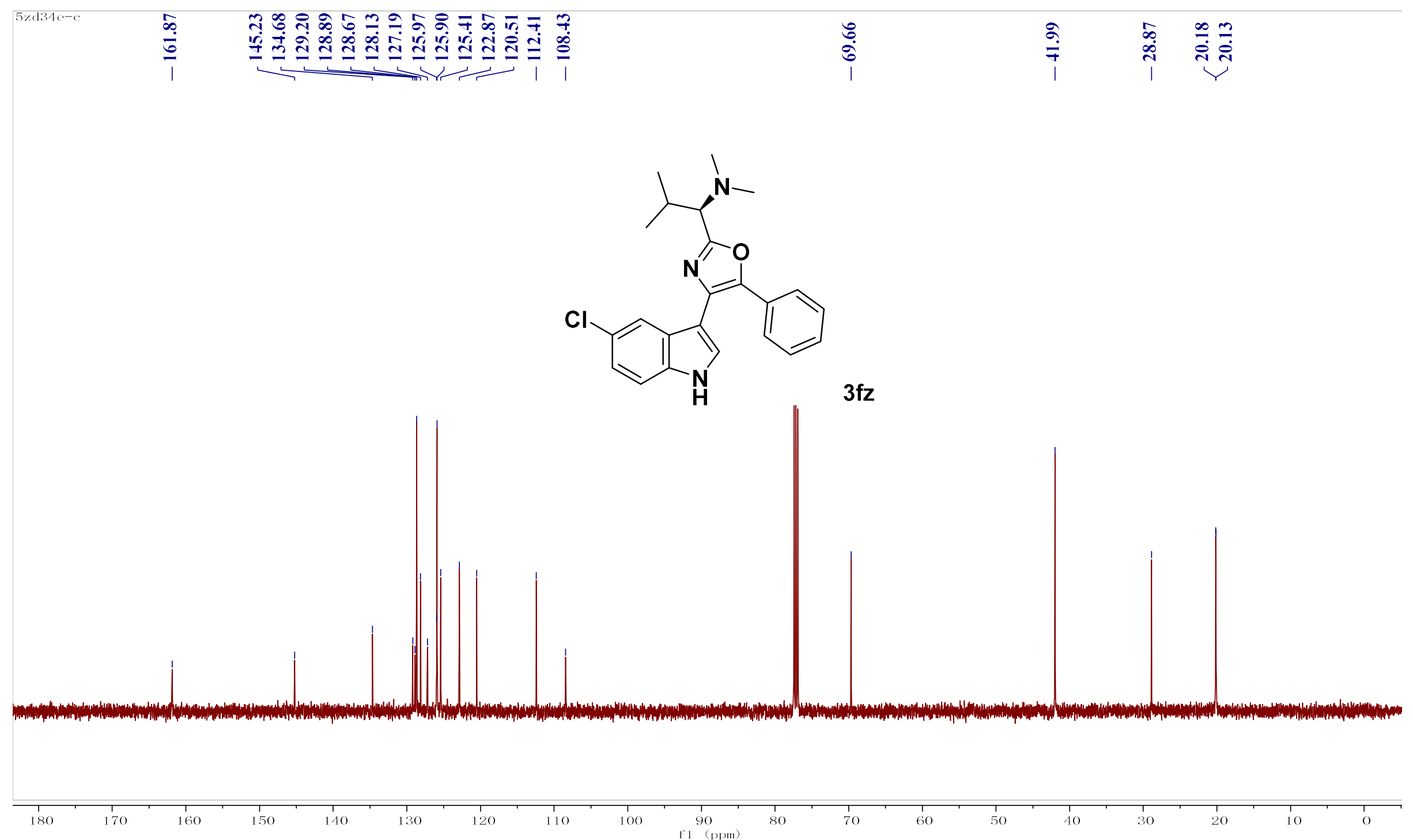

NMR-127 


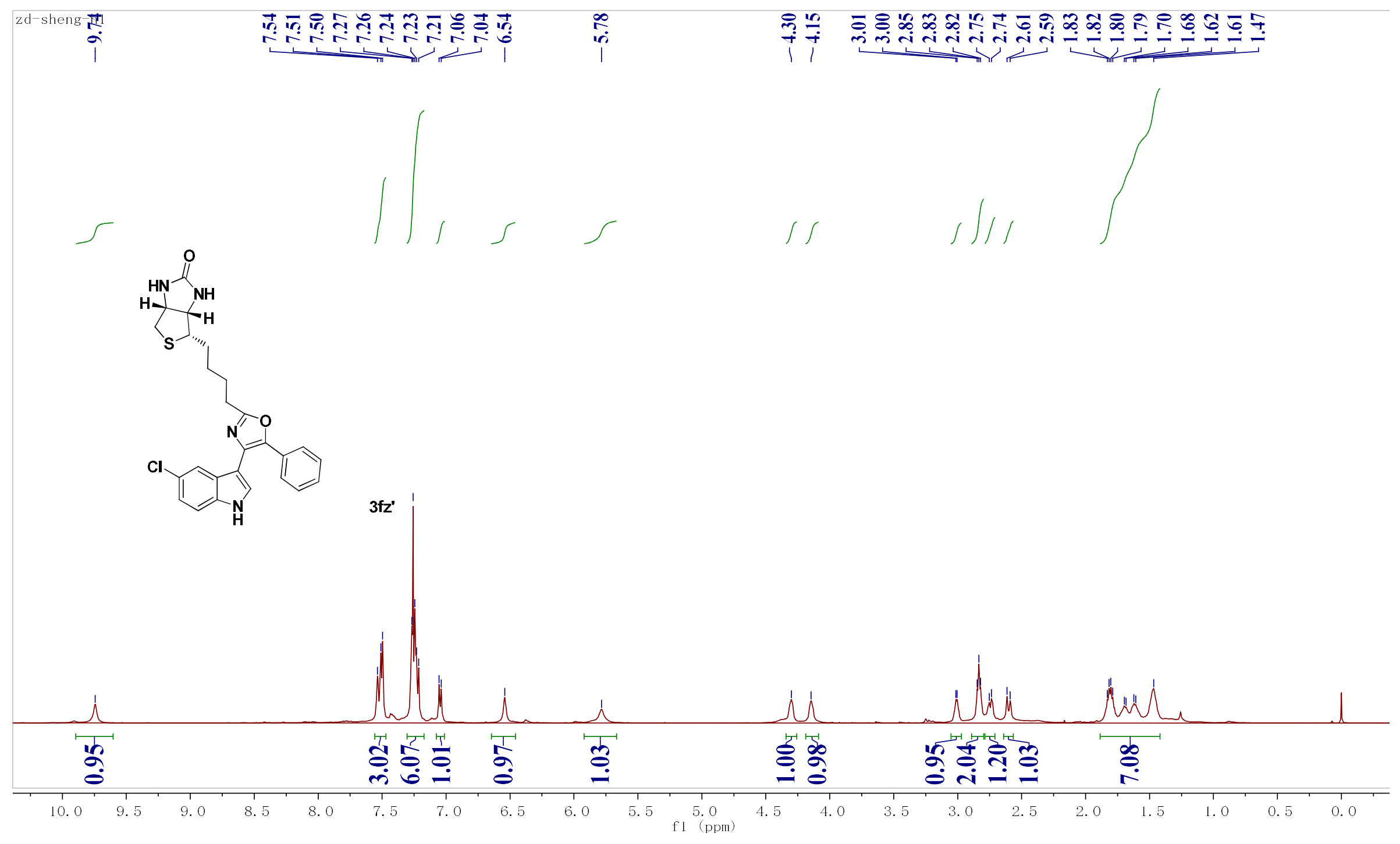

NMR-128 


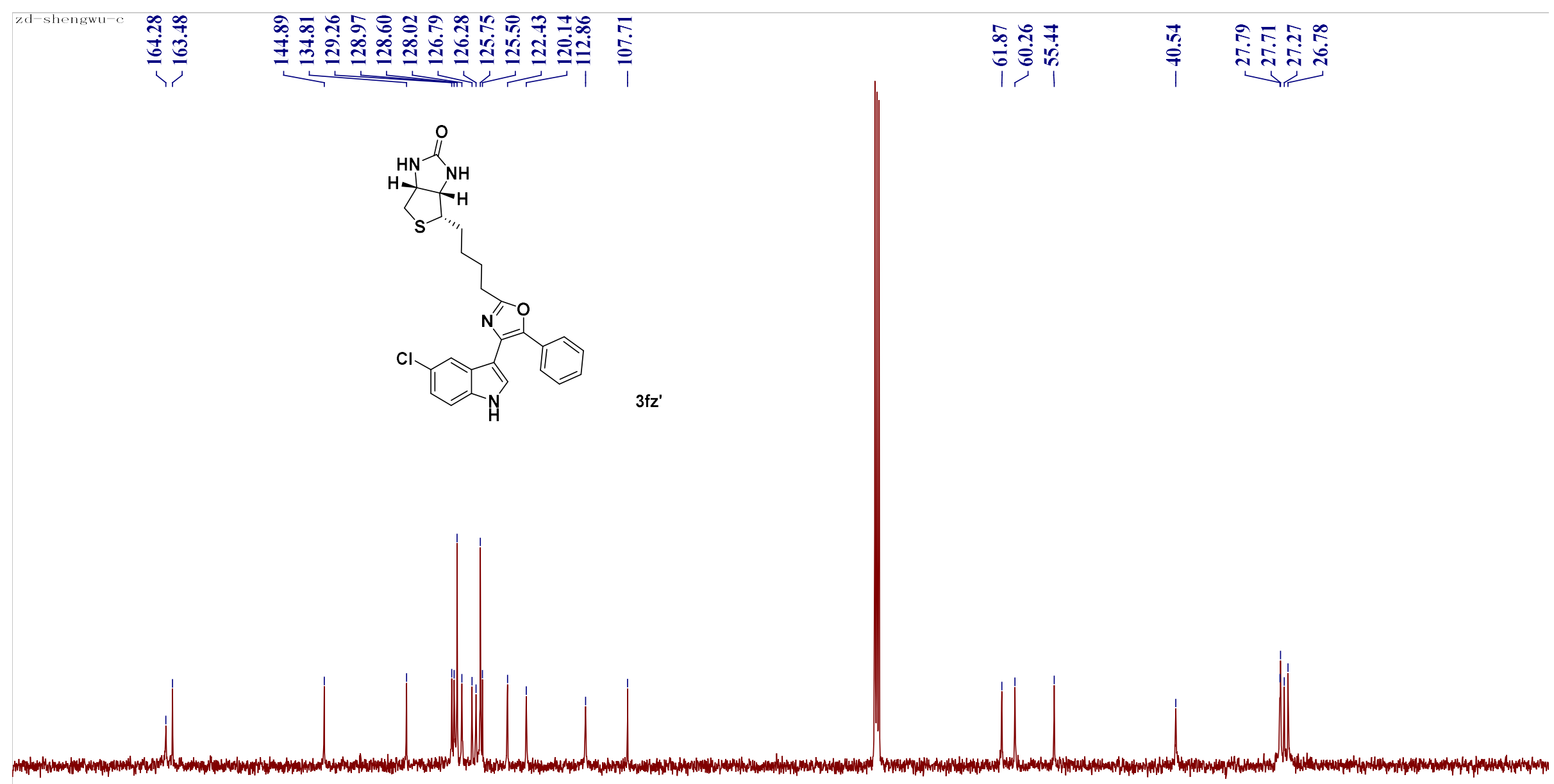




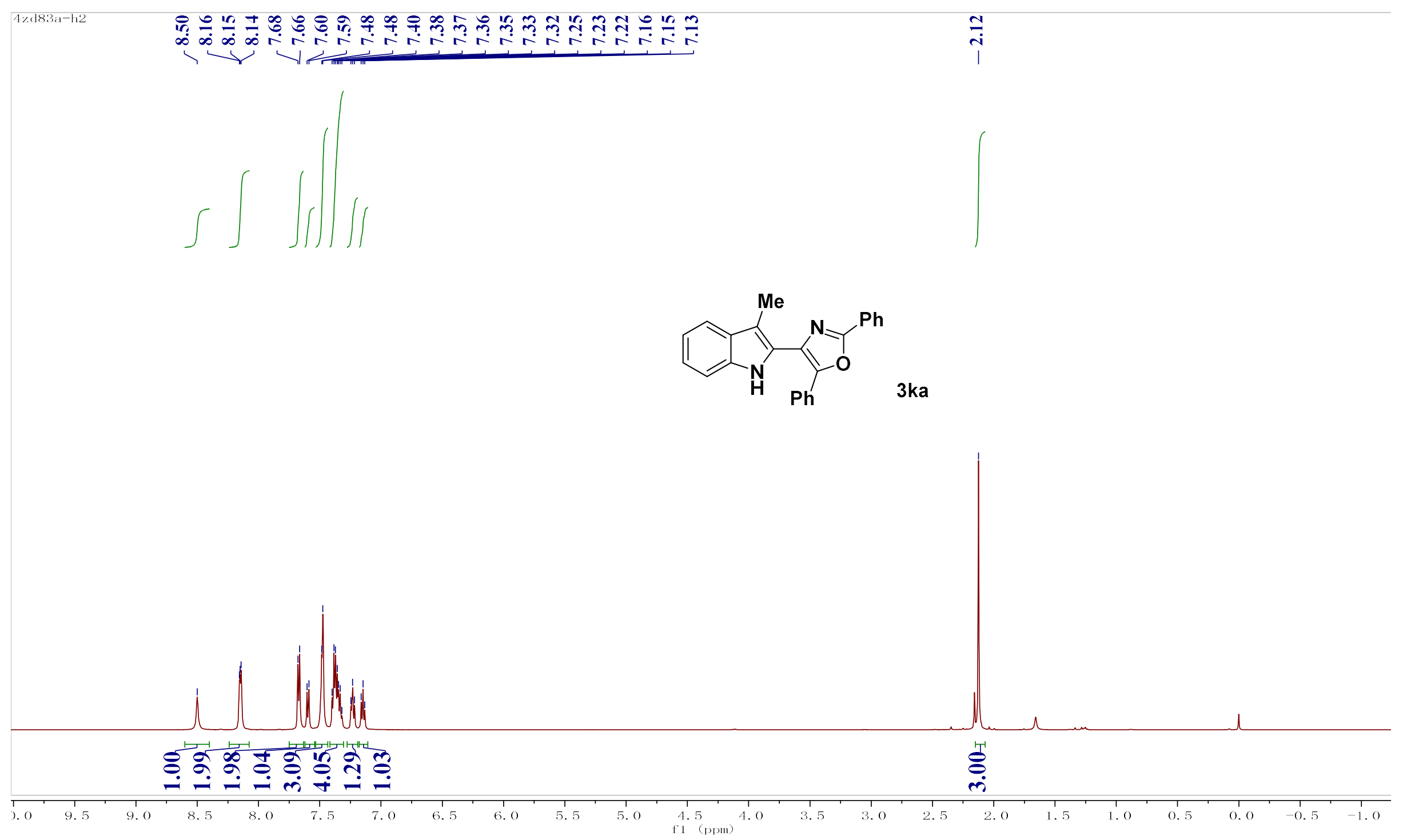

NMR-130 


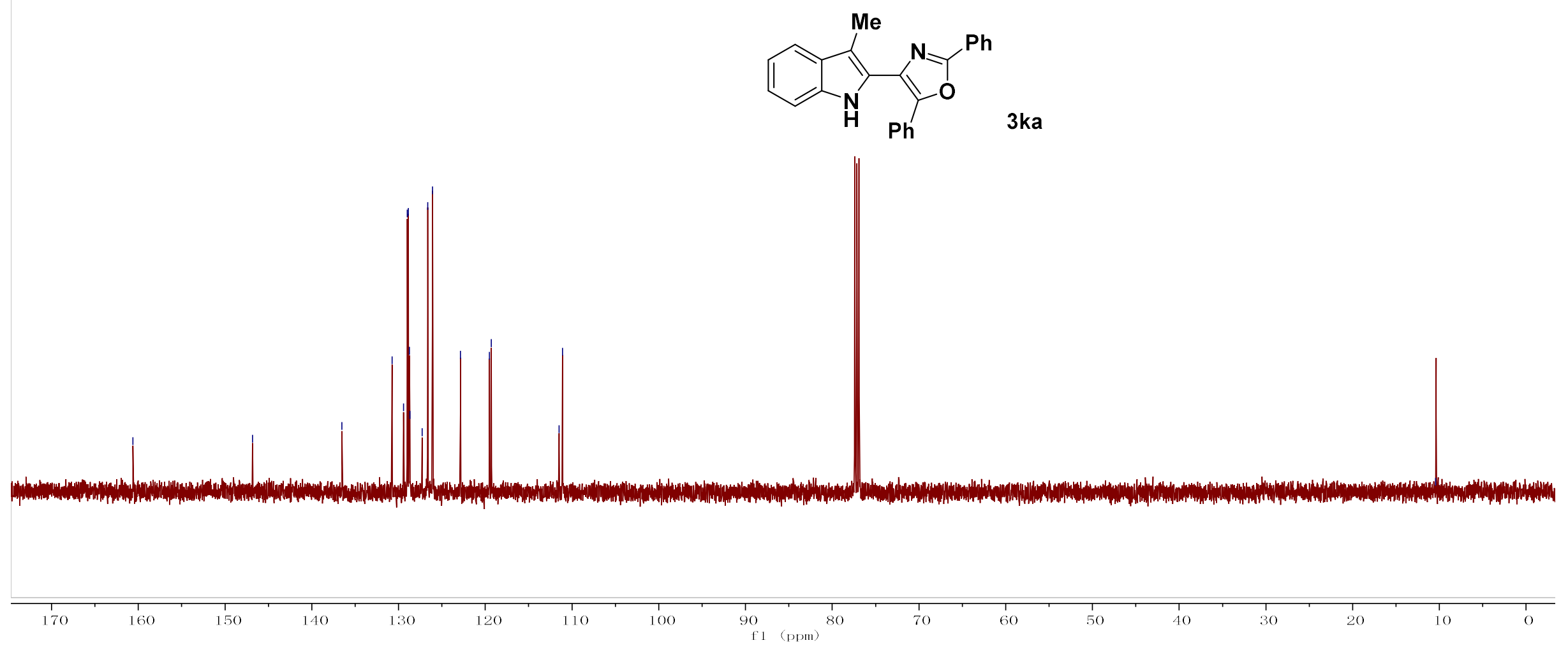




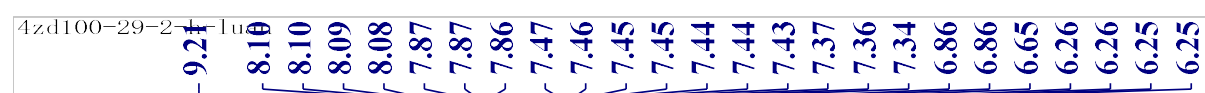
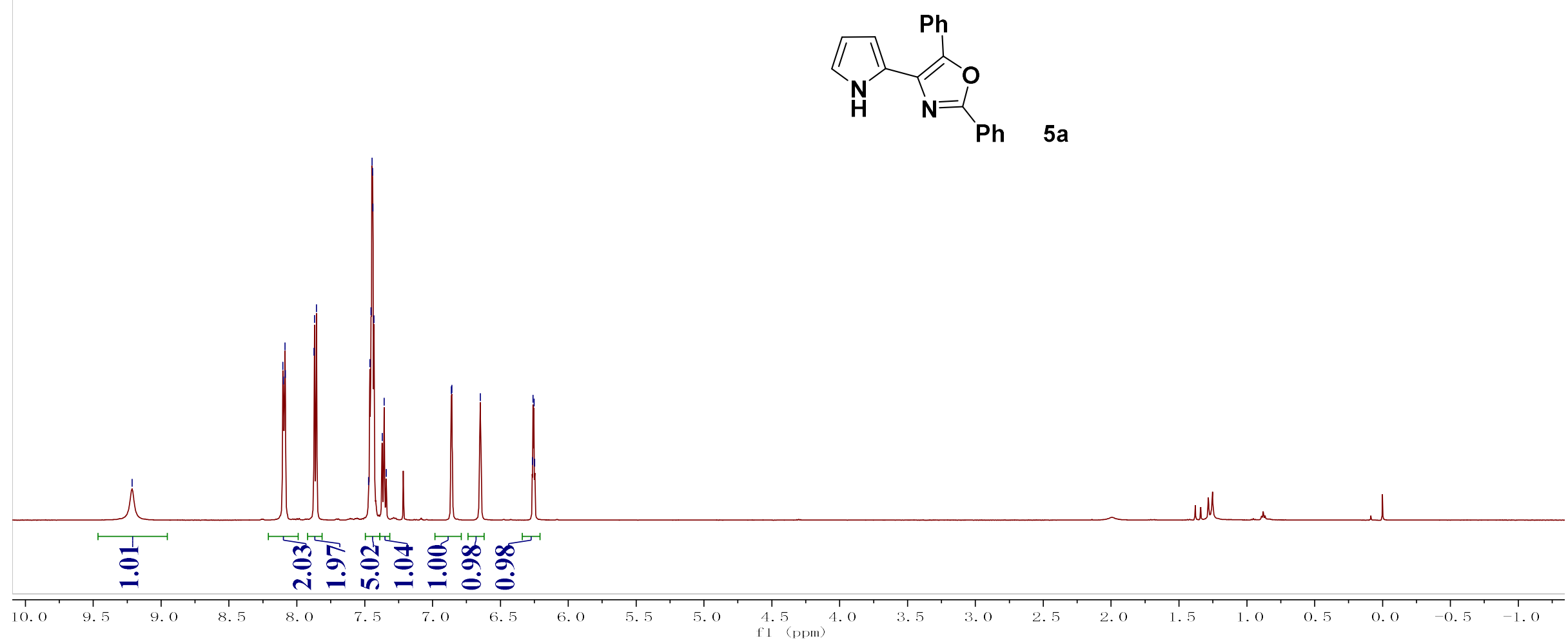

NMR-132 


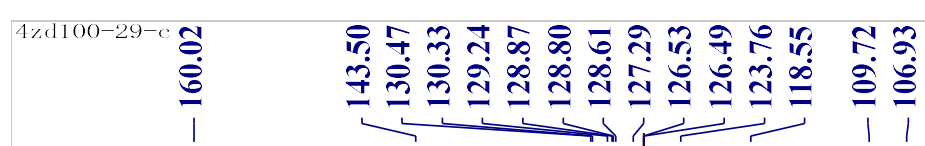

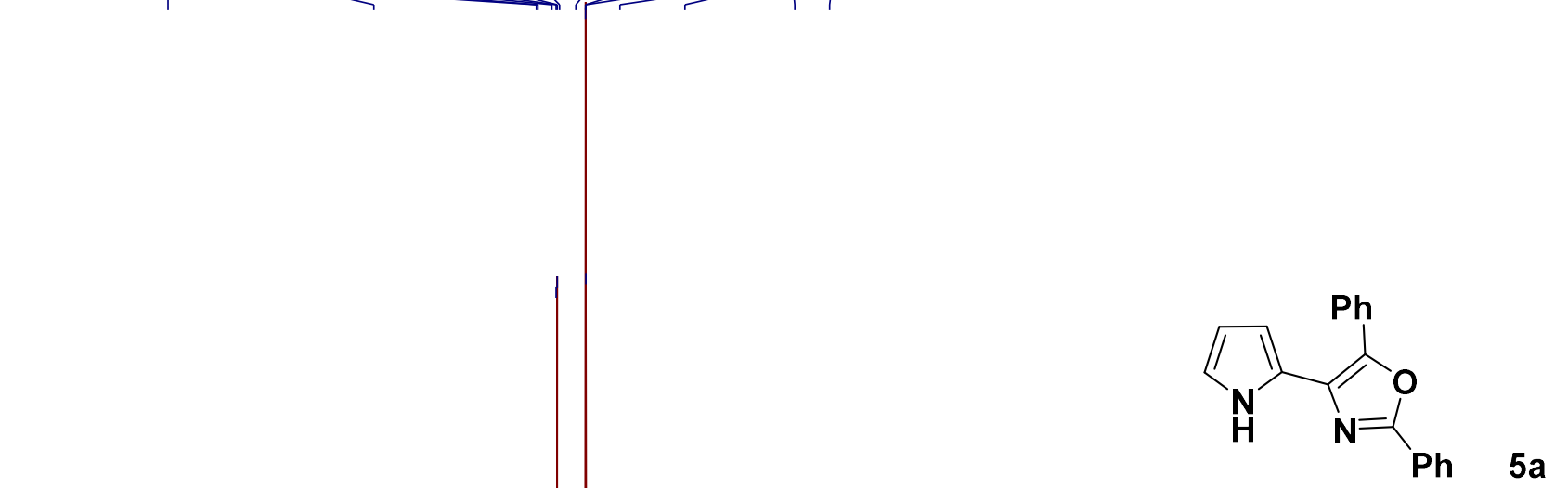

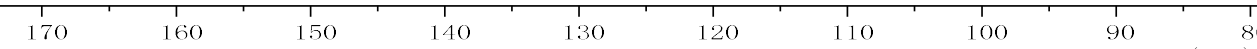




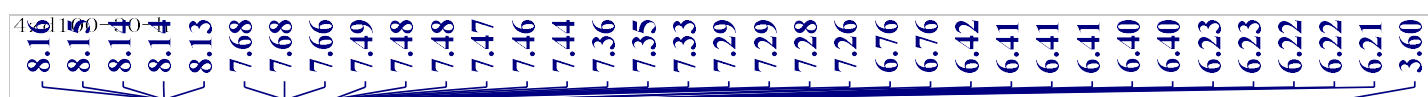

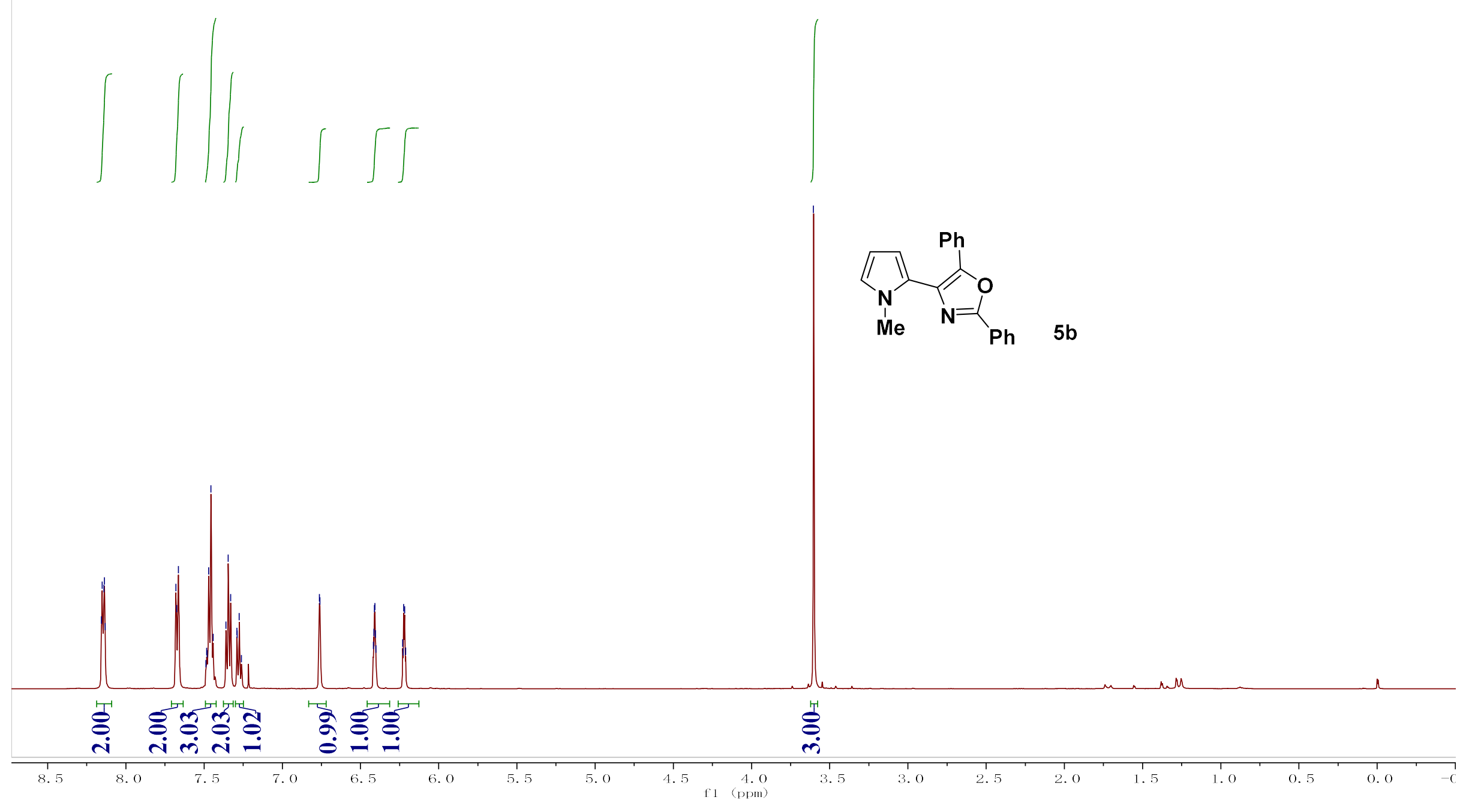

NMR-134 

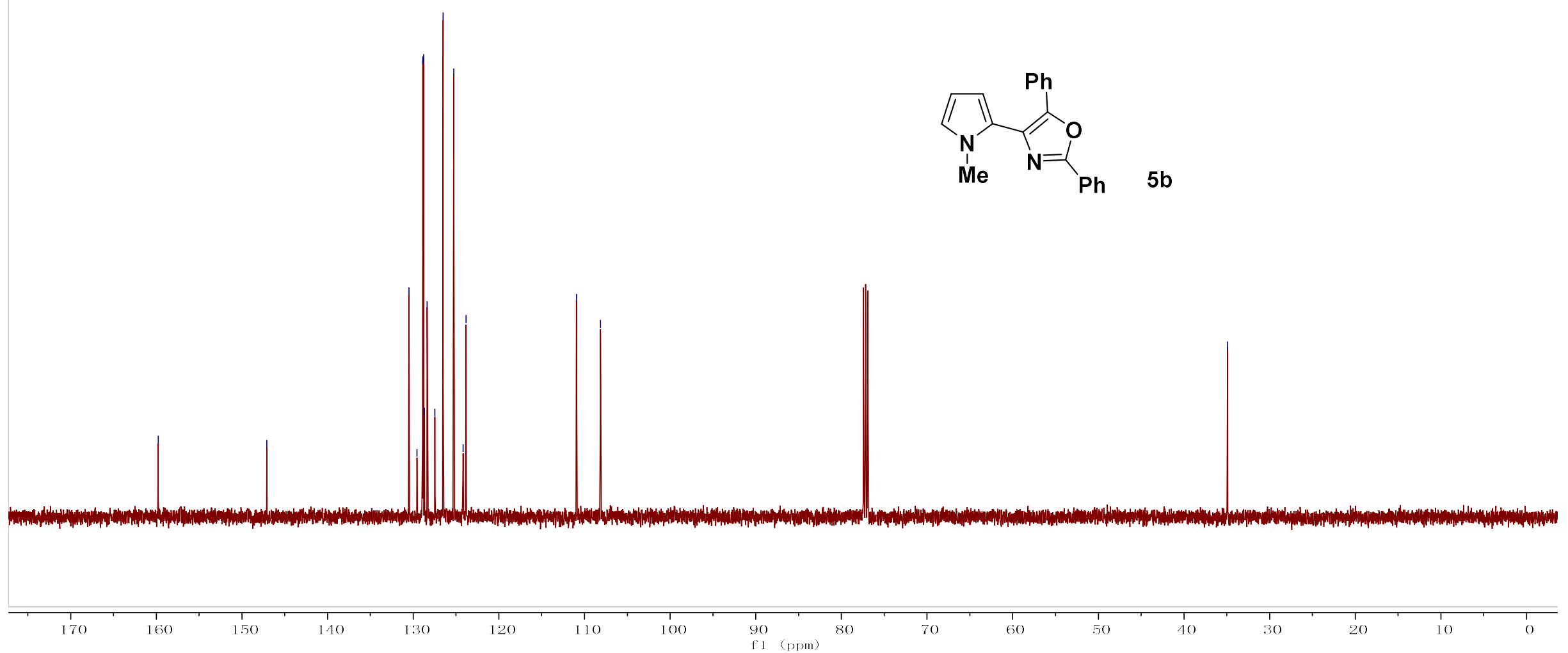
वd-57-p-ty
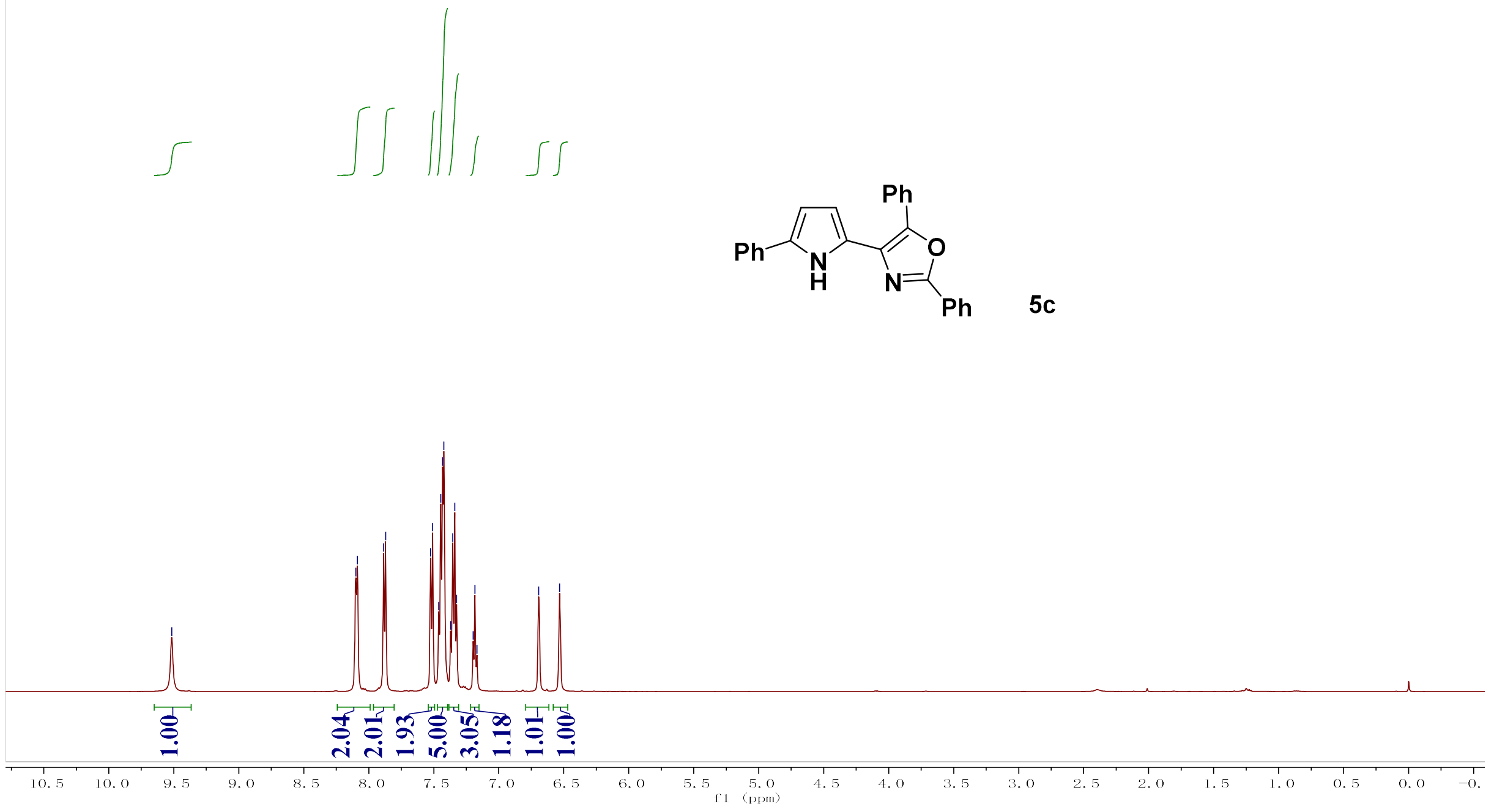

NMR-136 


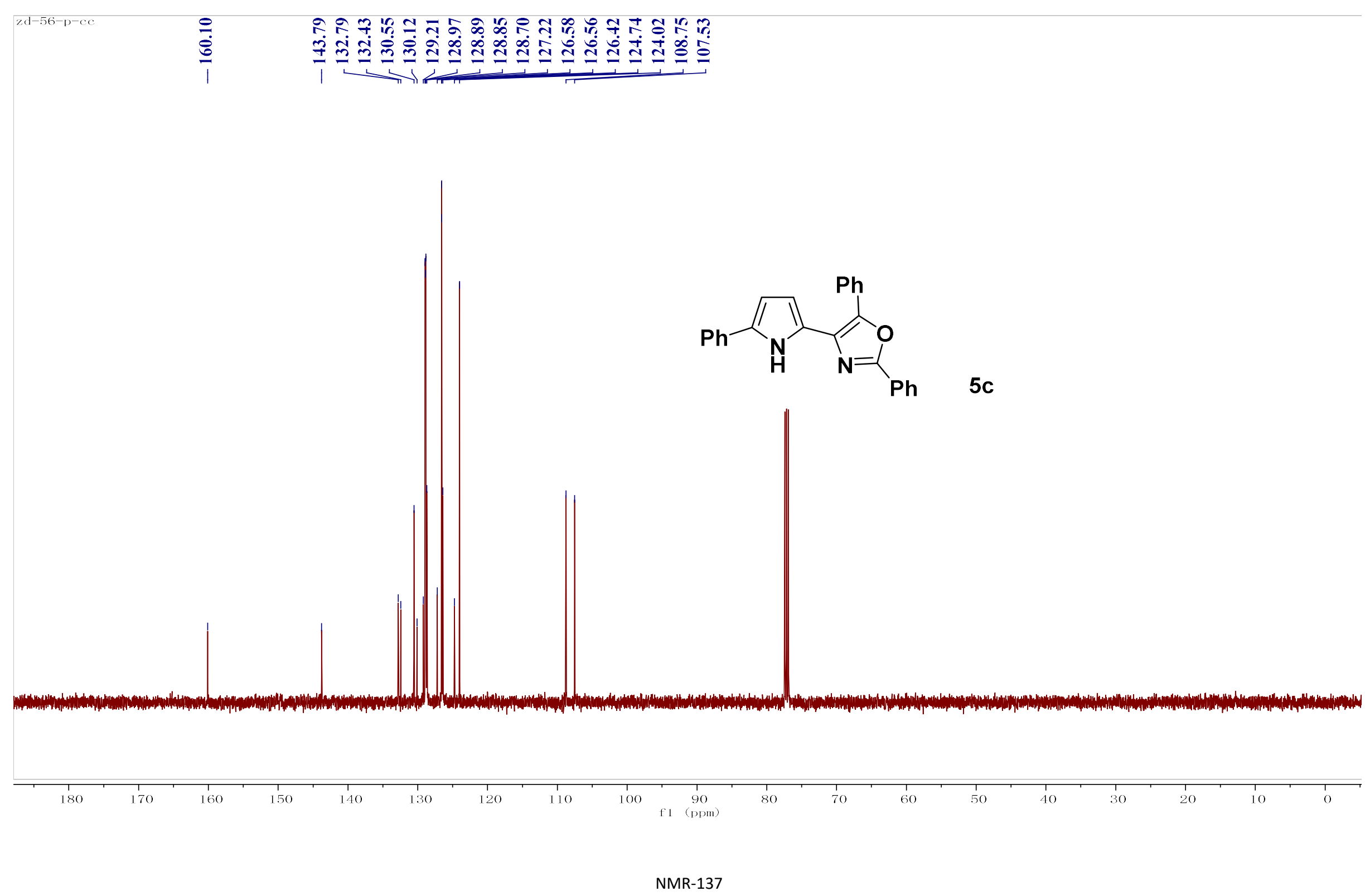




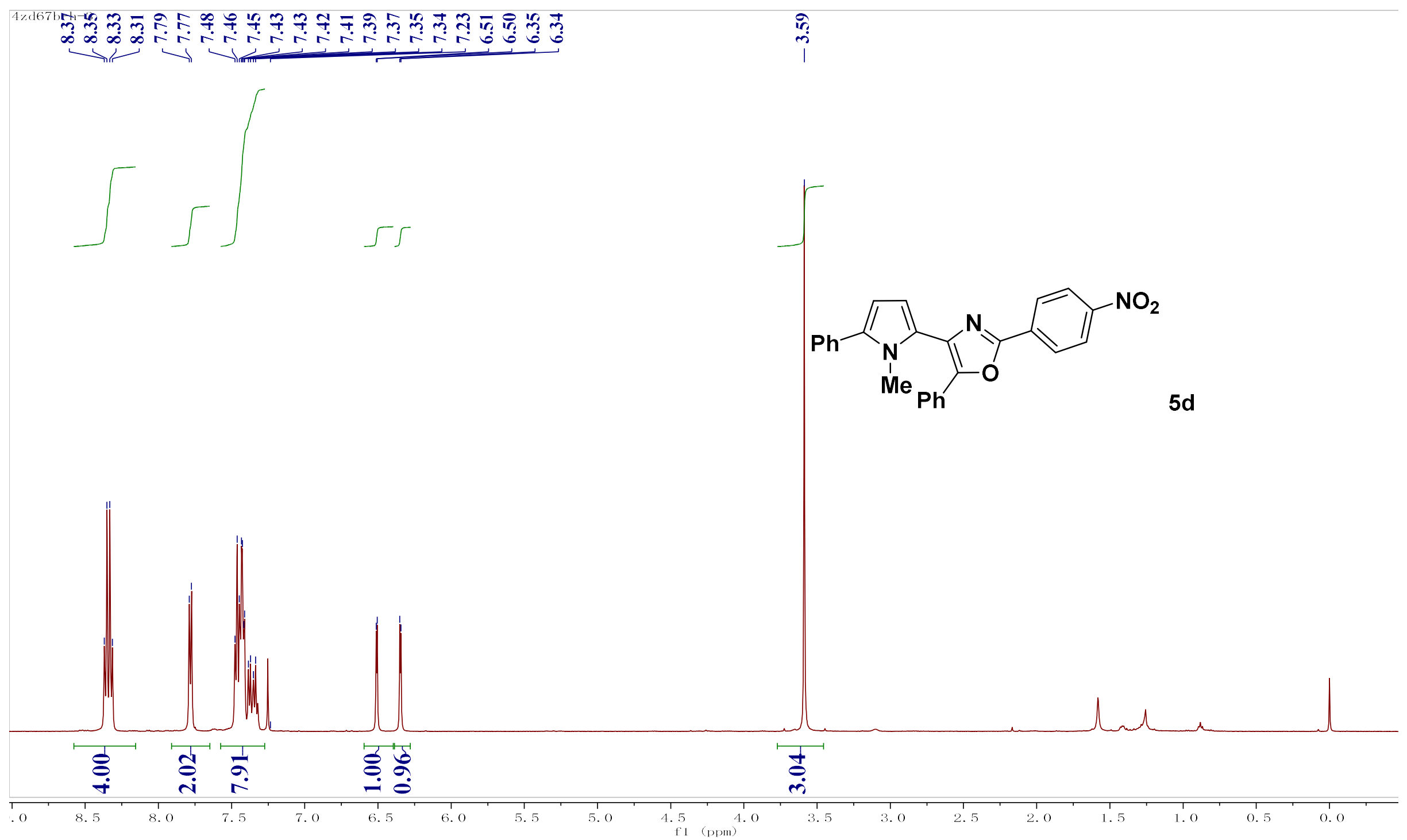



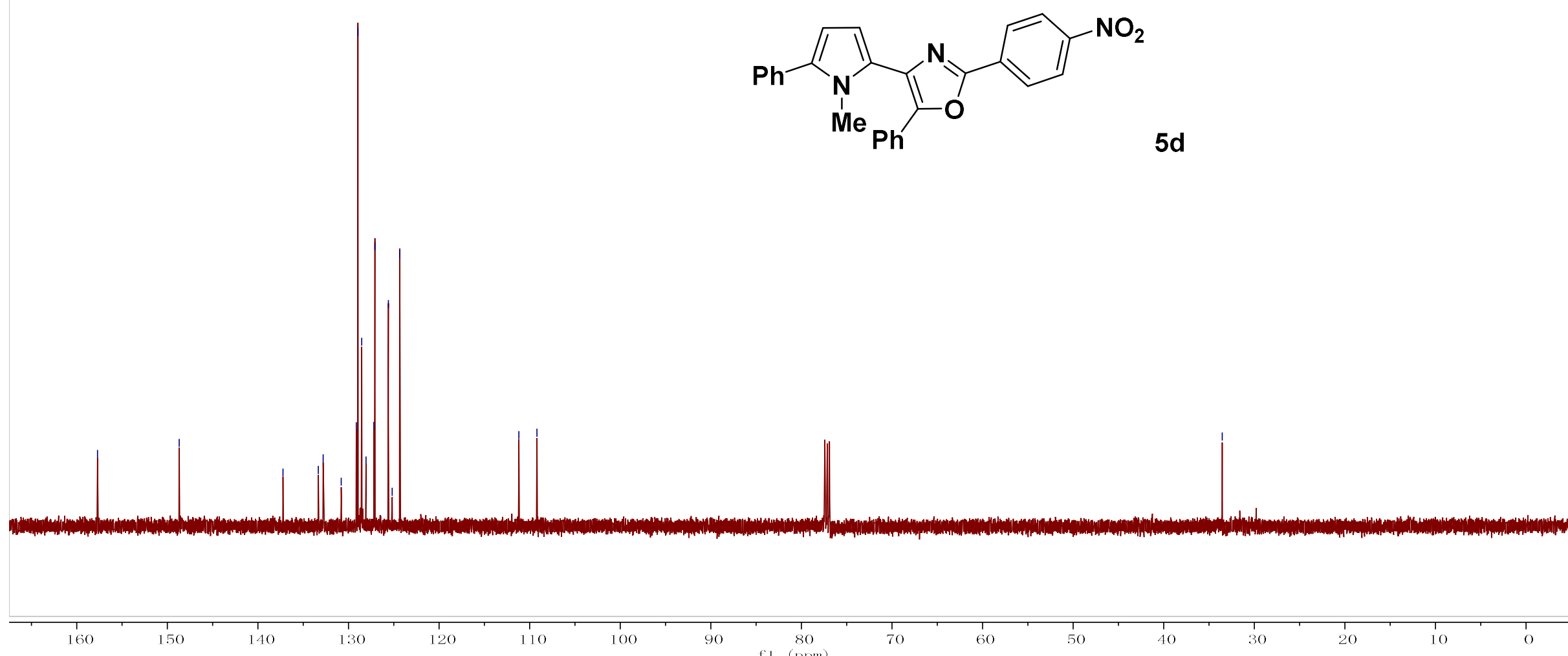


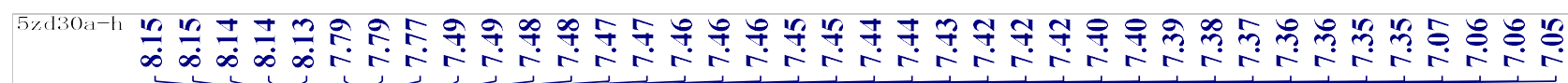
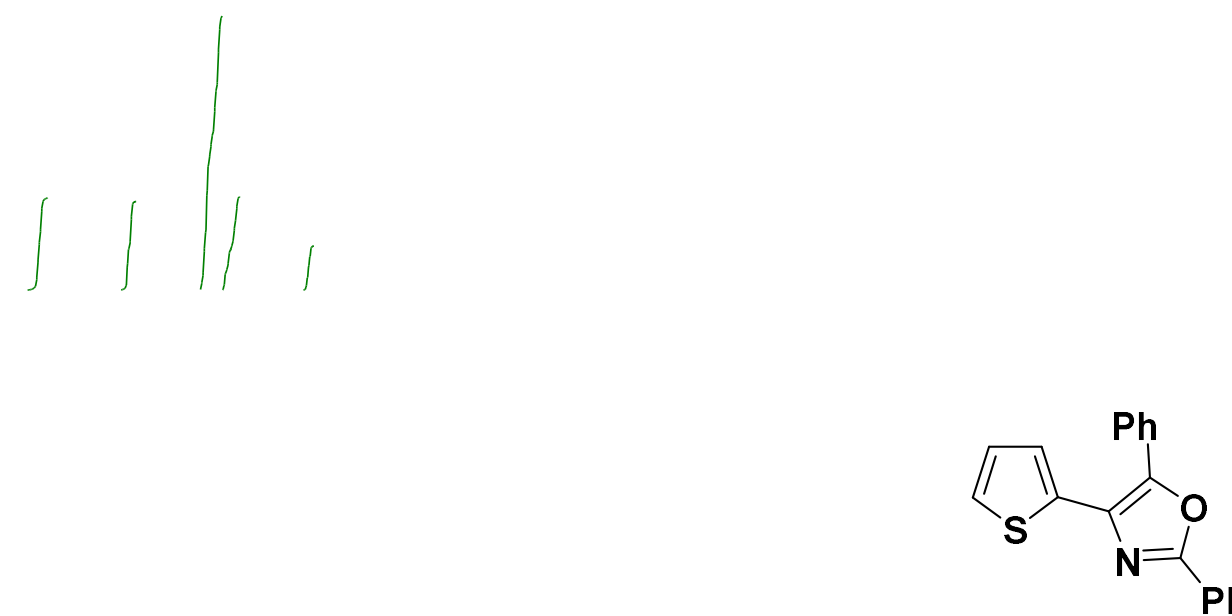

$5 e$

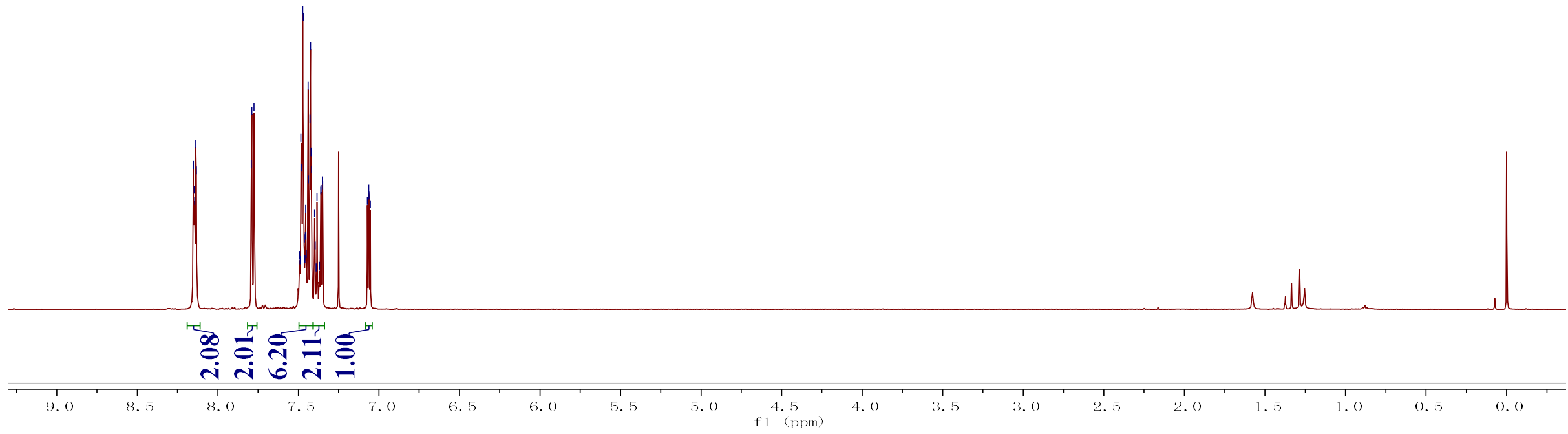

NMR-140 

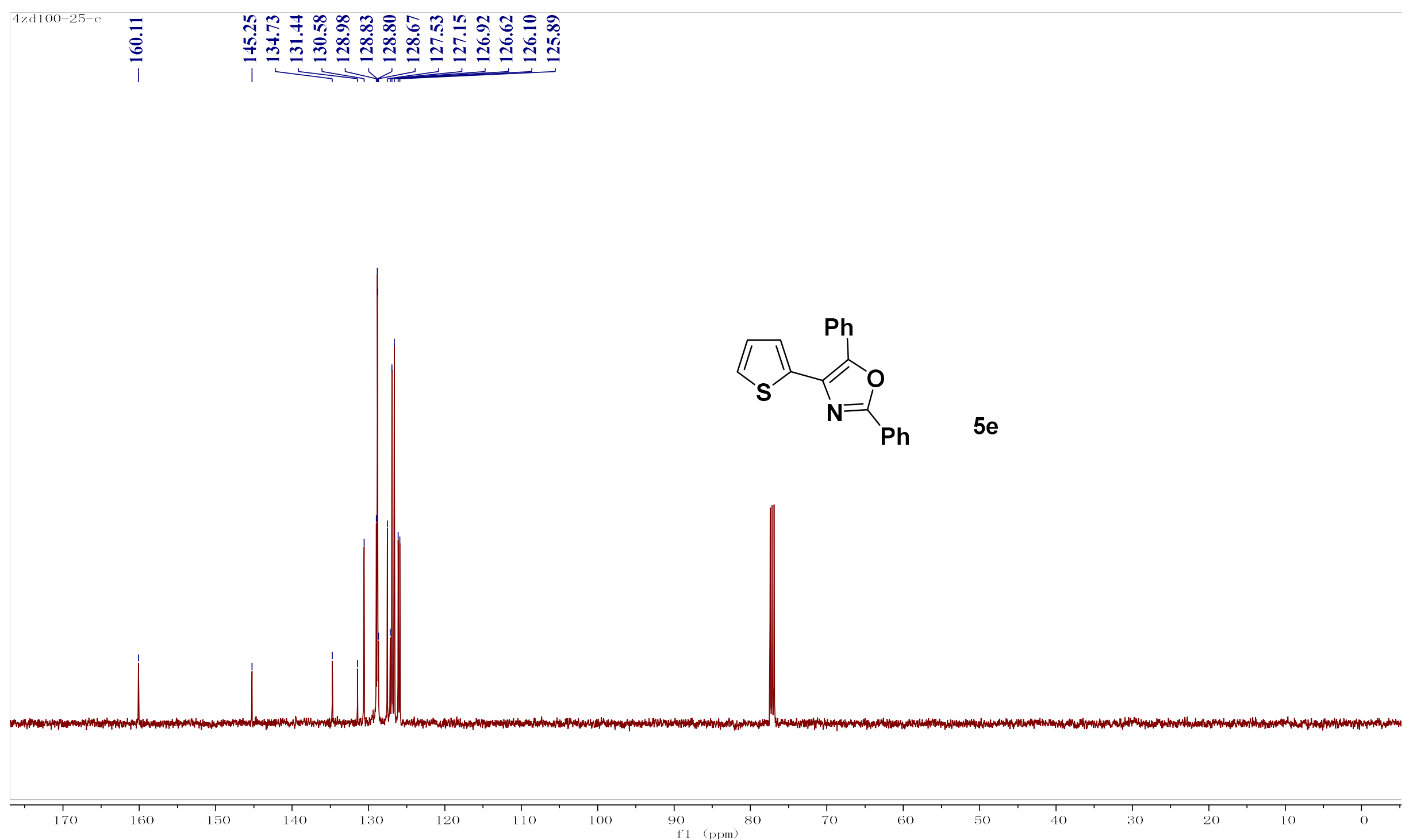

NMR-141 

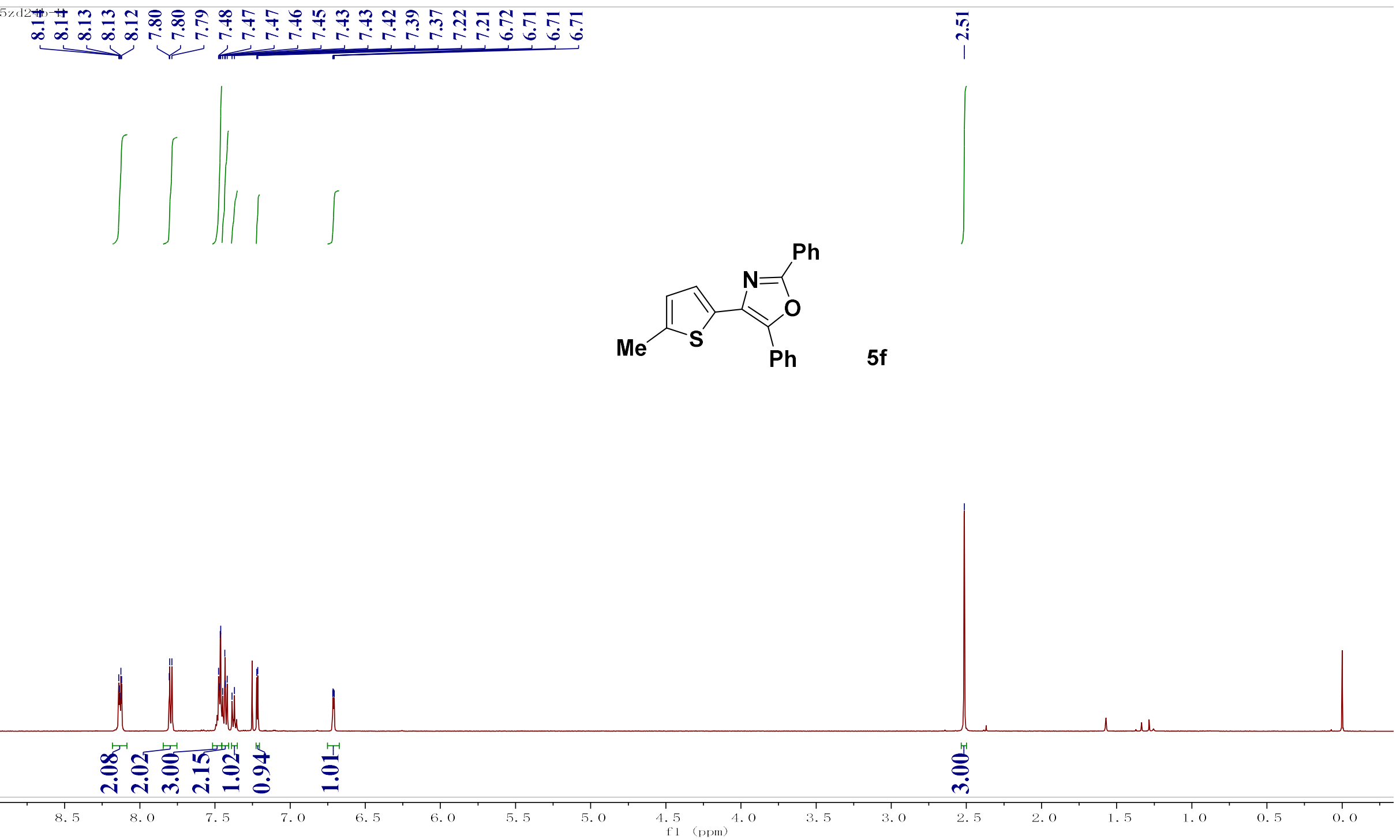

NMR-142 


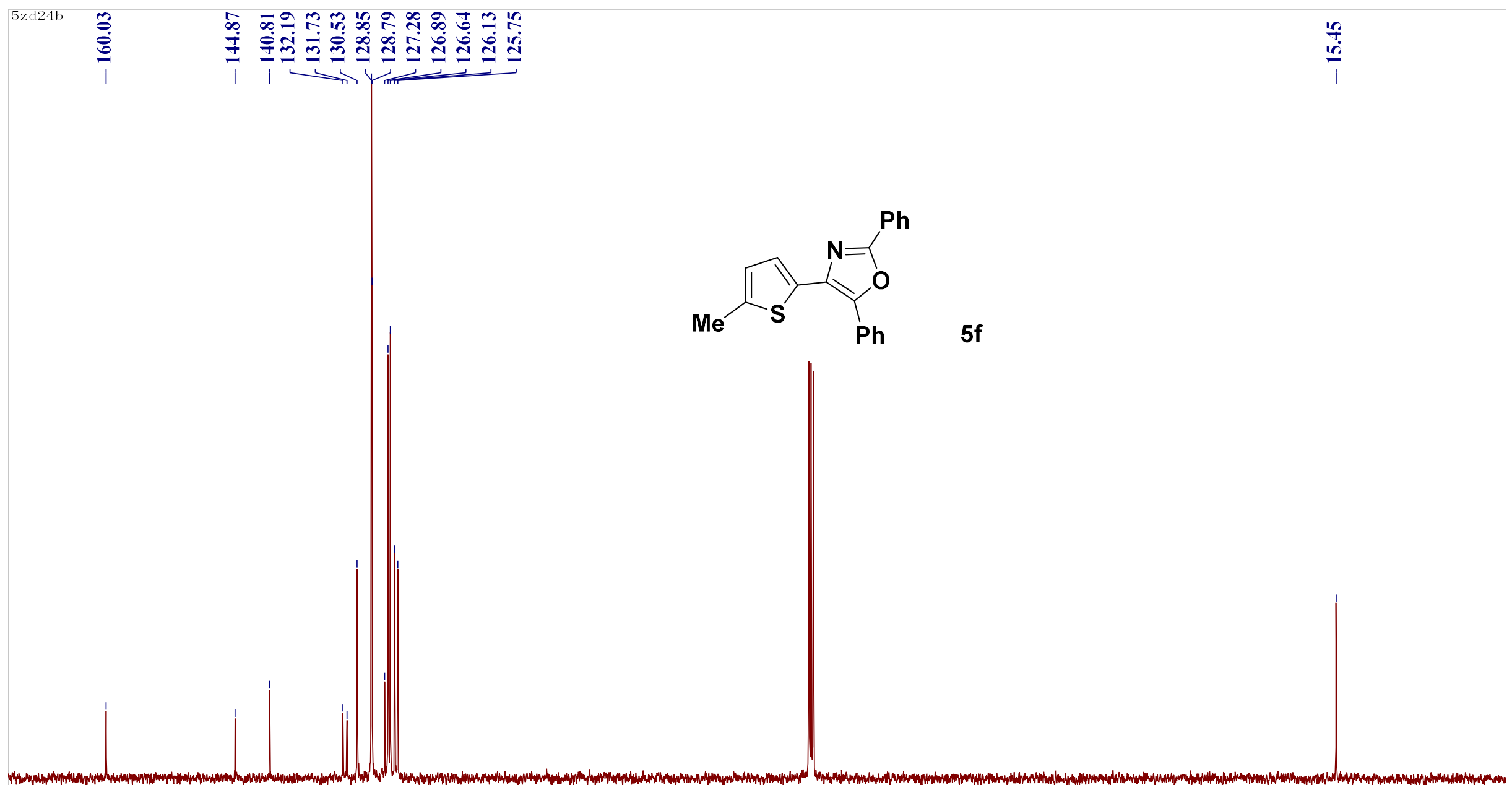

$\frac{1}{170}$

160

150

140

130

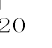

110

100

90

80
(ppmin)

NMR-143 


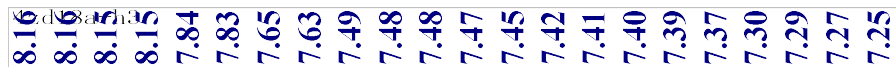
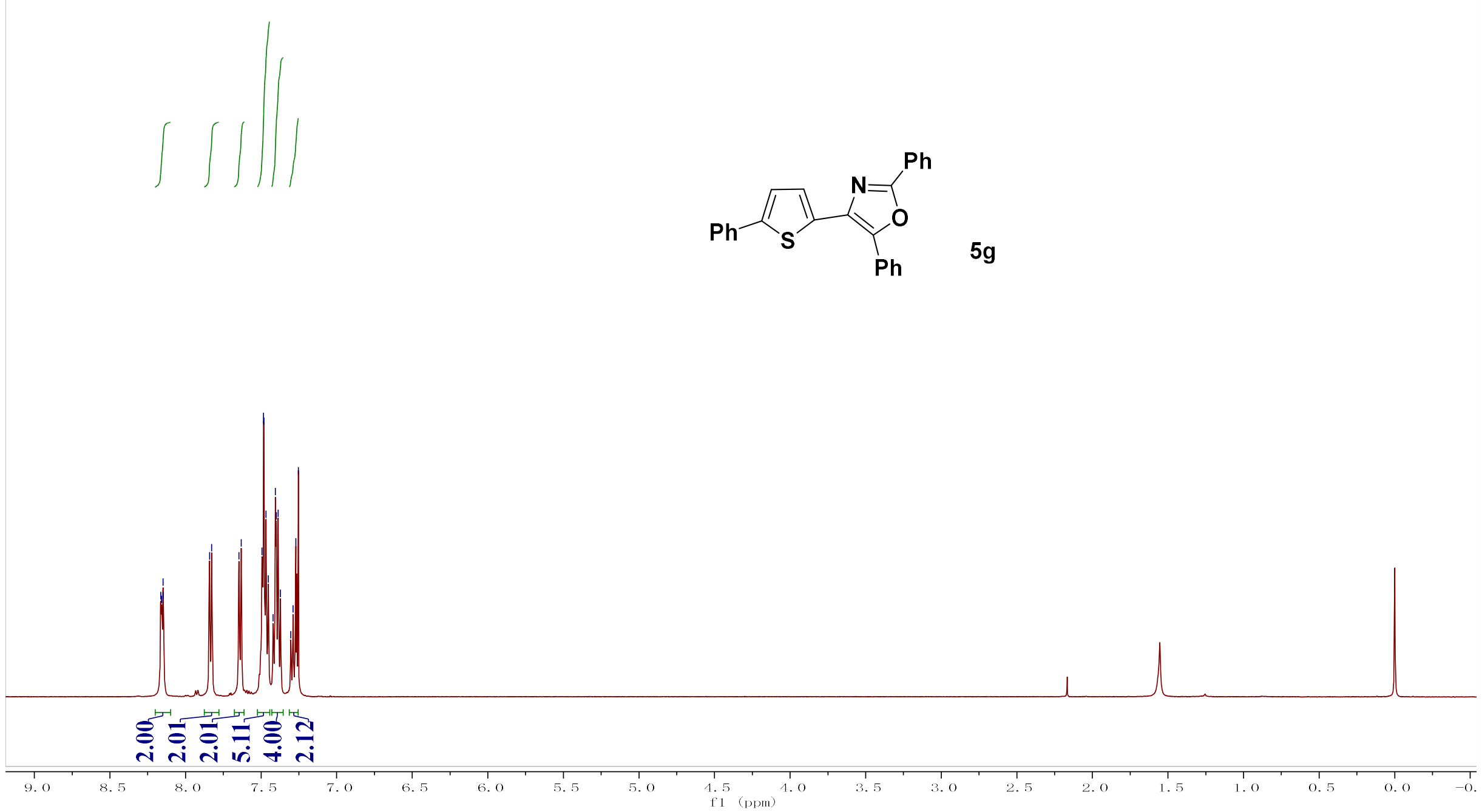

NMR-144 


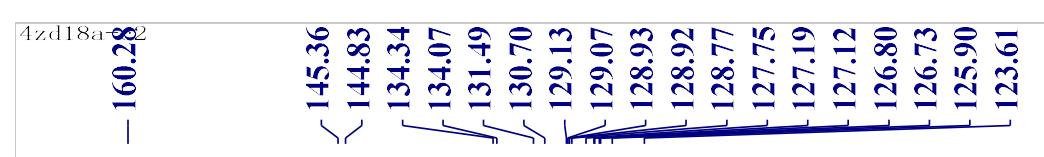
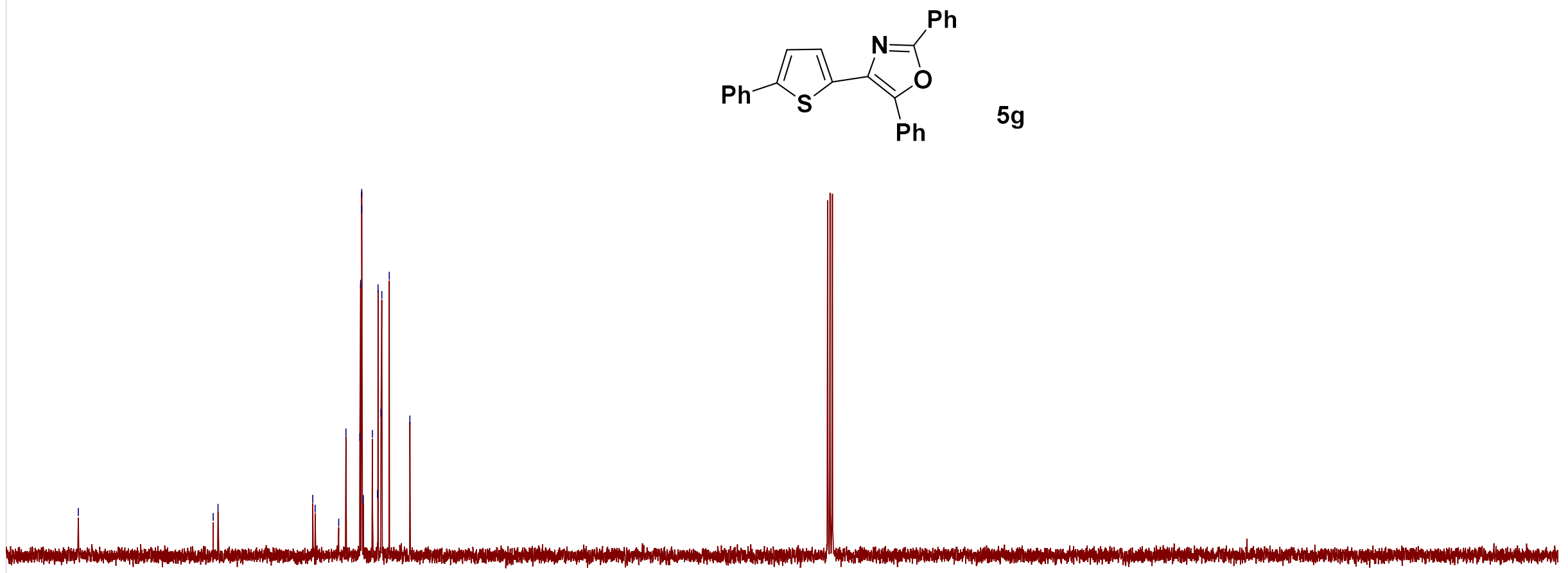
4zdfunan-h 我
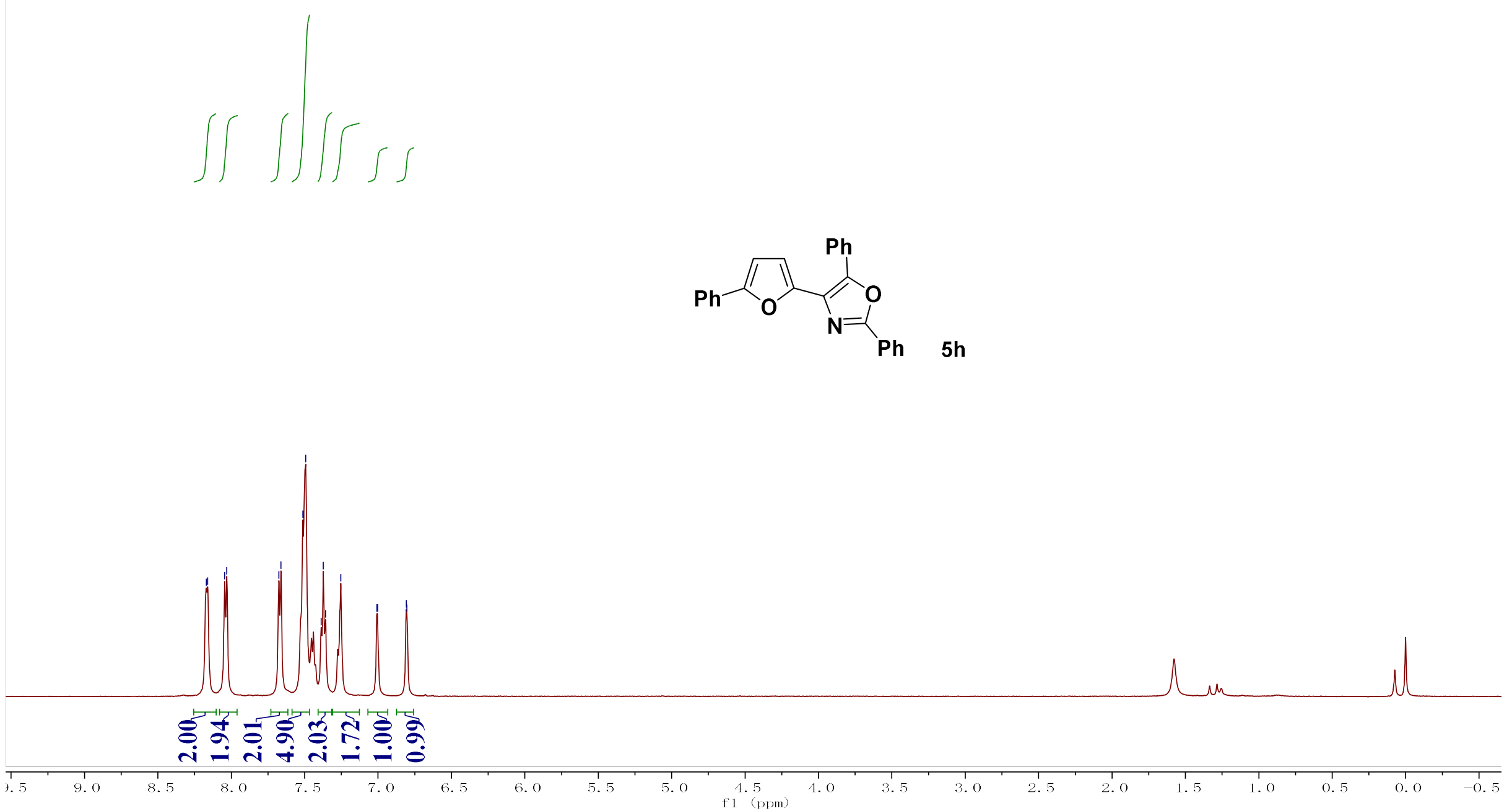

NMR-146 


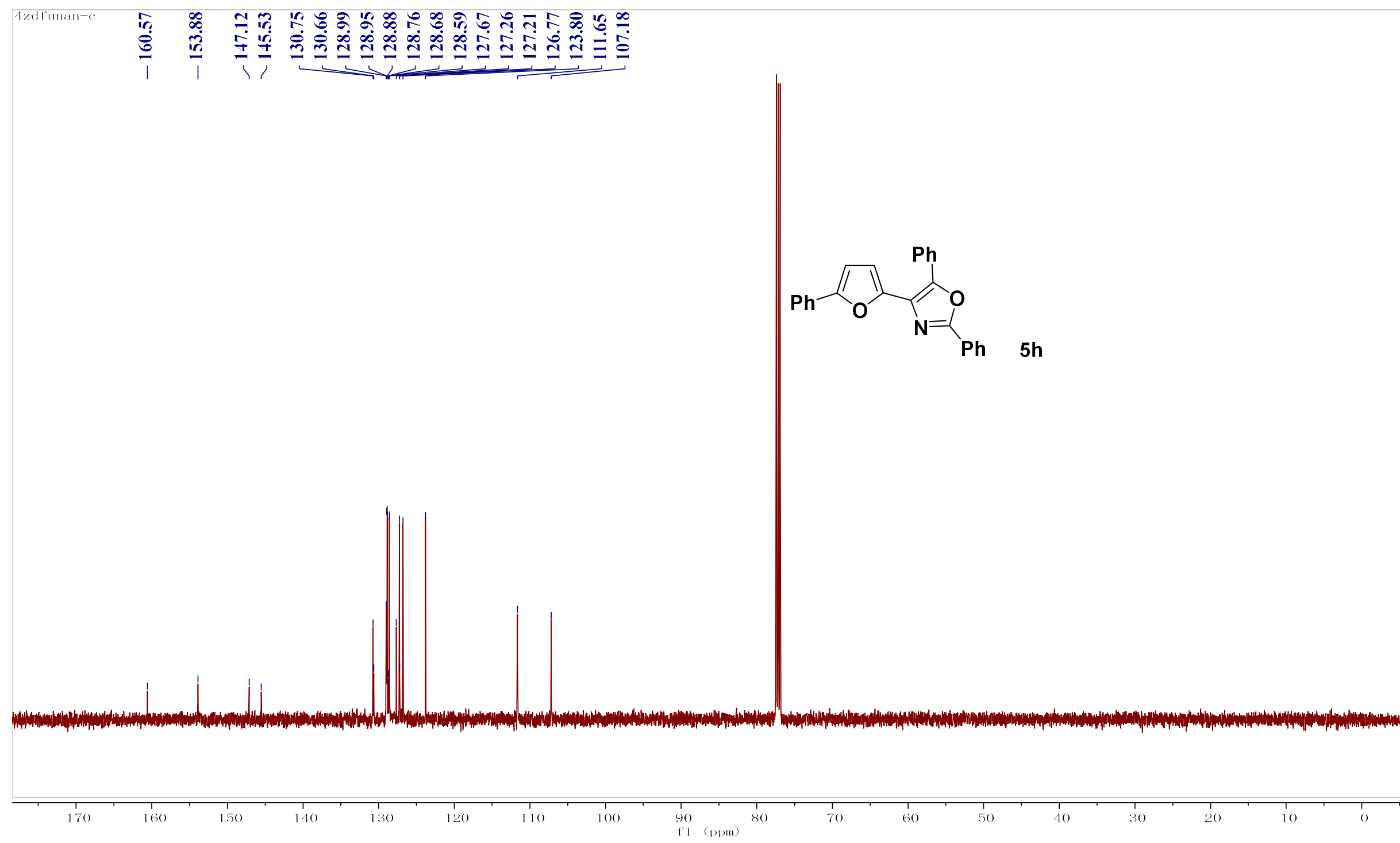

NMR-147 


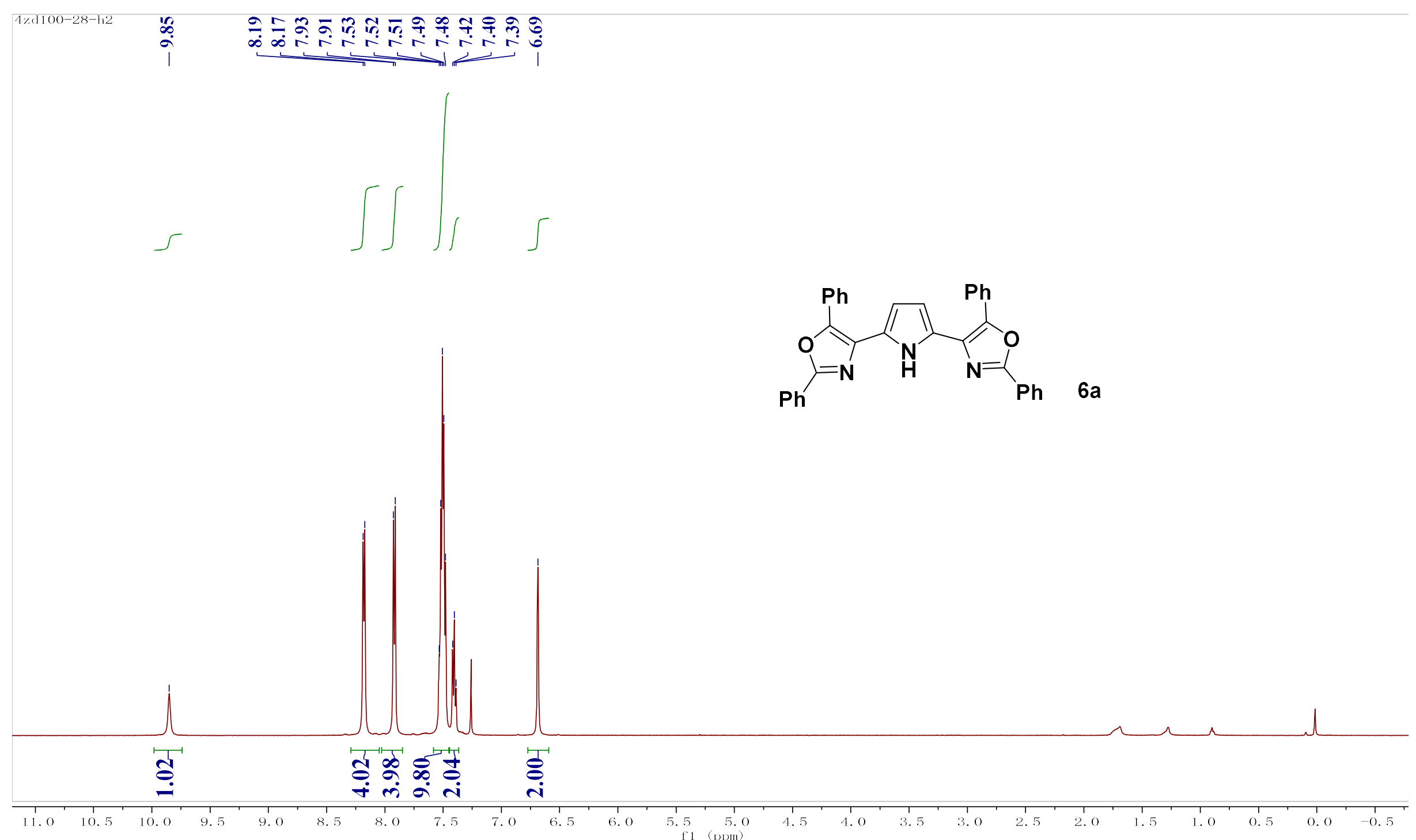

NMR-148 


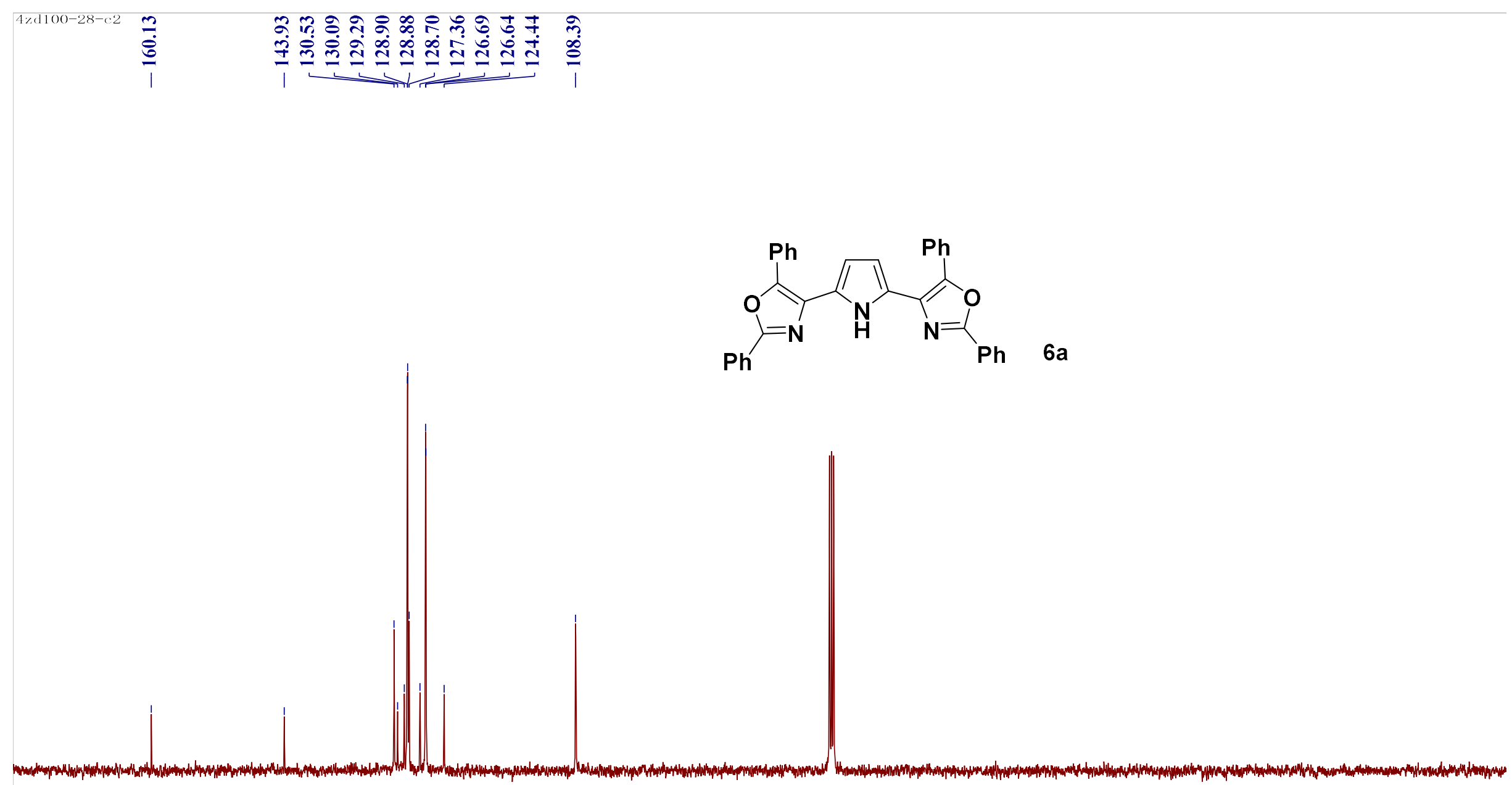




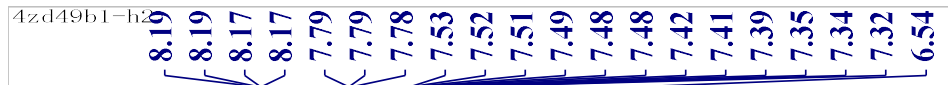
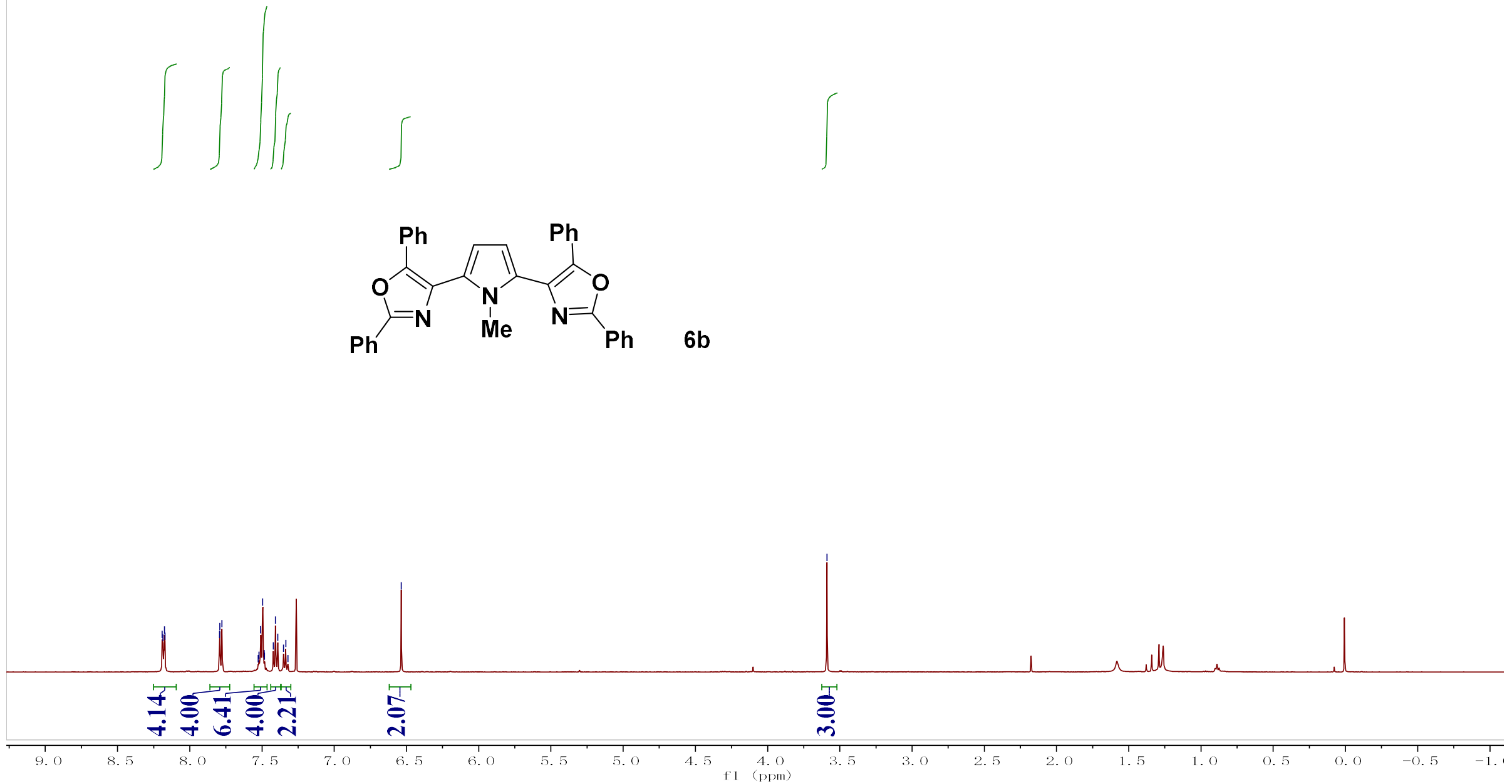

NMR-150 


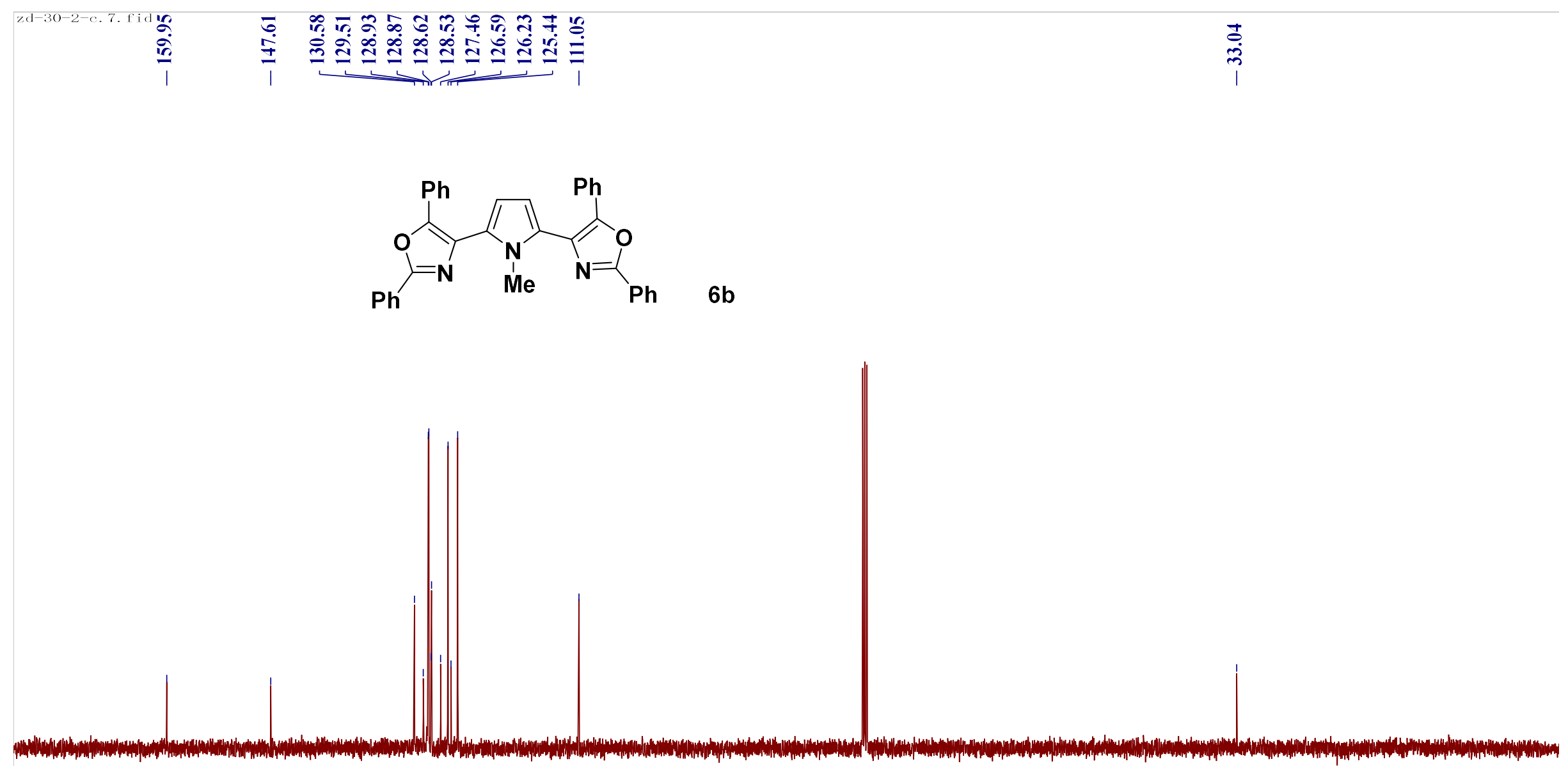




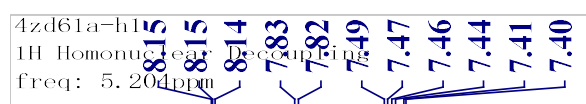
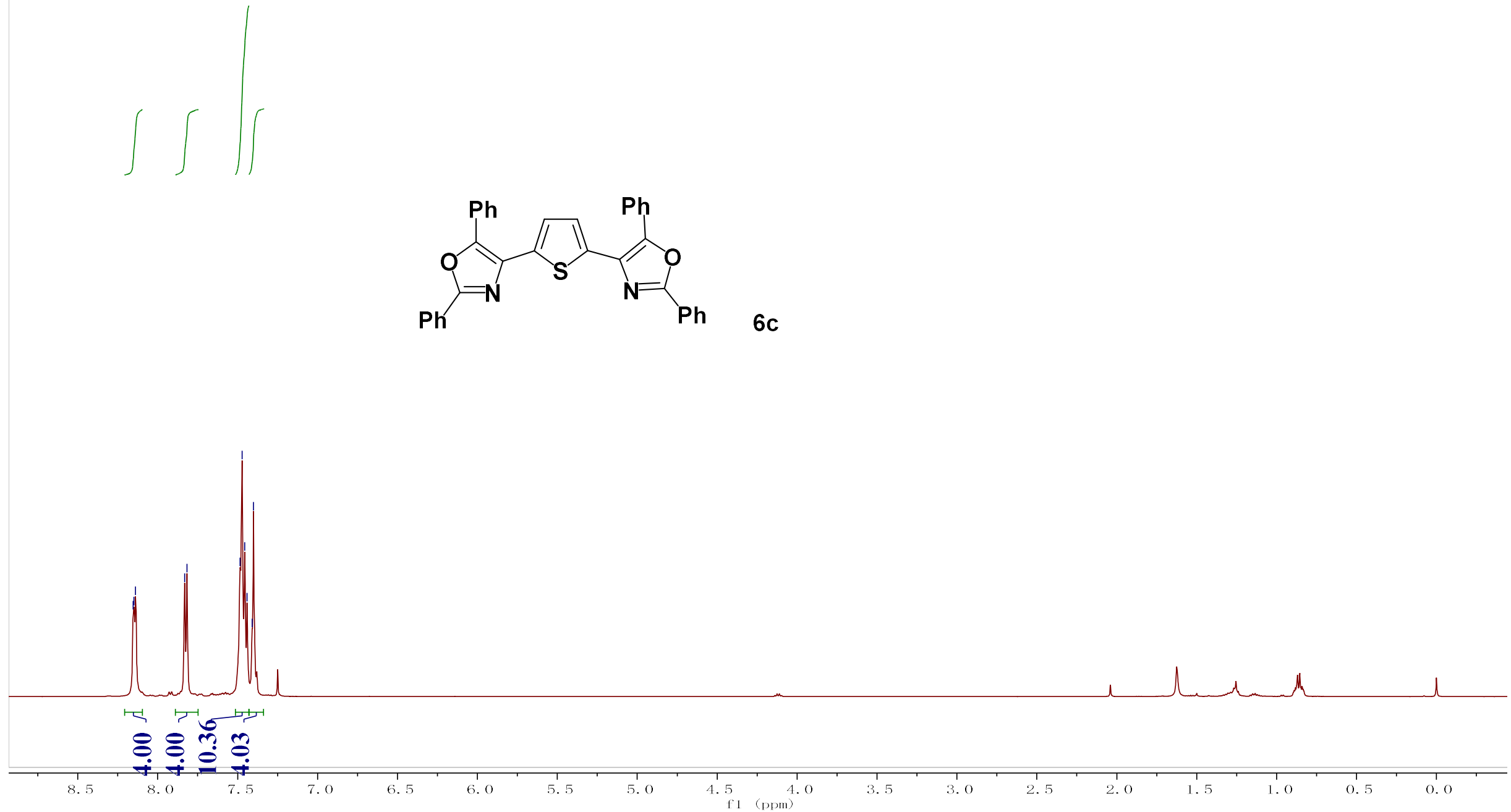

NMR-152 


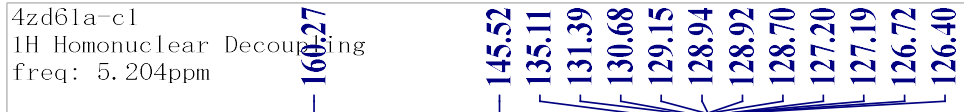
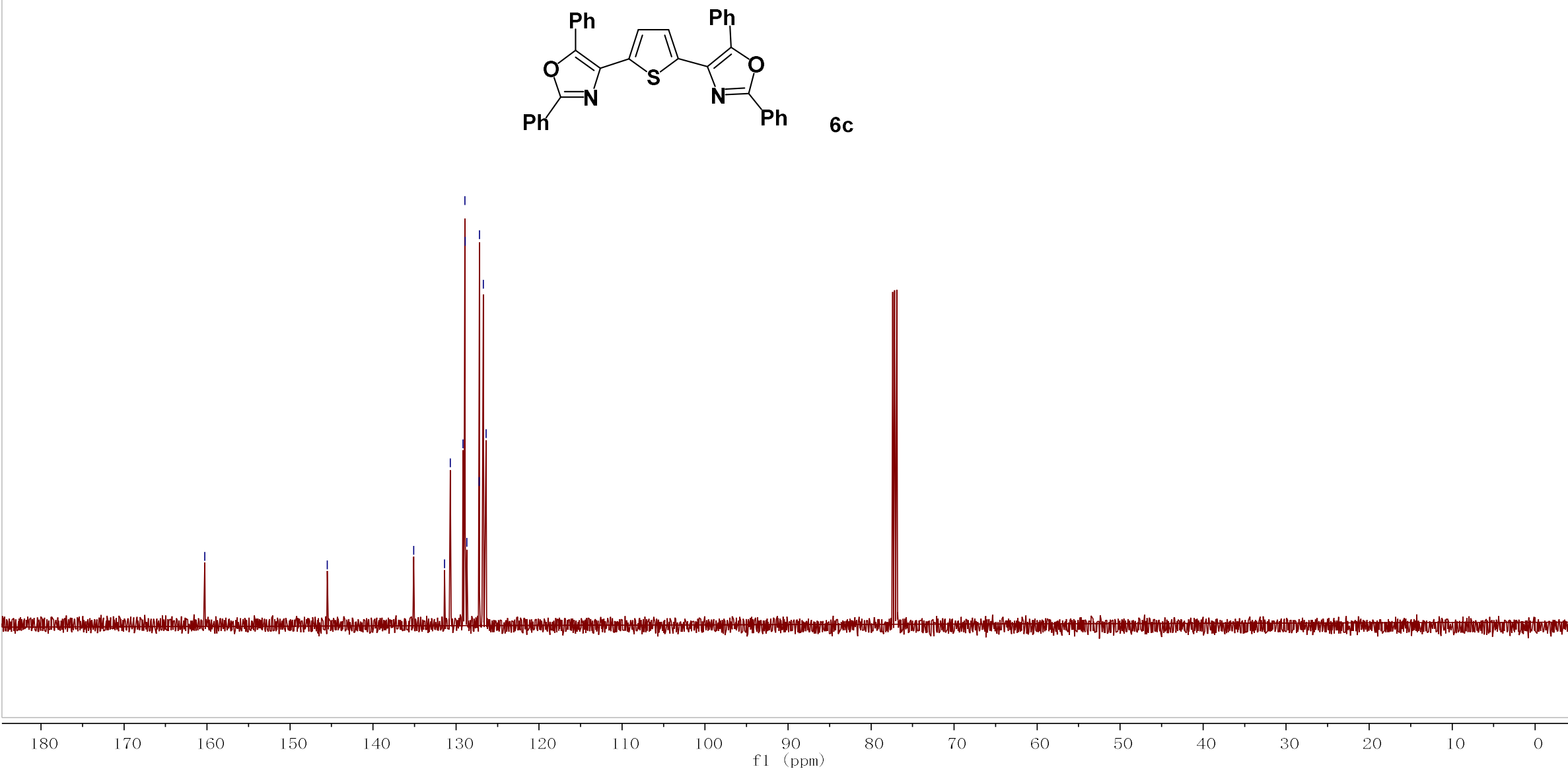


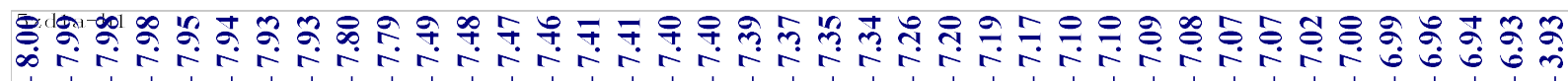
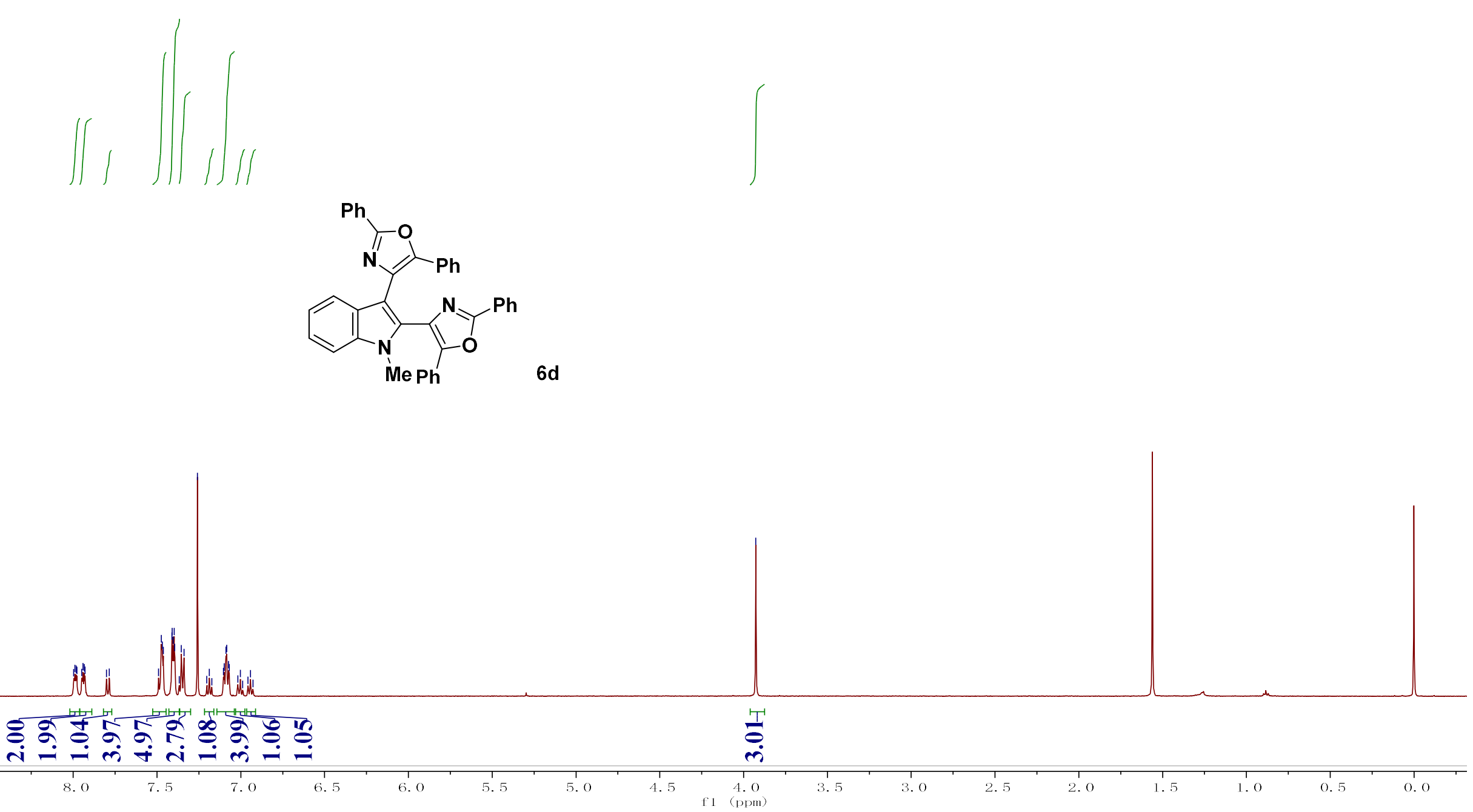

NMR-154 

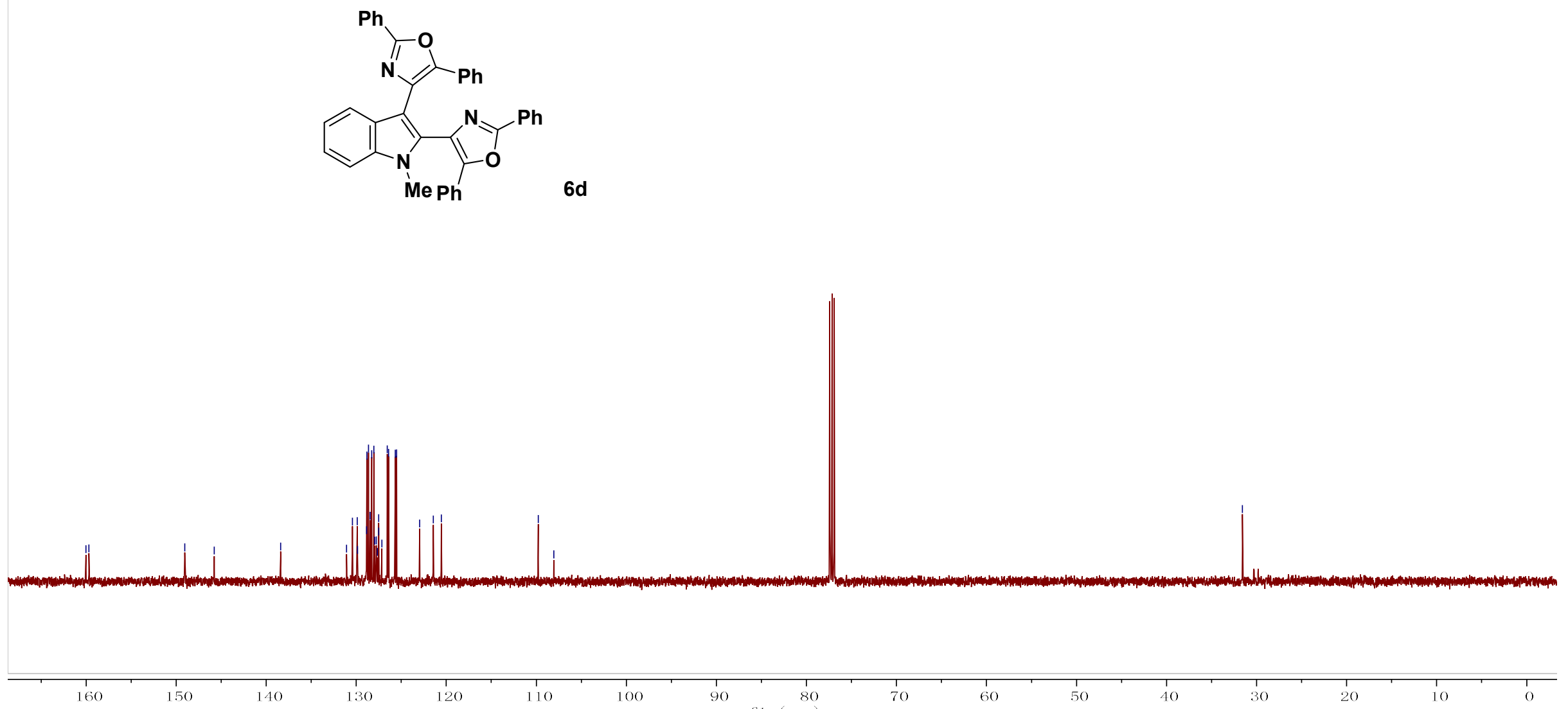

140

130
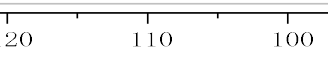


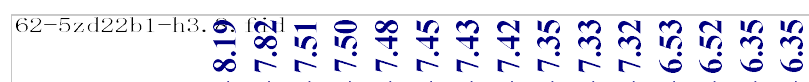

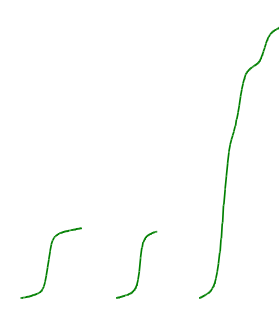

$\iint$
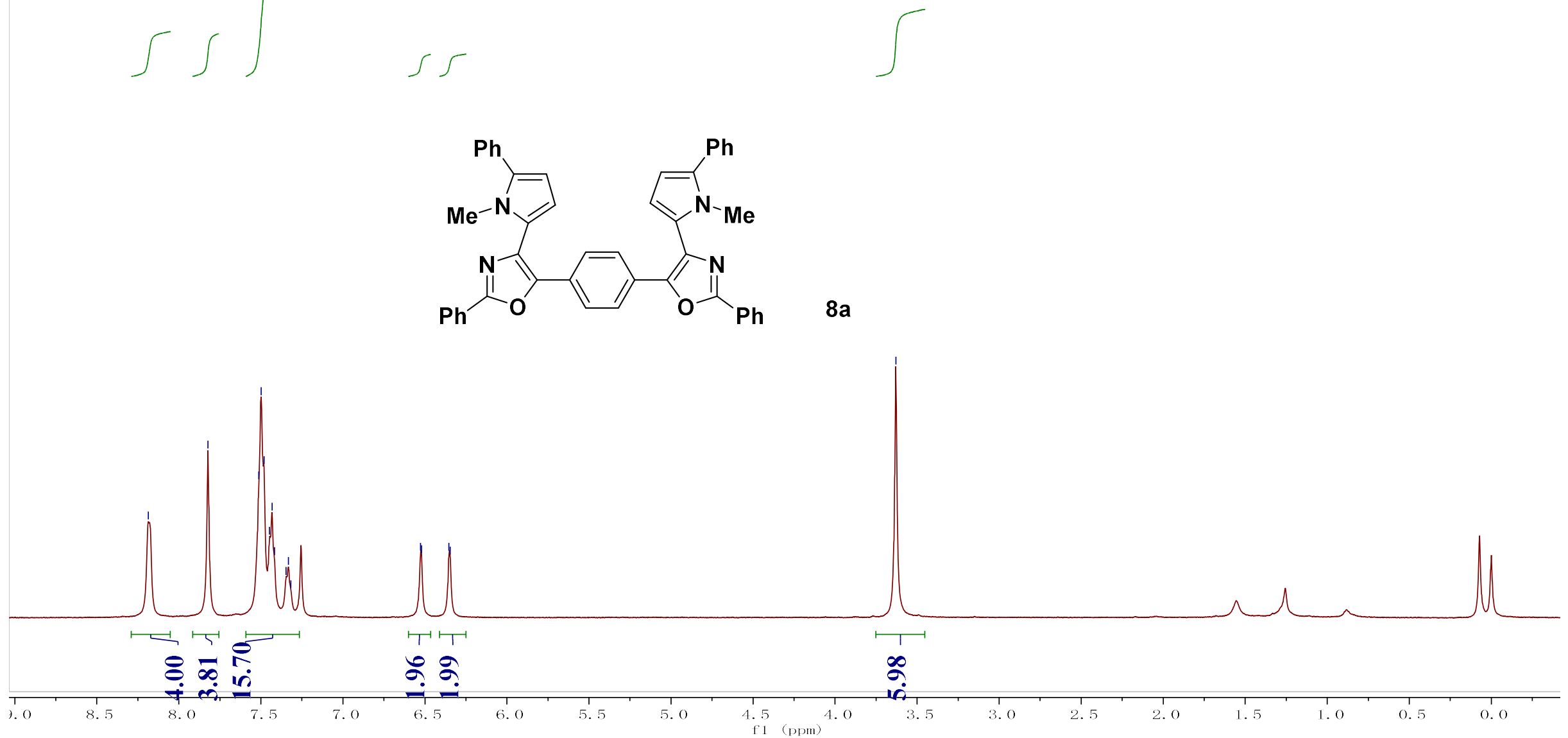

NMR-156 


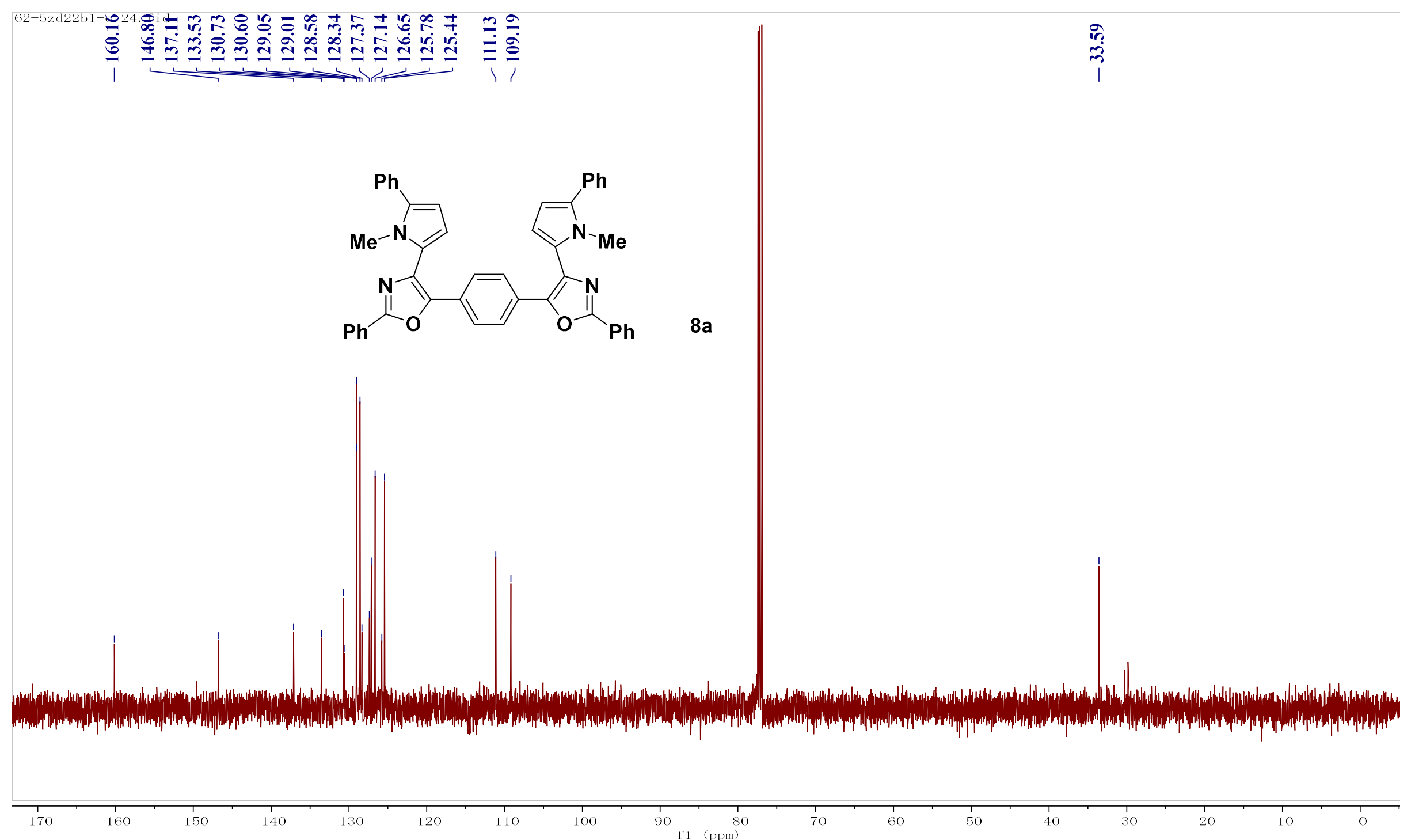

NMR-157 


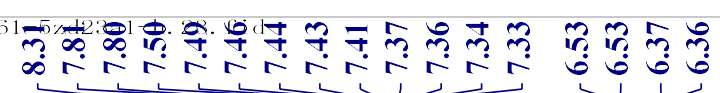

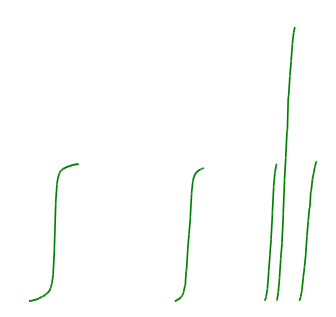

$\iint$
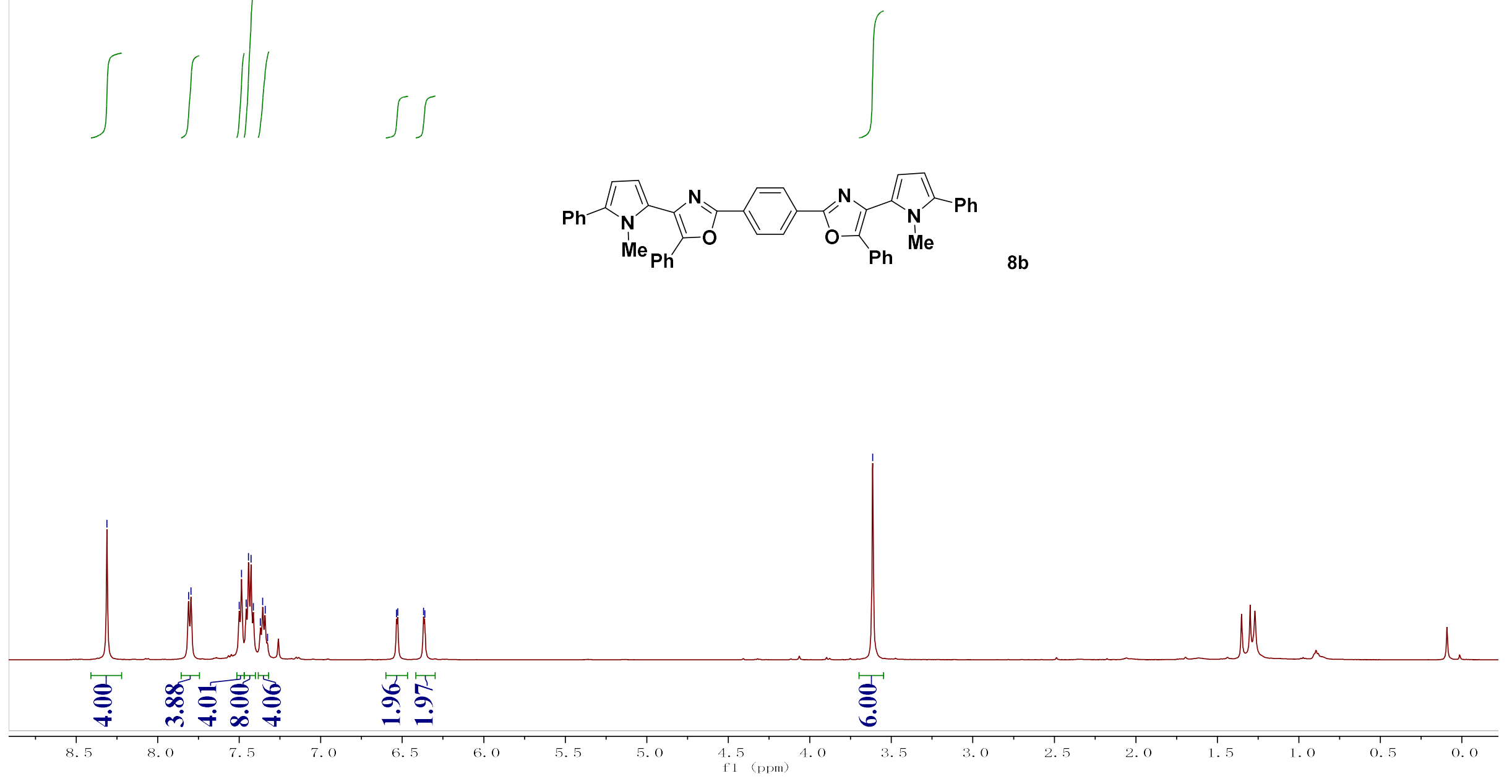

NMR-158 

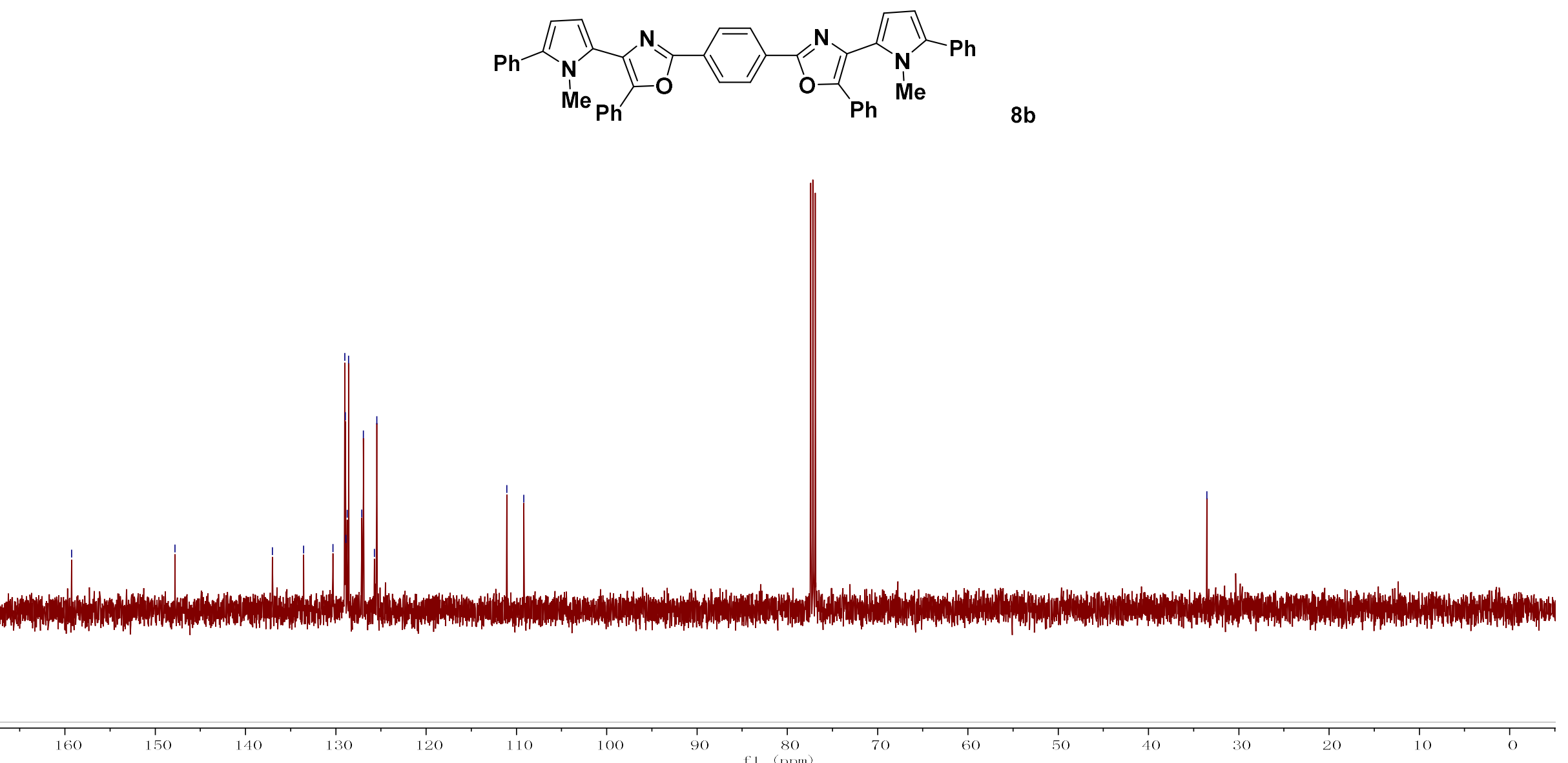